\title{
Funktionelle Analyse des Transkriptionsfaktors Uncx4.1 im murinen Mittelhirn
}

\author{
Dissertation \\ zur Erlangung des Doktorgrades \\ „Doctor rerum naturalium“ \\ der Mathematisch-Naturwissenschaftlichen Fakultäten \\ der Georg-August-Universität zu Göttingen
}

Vorgelegt von

Tamara Irmgard Rabe

aus Oldenburg

Göttingen Juni 2011 
Referent: Prof. Dr. Ernst A. Wimmer

Koreferent: Prof. Dr. Ahmed Mansouri

Tag der mündlichen Prüfung: 04.07.2011 


\section{Inhaltsverzeichnis}

1 Einleitung 1

1.1 Embryogenese der Maus $\ldots \ldots \ldots \ldots \ldots$

1.2 Entwicklung des zentralen Nervensystems von Vertebraten . . . . . . . . . 2

1.3 Die Entwicklung des Mittelhirns in Vertebraten und die Bedeutung des Isthmus' 3

1.3.1 Molekulare Mechanismen der Mittelhirnentwicklung . . . . . . . . . . 4

1.3.2 Morphologische Strukturen des murinen Mittelhirns . . . . . . . . . 7

1.4 Die neuronalen Subpopulationen des murinen Mittelhirns . . . . . . . . . . . . 9

1.4.1 Entwicklung der dopaminergen Neuronen des ventralen Mittelhirns . . 10

1.4.2 Entwicklung der serotonergen Neuronen im Hinterhirn . . . . . . . . 16

1.4.3 Entwicklung der GABAergen Neuronen im murinen Mittelhirn . . . . 17

1.4.4 Entwicklung der glutamatergen Neuronen im murinen Mittelhirn. . . . 19

1.4.5 Verschiedene Marker der neuronalen Subpopulationen des murinen Mittelhirns ..................... 20

1.5 Der Transkriptionsfaktor Uncx4.1 f . . . . . . . . . . . . . . . . . 21

1.5.1 Das Expressionsmuster von Uncx4.1 in Vertebraten . . . . . . . . . . . 22

1.5.2 Die Funktion von Uncx4.1 während der Embryonalentwicklung . . . . 23

1.6 Das Cre-LoxP System $\ldots \ldots \ldots$. . . . . . . . . . . . . . . . . . . . . . . . . . . . 24

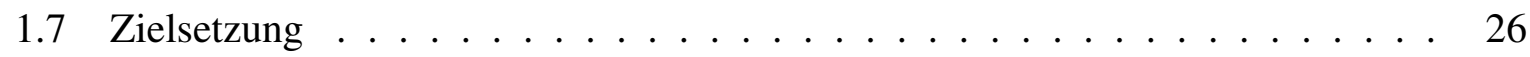

2 Ergebnisse 28

$2.1 \quad$ Expressionsanalyse von Uncx4.1 im embryonalen Mittelhirn der Maus . . . . . 28

2.1 .1 Uncx4.1 ist in der Mantelzone des Mittelhirns exprimiert . . . . . . . . 28

2.1.2 Uncx4.1 ist in allen neuronalen Subtypen des embryonalen Mittelhirns exprimiert. . . . . . . . . . . . . . . . . 29

2.2 Untersuchungen zur Funktion von Uncx4.1 während der Entwicklung dopami-

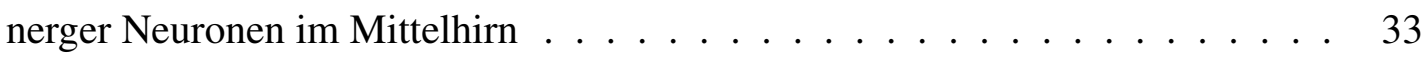

2.2.1 Der Verlust von Uncx4.1 führt zu einer Reduzierung dopaminerger Neuronen im ventralen Mittelhirn . . . . . . . . . . . . . . . . 33

2.2.2 In Abwesenheit von Uncx4.1 ist keine vermehrte Apoptose im Mittelhirn detektierbar $\ldots \ldots \ldots \ldots$. . . . . . . . . . . . 36 
2.2.3 Die Proliferation und Differenzierung des neuronalen Gewebes ist im Mittelhirn Uncx4.1-defizienter Mausembryonen nicht gestört . . . . . . 37

2.2.4 Die Positionierung dopaminerger und serotonerger Neuronen an der MHG ist in Abwesenheit von Uncx4.1 nicht beeinträchtigt . . . . . . . 38

2.2.5 Expressionsanalyse von Lmxla, Foxa2, Ngn2, Nurr1 und Mash1 im ventralen Mittelhirn von Uncx4.1 ${ }^{-/}$Embryonen . . . . . . . . . . . . . 40

2.2.6 Die Expression von Uncx4.1 im Mittelhirn Lmxla-defizienter Embryonen 44

2.2.7 Die Expression von Uncx4.1 im Mittelhirn Ngn2-defizienter Embryonen 45

2.2.8 Analyse der $\beta$-Catenin Expression im ventralen Mittelhirn Uncx4.1defizienter Embryonen . . . . . . . . . . . . . . . . . 46

2.2.9 Die Analyse dopaminerger Neuronen in Abwesenheit von Uncx4.1 mit Hilfe einer konditionalen Knockoutlinie . . . . . . . . . . . . . . . 47

2.3 Untersuchungen zur Funktion von Uncx4.1 während der Entwicklung GABAer-

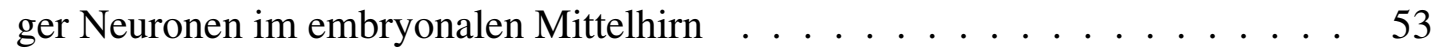

2.4 Untersuchungen zur Funktion von Uncx4.1 während der Entwicklung glutamaterger Neuronen im embryonalen Mittelhirn $\ldots \ldots \ldots$. . . . . . . . 55

2.4.1 Die Inaktivierung von Uncx4.1 hat Einfluss auf bestimmte Subtypen der glutamatergen Neuronen im Mittelhirn . . . . . . . . . . . . 55

2.4.2 Die Anzahl Pax6-positiver Zellen des ventralen Mittelhirns ist in Abwesenheit von Uncx4.1 ab E13.5 erhöht . . . . . . . . . . . . . . . . . 58

2.4.3 Uncx4.1 und Ngn2 sind in Pax6-defizienten Mäusen normal exprimiert 59

2.5 Protein-Interaktionsstudien von Uncx4.1 mit Ngn2 und Pax6 . . . . . . . . . . 61

2.5.1 In-vitro Analyse der potentiellen Interaktion von Uncx4.1, Ngn2 und Pax6 in HeLa und Hek293T Zellen . . . . . . . . . . . . . . 61

2.5.2 Ngn2 und Pax6 interagieren auf Protein-Protein Ebene miteinander . . 62

$2.6 \quad$ Analyse der Pax6-positiven Zellen in Ngn2-defizienten Mäusen . . . . . . . . . 63

$2.7 \quad$ Analyse der Oligodendrozyten in Abwesenheit von Uncx4.1 . . . . . . . . . . 64

2.8 Untersuchungen der Axone in Uncx4.1 $1^{-1-}$-Mausembryonen . . . . . . . . . . 66

2.8.1 Die Level der synaptischen Proteine sind nicht in Abwesenheit von $\mathrm{Un}$ $c x 4.1$ unverändert . . . . . . . . . . . . . . . . . . . . 66

2.8.2 Die Axone der Colliculi superiores sind in Uncx4.1-Nullmutanten verändert . . . . . . . . . . . . . . . . . 68 
2.8.3 Die Inaktivierung von Uncx4.1 führt zu verkürzten Axonen und einer verringerten Anzahl axonaler Auswüchse

3 Diskussion

3.1 Uncx4.1 ist in postmitotischen Neuronen des Mittelhirns exprimiert . . . . . . 75

3.2 Die Funktion von Uncx4.1 während der Entwicklung dopaminerger Neuronen im Mittelhirn . . . . . . . . . . . . . . . . . 76

3.3 Uncx4.1 spielt keine Rolle während der Entwicklung der GABAergen Neuro-

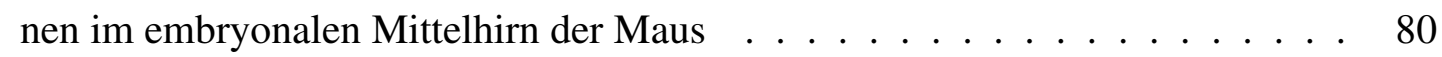

3.4 Die Funktion von Uncx4.1 während der Entwicklung der glutamatergen Neuronen des Mittelhirns . . . . . . . . . . . . . . . . . . . . . . . . 82

3.5 Potentielle Rolle von Uncx4.1 während der Gliogenese . . . . . . . . . . . . 85

3.6 Potentielle Rolle von Uncx4.1 bei der Bildung der Axone in den Colliculi superiores

\begin{tabular}{lll}
\hline & Zusammenfassung & 89
\end{tabular}

5 Material und Methoden $\quad 91$

5.1 Molekularbiologische Methoden . . . . . . . . . . . . . . . . 91

$5.1 .1 \quad$ Extraktion genomischer DNA aus Gewebeproben . . . . . . . . . . . . 91

$5.1 .2 \quad$ Präparation von Plasmid-DNA aus E.coli . . . . . . . . . . . . . . . . 91

5.1 .3 Ethanolpräzipitation von DNA . . . . . . . . . . . . . . 92

5.1 .4 Phenol-Chloroform-Extraktion von DNA . . . . . . . . . . . . . . . . 92

$5.1 .5 \quad$ Konzentrationsbestimmung der DNA und RNA . . . . . . . . . . . . 93

$5.1 .6 \quad$ Polymerase-Kettenreaktion (PCR) . . . . . . . . . . . . . . . . . 93

5.1 .7 Agarose-Gelelektrophorese . . . . . . . . . . . . . . . 95

5.1 .8 Extraktion von DNA aus Agarose-Gelen . . . . . . . . . . . . . 95

5.1 .9 Aufreinigung von PCR-Produkten . . . . . . . . . . . . . . . 95

5.1 .10 Restriktionsverdau von DNA . . . . . . . . . . . . . . . . . . . 96

5.1 .11 DNA-Ligation $\ldots \ldots \ldots \ldots \ldots \ldots$

5.1 .12 Sequenzierungen $\ldots \ldots \ldots$. . . . . . . . . . . . . 97

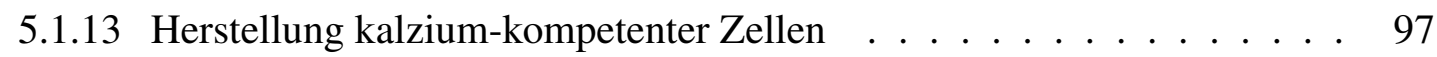

5.1 .14 Transformation von DNA in kalzium-kompetente Zellen . . . . . . . . 98 
5.1 .15 Herstellung von Glycerolstocks $\ldots \ldots$. . . . . . . . . . . . . . . . . 98

5.1 .16 Aufreinigung von total RNA aus Hefe . . . . . . . . . . . . . . . 98

5.1 .17 Herstellung DIG und Fluorescein markierter Proben . . . . . . . . . . 99

5.2 Tierexperimentelle Methoden . . . . . . . . . . . . . . . . . . 100

5.2 .1 Tiere $\ldots \ldots \ldots \ldots \ldots$

5.2 .2 Generierung konditionaler Uncx4.1 Mausmutanten . . . . . . . . . . 100

5.2 .3 Tamoxifenverabreichung . . . . . . . . . . . . . . . 101

5.2 .4 BrdU-Injektion . . . . . . . . . . . . . . . . . . 102

5.3 Histologische Methoden . . . . . . . . . . . . . . . . . . 103

5.3 .1 Präparation von Embryonen und adulten Gehirnen ． . . . . . . . . . . 103

5.3 .2 Einbetten in Kryomatrix . . . . . . . . . . . . . . . 103

5.3 .3 Einbetten in Paraffin . . . . . . . . . . . . . . . . . . . 104

5.3 .4 Einbetten in 2\%, „Low Melting Point“Agarose . . . . . . . . . . . . . . 104

5.3 .5 Anfertigung von Gewebeschnitten . . . . . . . . . . . . . . . . 105

5.3 .6 Indirekte Immunfluoreszenzfärbung (IHC) auf Gewebeschnitten . . . . 105

$5.3 .7 \quad$ BrdU-Färbung . . . . . . . . . . . . . . . . . 106

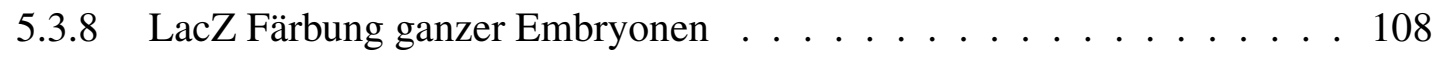

5.3 .9 LacZ Färbung von Kryoschnitten . . . . . . . . . . . . . . . . . 108

5.3 .10 TUNEL-Methode . . . . . . . . . . . . . . . . . . . . . . . . . . . . 109

5.3 .11 Golgi-Färbung . . . . . . . . . . . . . . . . . . . . . 109

5.3 .12 DiI-Färbung . . . . . . . . . . . . . . . . . . . 110

5.3.13 Detektion von mRNA mittels in situ Hybridisierung (ISH) auf Gewebeschnitten . . . . . . . . . . . . . . . . . 110

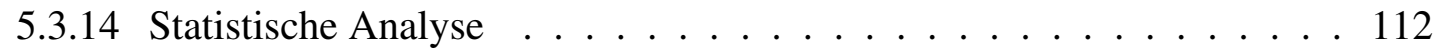

5.4 Zellbiologische Methoden . . . . . . . . . . . . . . . 113

5.4 .1 Zelllinien . . . . . . . . . . . . . . . . 113

5.4 .2 Transiente Transfektion . . . . . . . . . . . . . . . . . 113

5.4 .3 Indirekte Immunfluoreszenz auf Zellen (ICC) . . . . . . . . . . . . . 114

5.5 Proteinbiochemische Methoden . . . . . . . . . . . . . . . . . . . 114

5.5.1 Herstellung von Gesamtproteinextrakt aus Gewebe . . . . . . . . . . . 114

5.5 .2 Herstellung von Gesamtproteinextrakt aus Zellen . . . . . . . . . . . . 115

$5.5 .3 \quad$ Konzentrationsbestimmung von Proteinen . . . . . . . . . . . . . 115 
5.5 .4 Co-Immunopräzipitation . . . . . . . . . . . . . . . 115

5.5.5 $\quad$ SDS-Polyacrylamidgelelektrophorese (SDS-PAGE) . . . . . . . . . . . 116

5.5 .6 Western Blotting . . . . . . . . . . . . . . . 116

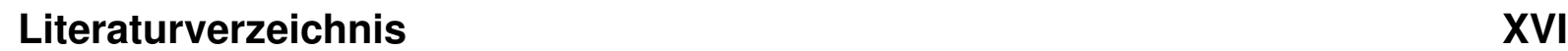

6 Danksagung $\quad$ XXXVI

\begin{tabular}{lll}
\hline 7 & Curriculum vitae & XXXVIII
\end{tabular} 


\section{Abbildungsverzeichnis}

$1 \quad$ Schematische Darstellung der Keimblätter in der Entwicklung von Vertebraten. 2

2 Schematische Darstellung der frühen Gehirnentwicklung in Vertebraten. . . . . 3

3 Schematische Darstellung der Expressionsdomänen verschiedener Signalmoleküle der $\mathrm{MHG} \ldots \ldots \ldots \ldots$. . . . . . . . . . . . . . . . . . . 6

$4 \quad$ Schematische Darstellung der morphologischen Strukturen und Kerngebiete ․ des Mittelhirns $\ldots \ldots \ldots \ldots \ldots \ldots$

5 Schematische Darstellung der neuronalen Populationen im embryonalen Mittelhirn . . . . . . . . . . . . . . . . . . . . . . . 10

$6 \quad$ Dopaminerge Neuronen des Mittelhirns und ihre Entwicklung . . . . . . . . . 11

$7 \quad$ Marker der verschiedenen neuronalen Populationen im Mittelhirn von Mausem-

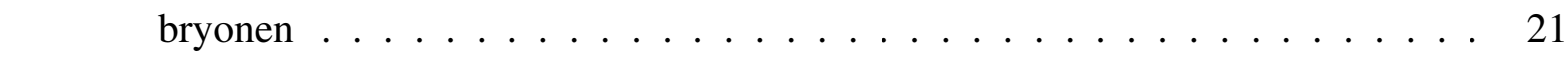

$8 \quad$ Schematische Darstellung des Uncx4.1-Proteins und seiner Domänen . . . . . 22

$9 \quad$ Expression von Uncx4.1 im Mittelhirn der Maus. . . . . . . . . . . . . . . . . 29

10 ISH von Uncx4.1-mRNA und verschiedener neuronaler Marker an E11.5 und E12.5 Wildtyp-Gehirnen. . . . . . . . . . . . . . . . . . 30

11 Uncx4.1 ist in dopaminergen, glutamatergen und GABAergen Neuronen des Mittelhirns exprimiert . . . . . . . . . . . . . . . 32

12 Die Expression von TH ist in Uncx4.1 homozygoten Embryonen reduziert . . . 34

13 Die Anzahl dopaminerger Neuronen des ventralen Mittelhirns ist in Uncx4.1defizienten Embryonen reduziert . . . . . . . . . . . . . . . . 35

14 Der Funktionsverlust von Uncx4.1 hat keinen Einfluss auf die Anzahl apoptoti-

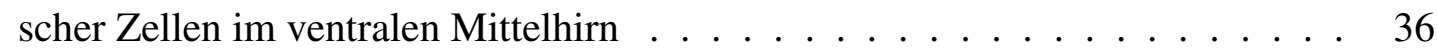

15 Weder die Proliferation noch die Differenzierung der Neuronen im Mittelhirn ist in der Abwesenheit von Uncx4.1 beeinflusst . . . . . . . . . . . . . . . . . 37

16 Dopaminerge und serotonerge Neuronen weisen in Uncx4.1 $1^{-/}$Embryonen unveränderte Expressionsdomänen an der MHG auf. . . . . . . . . . . . . . . . . 39

17 Analyse neuronaler Marker, die während der Bildung der dopaminergen Neu-

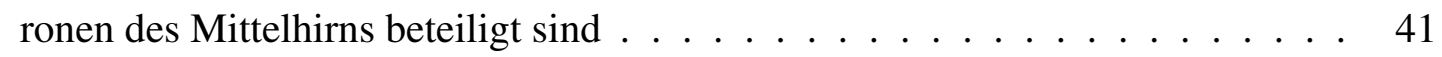

18 Die Anzahl Nurr1-positiver Neuronen ist während der Entwicklung in Abwesenheit von Uncx4.1 gleichbleibend. 


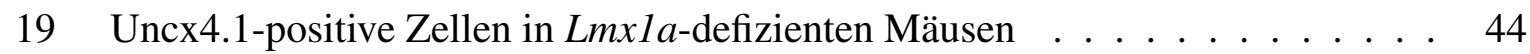

$20 \quad$ Ngn2-defiziente Neuronen der ventralen Mittellinie weisen keine Uncx4.1Expression auf .......................... 45

$21 \quad$ Analyse der $\beta$-Catenin Expression in Abwesenheit von Uncx4.1 . . . . . . . . 46

22 Cmv-Cre;Uncx4.1 $1^{f /-}$ Embryonen exprimieren kein Uncx4.1 im Mittelhirn der

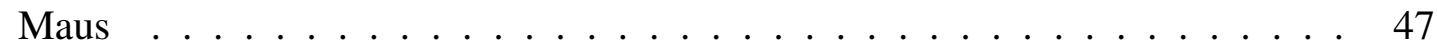

23 Der Expressionsverlust von Uncx4.1 in Cre-ER;Uncx4.1 $1^{\text {fl/ }}$ Mäusen im Mittelhirn 48

24 Analyse von Markern dopaminerger Neuronen des Mittelhirns auf coronalen

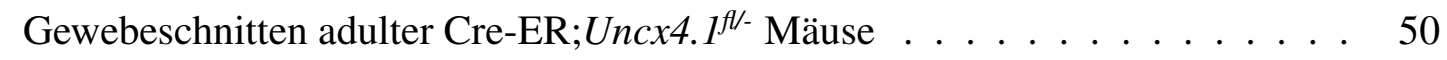

25 Foxa2-Cre;Uncx4.1 $1^{\text {fl- }}$ Mausmutanten zeigen einen Verlust der Uncx4.1Expression im ventralen Mittelhirn. . . . . . . . . . . . . . 51

26 Analyse von Markern dopaminerger Neuronen des Mittelhirns auf coronalen

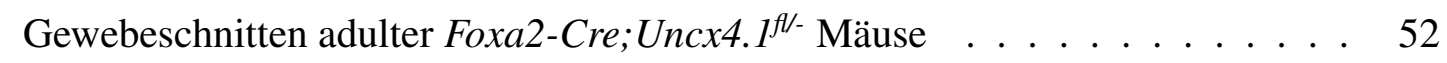

27 GABAerge Neuronen sind in Uncx4.1-defizienten Embryonen normal entwickelt. 54

28 Analyse glutamaterger Marker in Uncx4.1-defizienten und Kontrollembryonen 56

29 Die Anzahl der Isl1-positiven Oculomotorneuronen ist in Abwesenheit von Un$c x 4.1$ unverändert $\ldots \ldots \ldots \ldots \ldots$. . . . . . . . . . . . . . 57

30 Die Anzahl Pax6-positiver Zellen ist in Abwesenheit von Uncx4.1 ab E13.5 erhöht 59

31 Die Expression von Uncx4.1 und Ngn2 ist in Abwesenheit von Pax6 unverändert 60

32 Immunfärbung der transfizierten Zellen $\ldots \ldots \ldots$. . . . . . . . . . . 62

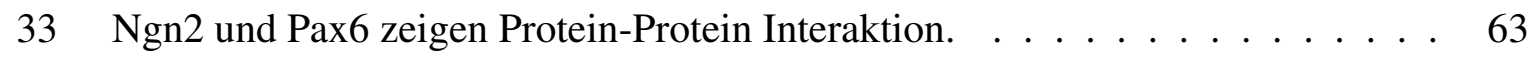

34 Die Anzahl Pax6-positiver Zellen ist in Ngn2-defizienten Mausembryonen im

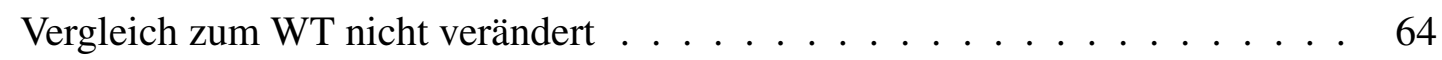

35 Die Expression von GFAP ist im Mittelhirn adulter Cre-ER;Uncx4.1 $1^{f /-}$ Mäuse . 65

36 Die Level verschiedener vesikulärer und nicht vesikulärer postsynaptischer Pro-

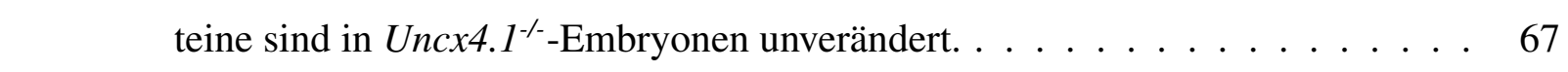

37 Die Inaktivierung von Uncx4.1 führt zu einer Kompensation der Synapsin I+II Expression in den Colliculi superiores . . . . . . . . . . . . . . 69

38 Die Inaktivierung von Uncx4.1 führt zu einer Veränderung der Calbindin Expression in den Colliculi superiores . . . . . . . . . . . . . . 70

39 Dil Färbung der Neuronen im dorsalen Mittelhirn an E16.5 und E18.5 . . . . . 72 
$40 \quad$ Uncx4.1-Nullembryonen zeigen morphologische Veränderungen der Neuronen im Mittelhirn . . . . . . . . . . . . . . . . . . . . . . 73

$41 \quad$ Verpaarungs-Strategie konditionaler Uncx4.1 Mausmutanten. . . . . . . . . . . 101

42 Zeitliche Übersicht der Tamoxifenverabreichung. . . . . . . . . . . . . . . . . 102 


\section{Tabellenverzeichnis}

1 Zusammenfassung der Veränderung dopaminerger Neuronen im ventralen Mittelhirn Uncx4.1-defizienter Embryonen. . . . . . . . . . . . . . . . . . 77

2 Zusammenfassung der Veränderung GABAerger Marker im ventralen Mittelhirn Uncx4.1-defizienter Embryonen. . . . . . . . . . . . . . . . . . . . . . 81

3 Zusammenfassung der Veränderung spezifischer Marker glutamaterger Neuronen im Mittelhirn Uncx4.1-defizienter Embryonen. . . . . . . . . . . . . . . . 83

4 Zusammensetzung des Lysispuffer $\ldots \ldots \ldots$. . . . . . . . . . . . . 91

$5 \quad$ Zusammensetzung des LB-Mediums . . . . . . . . . . . . . . . . . . . . 92

$6 \quad$ Zusammensetzung des TE-Puffers . . . . . . . . . . . . . . . . . . 92

7 Zusammensetzung einer PCR-Reaktion $\ldots \ldots \ldots$. . . . . . . . . . 93

$8 \quad$ Verwendete Primersequenzen. $\ldots \ldots \ldots \ldots$. . . . . . . . . . . . . 94

$9 \quad$ Standard-PCR Programm $\ldots \ldots \ldots \ldots$. . . . . . . . . . . . . . . . . 94

$10 \quad 10 x$ TBE Puffer $\ldots \ldots \ldots \ldots \ldots \ldots$

11 Liste der verwendeten Plasmide $\ldots \ldots \ldots$. . . . . . . . . . . . . . . . . . . 97

12 Ansatz zur Herstellung von DIG oder Fluorescein markierter RNA-Sonden . . 99

13 Liste der verwendeten Mauslinien $\ldots \ldots$. . . . . . . . . . . . 100

14 Dauer der PFA-Fixierung für das Einbetten in Kryomatrix _.. . . . . . . . 103

$15 \quad 20 x \mathrm{PBS} \ldots \ldots \ldots \ldots \ldots \ldots \ldots \ldots$

16 Aufbereitung des Gewebes für die Paraffineinbettung . . . . . . . . . . . . . 104

17 Übersicht über die Schritte der IHC . . . . . . . . . . . . . . . . . . . . 106

18 Verwendete Antikörper $\ldots \ldots$. . . . . . . . . . . . . . . 107

19 Zusammensetzung der Fix A Fixierlösung für die LaZ-Färbung . . . . . . . . . 108

20 Zusammensetzung der LacZ-Färbelösung . . . . . . . . . . . . . . . . . . 108

21 LacZ-Fixierungslösung für Kryoschnitte . . . . . . . . . . . . . . . . . . . 109

22 Zusammensetzung des Hybridisierungspuffers . . . . . . . . . . . . . 111

23 KTBT Zusammensetzung . . . . . . . . . . . . . . . . . . 111

24 NTMT Zusammensetzung $\ldots \ldots \ldots \ldots \ldots \ldots \ldots$

25 Zusammensetzung der Trenn- und Sammelgele für die SDS-PAGE . . . . . . . 116 


\section{Abkürzungsverzeichnis}

$\mu 1 \ldots \ldots \ldots . .$. Mikroliter

$\mu \mathrm{m} \ldots \ldots \ldots$. Mikrometer

$+/ ? \ldots \ldots \ldots \ldots$ heterozygot für das Knockout-Allel oder Wildtyp

$-/-\ldots \ldots \ldots . .$. homozygot für das Knockout-Allel

C. elegans

Caenorhabditis elegans

E. coli

Escherichia coli

Abb.

Abbildung

AP .......... Alarplatte

APS

Ammoniumpersulfat

BCA

„Bicinchoninic acid“

BCIP

5-Bromo-4-chloro-3-indolylphosphat

bHLH

„basic helix-loop-helix“

Bo

Bulbus olfactorius

BP

Basalplatte

BrdU

5'-Brom-2'-deoxyuridin

Brn3a

„Brain-specific homeobox/POU domain protein $3 A$ “

BSA

Rinderserumalbumin

ca.

Circa

$\mathrm{Cb}$

Cerebellum

Co-IP

Co-Immunopräzipitation

d.h. das heisst 
DAPI $\ldots \ldots \ldots$ 4,6-Diamidino-2-Phenylindol

DAT ........., ,dopamine transporter “

DEPC ....... Dimethylsulfid

dest. ......... destilliert

$\mathrm{dH}_{2} \mathrm{O} \ldots \ldots \ldots$ destilliertes Wasser

Di $\ldots . \ldots \ldots$..... Diencephalon

Dig $\ldots \ldots \ldots \ldots$ Digoxigenin-11-UTP

DMEM $\ldots . . .$. Dulbecco's Modified Eagle Medium

DMSO ........ Dimethylsulfoxid

DNA ......... Desoxyribonucleinsäure

dNTP ......... Desoxynukleosidtriphosphat

DP .......... Deckplatte

dTT .......... Dithiothreitol

E .......... Embryonalstadium oder Embryonaltag

EDTA $\ldots . . \ldots$ Ethylendiamintetraacetat

en $\ldots . . . \ldots \ldots$,engrailed“

engl. .......... englisch

et al. .......... und andere

etc. .......... und so weiter

EtOH $\ldots \ldots \ldots$ Ethanol

FCS ......... fätales Kälberserum

FGF ......... ,fibroblast growth factor"

fl $\ldots \ldots \ldots \ldots$ gefloxt 
Foxa2 ........., ,Forkhead box A 2“

FR $\ldots \ldots \ldots$ Formatio reticularis

g $\ldots \ldots \ldots \ldots$ Erdbeschleunigung

GABA $\ldots . . \ldots \gamma$-Aminobuttersäure

GABAerge Neuronen Neuronen, deren Neruotransmitter die $\gamma$-Aminobuttersäure ist

Gbx2 ........ „Gastrulation and brain-specific homeobox protein 2“

GP $\ldots \ldots \ldots \ldots$ Bodenplatte

$\mathrm{HCl} \ldots \ldots \ldots$ Salzsäure

HH $\ldots . . . \ldots$. Hinterhirn

Hox .......... Homöobox

IF $\ldots \ldots \ldots \ldots$ Colliculi inferiores

IHC $\ldots \ldots \ldots$ Immunohistochemie

ISH $\ldots \ldots \ldots \ldots$ in situ Hybridisierung

Lmx ......... „Lim homeodomain transcription factor“

loxP ......... „locus of crossing over in P1 “

$\mathrm{mA} \ldots \ldots \ldots . .$. Milliampere

Mash1 ........ „Achaete-scute complex-like 1“

$\max . \ldots \ldots \ldots$ maximal

mDA Neuronen .. Mittelhirn dopaminerge Neurone, dopaminerge Neurone des Mittelhirns

MH ........... Mittelhirn

$\min . . . \ldots \ldots$ Minute

$\mathrm{ml} \ldots \ldots \ldots \ldots$ Milliliter

mRNA ........ „messenger ribonucleic acid“ 
Msx1 ........ „msh homeobox homolog 1“

MZ ........... Mantelzone

$\mathrm{NaCl} \ldots \ldots \ldots$ Natriumchlorid

$\mathrm{NaOH} \ldots \ldots \ldots$ Natriumhydroxid

NBTC ........ „Nitro blue tetrazolium chloride“

Ngn2 ........ ,Neurogenin 2“

NGS $\ldots \ldots \ldots$ Ziegenserum

NGS $\ldots \ldots \ldots \ldots$ normales Ziegenserum

Nurr1 ........ „Nuclear receptor related 1 protein“

OD .......... Optische Dichte

Otx2 ........, ,orthodenticle homolog 2“

P $\ldots \ldots \ldots \ldots$ postnatales Stadium

PAG $\ldots . \ldots . .$. Substantia grisea periaquaeductalis

Pax6 .......... „Paired box gene 6“

PBS .......... „phosphat bufferd saline“

PBT .......... „phosphat bufferd saline“ mit 0,1\% Tween

PCR .......... Polymerase-Kettenreaktion

PFA $\ldots \ldots \ldots$. Paraformaldehyd

Pitx3 ........ „Paired-like homeodomain transcription factor 3“

r1-r4 .......... Rhombomer 1-4

rab3a $\ldots \ldots \ldots$ ras-related protein $3 a$

RM .......... Rückenmark

RN ......... Nucleus ruber 
RNA $\ldots \ldots \ldots$ Ribonucleinsäure

$\operatorname{rpm} \ldots \ldots \ldots$ Umdrehungen pro Minute

RT $\ldots \ldots \ldots \ldots$ Raumtemperatur

SC $\ldots \ldots \ldots \ldots$ Colliculi superiores

SDS-PAGE ...... SDS-Polyacrylamidgelelektrophorese

Shh .........., ,sonic hedgehog“

SN $\ldots \ldots \ldots$ Substantia Nigra

Synbrev ........ Synaptobrevin

Syntag ........ Syntagmin

Tab. .......... Tabelle

TBE $\ldots \ldots \ldots \ldots$ Tris-Borat-EDTA

Tc .......... Tectum

TEMED ....... N,N,N',N'-Tetramethyl-Ethylenediamin

$\operatorname{Tg} \ldots \ldots \ldots \ldots$ Tegmentum

TH $\ldots \ldots \ldots \ldots$ Tyrosinhydroxylase

Tuj1 ........ neuronales Klasse III $\beta$-Tubulin

TUNEL ......., „Terminal deoxynucleotidyltransferase-mediated dUTP-biotin nick end labeling “

v/v .......... Volumen/ Volumen

VACht $\ldots . . \ldots$ vesikulärer Acetylcholintransporter

VH $\ldots \ldots \ldots \ldots$ Vorderhirn

Vmat2 ........, ,vesicular monoamine transporter 2“

vMH $\ldots \ldots \ldots$ ventrales Mittelhirn 
VTA $\ldots \ldots \ldots$ ventrales tegmentales Areal

VZ ......... ventrikuläre Zone

WB .......... Western Blot

Wnt ........ „wingless-type MMTV integration site family, member 1 “

WT $\ldots \ldots \ldots \ldots$ Wildtyp

ZNS $\ldots \ldots \ldots \ldots$ zentrales Nervensystem

${ }^{\circ} \mathrm{C} \ldots \ldots \ldots \ldots$ Grad Celsius 


\section{Einleitung}

Die Entwicklung des Gehirns in seiner Komplexität unterliegt verschiedenen Vorgängen, wie Zellteilung, Induktion, Musterbildung, Differenzierung, Migration und vielen Weiteren. Morbus Parkinson ist die wohl bekannteste neurologische Krankheit die mit dem Mittelhirn assoziiert wird. Sie ist auf das Absterben dopaminerger Neuronen im ventralen Mittelhirn zurückzuführen. Für die erfolgreiche Behandlung dieser Krankheit ist es notwendig zu verstehen, welche genetischen und molekularbiologischen Faktoren an ihrer Entstehung beteiligt sind.

\subsection{Embryogenese der Maus}

Der Organismus und somit auch das Mittelhirn, entwickelt sich aus einer einzigen Zelle. Die gesamte Dauer der Embryogenese der Maus beträgt zwischen 18 und 20 Tagen, welche als Embryonalstadium oder Embryonaltag 18 (E18) und 20 (E20) bezeichnet werden. Nach der Befruchtung der Eizelle führen frühe Zellteilungen 3.5 Tage nach der Befruchtung (E3.5 ) zur Bildung der so genannten Blastocyste. Die Blastocyste besteht aus der inneren Zellmasse (engl. „,inner cell mass“) und dem Trophektoderm. Während aus der inneren Zellmasse später der Embryo hervorgehen wird, bildet sich aus dem Trophektoderm extraembryonales Gewebe, wie die Plazenta. Circa vier Tage nach der Befruchtung (E4) folgt die Implantation des Gewebes in die Gebärmutter, ehe die Gastrulation mit Bildung des Primitivstreifens (engl. „primitive streak") an E6 einsetzt. Während der Gastrulation werden die Körperachsen festgelegt und es entwickeln sich drei Keimblätter (engl. „,germ layers“): Das Endoderm, das Mesoderm und das Ektoderm (Abb. 1). Aus dem Endoderm geht später der Verdauungstrakt, die Leber, das Pankreas, sowie der Atmungstrakt hervor, während sich aus dem Mesoderm die Chorda dorsalis (engl. „,Notochord“), Muskeln, das Herz und die Niere bilden. Das Ektoderm differenziert sich schließlich in Hautgewebe und das Nervensystem. Nach 18-20 Tagen ist die Embryogenese abgeschlossen und es folgt die Geburt (Gilbert, 2006, Rossant \& Tam, 2009; Wolpert et al., 2011). 


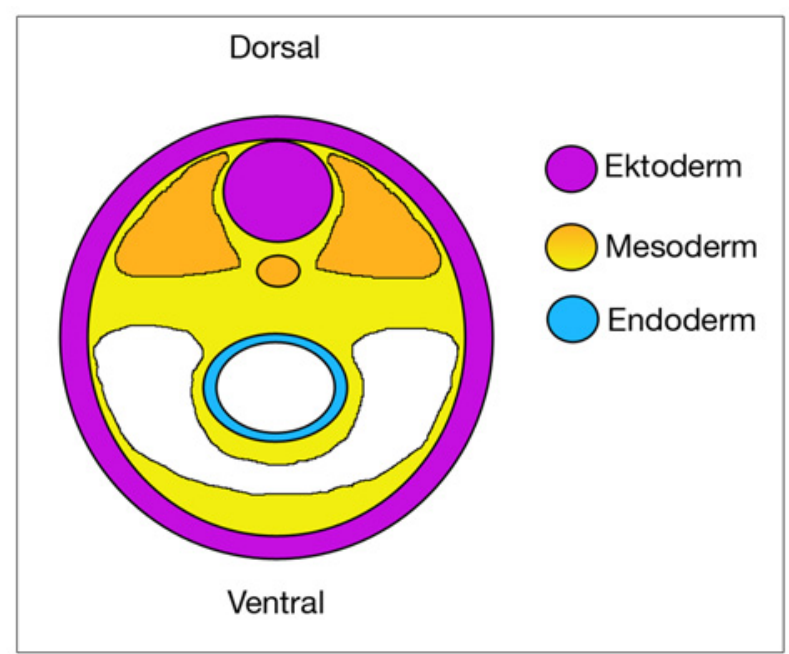

Abb. 1: Schematische Darstellung der Keimblätter in der Entwicklung von Vertebraten. Aus dem Endoderm (hellblau) geht der Verdauungstrakt, die Leber, sowie die Lunge hervor, während sich aus dem Mesoderm (gelb/orange) das Skelett, die Muskeln, die Niere und das kardiovaskuläre System entwickelt. Das Ektoderm (lila) differenziert sich in Hautgewebe und das Nervensystem. Modifiziert nach (Wolpert et al., 2011).

\subsection{Entwicklung des zentralen Nervensystems von Vertebraten}

Das zentrale Nervensystem (ZNS) geht aus dem Ektoderm hervor (Kap. 1.1). Seine Entstehung beginnt mit der neuralen Induktion. Hierfür sind verschiedene Signalzentren, wie z.B. der „Hensens’s node“ im Huhn von Bedeutung. In der Mausentwicklung ist neben dem Knoten (engl. „node“, ein Äquivalent zum „Hensens's node“) noch das anteriore, viscerale Endoderm (engl. ,anterior visceral endoderm") notwendig um die Bildung der rostral gelegenen Strukturen des Neuralrohres (Vorder-, Mittel- und Hinterhirn) einzuleiten. Während der Neurulation bildet sich zunächst aus dem dorsalen Bereich des Embryos die Neuralplatte, ehe sich aus Teilen der Neuralplatte das Neuralrohr formiert. Das Neuralrohr kann als Vorläufer des ZNS angesehen werden und gliedert sich in Vorder-, Mittel- und Hinterhirn, sowie Rückenmark (Abb. 2 , A). An der Regionalisierung des Neuralrohres in die einzelnen Bereiche des ZNS sind neben Transkriptionsfaktoren verschiedene Signalwege von entscheidender Bedeutung (Gilbert, 2006; Wolpert et al., 2011). In der weiteren Entwicklung entstehen aus den drei rostral gelegenen Gehirnvesikeln fünf Gehirnvesikel. Dabei entsteht aus dem Prosencephalon (Vorderhirn) das Telencephalon und das Diencephalon, während aus dem Rhombencephalon (Hinterhirn) das Meten- und Myelencephalon hervorgehen (Abb. 2, B). Einzig das Mesencephalon (Mittelhirn) bleibt als eine Struktur erhalten (Sanes et al., 2006). Zur Etablierung der dorso-ventralen Achse tragen Signalmoleküle bei, die von der ventral gelegenen Chorda dorsalis, sowie der dorsal gelegenen Epidermis sekretiert werden. Hierzu gehören unter anderem BMP4 (engl. „Bone 
morphogenetic protein 4“) und BMP7 (engl. „Bone morphogenetic protein 7“, (Lee \& Jessell, 1999), sowie Shh (engl. „Sonic Hedgehog“, (Echelard et al., 1993)). Das Ergebnis der dorsoventralen Musterbildung ist das Entstehen der Boden-, Basal-, Alar- und Deckplatte (Chizhikov \& Millen, 2005).

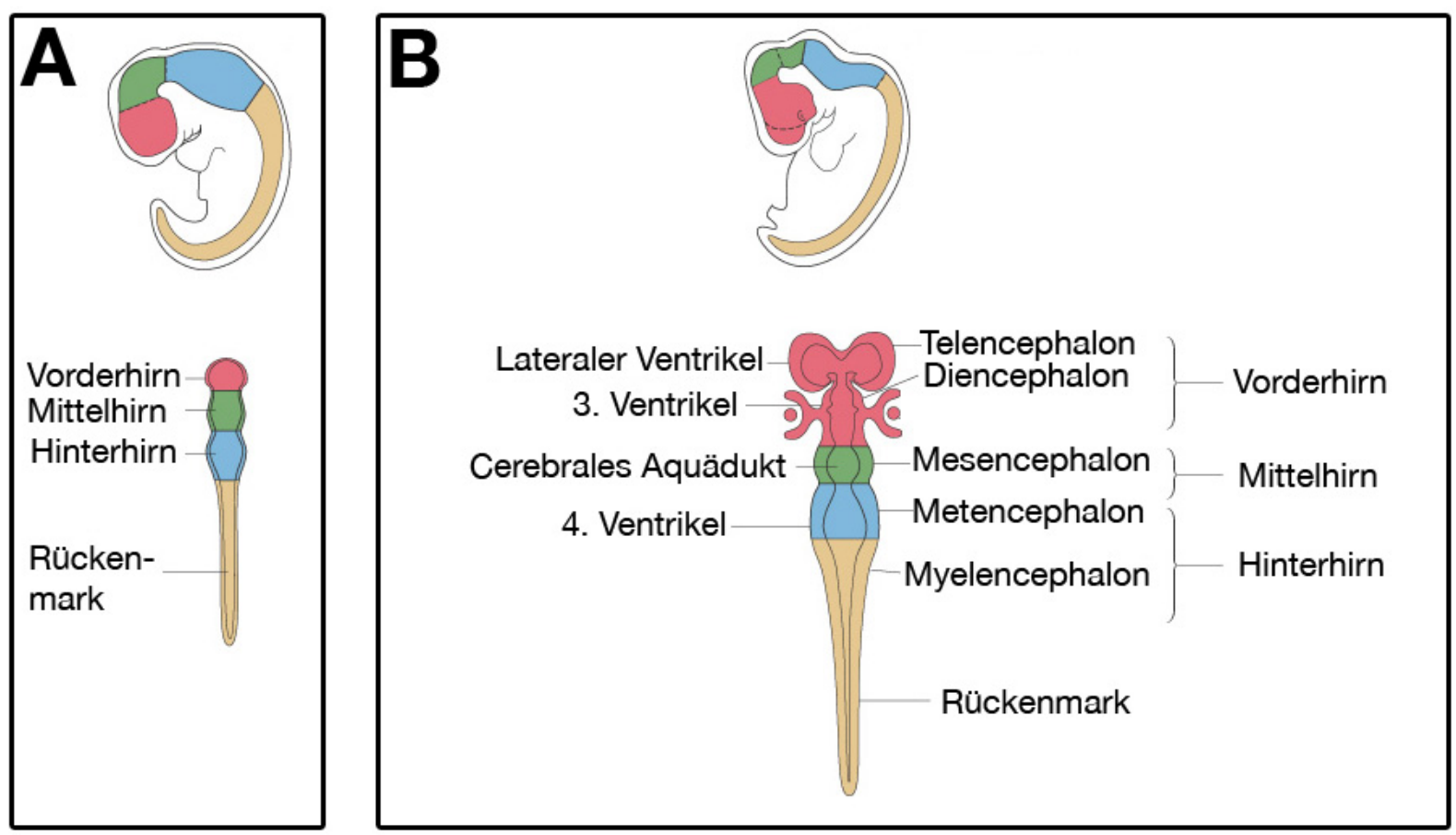

Abb. 2: Schematische Darstellung der frühen Gehirnentwicklung in Vertebraten. Zunächst ist das zentrale Nervensystem in Vorderhirn, Mittelhirn, Hinterhirn und Rückenmark gegliedert (A). In der weiteren Entwicklung differenziert sich das Vorderhirn in Telencephalon und Diencephalon, während sich das Hinterhirn in Metencephalon und Myelencephalon gliedert (B). Rot markiert den Bereich des Vorderhirns, grün den des Mittelhirns, blau das Hinterhirn (in A) bzw. das Metencephalon (in B). Braun markiert das Rückenmark (in A) bzw. das Myelencephalon und das Rückenmark (in B). Modifiziert nach (Sanes et al., 2006).

\subsection{Die Entwicklung des Mittelhirns in Vertebraten und die Bedeutung des Isthmus'}

In der Entwicklung des Nervensystems spielen Signalzentren, wie der „Hensens’ node“ im Huhn oder der Spemann-Organisator im Frosch eine wichtige Rolle. Während der Entwicklung des Mittelhirns von Vertebraten ist ebenfalls ein solches Signalzentrum von besonderer Bedeutung. So konnte in der Vergangenheit mit Hilfe von Transplantationsstudien gezeigt werden, dass diencephales Gewebe, wenn es ins Mittelhirn transplantiert wird, ein mesencephales Schicksal annimmt (Nakamura et al., 1986; H. Nakamura et al., 1991). Im Gegensatz dazu behält mesencephales Gewebe sein Schicksal bei, wenn es in das Vorderhirn transplantiert 
wird (Martinez et al., 1991). Verantwortlich hierfür ist das Signalzentrum der Mittel-HinterhirnGrenze (MHG): der Isthmus (Martinez et al., 1991; Bally-Cuif et al., 1992; Bally-Cuif \& Wassef, 1994). Der Isthmus ist somit hinreichend für die Induktion eines mesencephalen Schicksals. Ein Verlust des Isthmus' führt allerdings auch zu einer Deletion des Mesen- und Metencephalons. Dies macht deutlich, dass der Isthmus nicht nur hinreichend, sondern notwendig für die Entwicklung des Mittelhirns und des Cerebellums ist (Nieuwkoop, 1991). Im Folgenden wird eine Auswahl einiger wichtiger Transkriptionsfaktoren und Signalmoleküle vorgestellt, die eine Rolle während der Entwicklung des Isthmus’ spielen.

\subsubsection{Molekulare Mechanismen der Mittelhirnentwicklung}

Mehrere Studien der vergangenen Jahre haben verschiedene Transkriptionsfaktoren und Signalmoleküle identifizieren können, die wichtige Funktionen während der Mittelhirnentwicklung übernehmen. So sind u.a. Otx2, Gbx2, engrailed1/2 (en1/2), wnt1, Fgf8 und Lmx1b von zentraler Bedeutung.

Bereits früh in der Entwicklung (E7.5) spielen die beiden Transkriptionsfaktoren Otx2 (engl„orthodenticle homologue 2“) und Gbx2 (engl. ,gastrulation brain homeobox 2") eine entscheide Rolle bei der Entwicklung des Mittel- bzw. Hinterhirns und sind wichtig für die korrekte Positionierung des Isthmus'. Nach der neuralen Induktion ist Otx2 im anterioren Bereich des Neuroektoderms exprimiert, während Gbx2 posterior exprimiert ist (Abb. 3, A). In dem Bereich, in dem die Expressionsmuster von Otx2 und Gbx2 aufeinander treffen, bildet sich in der weiteren Entwicklung die Mittel-Hinterhirn-Grenze, an der sich der Isthmus formiert (Simeone, 2000). Ein Aktivitätsverlust von Otx2 führt zu einer Deletion des Vorder-, Mittel- sowie rostralen Hinterhirns (Acampora et al., 1995; Matsuo et al., 1995), während der Aktivitätsverlust von Gbx2 in Missbildungen des Isthmus' resultiert (Wassarman et al., 1997; Kikuta et al., 2003). Daneben führt der Verlust von $G b x 2$, ebenso wie eine ektopische Expression von Otx2 im rostralen Hinterhirn, zu einer caudalen Expansion des Mittelhirns (Wassarman et al., 1997; Broccoli et al., 1999; Kikuta et al., 2003). Trotz ihrer wichtigen Funktion sind Otx2 und Gbx2 für die Induktion der Gene an der MHG nicht notwendig. So werden in Abwesenheit beider Transkriptionsfaktoren noch immer verschiedene Gene der MHG, wie Pax2, Wnt1, En1 und Fgf8 exprimiert, wenn auch mit überlappendem Expressionsmuster im anterioren Neuroektoderm (Li \& Joyner, 2001). 
Nach der Expression von Otx2 und Gbx2 (E7.5), folgt die Expression von Wnt1 (E8.0) und En1/2 (E8.5) an der MHG (Abb. 3, B). Während die Expression von Wnt1 (engl. „winglesstype MMTV integration site family, member 1") im Mesencephalon zunächst weit nach anterior reicht, ist sie an E9.5 auf einen schmalen Bereich rostral des Isthmus' begrenzt ((Joyner et al. 2000), Abb. 3, B-C). Die Deletion von Wnt1 in Mäusen führt zu einem teilweisen Verlust des Mittelhirns, sowie des Cerebellums (McMahon \& Bradley, 1990). Jedoch beeinflusst eine ektopische Überexpression von Wntl im weiter rostral gelegenen Mittelhirn und weiter caudal gelegenen Hinterhirn die Positionierung und Musterbildung des Isthmus' nicht (Panhuysen et al. 2004). Diese Ergebnisse deuten darauf hin, dass Wnt1 nicht an der Induktion der Isthmusaktivität, wohl aber an der Aufrechterhaltung der Genexpression im Bereich der MHG beteiligt ist. So konnte gezeigt werden, dass der Aktivitätsverlust von Wnt1 zu einem Verlust der später einsetzenden Enl-Expression führt (McMahon et al., 1992). Die Expressionsmuster von Wnt1 und Enl zeigen in Wildtypen zunächst eine recht weite Überlappung (Abb. 3, B), ehe die Expression von Wht1 nach rostral und caudal expandiert, während die Expressionsdomäne von En1 kleiner wird (Abb. 3, C, (Wurst \& Bally-Cuif, 2001)). En1 Mausmutanten zeigen ähnliche Defekte, wie die Wnt1 Mutanten: das Mittelhirn wird, ebenso wie das rostrale Hinterhirn, nicht ausgebildet (Wurst et al., 1994).

Neben Otx2, Gbx2, Wnt1 und En1/2 spielt auch Fgf8 (engl. 'fibroblast growth factor 8') während der Mittel-Hinterhirnentwicklung eine entscheidende Rolle. Die Expression von Fgf8 beginnt (um E8.5) an der MHG und im rostralen Mittelhirn (Abb. 3, B), ehe sie später (um E9.5) nur noch als schmaler Ring im rostralen Hinterhirn detektierbar ist (Abb. 3. C, (Wurst \& BallyCuif, 2001)). Aufgrund seiner Funktion wird angenommen, dass Fgf8 eines der Schlüsselmoleküle des Isthmus' darstellt. So zeigen verschiedene Mutationen von Fgf8, dass Teile des Mittelhirns ebenso fehlen, wie das Cerebellum und sogar der Isthmus selbst (Meyers et al., 1998; Chi et al., 2003). Im Unterschied zu Gbx2- und Otx2-Mutanten werden in Fgf8-Mutanten Gene des Isthmus', wie Wnt1 und Gbx2 nicht länger exprimiert (Chi et al., 2003). Die beobachteten Defekte der Fgf8-Mutanten sind weitestgehend auf einen vermehrten Zelltod zurückzuführen (Chi et al., 2003). Weiterhin konnte gezeigt werden, dass Fgf8 ausreicht um die Bildung des Mittel- und Hinterhirns, ebenso wie die des Isthmus', ektopisch im Vorderhirn zu induzieren. Zusätzlich kann die Expression entscheidender Gene des Isthmus', wie En1/2, in dem ektopisch induzierten Gewebe detektiert werden (Crossley et al., 1996; Martinez et al., 1999; Liu et al., 1999). Seine Funktion übt Fgf8 über Otx2 aus, indem es Otx2 reprimiert (Martinez et al., 1999, 


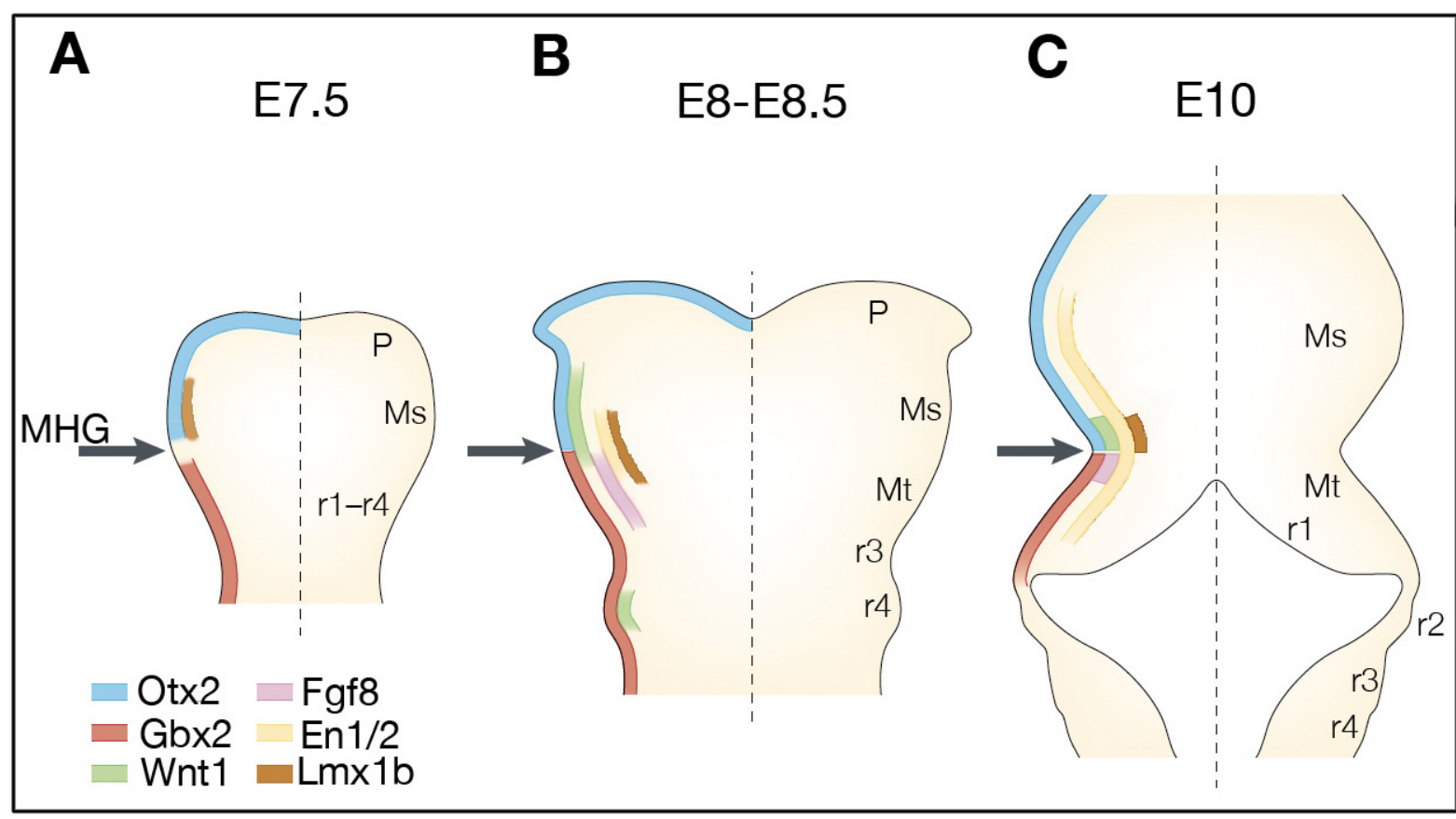

Abb. 3: Schematische Darstellung der Expressionsdomänen verschiedener Signalmoleküle der MHG. Dorsale Ansicht des frühen Mausembryos am Ende der Gastrulation an E7.5 (A), im sechs Somiten Stadium an E8-E8.5 (B) und an E10 (C). Es ist die dynamische Expression verschiedener Gene zu erkennen, die eine Rolle während der Mittelhirn- und Isthmusentwicklung spielen. Ms: Mesencephalon, Mt: Metencephalon, MHG: MittelHinterhirngrenze, P: Prosencephalon, r1-r4: Rhombomere 1 - 4. Die Pfeile deuten auf die MHG. Die gestrichelte Linie markiert die Mittellinie des Embryos. Modifiziert nach (Wurst \& Bally-Cuif, 2001).

Liu et al., 1999). Fgf8 ist für die Erhaltung des Isthmus' absolut notwendig (Chi et al., 2003).

Der Transkriptionsfaktor Lmx1b ist bereits an E7.5 an der MHG detektierbar und seine Expression reicht bis zum Vorderhirn (Abb. 3, A), während sie sich später auf den Isthmus beschränkt und nahezu vollständig mit Wnt1 co-lokalisiert ist (Abb. 3, B-C, (Matsunaga et al., 2002; Guo et al., 2007)). Ein Verlust der Lmxlb Aktivität führt zu einem Wegfall der Fgf8 Expression am Isthmus und infolge dessen zu einem schrittweisen Verlust der Wnt1, sowie En1/2 Expression (Matsunaga et al., 2002; Guo et al., 2007). Damit ist Lmxlb ebenfalls von entscheidender Bedeutung während der Entwicklung des Isthmus'.

Neben dem Isthmus und seinen Signalen sind noch intrinsische Faktoren der Zellen in der Bodenplatte, ebenso wie Signale des darunter befindlichen Mesoderms (Chorda dorsalis), von zentraler Bedeutung für die Entwicklung des Mittelhirns. Aus der Mittellinie der Neuralplatte geht schließlich das am ventralsten gelegene Gewebe des Mittelhirns hervor. Shh ist einer der Faktoren, der mit der Bodenplatte assoziiert ist und trägt entscheidend zu der Entwicklung des Mittelhirns und seiner ventralen Regionalisierung bei. An E8.5 ist die Expression von Shh an der ventralen Mittellinie des Mesencephalons detektierbar (Abb. ,D ,(Echelard et al., 1993), (Gale \& Li, 2008)). Knockout Studien haben gezeigt, dass ein Verlust von Shh zu einem Verlust der 
Bodenplatte und zu einer Degeneration der Chorda dorsalis führt (Chiang et al., 1996). Damit einhergehend konnte eine Reduzierung des Mittelhirns, ebenso wie eine Reduzierung entscheidender Marker wie Otx2 beobachtet werden (Chiang et al., 1996). Eine ektopische Expression von Shh führt wiederum zu der Aktivierung bestimmter Gene der Bodenplatte (Echelard et al. 1993). Es konnte ebenfalls gezeigt werden, dass aus Shh-positiven Zellen verschiedene Kerngebiete des ventralen Mittelhirns hervorgehen (Echelard et al., 1993; Joksimovic et al., 2009a). Aus diesen Ergebnissen wurde von den Autoren geschlussfolgert, dass die Expression von Shh hinreichend und notwendig ist um die Bildung der Bodenplatte einzuleiten und die neuralen Progenitoren des ventralen Mittelhirns korrekt zu etablieren.

\subsubsection{Morphologische Strukturen des murinen Mittelhirns}

Morphologisch gesehen gliedert sich das Mittelhirn an E11.5 in die Boden-, Basal-, Alar- und Deckplatte (Abb. 4, A, (Chizhikov \& Millen, 2005)), während es später von dorsal nach ventral in das Tectum und das Tegmentum unterteilt werden kann (Abb. 4. B).

Das Tectum (dorsal) gliedert sich in die rostral gelegenen Colliculi superiores (SC, engl. „superior colliculus") und die caudal gelegenen Colliculi inferiores (IC, engl. ,inferior colliculus") (Abb. 4, B). Die Colliculi superiores bestehen aus einer geschichteten Struktur und sind an der Verschaltung optischer Reflexe beteiligt. So erhalten die SC Reize optischer Signale retinocollicular von der Netzhaut und aus dem visuellen Cortex (O'Leary \& McLaughlina, 2005). Die geschichtete Struktur der SC wird durch das sequenzielle, dorsale Auswandern verschiedener Zellgruppen aus der ventrikulären Zone erreicht (Puelles, 2007).

Die caudal gelegenen Colliculi inferiores bestehen aus einer globulären Struktur und sind dem auditorischen System zugeordnet (Puelles, 2007). Sie erhalten ihre Reize unter anderem vom Nucleus cochlearis, sowie vom Nucleus olivaris superior (Puelles, 2007).

Im Gegensatz zum Tectum weist das Tegmentum auf der rostrocaudalen Achse eine eher homogene Struktur auf und ist nicht geschichtet angeordnet. Seine Struktur ist von verschiedenen Kerngebieten geprägt und weist somit eine Kernstruktur auf. Einige der nuklearen Bereiche sind klar voneinander abgrenzbar, während andere eine diffusere Struktur aufweisen (Puelles, 2007). Die am deutlichsten voneinander abgrenzbaren Strukturen sind das ventrale, tegmentale Areal (VTA, engl. „ventral tegmental area“), die Substantia nigra (SN, engl. „substantia nigra“), die Oculomotor Neuronen (OM, engl. „oculomotor neurons“) und der Nucleus ruber (engl. 
„red nucleus “, (Puelles, 2007)). Daneben gibt es u.a. noch den Bereich der Substantia grisea periaquaeductalis (PAG, engl. „periaqueductal gray“) und die Kerne der Formatio reticularis (Abb. 4, C, (Puelles, 2007)).
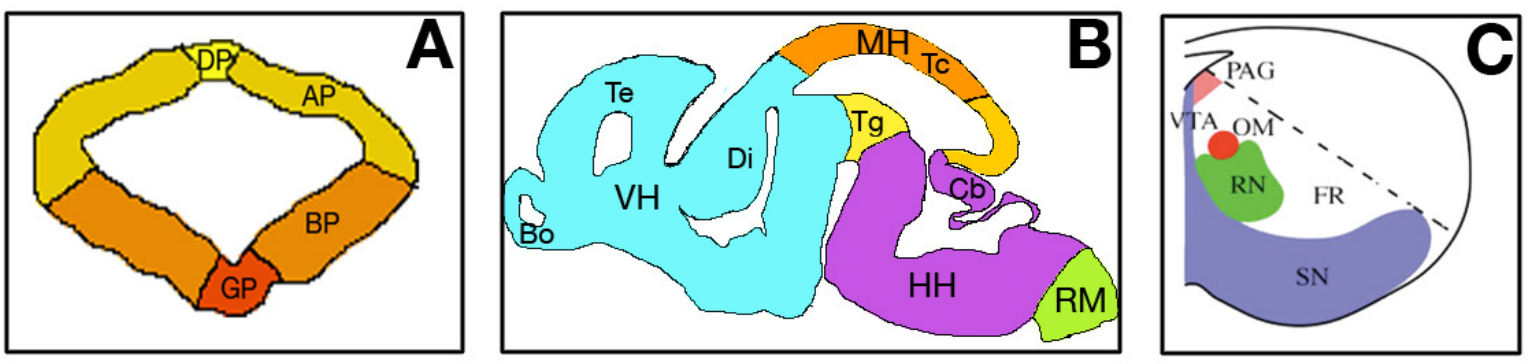

Abb. 4: Schematische Darstellung der morphologischen Strukturen und Kerngebiete des Mittelhirns. (A) Coronale Ansicht des embryonalen Mittelhirns von Mäusen und seine morphologische Struktur an E11.5. (B) Sagittale Ansicht des embryonalen Maushirns an E15.5. Dorsal liegt das Tectum und ventral das Tegmentum. Der dunkel-orange Bereich umfasst die Colliculi superiores, während der hell-orange Bereich die Colliculi inferiores umfasst. Der gelbe Bereich umfasst das Tegmentum im ventralen Mittelhirn. (C) Coronale Ansicht des embryonalen Mittelhirns an E15.5. Die Kernbereiche des Mittelhirns sind schematisch dargestellt. AP: Alarplatte, BP: Basalplatte, Bo: Bulbus olfactorius, Cb: Cerebellum, Di: Diencephalon, DP: Deckplatte, FR: Formatio reticularis GP: Bodenplatte, MH: Mittelhirn, HH: Hinterhirn, OM: Oculomotor Neuronen, PAG: Substantia grisea periaquaeductalis, RM: Rückenmark, RN: Nucleus ruber, SN: Substantia nigra, Tc: Tectum, Te: Telencephalon, Tg: Tegmentum, VH: Vorderhirn, VTA: Ventrales tegmentales Areal. (C) ist modifiziert nach (Puelles, 2007).

Die VTA ist in dem medialen Bereich der Mantelzone lokalisiert (Abb. 4, C) und ihre Axone innervieren u.a. den präfrontalen Cortex und die Amygdala (Prakash \& Wurst, 2006). Die Neuronen der VTA sind an der Modulation kognitiver Prozesse, wie emotionalem und Belohnungsverhalten beteiligt (Prakash \& Wurst, 2006). Der hauptsächliche Transmitter dieser Neuronen ist das Dopamin, daher gehören sie neben den Neuronen der SN zu den dopaminergen Neuronen des ventralen Mittelhirns (mDA Neuronen) (Prakash \& Wurst, 2006). Die SN ist ebenfalls im ventralen Mittelhirn lokalisiert (Abb. 4, C) und ihre Axone innervieren hauptsächlich das Striatum (Prakash \& Wurst, 2006). Die Neuronen der SN sind u.a. an willkürlichen Bewegungsabläufen beteiligt (Prakash \& Wurst, 2006).

Neben den Kerngebieten der dopaminergen Neuronen ist der Nucleus ruber lokalisiert (Abb. 4 , C). Es ist zu erwähnen, dass nur ein Teil des Nucleus ruber (Pars magnocellularis) im Mittelhirn liegt (Puelles, 2007; Gruber \& Gould, 2010). Der Nucleus ruber bekommt Signale vom motorischen Cortex, ebenso wie vom Cerebellum und ist an den Bewegungsabläufen der distalen Extremitäten beteiligt (Puelles, 2007; Gruber \& Gould, 2010).

Oberhalb des Kerngebiets des Nucleus ruber liegt das Kerngebiet der Oculomotorneuronen (Puelles, 2007). Seine Nervenbahnen innervieren verschiedene Muskeln des Auges und sind somit an der Augenbewegung beteiligt. 
Die Kerne der Substantia grisea periaquaeductalis sind nahe dem Ventrikel lokalisiert und an der Modulation von Schmerz und Verhalten beteiligt, während die Kerne der Formatio reticularis (FR) u.a. auch in motorische Prozesse involviert sind (Abb. 4, C, (Puelles, 2007)). Die Kerne der FR gehören zu den diffusen Kerngebieten des Mittelhirns (Puelles, 2007).

\subsection{Die neuronalen Subpopulationen des murinen Mittelhirns}

Wie bereits erwähnt, ist der Isthmus um E9.5 vollständig entwickelt und grenzt das Mittelhirn vom Hinterhirn ab (Abb. 6, B ). Die Regionalisierung des Mittelhirns ist damit abgeschlossen und es folgt die Spezifikation und Differenzierung der einzelnen Neuronengruppen (Gale \& Li, 2008). Morphologisch gliedert sich das Mittelhirn, zu diesem Zeitpunkt von ventral nach dorsal in die Boden-, Basal-, Alar- und Deckplatte (Abb. 4, A). Diese Strukturen können jeweils in die ventrikuläre Zone und die Mantelzone gegliedert werden, wobei sich die Mantelzone wiederum in die intermediäre und marginale Zone aufteilt. Die Zellen der ventrikulären Zone können als neuronale Stammzellen angesehen werden. Sie besitzen die Fähigkeit sich symmetrisch, ebenso wie asymmetrisch, zu teilen und können zu einem neuronalen Subtypen spezifizieren und differenzieren. Nach Beendigung des Zellzyklus' verlassen die Zellen den Bereich der ventrikulären Zone und migrieren über die intermediäre Zone zunächst entlang der dorsoventralen Achse, ehe sie nach lateral auswandern. Die Migration der Neuronen erfolgt entlang der sogenannten radialen Gliazellen (Bonilla et al., 2008). Mit Verlassen des Zellzyklus' sind die Zellen postmitotisch und es beginnt ihre Differenzierung in einen neuronalen Subtyp.

Die Kerngebiete des ventralen Mittelhirns grenzen sich in frühen Embryonalstadien recht deutlich voneinander ab und es herrscht meistens ein Transmittertyp vor. So haben die Neuronen der VTA und SN hauptsächlich ein dopaminerges Zellschicksal, während die Neuronen des Nucleus ruber glutamaterg sind. Aber auch im dorsalen Mittelhirn lassen sich bestimmte Transmittertypen identifizieren. In Abbildung 5 ist eine schematische Darstellung der verschiedenen Transmittertypen im embryonalen Mittelhirn an E11.5 dargestellt.

In den folgenden Kapiteln wird näher auf die einzelnen Neuronentypen und die molekularen Mechanismen, die an ihrer Entwicklung beteiligt sind, eingegangen. 


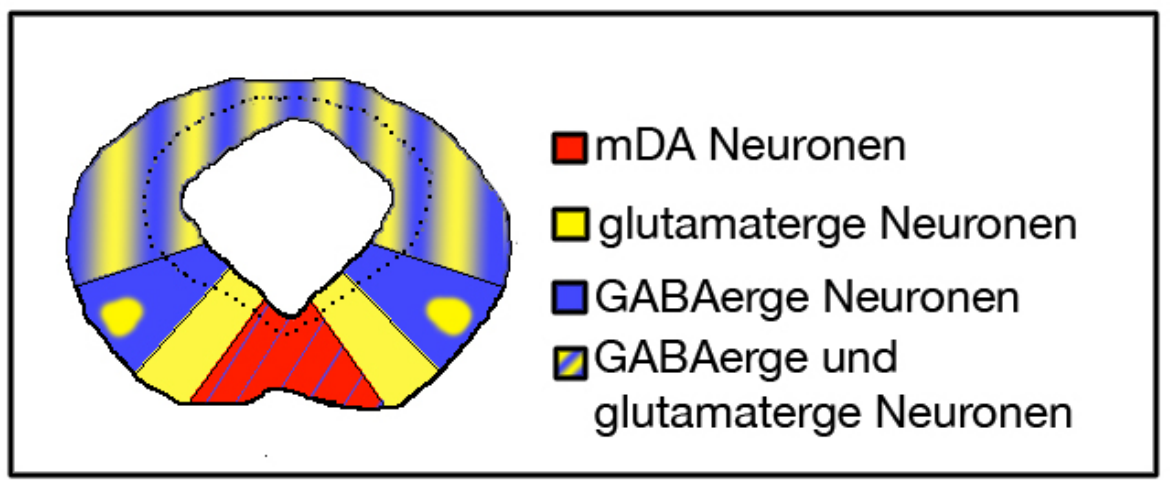

Abb. 5: Schematische Darstellung der neuronalen Populationen im embryonalen Mittelhirn. Die Darstellung zeigt eine coronale Ansicht des embryonalen Mittelhirns an E12.5. Die ventral angeordneten dopaminergen Neuronenpopulationen sind in rot dargestellt. Sie befinden sich in der Bodenplatte, sowie den angrenzenden Bereichen der Basalplatte. Die blaue Linie in dem roten Bereich deutet an, dass hier auch wenige GABAerge Neuronen lokalisiert sind. In der späteren Entwicklung sind in dem Bereich der dopaminergen Neuronen größere Populationen GABAerger Neuronen vorhanden. Gelb zeigt die Bereiche der glutamatergen Neuronen an. Sie sind in der Basal- und Alarplatte lokalisiert. Blau zeigt die Bereiche GABAerger Neuronenpopulationen an. Sie sind in allen Bereichen des murinen Mittelhirns zu finden. Der kleine Bereich der glutamatergen Neuronen in dem Gebiet der ventral gelegenen GABAergen Neuronen zeichnet sich durch die einzigartige Expression von Pax6 aus. Der blaugelbe Bereich im dorsalen Mittelhirn zeigt eine gemischte Population GABAerger und glutamaterger Neuronen an. Die gestrichelte Linie trennt den Bereich der ventrikulären Zone von der Mantelzone. Das Modell basiert auf den Ergebnissen von Nakatani et al. (2007), Kala et al. (2009) und Waite et al. (2011).

\subsubsection{Entwicklung der dopaminergen Neuronen des ventralen Mittelhirns}

Dopamin gehört zu den katecholaminergen Neurotransmittern (Elsworth \& Roth, 1997) und bildet die Vorstufe von Noradrenalin und Adrenalin. Neuronen, die Dopamin als Transmitter verwenden, werden dopaminerge Neuronen genannt. Im ZNS adulter Mäuse sind ca. $75 \%$ der dopaminergen Neuronen im ventralen Mittelhirn lokalisiert, während die restlichen 25\% im Vorderhirn, genauer dem Diencephalon sowie dem Bulbus olfactorius, zu finden sind (Wallen \& Perlmann, 2003).

Im Mittelhirn gibt es drei Kerngebiete in denen die mDA Neuronen lokalisiert sind: die VTA (auch A10 genannt), die SN (auch A9) und das retrorubale Feld (RRF, auch A8 genannt, Abb. 6). Die Neuronen der VTA gehören ebenso wie die des RRF zu dem mesolimbischen Signalweg (Prakash \& Wurst, 2006). Ihre Projektionen reichen u.a. in den präfrontalen Cortex, den Thalamus und den Hippocampus (Abb. 6, C). Sie spielen eine Rolle bei emotionalem Verhalten, Drogenabhängigkeit und dem Belohnungsverhalten (Kelley \& Berridge, 2002; Cagniard et al., 2006). Die dopaminergen Neuronen der SN bilden den nigrostriatalen Signalweg und projizieren in das Striatum und die Kerngebiete des Globus pallidus (Abb. 6, C). Ihre Hauptaufgabe ist die Kontrolle von Bewegungsabläufen. Es ist bekannt, dass die Neuronen der SN in Patienten mit Morbus Parkinson degeneriert sind (Lang \& Lozano, 1998a b; Fahn, 2003). 

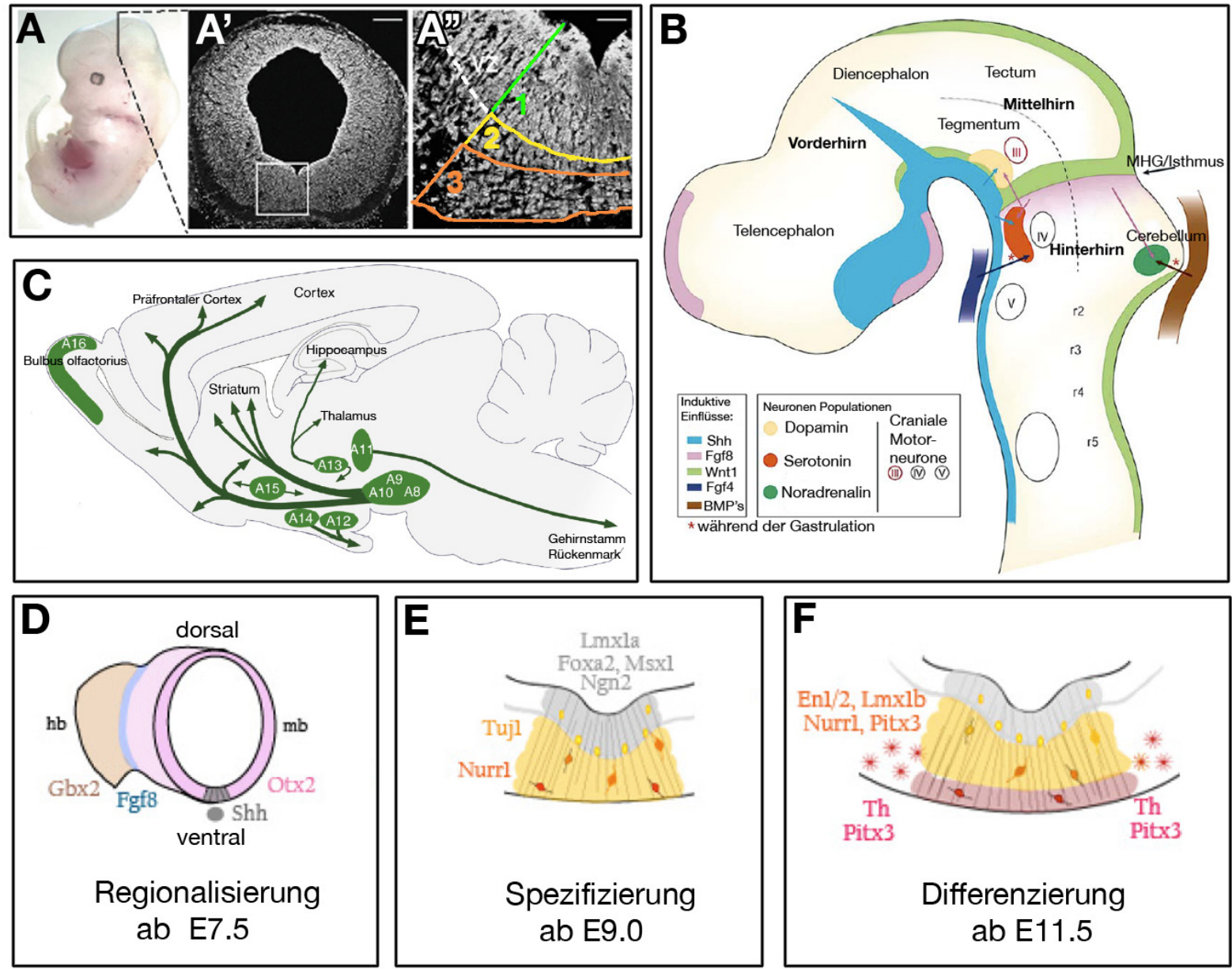

Abb. 6: Dopaminerge Neuronen des Mittelhirns und ihre Entwicklung. (A) Laterale Ansicht eines Mausembryos an E12.5. Die schwarze Linie markiert den Bereich des coronalen Gewebeschnitts in (A'). (A") ist eine Vergrößerung des Ausschnitts von (A'). Die grüne Linie (1) markiert den Bereich der ventrikulären Zone und somit der Vorläuferzellen, der gelbe Bereich (2) den Bereich der intermediären Zone und somit der unreifen mDA Neuronen, während die orange Linie (3) den Bereich der Mantelzone und reifen mDA Neuronen markiert. (B) Schematische Darstellung der Anordnung der dopaminergen und serotonergen Neuronen an der MHG an E11.5, sagittale Ansicht. Daneben ist die Expression einiger Transkriptionsfaktoren und Signalmoleküle zu sehen. Die Pfeile deuten an, welche Signale die verschiedenen Neuronenpopulationen beeinflussen. Die mit einem Sternchen markierten Pfeile sind nur während der Gastrulation von Bedeutung. (C) Lokalisation der mDA Neuronen im adulten Gehirn, Lateralansicht. (D) Regionalisierung des Neuralrohres und die wichtigsten Expressionsdomänen. Das Mittelhirn ist in rosa dargestellt, die MGH in blau und das Hinterhirn in braun. Der graue Kreis stellt die Chorda dorsalis dar. (E-F) Ausschnitt des ventralen Mittelhirns in coronaler Ansicht um E10.0 (E) und E12.0 (F). Der graue Bereich markiert den Bereich der Vorläufer während der gelbe Bereich die frühen mDA Neuronen markiert. Die Spezifikation der mDA Neuronen erfolgt im Bereich der mDA Vorläufer. Die beteiligten Faktoren sind u.a. Lmx1a, Foxa2, Msx1 und Ngn2. Wenn die mDA Neuronen postmitotisch werden, treten sie in die intermediäre Zone ein (gelb) und exprimieren u.a. Nurr1 (E-F). Die reifen mDA Neuronen sind im peripheren Bereich (rot in F) lokalisiert und u.a. durch die Expression von Pitx3 und TH gekennzeichnet (F). Die Abbildungen wurden modifiziert nach: (Prakash \& Wurst, 2004; Ang, 2006; Björklund \& Dunnett, 2007, Gale \& Li, 2008) 


\section{Transkriptionsfaktoren während der Initiierung und Spezifizierung der mDA Neuronen}

Von der Initiierung bis zur Differenzierung ist eine Vielzahl verschiedener Transkriptionsfaktoren und Signalmoleküle von Bedeutung. Neben der Bedeutung des Isthmus' für die Entwicklung des Mittel- und Hinterhirns spielt er, ebenso wie die intrinsischen Faktoren der Neuronen in der Bodenplatte, eine entscheidende Rolle bei der Generierung dopaminerger Neuronen. Die Population der mDA Neuronen grenzt, ebenso wie die Population der serotonergen Neuronen an den Isthmus an (Abb. 6, B). Das Zusammenspiel der einzelnen Faktoren, die bereits in Kapitel 1.3 angesprochen wurden, ist von zentraler Bedeutung für die Initiierung der dopaminergen Neurogenese. So zeigen Wnt1-Knockout-Mäuse eine stark reduzierte Anzahl dopaminerger Neuronen im Mittelhirn, welche im Verlauf der Entwicklung ebenfalls degenerieren (Prakash \& Wurst, 2006). Neben Wntl ist auch Enl für das Überleben der frühen mDA Neuronen not-

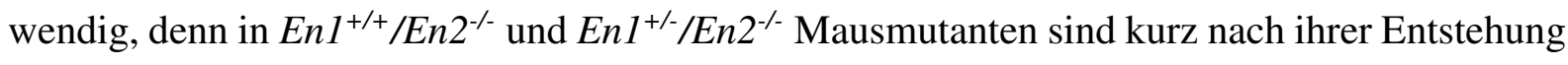
keine mDA Neuronen mehr detektierbar (Simon et al., 2001). Es konnte gezeigt werden, dass Fgf8 und Shh gemeinsam die Bildung von mDA Neuronen im Vorderhirn induzieren können (Ye et al. 1998), was die Wichtigkeit beider Faktoren in der Entstehung der mDA Neuronen verdeutlicht. Spätere Studien konnten zudem demonstrieren, dass zwischen Shh und Wntl ein sogenannter „feedback-loop “ (engl.) besteht um das dopaminerge Zellschicksal einzuleiten und ihre Neurogenese zu initiieren (Joksimovic et al., 2009b).

Nachdem der Vorgang der Regionalisierung, und somit die Anlage der molekularen Identität der Zellen des ventralen Mittelhirns ein dopaminerges Zellschicksal annehmen zu können, abgeschlossen ist (um E9.0) erfolgt die Spezifikation der mDA Neuronen. Die Vorläufer der mDA Neuronen sind in der ventrikulären Zone detektierbar und zeichnen sich u.a. durch die Expression von Otx2, Lmxla/b, Msx1/2, Foxa2 und En1/2 aus (Ang, 2006). Es wird angenommen, dass Lmx1a (engl. „Lim homeodomain transcription factor 1a “) ein früher Aktivator des dopaminergen Zellschicksals im ventralen Mittelhirn ist und die Spezifikation der mDA Neuronen einleitet (Andersson et al., 2006b). Durch den Beginn der Expression von Lmx1a um E9.0 wird vermutet, dass Lmxla aufwärts von Msxl liegt und möglicherweise seine Expression initiiert (Andersson et al., 2006b). Diese Vermutung wird dadurch verstärkt, dass die ektopische Expression von Lmx1a in Hühnerembryonen die Expression von Msxl induziert Andersson et al., 2006b). Während die Expression von Lmx 1a jedoch nicht nur in den Vorläufern, sondern auch in den postmitotischen mDA Neuronen detektierbar ist, wird Msx 1 nur von Vorläufern der 
mDA Neuronen exprimiert (Andersson et al., 2006b; Ono et al., 2007). Die Aktivierung von Lmxla erfolgt möglicherweise über Shh, denn es wurde gezeigt, dass Shh die Expression von Lmxla und Msxl einleiten kann (Andersson et al., 2006b). Interessanterweise führt der spezifische Verlust von Shh in der Bodenplatte jedoch nicht zu einer signifikanten Veränderung in der Anzahl Lmx 1a-positiver Zellen (Lin et al., 2009). Dies lässt vermuten, dass nicht allein Shh an der Induktion der Lmxla Expression beteiligt ist, sondern dies eher auf einem Zusammenspiel verschiedener Signalmoleküle und Transkriptionsfaktoren beruht. Während Lmx1a notwendig und hinreichend für die Bildung von mDA Neuronen ist (Andersson et al., 2006b; Lin et al., 2009; Nakatani et al., 2010), ist Msx1 dies nicht. So wurde gezeigt, dass die ektopische Expression von Lmx1a im Mittelhirn von Hühnerembryonen zur Induktion von mDA Neuronen führt, während Msx1 nicht in der Lage ist die Bildung ektopischer mDA Neuronen einzuleiten (Andersson et al., 2006b). Es wird angenommen, dass Msx 1 durch die Repression von Nkx6.1 die Differenzierung in ein anderes Zellschicksal verhindert und dadurch zur Generierung der mDA Neuronen beiträgt (Andersson et al., 2006b).

Vergangene Studien haben gezeigt, dass Lmx1a und Msx1 notwendig sind um die Expression von Ngn2 (engl. „Neurogenin 2“) einzuleiten (Andersson et al., 2006b). Ngn2 gehört zu den proneuralen Genen mit einer bHLH Domäne (engl. „,basic-helix-loop-helix “). Die Expression von Ngn2 ist ab E10.75 im ventralen Mittelhirn detektierbar (Andersson et al., 2006a) und ist an E11.5 auf die Vorläuferzellen, sowie die mDA Neuronen in der intermediären Zone beschränkt (Andersson et al., 2006a; Kele et al., 2006). In Ngn2 ${ }^{-/-}$Mausembryonen sind an E11.5 nahezu keine reifen mDA Neuronen mehr in der Mantelzone detektierbar. An E13.5 sind jedoch wieder vermehrt Nurr1-positive Neuronen im Bereich der Bodenplatte detektierbar, was verdeutlicht, dass eine Regeneration reifer mDA Neuronen stattgefunden hat (Kele et al., 2006).

Die Autoren erklären dies mit einer Kompensation durch das proneurale Gen Mash1. Des Weiteren ist Ngn2 notwendig, aber nicht ausreichend für die Differenzierung der mDA Neuronen, wie die ektopische Expression von Ngn2 in Zellkulturexplanaten des dorsalen Mittelhirns zeigt (Andersson et al., 2006b). Ngn2 spielt also eine wichtige Rolle während der Generierung postmitotischer mDA Neuronen und ist notwendig für deren Differenzierung in reife mDA Neuronen. Daneben vermittelt Ngn2 den Übergang der mDA Neuronen aus der proliferativen Zone in die intermediäre Zone (Andersson et al., 2006b; Kele et al., 2006). 


\section{Transkriptionsfaktoren während der Differenzierung von mDA Neuronen}

Nachdem die Vorläufer der mDA Neuronen den Zellzyklus verlassen haben erfolgt die Differenzierung. Dabei zeichnen sich unreife mDA Neuronen u.a. durch die Expression von Lmx1a/b, Ngn2, Nurr1, En1/2, Foxa2 und Tuj1 aus (Ang, 2006). Reife, vollständig differenzierte mDA Neuronen hingegen exprimieren u.a. noch Pitx3 und TH, wohingegen kein Ngn2 Protein mehr detektierbar ist (Ang, 2006). Die ersten reifen mDA Neuronen können an E11.5 in der Mantelzone des ventralen Mittelhirns detektiert werden. Ein Auswahl von Faktoren, die an der frühen und terminalen Differenzierung beteiligt und für die vorliegende Arbeit von Bedeutung sind, werden im Folgenden vorgestellt.

Nurr1: Die Expression von Nurr1 (engl. „Nuclear receptor related protein 1 “) ist im ventralen Mittelhirn muriner Embryonen ab E10.5 detektierbar (Zetterstrom et al., 1997). In Nurr1defizienten Mausembryonen werden mDA Neuronen zwar generiert und nehmen einen dopaminergen Phänotyp an (Saucedo-Cardenas et al., 1998), die Expression von TH (Tyrosin Hydroxylase) bleibt jedoch aus. TH ist das limitierende Enzym der Dopaminsynthese und wird daher allgemein als Marker ausdifferenzierter dopaminerger Neuronen verwendet. Neben TH ist auch das Protein VMAT2 (engl. „vesicular monoamine transporter 2“), ebenso wie DAT (engl. „,dopamine transporter “) in Nurrl-defizienten Mausembryonen abwesend (Smits et al., 2003). Diese Ergebnisse machen deutlich, dass Nurrl notwendig ist für die Regulation verschiedener Proteine, die an der Dopaminsynthese beteiligt sind und somit die Transmittersynthese reguliert. Zusätzlich konnte in Nurr1-Knockout-Mäusen beobachtet werden, dass Marker wie Pitx3, En1 und Lmx1b zunächst normal exprimiert, später jedoch herunter reguliert sind (SaucedoCardenas et al., 1998). Es wird vermutet, dass Nurr1 nicht nur an der Regulation der Transmittersynthese, sondern auch an der frühen Differenzierung und dem Erhalt der mDA Neuronen beteiligt ist. Übereinstimmend damit hat eine Inaktivierung von Nurrl in adulten Mäusen einen Verlust der TH Expression zur Folge (Kadkhodaei et al., 2009).

Pitx3: Pitx3 gehört zu den „paired-like related“ Homöobox enthaltenden Transkriptionsfaktoren und seine Expression startet um E11.5 im ventralen Mittelhirn der Maus, kurz nach der Expression von Nurrl (Smidt et al., 1997). In späteren Entwicklungsstadien (E13.5) liegt eine nahezu vollständige Co-Expression von TH und Pitx3 vor. Pitx3 wird also vermutlich in allen dopaminergen Neuronen des ventralen Mittelhirns exprimiert (Smidt et al., 1997; Maxwell et al., 2005). Pitx3 ist der einzige bekannte Faktor, dessen Expression nur in mDA Neuronen, 
jedoch nicht in dopaminergen Neuronen des Vorderhirns, detektierbar ist (Smidt et al., 1997). Studien an der natürlich vorkommenden „aphakia“ Maus, bei der kein Pitx3 Protein gebildet wird, zeigten, dass Pitx3 für die korrekte Bildung der mDA Neuronen in der SN notwendig ist (Nunes et al., 2003; van den Munckhof et al., 2003; Smidt et al., 2004). Deutlich wird dies u.a. durch den Verlust der TH Expression in der SN, aber nicht der VTA, in „aphakia“ Mausmutanten (Maxwell et al., 2005). Da die Neuronen der VTA nicht so stark betroffen sind, wie die der SN, scheinen verschiedene Signalkaskaden an der Differenzierung und dem Erhalt der mDA Neuronen in den einzelnen Domänen notwendig zu sein. Bei Patienten mit Morbus Parkinson ist ein ähnliches Phänomen zu beobachten: Die Neuronen der SN degenerieren, während die der VTA und des RRF nicht so stark betroffen sind. Neuere Studien konnten zeigen, dass Pitx3 ebenso wie Nurr1 die Expression von VMAT2 und DAT reguliert (Hwang et al., 2009), was auf eine gemeinsame Funktion von Pitx3 und Nurr1 hinweist. Unterstützt wird diese Annahme durch die Tatsache, dass Pitx3 und Nurr1 an dieselben Promotorregionen binden (Jacobs et al. 2009).

Lmx1b: Neben Pitx3 und Nurr1 spielt ebenso Lmxlb eine Rolle zur Erhaltung von mDA Neuronen. So zeigen $L m x l b$-defiziente Mäuse eine nahezu vollständig fehlende Expression von Pitx3, während die Expression von Nurr1 nicht betroffen zu sein scheint (Smidt et al., 2000). Auch TH wird anfänglich exprimiert (Smidt et al., 2000). Diese Ergebnisse unterstützen die Theorie, dass mindestens zwei verschiedene Signalwege zur Differenzierung dopaminerger Neuronen im ventralen Mittelhirn existieren, da die Expression von Lmx1b in den „aphakia“ Mausmutanten, ebenso wie in den Nurrl-defizienten Tieren nicht verändert ist (Wallen \& Perlmann, 2003).

Foxa2: Der Transkriptionsfaktor Foxa2 (engl. ,forkhead box a 2 “), auch bekannt als $\operatorname{Hnf} 3 \beta$ ist neben seiner Rolle bei der Entwicklung der Bodenplatte, auch wichtig für die Differenzierung der mDA Neuronen. So zeigen Studien von Foxa2-defizienten Mausembryonen, dass in diesen Tieren die Differenzierung der mDA Neuronen inhibiert ist (Ferri et al., 2007). Foxal und Foxa2 Doppelmutanten weisen sogar eine verminderte Neurogenese, ebenso wie eine unvollständige Differenzierung der mDA Neuronen auf (Ferri et al., 2007). 


\subsubsection{Entwicklung der serotonergen Neuronen im Hinterhirn}

Die serotonergen Neuronen des Hinterhirns, auch 5-HT Neuronen genannt, grenzen an die dopaminergen Neuronen des Mittelhirns (Abb.6, B) und können in zwei Hauptgruppen, bestehend aus verschiedenen Kerngebieten, eingeteilt werden. Die eine Gruppe wird als rostrale Gruppe bezeichnet, während die andere als caudale Gruppe bezeichnet wird (Gaspar et al., 2003). Die 5-HT Neuronen der caudalen Gruppe liegen größtenteils in der Medulla oblongata und projizieren hauptsächlich ins Cerebellum. Die serotonergen Neuronen der rostral gelegenen Kerngebiete sind im Mesencephalon und Pons lokalisiert. Ihre Projektionen sind weitreichend und sie innervieren u.a. den Hippocampus, die Amygdala, den Thalamus und Hypothalamus, sowie die Basalganglien (Azmitia \& Whitaker-Azmitia, 2008). Die 5-HT Neuronen werden um E10.0 und E12.5 im Mausembryo generiert.

\section{Initiierung und Spezifikation der serotonergen Neuronen}

Notwendig für die Induktion und Entwicklung der serotonergen Neuronen sind die Signale des Isthmus' und der Bodenplatte. Insbesondere Fgf8, Shh und Gbx2 spielen eine Rolle während ihrer Entwicklung. So zeigte sich, dass bei einer Verschiebung der Fgf8 und Gbx2 Expression Richtung rostral die Bildung 5-HT-positiver Neuronen im Mittelhirn erfolgt (Brodski et al. 2003). Da die Signale von $F g f 8$ und $S h h$ auch für die Entwicklung der dopaminergen Neuronen wichtig sind und sie deren Entwicklung sogar induzieren können, ergab sich der Schluss, dass weitere Signalmoleküle oder intrinsische Faktoren an der Induktion der serotonergen Neuronen beteiligt sind. Diese Hypothese konnte durch Studien von Ye et al. (1998) belegt werden. So ist es möglich, 5-HT Neuronen ektopisch im Gewebe des ventralen Mesencephalons zu induzieren, wenn Fgf4 hinzu gegeben wird. Somit zeigt sich, dass Fgf8 und Shh allein nicht hinreichend, wohl aber notwendig sind für die Induktion der serotonergen Neurogenese (Ye et al., 1998).

Ein früher Marker der Vorläuferzellen der 5-HT Neuronen ist Nkx2.2. Die Expression von $N k x 2.2$ ist notwendig für die Bildung der 5-HT Neuronen, was eine Studie an Nkx2.2-defizienten Tieren zeigte (Briscoe et al., 1999). Es ist allerdings zu erwähnen, dass offenbar nicht alle 5-HT Neuronen abhängig von Nkx2.2 sind, da im rostralen Bereich weiterhin 5-HT-positive Neuronen detektierbar sind (Briscoe \& Ericson, 1999; Briscoe et al., 1999). Nachfolgend auf die Expression von $N k x 2.2$ folgt die Expression von $N k x 6.1$. Nkx6.1 ist notwendig für die Induktion der Genexpression verschiedener Transkriptionsfaktoren, die an der Spezifizierung der 5-HT 
Neuronen beteiligt sind. So sind Nkx2.2 und Nkx6.1 gemeinsam an der Induktion der Expression von Gata2 und Gata3 beteiligt (Craven et al., 2004). Eine Studie an avianen und murinen Embryonen, bei denen Gata2 inaktiviert, sowie überexprimiert wurde, zeigt, dass Gata2 notwendig und ausreichend ist um die Transkription von Lmxla und Petl zu induzieren (Craven et al., 2004). Gata3 hingegen scheint nicht an der Spezifizierung der 5-HT Neuronen beteiligt zu sein und kann den Verlust von Gata2 nicht kompensieren (Craven et al., 2004).

\section{Transkriptionsfaktoren während der Differenzierung der serotonergen Neuronen}

Während Gata2 eine Rolle während der Spezifizierung spielt, sind Lmxla und Pet1 an der Differenzierung der serotonergen Neuronen beteiligt und ihre Expression wird durch Gata2 induziert (Craven et al. 2004). Petl ist allerdings nur in den Neuronen der Nuclei raphes (engl. „raphe nucleus ") exprimiert. Die Analyse Pet1-defizienter Mäuse zeigte, dass Pet1 für die terminale Differenzierung dieser 5-HT-positiven Neuronenpopulation notwendig ist (Hendricks et al., 2003). Ebenso wie Petl ist Lmxlb für die Differenzierung serotonerger Neuronen in den Nuclei raphe notwendig. So zeigen $L m x 1 b^{-/}$Mausembryonen ebenfalls eine gestörte Entwicklung der 5-HT Neuronen in diesem Bereich (Ding et al., 2003). Daneben scheint Lmxlb für die Aufrechterhaltung der differenzierten 5-HT Neuronen notwendig zu sein, wie eine neuere Studie in konditionalen Mausembryonen zeigt. In diesen Mausmutanten ist Lmx1b in der Pet1-Domäne deletiert (Zhao et al., 2006).

\subsubsection{Entwicklung der GABAergen Neuronen im murinen Mittelhirn}

Der weitverbreitetste inhibitorische Neurotransmitter im Gehirn ist die $\gamma$-Aminobuttersäure. Neuronen die diesen Transmittertyp verwenden, werden GABAerge Neuronen genannt. GABAerge Neuronen sind im gesamten ZNS vorhanden und variieren in ihrer Morphologie, Genexpression und in ihren Projektionen (Bennett \& Balcar, 1999). Im embryonalen Mittelhirn sind GABAerge Neuronen in der frühen Entwicklung (E11.5), wie bereits in Kapitel 1.4 beschrieben, zunächst im dorsalen Teil der Basalplatte, ebenso wie in der Alarplatte lokalisiert (Abb. 5, (Nakatani et al., 2007; Kala et al., 2009). Später (E16.5) können sie auch in der Domäne der dopaminergen Neuronen, genauer in der $\mathrm{SN}$, detektiert werden (Kala et al., 2009). Daneben sind sie im Tectum, der PAG und der Formatio reticularis lokalisiert. 
Frühere Studien haben gezeigt, dass an der Entwicklung der GABAergen Neuronen in verschiedenen Gehirnarealen von Vertebraten ganz unterschiedliche regulatorische Netzwerke involviert sind. So konnte gezeigt werden, dass in der Neurogenese GABAerger Neuronen im Vorderhirn neben Shh u.a. Gsh2 in der Musterbildung eine Rolle spielt (Corbin et al., 2000), während z.B. im ventralen Rückenmark Shh, Nkx6.1 und Irx3 involviert sind (Briscoe et al., 2000). In dem Spezifikationsprozess sind ebenfalls unterschiedliche Transkriptionsfaktoren beteiligt. So ist im Vorderhirn die Expression von Dlx1/2 für die Spezifizierung GABAerger Neuronen von Bedeutung (Anderson et al., 1997), während im ventralen Rückenmark Gata2 eine Rolle spielt (Zhou \& Engel, 2000). Einzig das proneurale Gen Mashl ist für die Entwicklung aller GABAergen Neuronen in allen Gehirnarealen von Bedeutung (Casarosa et al., 1999; Miyoshi \& Bessho, 2004; Li et al., 2005).

Über die Entwicklung der GABAergen Neuronen im murinen Mittelhirn ist bislang nur wenig bekannt, da der Fokus aufgrund seiner klinischen Relevanz deutlich auf der Entwicklung der dopaminergen Neuronen lag. Es wird angenommen, dass Mashl und der Transkriptionsfaktor Helt an der GABAergen Neurogenese beteiligt sind. So konnte gezeigt werden, dass Mashl für die Generierung der dorsal gelegenen GABAergen Neuronen absolut notwendig ist, während seine Inaktivierung im ventralen Mittelhirn nur zu einer verzögerten Differenzierung führt (Peltopuro \& Kala, 2010).

Eine funktionelle Analyse Helt-defizienter Mausembryonen zeigte, dass neben Mash1 ebenfalls Helt eine entscheidende Rolle spielt. So nehmen die GABAergen Neuronen in Abwesenheit von Helt ein glutamaterges Zellschicksal an (Nakatani et al., 2007). Dies deutet darauf hin, dass Helt die Entscheidung ein GABAerges Zellschicksal anzunehmen begünstigt und somit an der Spezifikation beteiligt ist. Des Weiteren scheint Helt den Austritt aus dem Zellzyklus und den Eintritt in die intermediäre Zone zu fördern (Kala et al., 2009). Diese Aufgabe kommt in dopaminergen Neuronen Ngn2 zu (Kap. 1.4.1).

Ein ähnlicher Phänotyp wie in Helt-defizienten Mausembryonen kann in Gata2 $2^{-/-}$Mausembryonen beobachtet werden. Auch hier nehmen nahezu alle GABAergen Neuronen ein glutamaterges Zellschicksal an (Kala et al., 2009). Die einzige Ausnahme bilden hierbei die GABAergen Neuronen in der Domäne der dopaminergen Neuronen (Abb. 5, (Kala et al., 2009)). Dies deutet darauf hin, dass auch hier möglicherweise verschiedene Signalwege für die Differenzierung der Neurotransmitteridentität in verschiedenen morphologischen Strukturen notwendig sind. Da Gata2 ausschließlich von postmitotischen Neuronen exprimiert wird, wird angenommen, 
dass es sich hierbei um ein postmitotisches Selektorgen handelt und an der Differenzierung der GABAergen Neuronen beteiligt ist (Kala et al., 2009).

\subsubsection{Entwicklung der glutamatergen Neuronen im murinen Mittelhirn}

Die glutamatergen Neuronen gehören zu der größten Gruppe der exitatorischen Neuronen im Gehirn. Daher sind sie ebenso wie die GABAergen Neuronen in vielen Bereichen des ZNS lokalisiert. So u.a. auch im Vorderhirn, Mittelhirn und Hinterhirn (Bennett \& Balcar, 1999). Im ventralen Mittelhirn muriner Embryonen grenzen die glutamatergen Neuronen dorsal an die Domäne der dopaminergen Neuronen an, wobei sie sich hauptsächlich im Nucleus ruber und den Oculomotorneuronen befinden (Nakatani et al., 2007; Waite et al., 2011). Daneben ist eine kleine Subpopulation Pax6-positiver glutamaterger Neuronen in der Domäne der GABAergen Neuronen lokalisiert (Abb. 5, (Kala et al., 2009; Waite et al., 2011)). Darüber hinaus sind sie auch im dorsalen Mittelhirn zu verzeichnen (Abb. 5, (Nakatani et al., 2007; Kala et al., 2009; Waite et al., 2011)). Bislang gibt es nicht viele Studien zur glutamatergen Neurogenese im Mittelhirn. Erst kürzlich rückten diese in das Interesse der Wissenschaft. Es ist, wie bei den GABAergen Neuronen auch, davon auszugehen, dass verschiedene Signalwege zur Entwicklung der einzelnen glutamatergen Neuronenpopulationen in den verschiedenen Gehirnarealen führen. So konnte zum Beispiel im Rückenmark gezeigt werden, dass die Transkriptionsfaktoren Tlx1 und Tlx3 die Differenzierung in ein glutamaterges Zellschicksal fördern, während das GABAerge Zellschicksal unterdrückt wird (Cheng et al., 2004). Im Telencephalon wird diese Aufgabe von Otx2 wahrgenommen (Puelles et al., 2006). Ein gemeinsames Merkmal der glutamatergen Neurogenese scheint zu sein, dass das GABAerge Schicksal unterdrückt wird, wenn die Zellen zu glutamatergen Neuronen ausdifferenzieren (Casarosa et al., 1999; Fode et al., 2000; Parras et al., 2002; Cheng et al., 2004; Schuurmans et al., 2004; Cheng et al., 2005). Dies konnte, ebenso wie die Tatsache, dass das glutamaterge Schicksal zu Gunsten des GABAergen Schicksals unterdrückt wird, auch im Mittelhirn gezeigt werden (Nakatani et al., 2007; Kala et al., 2009).

Auf der molekularen Ebene sind bislang nur wenige Faktoren bekannt, die eine Rolle während der Einleitung des glutamatergen Zellschicksals spielen. Nakatani et al. (2007) konnten zeigen, dass Helt ein GABAerges Zellschicksal fördert (Kapitel 1.4.3).

Studien im Vorderhirn zeigen, dass sowohl Ngn1, als auch $N g n 2$, für die Entwicklung eines 
glutamatergen Transmitterphänotyps wichtig sind und beide Gene bereits in den Vorläufern exprimiert werden. Daher ist anzunehmen, dass sie bereits bei der Spezifikation eine Rolle spielen (Schuurmans et al., 2004). Neuere Ergebnisse zeigen, dass dies auch im Mittelhirn der Fall ist (Nakatani et al., 2007).

Darüber hinaus konnten die Autoren zeigen, dass Ngn1 das Potenzial hat ein glutamaterges Zellschicksal zu induzieren (Nakatani et al., 2007). Somit liegen die Ngn-Gene in der Genkaskade abwärts von Helt und ihre Expression wird von dem Helt-Protein induziert.

Welche Faktoren die Differenzierung der glutamatergen Neuronen steuern ist bislang relativ unbekannt. Kala et al. (2009) zeigten, dass Gata2 als postmitotisches Selektorgen fungiert und direkt von Helt aktiviert wird. Somit unterdrückt nicht Helt, sondern Gata2 die Differenzierung in ein glutamaterges Zellschicksal (Kala et al., 2009).

Nkx6.1 ist unter anderem in den glutamatergen Neuronen des Nucleus ruber exprimiert, die sich durch das Vorhandensein Brn3a-positiver Neuronen auszeichnen (Nakatani et al., 2007; Prakash et al., 2009). Prakash et al. (2009) konnten zeigen, dass Otx2 notwendig und hinreichend ist, um die Expression von Nkx6.1 einzuleiten, während Nkx6.1 für die Generierung Brn3apositiver Neuronen notwendig ist. Somit scheint Otx2 in den glutamatergen Neuronen, ebenso wie im Telencephalon, ein wichtiger Transkriptionsfaktor zu sein, der an der Entwicklung der glutamatergen Neuronen beteiligt ist (Prakash et al., 2009).

\subsubsection{Verschiedene Marker der neuronalen Subpopulationen des murinen Mittelhirns}

In den vorangegangenen Kapiteln wurden die Transkriptionsfaktoren vorgestellt, die an der Entwicklung der verschiedenen Neuronenpopulationen beteiligt sind. Zum besseren Verständnis dieser Arbeit ist hier noch einmal eine Darstellung der einzelnen Neuronenpopulationen im Vergleich aufgezeigt und welche molekularen Marker von diesen exprimiert werden. Es sind nur die Marker aufgeführt, die auch in dieser Arbeit verwendet wurden. 


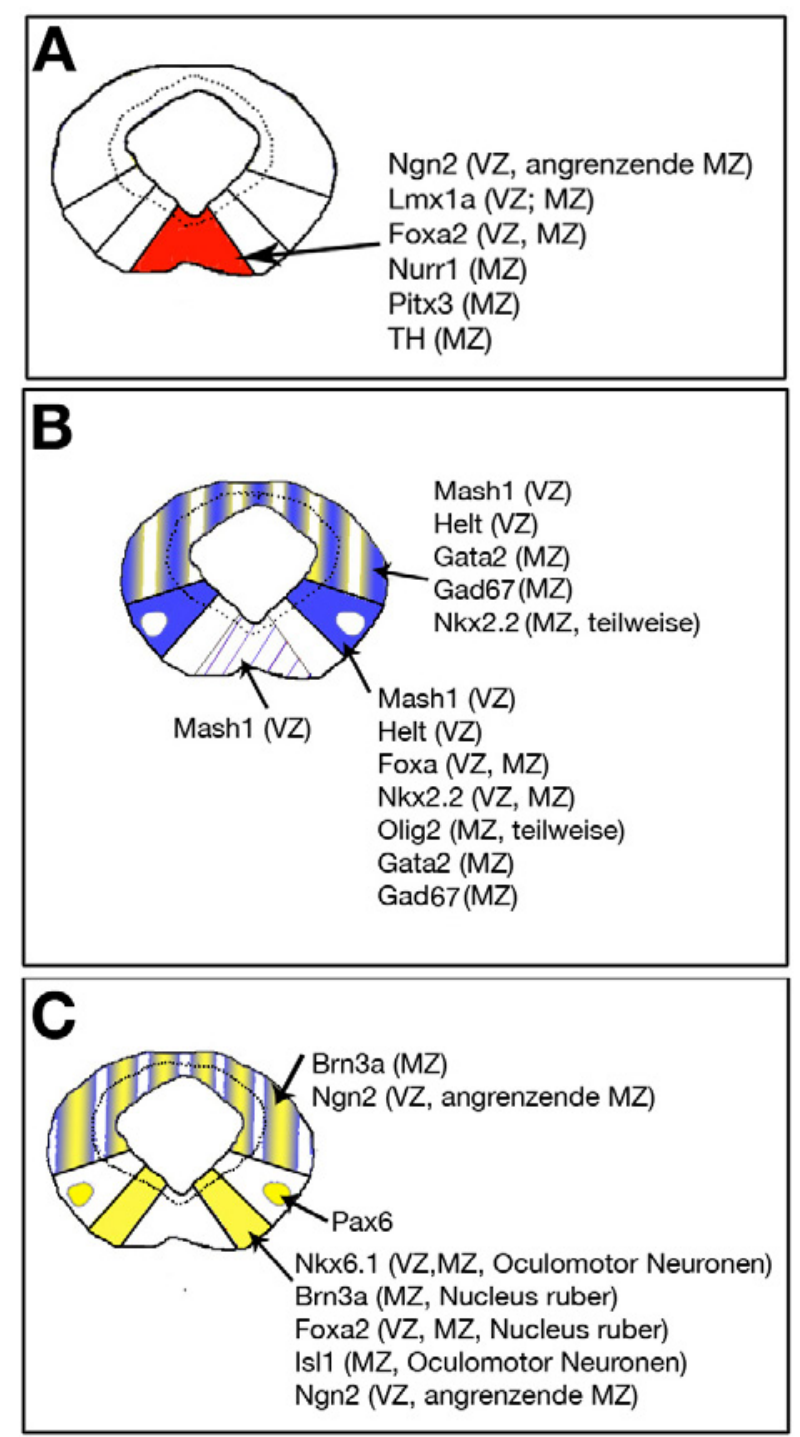

Abb. 7: Marker der verschiedenen neuronalen Populationen im Mittelhirn von Mausembryonen. (A-C) Schematische Darstellung coronaler Gewebeschnitte des murinen Gehirns an E12.5. Der rote Bereich markiert das Areal, in dem die dopaminergen Neuronen lokalisiert sind (A), während der gelbe Bereich zeigt, wo die glutamatergen (B) und der Blaue wo die GABAergen Neuronen lokalisiert sind (C). Im dorsalen Mittelhirn zeigt der blau-gelbe Bereich an, dass hier eine gemischte Population glutamaterger und GABAerger Neuronen vorliegt (BC). VZ zeigt an, dass die Marker von Neuronen der Subpopulation in der ventrikulären Zone exprimiert werden, während MZ anzeigt, dass sie in der Mantelzone exprimiert werden. Oculomotor Neuronen und Nucleus ruber bedeutet, dass die Marker von Neuronen dieser speziellen Kerngebiete exprimiert werden. VZ: ventrikuläre Zone, MZ: Mantelzone. Das vorliegende Schema wurde erstellt nach (Nakatani et al., 2007; Kala et al., 2009, Waite et al. 2011).

\subsection{Der Transkriptionsfaktor Uncx4.1}

Der Transkriptionsfaktor Uncx4.1 gehört zu der Gen-Gruppe, die eine „paired-type-related “ (engl.) Homöodomäne enthalten. Es wurde 1996 als erstes von Rovescalli et al. beschrieben. Später konnte Uncx4.1 von zwei weiteren unabhängigen Forschungsgruppen isoliert und näher charakterisiert werden (Mansouri et al., 1997; Neidhardt et al., 1997). 
Die Homöodomäne ist eine ca. 60 Aminosäuren umfassende Proteindomäne. Sie bindet DNA und kann so die Expression verschiedener Gene regulieren. Oft stehen Homöoboxgene am Beginn einer Signalkaskade und spielen eine weitreichende Rolle während der Entwicklung. Sie sind unter anderem an der Formierung der Körperachsen beteiligt. Ihre notwendige Rolle wird durch ihre starke Konservierung in verschiedenen Spezies deutlich (Manak \& Scott, 1994; Gellon \& McGinns, 1998; Garcia-Fernàndez, 2005; Joseph C. Pearson \& McGinnis, 2005). Die bekanntesten Gene, die eine Homöobox enthalten sind die Hox-Gene. Sie sind in Gruppen (engl. „cluster “) angeordnet und wurden als erstes in Drosophila melanogaster entdeckt (Deschamps, 2007).

Uncx4.1 gehört ebenfalls zu den Transkriptionsfaktoren, die eine Homöodomäne enthalten (Abb. 8) und ist in der Maus in der distalen Region des Chromosoms fünf lokalisiert. Uncx4.1 zeigt eine 88\%ige Homologie mit dem Unc-4 Protein des Fadenwurms Caenorhabditis elegans (Rovescalli et al., 1996; Mansouri et al., 1997; Neidhardt et al., 1997). Der Homöodomäne vorgelagert ist das Aminosegment: PFSIDGLLS, das von zwei alaninreichen Domänen eingerahmt ist (Abb. 8). Am C-Terminus ist ein weiteres Aminomotiv zu finden: PFSVESLLS, dem eine Prolin und Glycin reiche Domäne vorangeht (Abb. 8).

\begin{tabular}{|l|l|l|l|} 
Alanin Alanin & Prolin/Glycin & 9AS \\
\hline
\end{tabular}

Abb. 8: Schematische Darstellung des Uncx4.1-Proteins und seiner Domänen. Rot: Zeigt den Bereich der Homöodomäne, grün: ist eine Prolin und Glycin reiche Domäne, 9AS sind zwei Bereiche in denen ein Aminosegment mit neun Aminosäuren zu finden ist. Links gelegen: PFSIDGLLS, rechts gelegen: PFSVESLLS. Orange: Alanin reiche Domäne. Die Abbildung wurde modifiziert nach (Mansouri et al. 1997).

\subsubsection{Das Expressionsmuster von Uncx4.1 in Vertebraten}

Eine Expressionsanalyse von Uncx4.1 in Vertebraten erfolgte bisher nur in murinen und avianen Embryonen. Sowohl in der Maus, als auch im Huhn, ist Uncx4.1 in den Somiten, dem ZNS und der Nierenanlage exprimiert, was auf eine konservierte Funktion hindeutet (Mansouri et al., 1997; Neidhardt et al., 1997; Schrägle et al., 2004).

Im Mausembryo ist die Expression von Uncx4.1 bereits früh in der Entwicklung (ab E8.5) im ersten Branchialbogen und den Somiten zu verzeichnen (Mansouri et al., 1997; Neidhardt et al. 1997). Etwas später folgt die Expression in der Nierenanlage (E9.5), während Uncx4.1 in den 
Somiten nur noch im caudalen Teil detektierbar ist (Mansouri et al., 1997; Neidhardt et al., 1997). Die ersten Transkripte im ZNS sind an E9.5 im ventralen Mesencephalon detektierbar, während die Expression einen Tag später auch im dorsalen Mesencephalon verzeichnet werden kann. Aber nicht nur im Mittelhirn, sondern auch im Vorderhirn, dem Bulbus olfactorius und dem Rückenmark wird Uncx4.1 an späteren Embryonalstadien exprimiert. So unter anderem im anterioren Teil des Hypothalamus, dem Telencephalon und den Eminentia Thalami (Mansouri et al., 1997; Neidhardt et al., 1997; Sammeta et al., 2010). Die Expression beschränkt sich in allen Bereichen des ZNS weitestgehend auf die Mantelzone (Mansouri et al., 1997), wobei das Uncx4.1-Protein auch in proliferierenden Zellen des Bulbus olfactorius zu verzeichnen ist (Sammeta et al., 2010).

\subsubsection{Die Funktion von Uncx4.1 während der Embryonalentwicklung}

Da die Inaktivierung von Uncx4.1 zu einem lethalen Phänotyp führt (Leitges et al., 2000; Mansouri et al., 2000), wurde seine Funktion bisher nur in embryonalen Stadien untersucht und eine Analyse adulter Mäuse blieb bisher aus.

Der wohl prägnanteste Phänotyp von Uncx4.1-defizienten Mäusen ist im Skelett zu finden. So führt der Verlust des Uncx4.1-Proteins zu einer starken Lordosis, missgebildeten, sowie fehlenden Rippen und Pedikeln (Leitges et al., 2000; Mansouri et al., 2000). Neben den Studien in Mausembryonen zeigen Schrägle et al. (2004), dass Uncx4.1 ebenfalls für die korrekte Etablierung der Somiten in avianen Embryonen notwendig ist. Dies deutet darauf hin, dass Uncx4.1 in allen Vertebraten eine ähnlich Funktion während der Somatogenese erfüllt.

Trotz weitreichender Expression von Uncx4.1 im ZNS sind keine morphologischen Defekte im Gehirn Uncx4.1-defizienter Mausembryonen detektierbar (Leitges et al., 2000; Mansouri et al., 2000). Erst detaillierte, molekulare Analysen konnten einige Funktionen von Uncx4.1 im ZNS entschlüsseln. So übt Uncx4.1 eine selektive Funktion bei der Entwicklung der axonalen Verbindungen des Hypothalamus zur Hypophyse aus. Hierbei scheinen die Axone des Nucleus paraventricularis, ebenso wie die des hypothalamischen Nucleus supraopticus, in die Adenohypophysis einzuwachsen (Asbruek et al., 2006). Daneben konnte eine weitere Studie zeigen, dass Uncx4.1 die Zellproliferation neuraler Vorläuferzellen im Bulbus olfactorius steuert (Sammeta et al., 2010). 


\subsection{Das Cre-LoxP System}

Unter einem klassischen oder auch globalen Knockout-Mausmodell wird die vollständige Inaktivierung eines Zielgens in allen Zellen des Organismus Maus verstanden, was durch homologe Rekombination in embryonalen Stammzellen erreicht wird (Mansouri, 2001b a). Häufig führt die vollständige Inaktivierung eines Gens zu einem lethalen Phänotyp, so dass eine Analyse der Mausmutanten in späteren Embryonalstadien oder nach der Geburt nicht möglich ist (Mansouri et al., 2000; Mukhopadhyay et al., 2006; Cortázar et al., 2011). In anderen Fällen soll die Funktion des gewünschten Gens in einer bestimmten Gewebegruppe untersucht und somit nicht in allen Zellen inaktiviert werden. Zur zellspezifischen oder zeitlich veränderten Inaktivierung eines Gens kann das sogenannte Cre/LoxP-System zur Hilfe herangezogen werden (Mansouri, 2001a; Hayashi \& McMahon, 2002). Hierbei werden in die DNA-Sequenz des zu inaktivierenden Gens sogenannte „lox-P sites“ (engl.) eingefügt. Dabei ist darauf zu achten, dass der spezifisch zu deletierende Bereich an beiden Seiten eine LoxP-Sequenz besitzt. Der nun von den LoxP-Sequenzen eingerahmte Bereich wird als gefloxt bezeichnet. Dies allein reicht jedoch nicht zur Inaktivierung des Gens. Um das Gen ausschalten zu können, ist eine zweite Mauslinie von Nöten: die sogenannte Cre-Linie. Hierbei wird die Cre-Rekombinase des Bakteriophagen P1 spezifisch unter einem bestimmten Promotor (z.B. für Neuronen) exprimiert. Durch die CreRekombinase wird die Rekombination der gefloxten Sequenz vermittelt und es kommt zu einem Ausschneiden des Zielabschnitts (Lewandoski, 2001). So wird die Inaktivierung in einem bestimmten Gewebe ermöglicht. Um auch die spezifische Inaktivierung zu einem gewünschten Zeitpunkt, z.B. nach der Geburt, zu erreichen, wird ein Fusionsgen bestehend aus Cre und einer mutierten Bindedomäne des Östrogenrezeptors verwendet (Hayashi \& McMahon, 2002). Die Mutation verhindert eine Bindung des natürlichen Liganden Östrogen, wohingegen aber der synthetische Ligand 4-Hydroxytamoxifen binden kann. Durch Verabreichung von Tamoxifen kann das Protein in den Zellkern gelangen, wo es dann die Rekombination der „loxP sites“ vermittelt. Dies ist zu jedem beliebigen Zeitpunkt möglich (Danielian et al., 1998; Hayashi \& McMahon, 2002). Um die Inaktivierung zu erreichen, müssen zunächst Tiere der Cre-Linie mit Tieren der gefloxten Linie verpaart werden. Als Nachkommen entstehen doppeltransgene Mäuse. Sie sind heterozygot für das Cre tragende, sowie für das gefloxte Allel. Durch weitere Verpaarungen dieser Tiere können Mäuse generiert werden, die für das gefloxte Allel homozygot und für das Cre Allel heterozygot sind. Dadurch erfolgt die Ablation des gewünschten 
Zielgens in allen Zellen, in denen Cre exprimiert wird. Wurde ein induzierbares System verwendet, erfolgt die Ablation nach Zugabe von Tamoxifen. Ein Beispiel für die Verpaarung zur Generierung einer induzierbaren Knockoutlinie findet sich in Abbildung 41] in Kapitel 5.2.2 des Material und Methoden Teils dieser Arbeit. 


\subsection{Zielsetzung}

Welche molekularen Mechanismen tragen zur Entwicklung des Gehirns bei? Welche Faktoren bestimmen die neuronale Identität einer Zelle? Obwohl in den letzten Jahren viele Transkriptionsfaktoren identifiziert und beschrieben wurden, die an der Entwicklung des Mittelhirns, sowie der transkriptionalen Kontrolle zur Festlegung der neuronalen Identität beteiligt sind, wurden noch immer nicht alle Faktoren und deren Funktion entschlüsselt. Wie bereits in Kapitel 1.5.1 erwähnt, liefert die frühe Expression von Uncx4.1 im Mittelhirn muriner, ebenso wie avianer Embryonen Hinweise auf eine konservierte Funktion im embryonalen Mittelhirn von Vertebraten (Mansouri et al., 1997; Neidhardt et al., 1997; Schrägle et al., 2004). Dennoch wurde bis zum heutigen Zeitpunkt keine Funktionsstudie von Uncx4.1 in diesem Gehirnareal durchgeführt.

In der Vergangenheit konnte gezeigt werden, dass Uncx4.1 in neuronalem Gewebe exprimiert wird. So zeigten schon Saito et al., dass die Expression von Uncx4.1 in allen neuronalen Subgruppen des Bulbus olfactorius detektiert werden kann (Saito et al., 1996). Diese Ergebnisse konnten in einer neueren Studie bestätigt und spezifiziert werden (Sammeta et al., 2010). In dieser Arbeit sollte zunächst die Expression von Uncx4.1 im Mittelhirn muriner Embryonen untersucht und charakterisiert werden. Die Ergebnisse der in dieser Arbeit durchgeführten Expressionsanalyse deuten, ebenso wie die Ergebnisse im Bulbus olfactorius darauf hin, dass Uncx4.1 unabhängig von dem neuronalen Subtyp im Mittelhirn exprimiert wird.

Hieraus ergab sich die Fragestellung, welche Funktion Uncx4.1 in den verschiedenen Neuronengruppen des Mittelhirns ausübt. Zur Klärung dieser Frage wurden Mittelhirne Uncx4.1defizienter Mausembryonen (Kap. 5.2.1) untersucht. Die Krankheit Morbus Parkinson ist mit dem Verlust dopaminerger Neuronen der Substantia nigra assoziiert. Daher wurde in dieser Arbeit vornehmlich die Rolle von Uncx4.1 während der dopaminergen Neurogenese analysiert. Um zu untersuchen, ob die Population der dopaminergen Neuronen in adulten Tieren bei Abwesenheit von Uncx4.1 beeinträchtigt ist, wurde neben der globalen Uncx4.1-Knockoutlinie noch eine konditionale Uncx4.1-Knockoutlinie in die Betrachtung mit einbezogen. Zur besseren Einsicht der Rolle von Uncx4.1 bei der Entwicklung dopaminerger Neuronen, wurden auch embryonale Mittelhirne Lmxla- und Ngn2-defizienter Tiere (Kap. 5.2.1) hinsichtlich der Expression von Uncx4.1 untersucht, da Ngn2 und Lmxla wichtige Funktionen während der dopaminergen Neurogenese zukommen. 
Um Aufschluss darüber zu erlangen, welche Rolle Uncx4.1 während der GABAergen, sowie glutamatergen Neurogenese spielt, sollten zudem die Konsequenzen des Uncx4.1 Verlustes hinsichtlich dieser neuronalen Subgruppen analysiert werden. Aufgrund der Expression von Pax6 in einer Subgruppe der glutamatergen Neuronen und den in dieser Arbeit gewonnenen Ergebnissen, wurde zusätzlich eine Pax6-Knockoutlinie (Kap. 5.2.1) analysiert.

Der Verlust des Unc-4 Gens in C. elegans führt zu Defekten bei der Innervierung der Axone zu den Motorneuronen. Außerdem konnten Asbruek et al. (2006) zeigen, dass die Deletion von Uncx4.1 im murinen Vorderhirn ebenfalls zu axonalen Defekten führt. Daher war die Analyse Uncx4.1-defizienter Mausembryonen hinsichtlich axonaler Defekte im Mittelhirn ein weiteres Ziel dieser Arbeit. 


\section{Ergebnisse}

\subsection{Expressionsanalyse von Uncx4.1 im embryonalen Mittelhirn der Maus}

\subsubsection{Uncx4.1 ist in der Mantelzone des Mittelhirns exprimiert}

In der Vergangenheit wurde gezeigt, dass der Transkriptionsfaktor Uncx4.1 in den Somiten, der Niere sowie dem Nervensystem von Säugetieren exprimiert ist (Mansouri et al., 1997; Neidhardt et al., 1997). Die ersten niedrigen Expressionslevel von Uncx4.1 im Mesencephalon, können bereits ab E9.5 detektiert werden (Mansouri et al., 1997). Um weitere Kenntnisse über die Expression von Uncx4.1 im Mittelhirn der Maus zu gewinnen, wurde eine detaillierte Expressionsstudie durchgeführt. Die Detektion des Uncx4.1-Proteins erfolgte mittels Immunfluoreszenz auf Gewebeschnitten von WT-Embryonen oder mittels X-Gal Färbung heterozygoter Uncx4.1 $1^{\text {lacz/+ }}$ Embryonen. Die Expressionsanalyse zeigt, dass Uncx4.1 bereits ab E10.5 im ventralen, sowie dorsalen Mittelhirn exprimiert ist (Abb. 9, A-B). Zu diesem Zeitpunkt ist die Expression auf die Mantelzone der Basal- und Alarplatte (BP, AP) beschränkt, während keine Transkripte in der Boden- (GP) oder Deckplatte (DP) detektiert werden können (Abb.9. A-B). Am Embryonaltag 11.5 ist Uncx4.1 auch in der Bodenplatte detektierbar und somit fast in der gesamten Mantelzone des Mittelhirns exprimiert (Abb. 9, D). In der späteren Embryonalentwicklung können Transkripte von Uncx4.1 weiterhin nur noch in Teilbereichen der Mantelzone detektiert werden (Abb. 9, E-F). An E13.5 und E17.5 liegen Uncx4.1 positive und Uncx4.1-negative Zellen in einem Salz-und-Pfeffer (engl. ,salt-and-pepper“) Muster in der Mantelzone vor (Abb. 9, E und G). Die Abwesenheit von Uncx4.1-Transkripten in der proliferativen Zone führte zu der Annahme, dass Uncx4.1 nur in postmitotischen Zellen exprimiert ist. Zur Überprüfung dieser Hypothese wurde eine Antikörperfärbung von Uncx4.1 zusammen mit $\beta$-Tubulin III (Tuj1), einem Marker postmitotischer Neuronen, durchgeführt (Ferreira \& Caceres, 1992). Die Analyse zeigt, dass Uncx4.1 an E11.5 nahezu in allen Zellen mit Tuj1 co-lokalisiert ist (Abb.9. F, H und I). Im dorsalen Mittelhirn können allerdings einige wenige Zellen detektiert werden, die zwar Uncx4.1, nicht jedoch Tuj1 exprimieren (Pfeile in Abb. 9. H). Zusammengefasst zeigt die Expressionsanalyse, dass Uncx4.1 nicht von neuronalen Vorläufern, sondern von postmitotischen Neuronen in der Mantelzone des Mittelhirns exprimiert wird. 

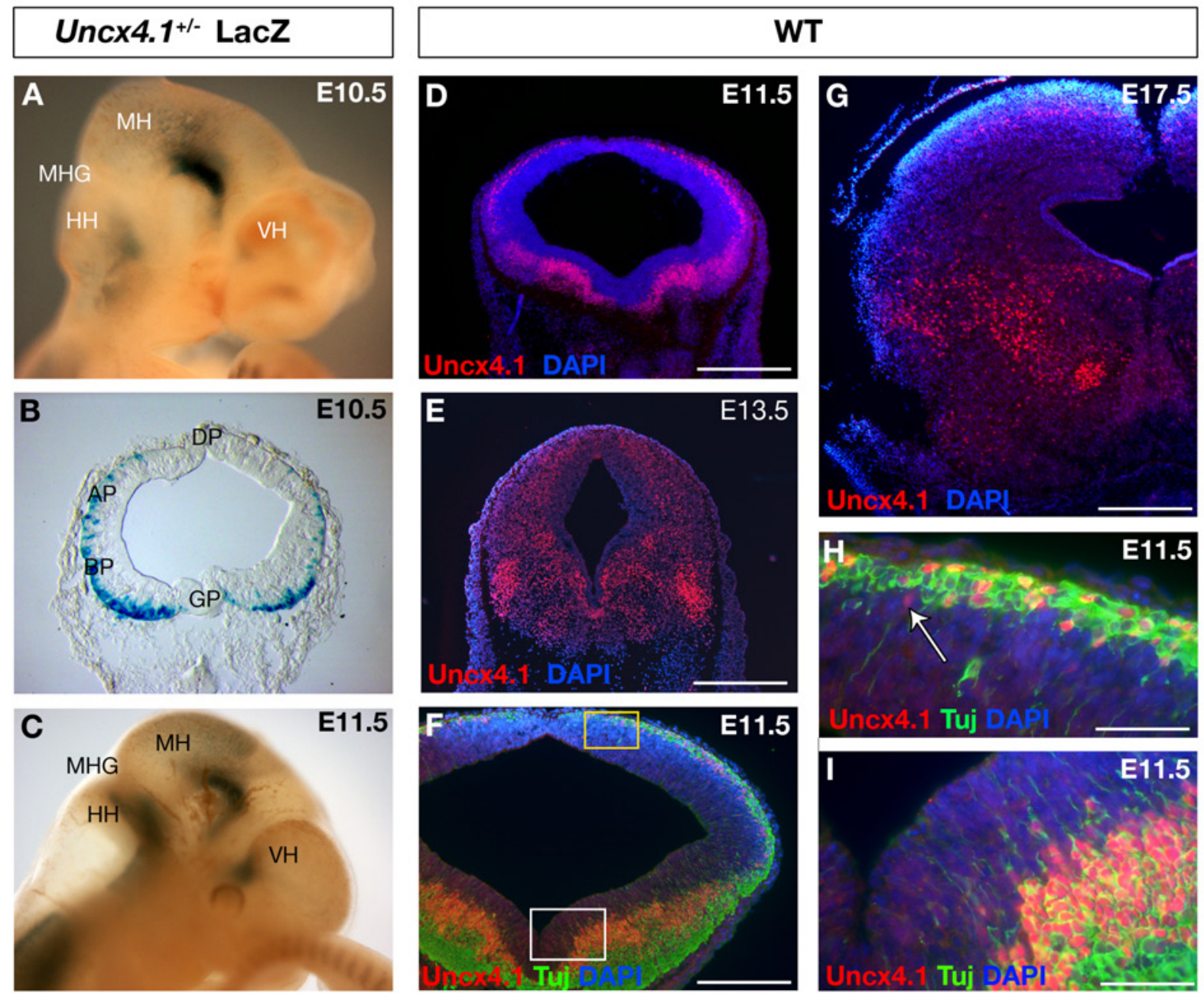

Abb. 9: Expression von Uncx4.1 im Mittelhirn der Maus. (A-C) LacZ-Färbung Uncx4.1 heterozygoter Mausmutanten an E10.5 (A, B) und E11.5 (C). (B) LacZ-Färbung von coronalen Gewebeschnitten des embryonalen Stadiums 10.5. (D-G) IHC von coronalen Gewebeschnitten von Wildtyp-Embryonen mit anti-Uncx4.1 (rot) der Stadien E11.5 (D) E13.5 (E) und E17.5 (G). (F, H, I) Immunfluoreszenzfärbung von coronalen Gewebeschnitten des Stadiums E11.5. mit anti-Uncx4.1 (rot) und Tuj1 (grün). (H) stärkere Vergrößerung des gelben Ausschnitts.(I) Vergrößerung des weißen Ausschnitts. Der Pfeil deutet auf Uncx4.1-positive und Tuj1-negative Zellen. Die Gegenfärbung erfolgte mit DAPI. Maßstabsbalken $=500 \mu \mathrm{m}(\mathrm{D}, \mathrm{E}, \mathrm{F}, \mathrm{G})$. Maßstabsbalken $=100 \mu \mathrm{m}(\mathrm{H}, \mathrm{I})$. VH: Vorderhirn, MH: Mittelhirn, HH: Hinterhirn, MHG: Mittel-Hinterhirn-Grenze, AP: Alarplatte, DP: Deckplatte, BP: Basalplatte, GP: Bodenplatte.

\subsubsection{Uncx4.1 ist in allen neuronalen Subtypen des embryonalen Mittelhirns exprimiert}

Im embryonalen Mittelhirn der Maus gibt es verschiedene Regionen in denen neuronale Vorläuferzellen auftreten. Von ihnen wird angenommen, dass sie in unterschiedliche neuronale Subtypen differenzieren (Nakatani et al., 2007; Ono et al., 2007; Prakash et al., 2009). Da Uncx4.1 an E11.5 in der Mantelzone des gesamten Mittelhirns exprimiert ist (Abb. 9, D), liegt die Vermutung nahe, dass dessen Expression nicht auf einen neuronalen Subtypen begrenzt ist. Zudem 
weisen die meisten Tuj1-positiven Zellen an E11.5 auch eine Co-Lokalisation mit Uncx4.1 auf (Abb.9, F, H und I).
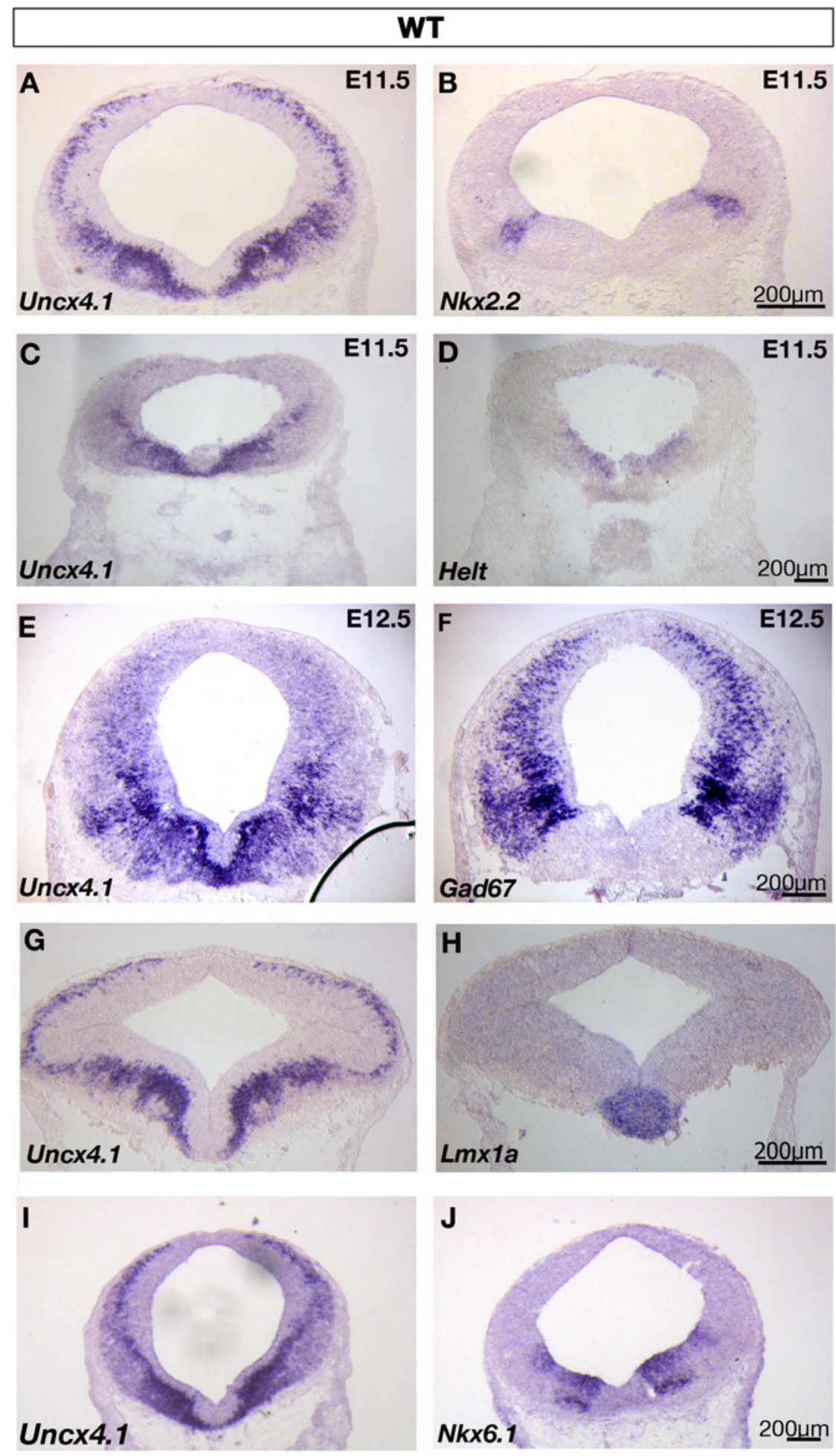

Abb. 10: ISH von Uncx4.1-mRNA und verschiedener neuronaler Marker in E11.5 und E12.5 WildtypGehirnen. (A-J) Expression von Uncx4.1 (A, C, E, G und I) und Nkx2.2 (B), Helt (D), Gad67 (F), Lmxla (H) und $N k x 6.1$ (J) auf alternierenden Schnitten. Die Bilder E-H wurden von Dr. G. Griesel zur Verfügung gestellt.

Um diese Hypothese zu überprüfen wurde die Expression von Uncx4.1 mit spezifischen Mar- 
kern neuronaler Subtypen auf alternierenden Gewebeschnitten verglichen. Als genereller Marker GABAerger Neuronen diente Gad67 (Glutamat-Decarboxylase 1, Isoform mit 67kD), ein Enzym dass in der Biosynthese des Transmitters GABA involviert ist (Erlander et al., 1991). Gad67 zeigt ein vollständig überlappendes Expressionsmuster mit Uncx4.1 an E12.5 (Abb. 10 , E-F), was darauf hindeutet, dass Uncx4.1 zu diesem Zeitpunkt in GABAergen Neuronen exprimiert wird. Bestätigt wird dies durch die überlappende Expression von Nkx2.2 mit Uncx4.1 in Zellen der Mantelzone an E11.5 (Abb. 10, A-B). Nkx2.2 ist an E11.5 in einer Untergruppe GABAerger Neuronen, sowie in Pax6-positiven glutamatergen Neuronen exprimiert Kala et al. 2009). Der Marker Helt, der ausschließlich in proliferierenden GABAergen Neuronen des Mittelhirns an E11.5 exprimiert ist (Nakatani et al. 2007), zeigt keine Überlappung der Expressionsdomänen von Uncx4.1. Die Ergebnisse weisen zusammenfassend auf eine Expression von Uncx4.1 in GABAergen Neuronen des Mittelhirns hin.

Zur Analyse glutamaterger Neuronen wurde die Expression von $N k x 6.1$ mit der von Uncx4.1 verglichen. Nkx6.1 ist in glutamatergen Neuronen der Basalplatte exprimiert und spielt eine entscheidende Rolle während der Entwicklung Brn3a-positiver Neuronen des Nucleus ruber (Prakash et al., 2009). Der Expressionsvergleich zeigt eine vollständige Überlappung von Nkx6.1 und Uncx4.1 in der Mantelzone der Basalplatte (Abb. 10, I-J), was den Schluss zulässt, dass Uncx4.1 neben GABAergen Neuronen auch in glutamatergen Neuronen des Mittelhirns exprimiert ist. Die dopaminergen Neuronen des Mittelhirns sind im ventralen Teil, der Bodenplatte, sowie in Teilen der angrenzenden Basalplatte lokalisiert. Als Marker dopaminerger Neuronen wurde Lmxla verwendet. Auch hier ließ sich eine Überlappung von Uncx4.1 und Lmxla in der Mantelzone des ventralen Mittelhirns feststellen (Abb. 10, G-H).

Aus der Analyse dieser Expressionsmuster lässt sich folgern, dass Uncx4.1 in allen neuronalen Subtypen des Mittelhirns exprimiert wird. Zur Verifizierung dieser Ergebnisse wurden Doppelfärbungen von Uncx4.1 und spezifischen Markern durchgeführt. Dabei zeigte sich, dass Uncx4.1 in einigen Zellen mit Ngn2 co-lokalisiert. Doppelpositive Zellen finden sich sowohl im dorsalen (Abb. 11, A und C), als auch im ventralen Mittelhirn (Abb.11, B und D) und deuten auf eine Expression von Uncx4.1 in dopaminergen und glutamatergen Neuronen hin. Die Co-Lokalisation von Uncx4.1 mit TH, einem Marker reifer dopaminerger Neuronen, und Foxa2 (Abb. 11, E), bestätigt, dass Uncx4.1 in dopaminergen, glutamatergen und GABAergen Neuronen exprimiert wird (Nakatani et al., 2007; Kala et al., 2009; Ferri et al., 2007). Zusammengefasst lassen diese Ergebnisse den Schluss zu, dass die Expression von Uncx4.1 nicht auf einen neuronalen Subtyp 
begrenzt ist, sondern in nahezu allen Neuronengruppen des Mittelhirns exprimiert wird.

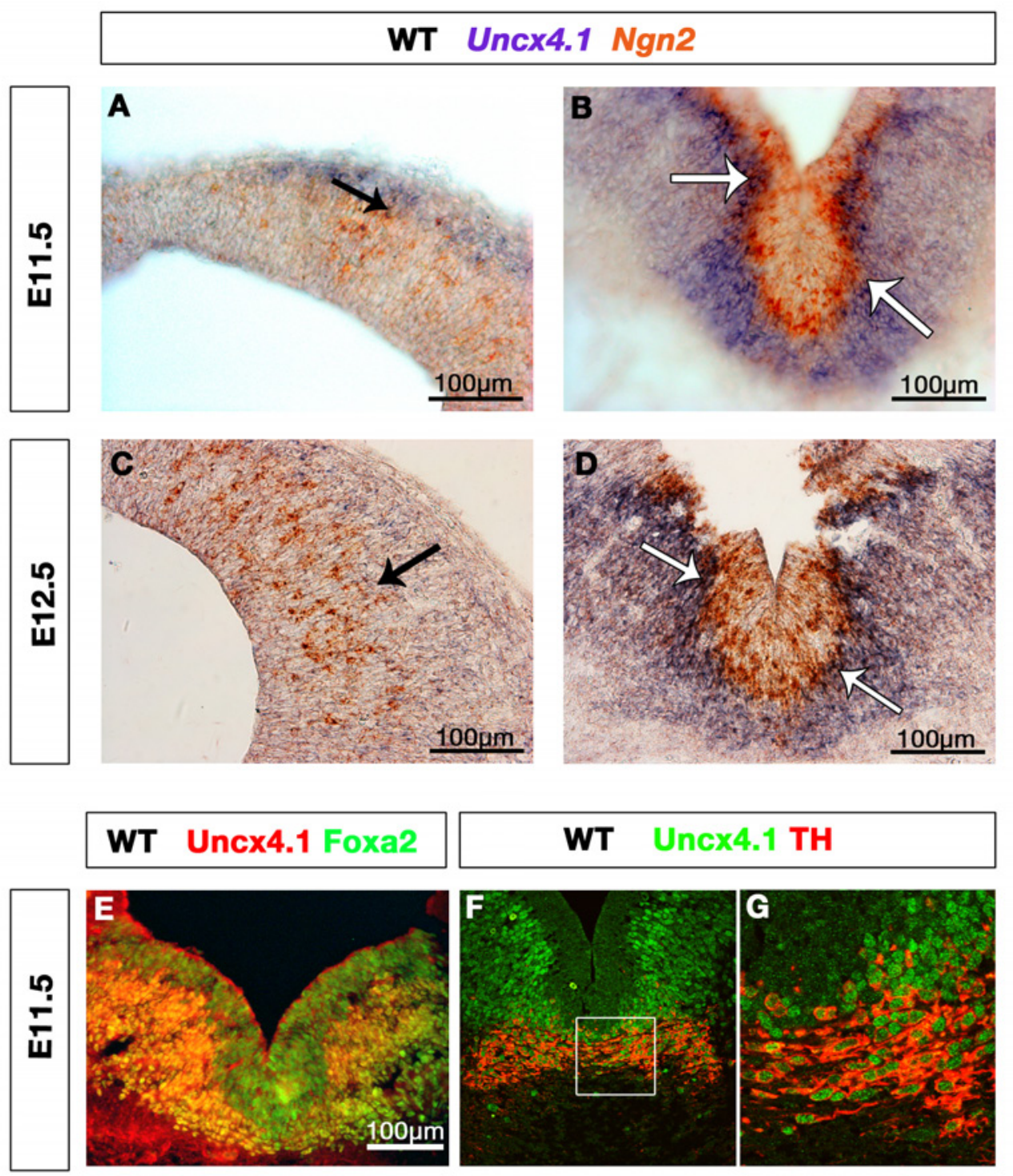

Abb. 11: Uncx4.1 ist in dopaminergen, glutamatergen und GABAergen Neuronen des Mittelhirns exprimiert. (A-D) Doppel-ISH von Ngn2 (orange) und Uncx4.1 (violett) auf coronalen Gefrierschnitten von Mausembryonen an E11.5 (A-B) und E12.5 (C-D). (A, C) Zeigt einen Ausschnitt des dorsalen Mittelhirns. (B, D) Zeigt einen Ausschnitt des ventralen Mittelhirns. Die schwarzen Pfeile deuten auf Uncx4.1 und Ngn2 doppelpositive Zellen im dorsalen Mittelhirn (A, C). Die weißen Pfeile deuten auf Uncx4.1 und Ngn2 co-positive Zellen im ventralen Mittelhirn. (E) zeigt eine IHC an E11.5 gegen anti-Uncx4.1 (rot) und anti-Foxa2 (grün). Gelbe Zellen sind co-positiv für Uncx4.1 und Foxa2. (F, G) Konfokale Aufnahmen einer IHC auf Gewebeschnitten von Wildtypembryonen an E11.5 mit anti-Uncx4.1 (grün) und anti-TH (rot). Uncx4.1 und TH zeigen eine Co-Lokalisation im ventralen Mittelhirn. (G) Vergrößerung des Ausschnitts in (F). 


\subsection{Untersuchungen zur Funktion von Uncx4.1 während der Entwicklung dopaminerger Neuronen im Mittelhirn}

Die Expressionsanalyse von Uncx4.1 zeigt, dass Uncx4.1 an E11.5 mit TH co-lokalisiert ist (Abb. 11, F). Zusätzlich konnten Uncx4.1/Ngn2, sowie Uncx4.1/Foxa2 doppelpositive Zellen im ventralen Mittelhirn detektiert werden (Abb.11, B, D und E). Diese Ergebnisse suggerieren, dass Uncx4.1 eine Rolle während der Entwicklung dopaminerger Neuronen des Mittelhirns spielt. Um dies zu untersuchen, wurden die dopaminergen Neuronen des Mittelhirns Uncx4.1defiziente Tiere analysiert. Zudem wurden $\mathrm{Lmxla}^{-{ }^{--}}$- und $\mathrm{Ngn}^{-{ }^{-}-}$- Mausembryonen mit in die Betrachtung einbezogen um weitere Erkenntnisse über die Rolle von Uncx4.1 während der dopaminergen Neurogenese zu erlangen.

\subsubsection{Der Verlust von Uncx4.1 führt zu einer Reduzierung dopaminerger Neuronen im ventralen Mittelhirn}

Zunächst wurde eine IHC mit anti-TH der Stadien E11.5 und E17.5 durchgeführt (Abb. 12 A-F). Die Domäne der TH-Expression ist in Uncx4.1-defizienten Embryonen nicht verändert. So können TH-positive Neuronen in der VTA, sowie SN detektiert werden (Abb. 12, A-F). Dennoch ist die Anzahl der TH-positiven Zellen an E11.5 und E17.5 um ca. $26 \%$ reduziert (Abb. 12, G).

Um aufzuklären, ob die Inaktivierung von Uncx4.1 sich nur auf die Expression von TH auswirkt, oder ob die Anzahl dopaminerger Neuronen im Allgemeinen verringert ist, wurde die Expression weiterer dopaminerger Marker an E16.5 oder E17.5 analysiert. Neben TH ist auch die Expression des Dopamintransporters (DAT) in der VTA und SN in Abwesenheit von Uncx4.1 vermindert (Abb. 13, A-B). Weiterhin konnte der Verlust der dopaminergen Neuronen mit Antikörperfärbungen gegen Pitx3, Nurr1, Calbindin und Calretinin nachgewiesen werden. Pitx3 ist spezifisch in dopaminergen Neuronen des Mittelhirns exprimiert (Smidt et al., 1997, 2004; Maxwell et al., 2005). Die Reduzierung Pitx3- und Nurr1-positiver Zellen ähnelt der THpositiver Zellen (-31 \% bei Pitx3 und - $24 \%$ bei Nurr1, Abb. 13, C-D, E-F und K). Anders verhält es sich mit der Anzahl Calbindin- und Calretinin-positiver Zellen in der Abwesenheit von Uncx4.1. So liegt bei Calbindin eine Reduzierung von $43 \%$ vor (Abb. 13, G-H, K), während die Anzahl Calretinin-positiver Zellen um $58 \%$ vermindert ist (Abb. 13, I-J, K). 


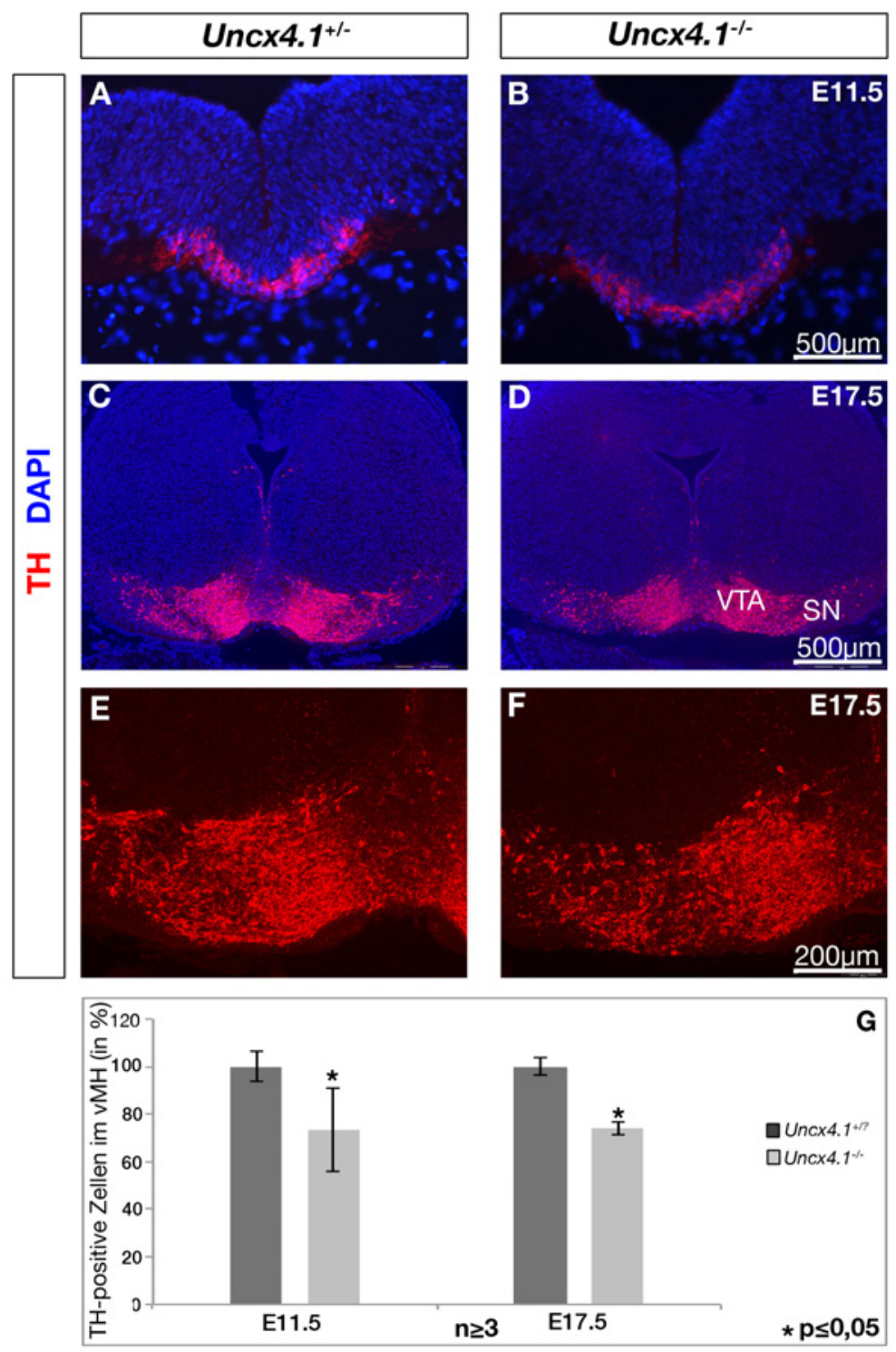

Abb. 12: Die Expression von TH ist in Uncx4.1 homozygoten Embryonen reduziert. (A-F) IHC von Uncx4. $1^{-1-}$ und Kontrollembryonen an E11.5 (A-B) und E17.5 (C-F). (G) Statistische Auswertung der TH-positiven Zellen in Kontrolltieren und Uncx4.1-Mutanten. Die Fehlerbalken zeigen die Standardabweichung. Für die Ermittlung des p-Wertes wurde der „Student's t-test“ angewendet. SN: Substantia nigra, vMH: ventrales Mittelhirn, VTA: Ventrales tegmentales Areal.

Calbindin und Calretinin sind unter anderem in spezifischen Subgruppen von mDA Neuronen, welche hauptsächlich in der VTA lokalisiert sind, detektierbar (Liang et al., 1996; Nemoto et al., 1999). Die starke Reduzierung Calbindin- und Calretinin-positiver Zellen deutet darauf hin, dass die Neuronen der VTA stärker betroffen sind als die der SN. Zusammenfassend kann festgehalten werden, dass die Inaktivierung von Uncx4.1 in einem Verlust der mDA Neuronen resultiert. 

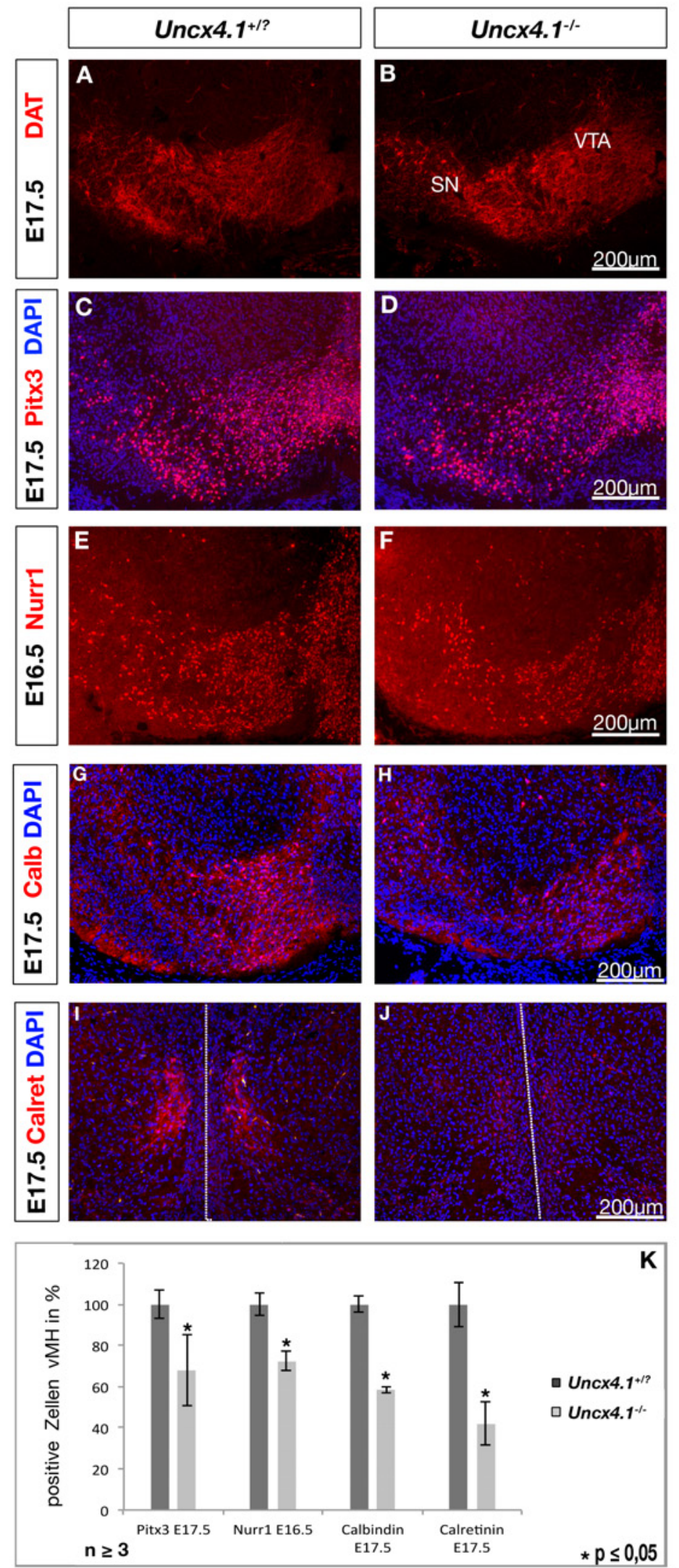

Abb. 13: Die Anzahl dopaminerger Neuronen des ventralen Mittelhirns ist in Uncx4.1-defizienten Embryonen reduziert. IHC coronale Gewebeschnitte von Mausembryonen an E17.5 mit anti-DAT (A-B), anti-Pitx3 (CD), anti-Calbindin (G-H) und anti-Calretinin (I-J). (E-F) IHC mit anti-Nurr1 an E16.5 auf coronalen Gewebeschnitten. (K) Quantifizierung der verwendeten Marker. Die Fehlerbalken repräsentieren die Standardabweichung. Der p-Wert wurde mit dem „student's t-test“ ermittelt. Die gestrichelte Linie markiert die Mittellinie des MH. VTA: Ventrales tegmentales Areal, SN: Substantia nigra, vMH: ventrales Mittelhirn. 


\subsubsection{In Abwesenheit von Uncx4.1 ist keine vermehrte Apoptose im Mittelhirn detektierbar}

Es konnte gezeigt werden, dass die Inaktivierung von Uncx4.1 zu einer vermehrten Apoptose bei den Zellen des Bulbus olfactorius führt (Sammeta et al., 2010). Um zu ermitteln, ob ebenfalls eine erhöhte apoptotische Aktivität in Uncx4.1-defizienten Embryonen der Reduzierung der dopaminergen Neuronen des Mittelhirns zu Grunde liegt, wurde der sogenannte TUNELTest durchgeführt. Mit Hilfe dieser Methode ist es möglich, apoptotische Zellen zu detektieren (Gavrieli et al., 1992). Die Analyse von E11.5 (Abb. 14) und E17.5 (Daten nicht gezeigt) alter Embryonen zeigt jedoch weder im ventralen noch im dorsalen Mittelhirn eine Veränderung in der Anzahl apoptotischer Zellen verglichen mit WT-Embryonen. Eine Inaktivierung von Uncx4.1 führt somit nicht zu einer vermehrten Apoptose im Mittelhirn, so dass die Reduzierung der dopaminergen Neuronen nicht durch verstärkte Apoptose erklärbar ist. Der Verlust könnte daher entweder auf Störungen in der Differenzierung der mDA Neuronen zurückzuführen sein, oder auf eine Veränderung des Zellschicksals in einen anderen Neuronen- oder Zelltyp.

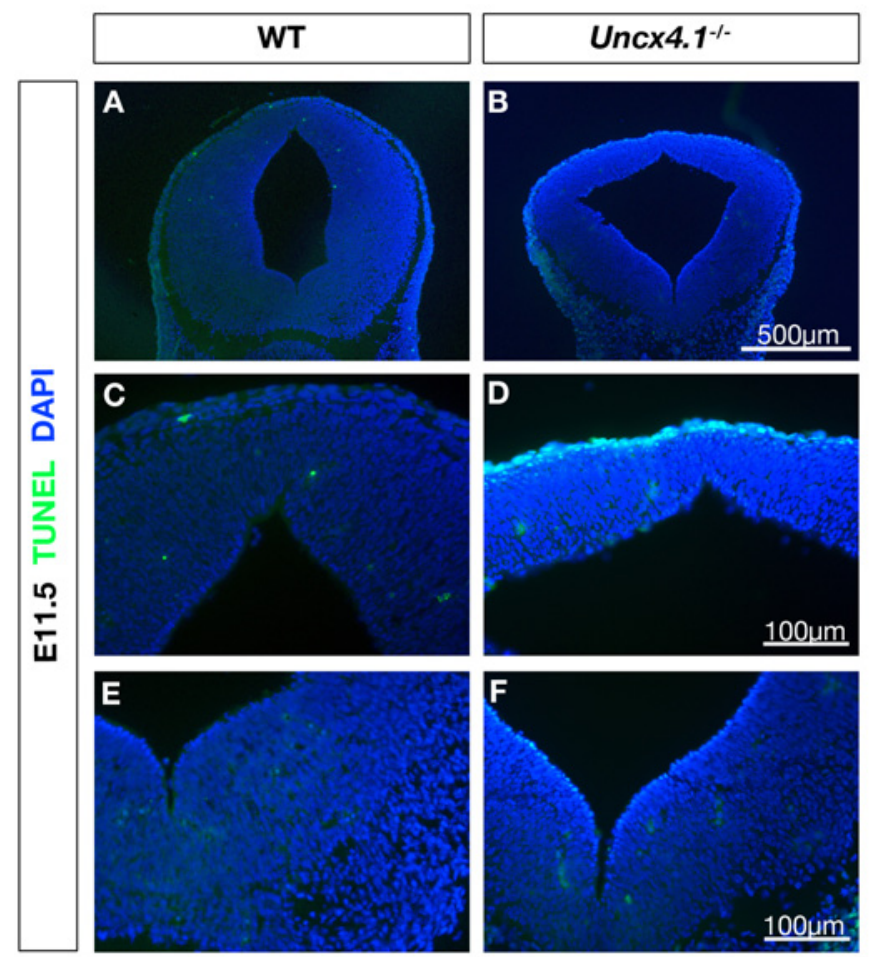

Abb. 14: Der Funktionsverlust von Uncx4.1 hat keinen Einfluss auf die Anzahl apoptotischer Zellen im ventralen Mittelhirn. TUNEL-Test zum Nachweis apoptotischer Zellen auf Gewebeschnitten von WT und Uncx4.1defizienten Mausembryonen des Embryonalstadiums 11.5. (A-B) zeigt eine coronale Ansicht des Mittelhirns. (C) und (D) zeigen eine Vergrößerung des dorsalen Mittelhirns, während (E) und (F) eine Vergrößerung des ventralen Mittelhirns zeigen. Die Gegenfärbung erfolgte mit DAPI. 


\subsubsection{Die Proliferation und Differenzierung des neuronalen Gewebes ist im Mittelhirn Uncx4.1-defizienter Mausembryonen nicht gestört}

BrdU ist ein Thymidinanalogon, das Zellen in der Replikations-Phase detektiert. Daher wurde die Proliferation Uncx4.1-defizienter Embryonen mittels BrdU-Färbung analysiert. Sowohl in Uncx4.1-Mutanten, als auch in Kontrolltieren können BrdU-positive Zellen entlang der ventrikulären Zone des Mittelhirns nachgewiesen werden (Abb. [15, A-B). Des Weiteren konnte kein Unterschied in der Anzahl der BrdU-positiven Zellen detektiert werden (Daten nicht gezeigt).
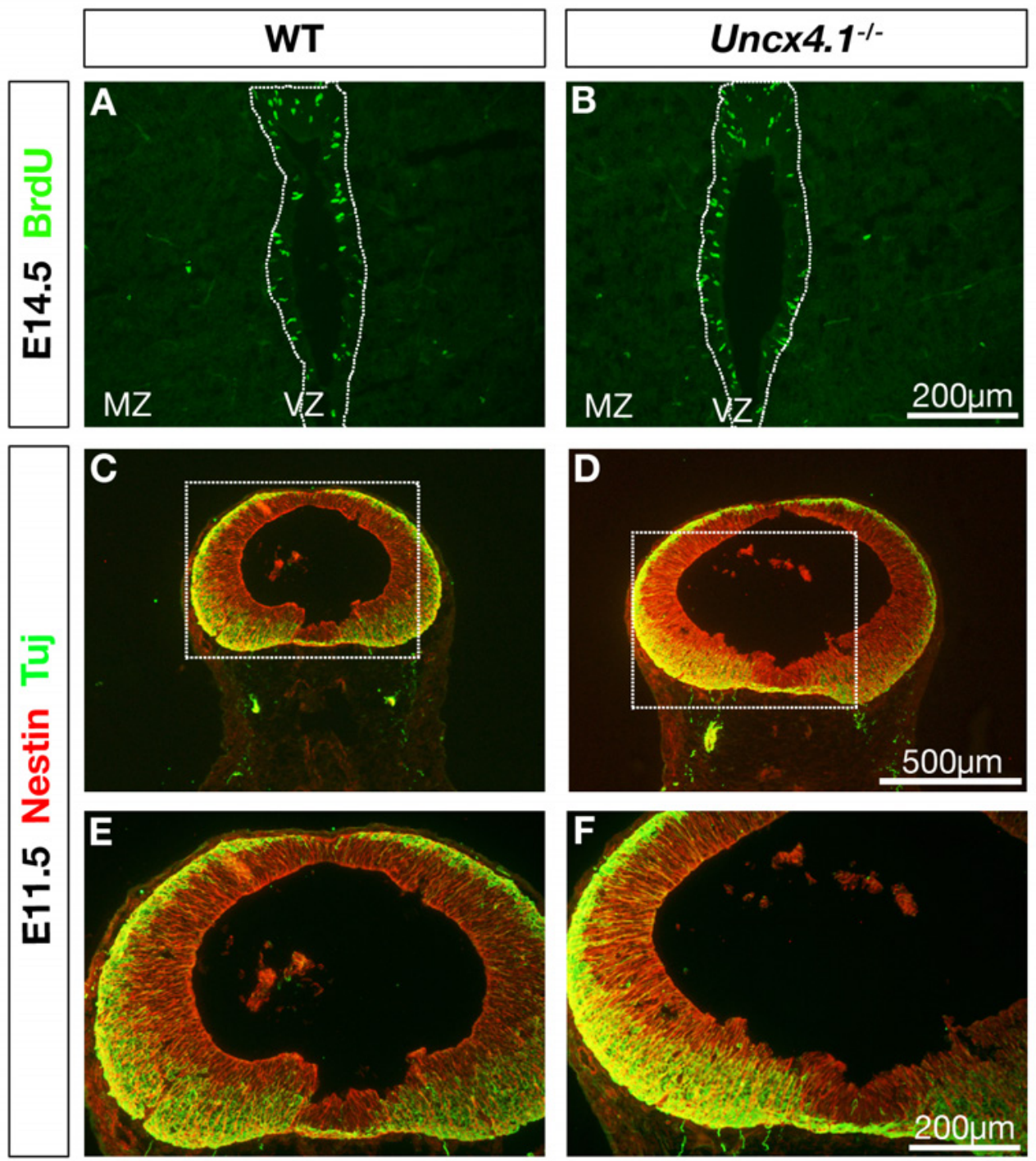

Abb. 15: Weder die Proliferation noch die Differenzierung der Neuronen im Mittelhirn ist in der Abwesenheit von Uncx4.1 beeinflusst. (A-B) Nachweis proliferierender Zellen mittels BrdU-Färbung auf coronalen Kryoschnitten von WT und Uncx4.1\% Mausembryonen des Embryonalstadiums 14.5. (C-F) IHC mittels anti-Nestin (rot) und anti-Tuj1 (grün). Nestin und Tuj1 doppelpositive Zellen sind gelb angefärbt. (E-F) zeigen Vergrößerungen des Ausschnitts in (C-D). Die weiße Linie in (A) und (B) grenzt die ventrikuläre Zone von der Mantelzone ab. VZ: ventrikuläre Zone, MZ: Mantelzone. 
Um sicherzustellen, dass der Funktionsverlust von Uncx4.1 nicht in einer verzögerten Differenzierung neuronaler Zellen resultiert und dies zum Verlust der dopaminergen Neuronen führt, wurde eine Doppelfärbung gegen Nestin und Tuj1 durchgeführt. Nestin ist ein Marker neuronaler Vorläuferzellen (Lendahl et al., 1990), während Tuj1, wie bereits in Kapitel 2.1.1 erwähnt, als Marker postmitotischer Neuronen verwendet werden kann. Die Analyse coronaler Gewebeschnitte Uncx4.1-defizienter Embryonen des Embryonalstadiums 11.5 ergab keine Unterschiede in den beiden Färbungen verglichen mit Kontrollembryonen. Daraus lässt sich schließen, dass keine verzögerte Differenzierung in der Abwesenheit von Uncx4.1 vorliegt. Die hier vorgestellten Ergebnisse zeigen, dass eine Inaktivierung von Uncx4.1 keinen signifikanten Einfluss auf die Proliferation oder die neuronale Differenzierung im Mittelhirn hat.

\subsubsection{Die Positionierung dopaminerger und serotonerger Neuronen an der MHG ist in Abwesenheit von Uncx4.1 nicht beeinträchtigt}

Die Expressionsdomänen der dopaminergen und serotonergen Neuronen an der MHG grenzen sich deutlich voneinander ab und zeigen keine Überlappung (Ye et al., 1998). Vorangegangene Studien haben gezeigt, dass die Inaktivierung verschiedener Gene in einer Verschiebung der Expressionsgrenze in Richtung der Domäne der jeweils anderen Neuronenpopulation resultiert (Blaess et al., 2006; Griesel et al., 2006). Da die dopaminergen Neuronen des ventralen Mittelhirns in Abwesenheit von Uncx4.1 reduziert sind und dieser Verlust nicht auf vermehrte Apoptose oder Proliferationsdefekte zurückzuführen ist, wurde überprüft ob eine ektopische Expression serotonerger Neuronen in der Domäne der dopaminergen Neuronen vorliegt. Die Ergebnisse der Doppelimmunfärbung gegen TH (dopaminerge Neuronen) und 5-HT (serotonerge Neuronen) zeigen, dass die Grenzen der Expressionsdomänen dopaminerger und serotonerger Neuronen normal etabliert sind und keine ektopische Expression von 5-HT im Mittelhirn vorliegt. Hingegen kann eine leichte Erhöhung 5-HT-positiver, serotonerger Neuronen im Hinterhirn verzeichnet werden (Abb. 16, C-E) und es liegt eine dorsale Expansion der serotonergen Neuronen im caudalen Hinterhirn vor (Abb. 16, Pfeile in C und D). Die statistische Auswertung ergab jedoch, dass die beobachtete Erhöhung nicht signifikant ist. Eine Tendenz ist aber dennoch erkennbar und lässt auf eine Beteiligung von Uncx4.1 während der Entwicklung serotonerger Neuronen des Hinterhirns schließen. 


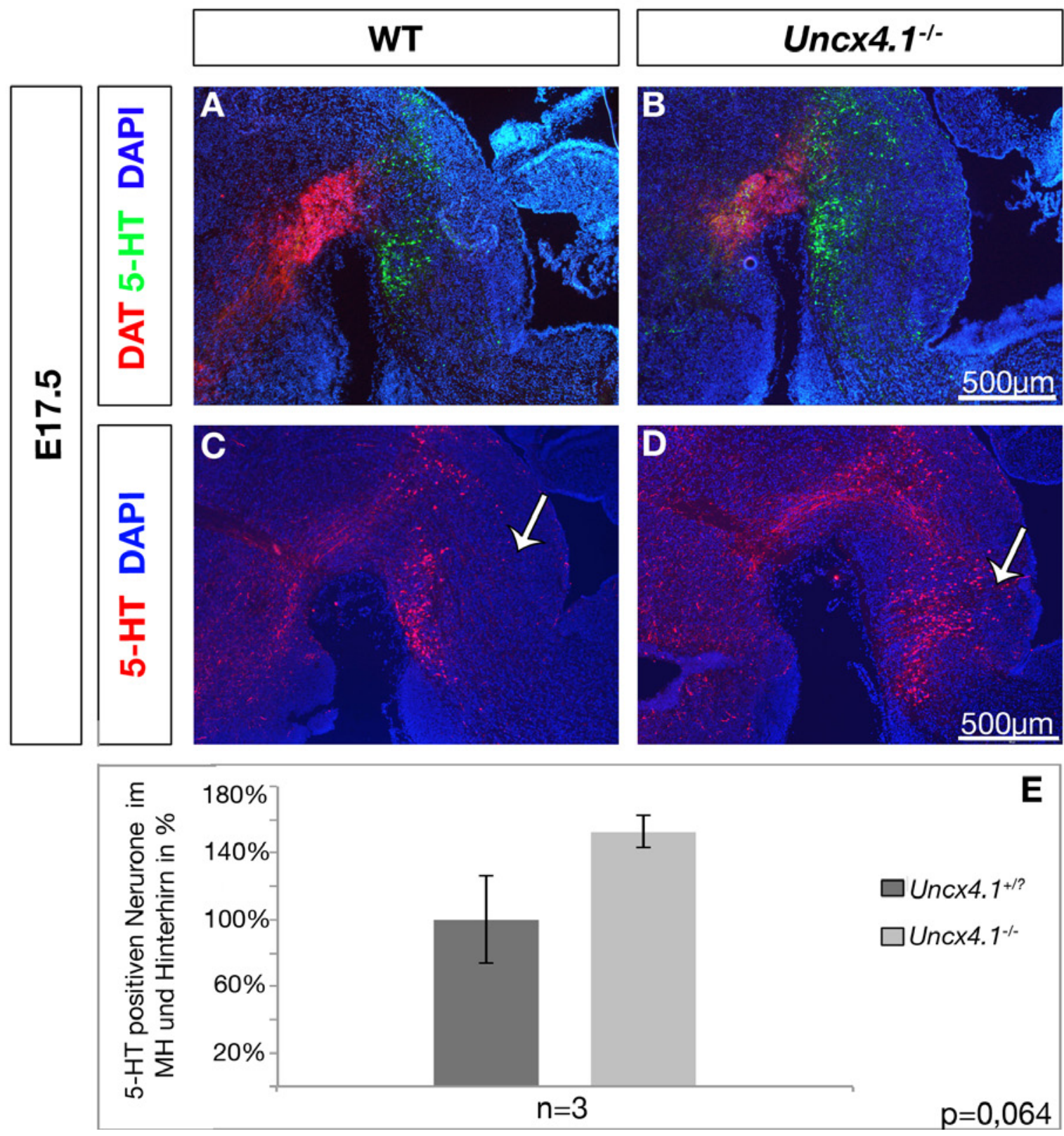

Abb. 16: Dopaminerge und serotonerge Neuronen weisen in Uncx4.1 ${ }^{-/-}$Embryonen unveränderte Expressionsdomänen an der MHG auf. (A-B) Doppel-IHC gegen DAT (rot) und 5-HT (grün) auf sagittalen Gewebeschnitten von Mausembryonen an E17.5. (C-D) IHC gegen 5-HT auf sagittalen Gewebeschnitten E17.5 alter Uncx4.1-Mutanten im Vergleich zu den Kontrolltieren. (E) Statistische Analyse der Anzahl 5-HT positive Neuronen. Die Fehlerbalken in (E) zeigen die Standardabweichung. Der p-Wert wurde mittels , student's t-test “ ermittelt. Die Pfeile deuten auf den Bereich, in dem die dorsale Expansion 5-HT positiver Neuronen detektierbar ist. MH: Mittelhirn. 


\subsubsection{Expressionsanalyse von Lmx1a, Foxa2, Ngn2, Nurr1 und Mash1 im ventralen Mittelhirn von Uncx4.1\% Embryonen}

Die vorhergehenden Ergebnisse zeigen, dass der Verlust der dopaminergen Neuronen im ventralen Mittelhirn nicht auf Proliferationsdefekte, eine vermehrte Apoptose oder eine Verschiebung der serotonergen Neuronen zurückzuführen ist. Um zu untersuchen, was die Reduzierung der dopaminergen Neuronen im Mittelhirn verursacht, wurden verschiedene neuronale Marker analysiert, die bereits in der frühen Entwicklung der dopaminergen Neuronen des Mittelhirns eine entscheidende Rolle spielen. Der Transkriptionsfaktor Lmxla ist bereits in den Vorläufern dieser Neuronen an E9.5 exprimiert (Andersson et al., 2006b) und eine spontane Mutation führt zu dem Verlust der caudalen Deckplatte (Millonig et al., 2000). Andersson et al. (2006) zeigten, dass Lmx la eine entscheidende Funktion als Schicksalsdeterminante während der Entwicklung der dopaminergen Neuronen zukommt.

Eine Expressionsanalyse von Lmxla in Uncx4.1-defizienten Embryonen zeigt keinen Unterschied im Vergleich zu WT Embryonen, weder an E11.0 noch an E12.5 (Abb. 17, A-D). Auch die Expression des Transkriptionsfaktors Foxa2, welcher für die korrekte Etablierung von mDA Neuronen notwendig ist (Lin et al., 2009; Mavromatakis et al., 2011; Nakatani et al., 2010), ist in Abwesenheit von Uncx4.1 nicht beeinflusst. Das proneurale Gen Ngn2 ist essenziell für die Differenzierung (Fode et al., 1998) und Spezifizierung (Parras et al., 2002; Ma et al., 1999, Scardigli et al., 2001) neuronaler Subpopulationen in verschiedenen Regionen des Nervensystems. Im Mittelhirn ist Ngn2 notwendig für die Bildung der dopaminergen Neuronen und wird von den Vorläufern und unreifen dopaminergen Neuronen exprimiert (Andersson et al., 2006a; Kele et al., 2006). In Uncx4.1-defizienten Mausembryonen ist eine deutliche Reduzierung der Ngn2-mRNA im ventralen (Abb. 17, G-H) und dorsalen (Abb. 28, I-J) Mittelhirn zu verzeichnen. Zudem ist der Verlust der Expression im ventralen Mittelhirn gleichmäßig, was bedeutet, dass die Zellen der ventrikulären Zone ebenso betroffen sind wie die der Mantelzone. 

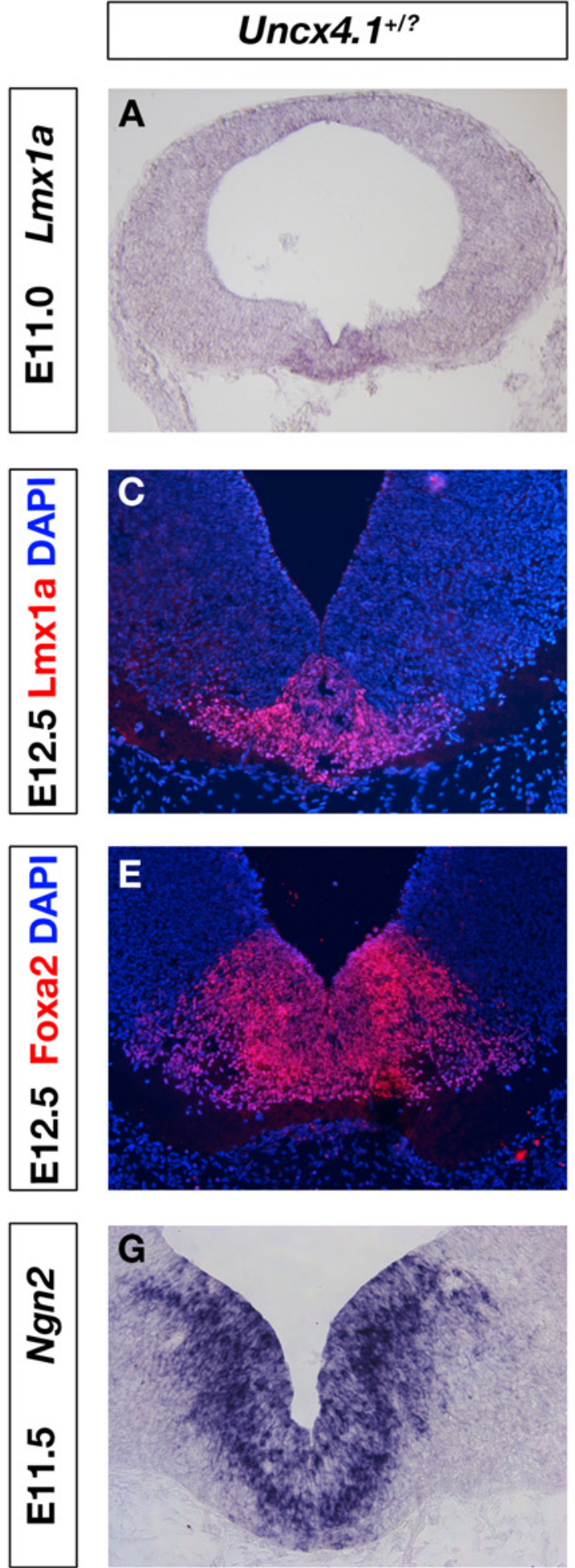
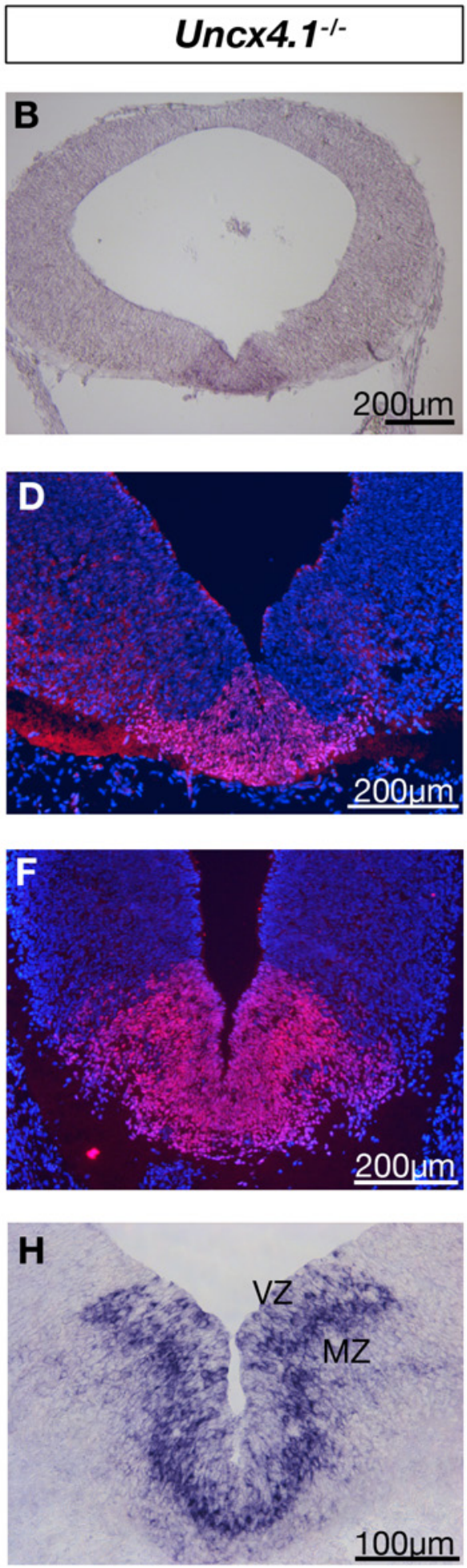

Abb. 17: Analyse spezifischer Marker, die während der Bildung der dopaminergen Neuronen des Mittelhirns beteiligt sind. (A-D) Sowohl eine ISH gegen Lmxla an E11.5 (A-B), als auch eine IHC mit anti-Lmx1a an E12.5 (C-D) auf coronalen Gewebeschnitten zeigen keine Veränderung in der Anzahl Lmx1a-positiver Neuronen in Uncx4.1 defizienten Mäusen. (E-F) zeigen eine IHC mit anti-Foxa2 an E12.5 auf coronalen Kryoschnitten. Die Gegenfärbung erfolgte mit DAPI. (G-H) ISH von coronalen Gewebeschnitten des Embryonalstadiums 11.5 mit einer gegen Ngn2 gerichteten Sonde. 
In $\mathrm{Ngn2}^{-/}$Embryonen ist nahezu keine Expression von Nurr1 an E11.5 zu verzeichnen, allerdings kann an E13.5 eine Wiederherstellung Nurr1-positiver Zellen beobachtet werden (Kele et al., 2006). Dies deutet auf eine progressive Erneuerung dieser Zellen hin. Aufgrund der starken Reduzierung der Ngn2-mRNA wurde dieser Umstand auch in Uncx4.1 $1^{-1}$ Embryonen untersucht. Mittels IHC wird deutlich, dass die Anzahl Nurr1-positiver Zellen sowohl an E11.5 (Abb. 18, C-D) als auch an E16.5 (Abb. 18, E-F) reduziert ist. Eine statistische Analyse (Abb. 18, G) ergibt, dass der Verlust Nurr1-positiver Zellen an E11.5 ca. $28 \%$ und an E16.5 ca. $23 \%$ beträgt. Anders als in Ngn2-defizienten Mäusen ist keine Regeneration Nurr1-positiver Zellen in Abwesenheit von Uncx4.1 detektierbar. Die Wiederherstellung Nurr1-positiver Zellen in $\mathrm{Ngn2}^{-/}$Embryonen kann durch die teilweise Regeneration des proneuralen Gens Mash1 erklärt werden. So fehlt Mashl an E11.5 an der ventralen Mittelinie des Mittelhirns fast vollständig, während an E13.5 wieder Transkripte von Mashl detektierbar sind (Kele et al., 2006). In Abwesenheit von Uncx4.1 sind keine Unterschiede in der Expression von Mash1 festzustellen (Abb.18, A-B).

Zusammenfassend weisen Uncx4.1 $1^{-/}$Embryonen keine veränderte Lmxla, Foxa2 oder Mash1 Expression auf. Hingegen ist die Expression von Ngn2 im ventralen Mittelhirn reduziert, während der Verlust der Nurr1-positiven Zellen in den untersuchten Entwicklungsstadien konstant bleibt. 

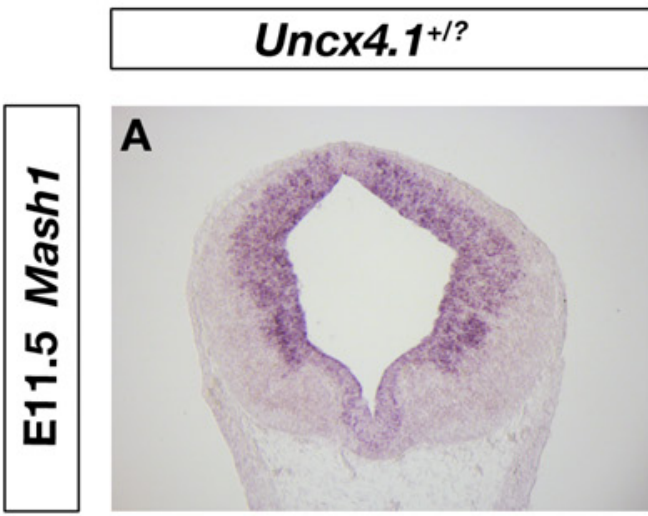

A
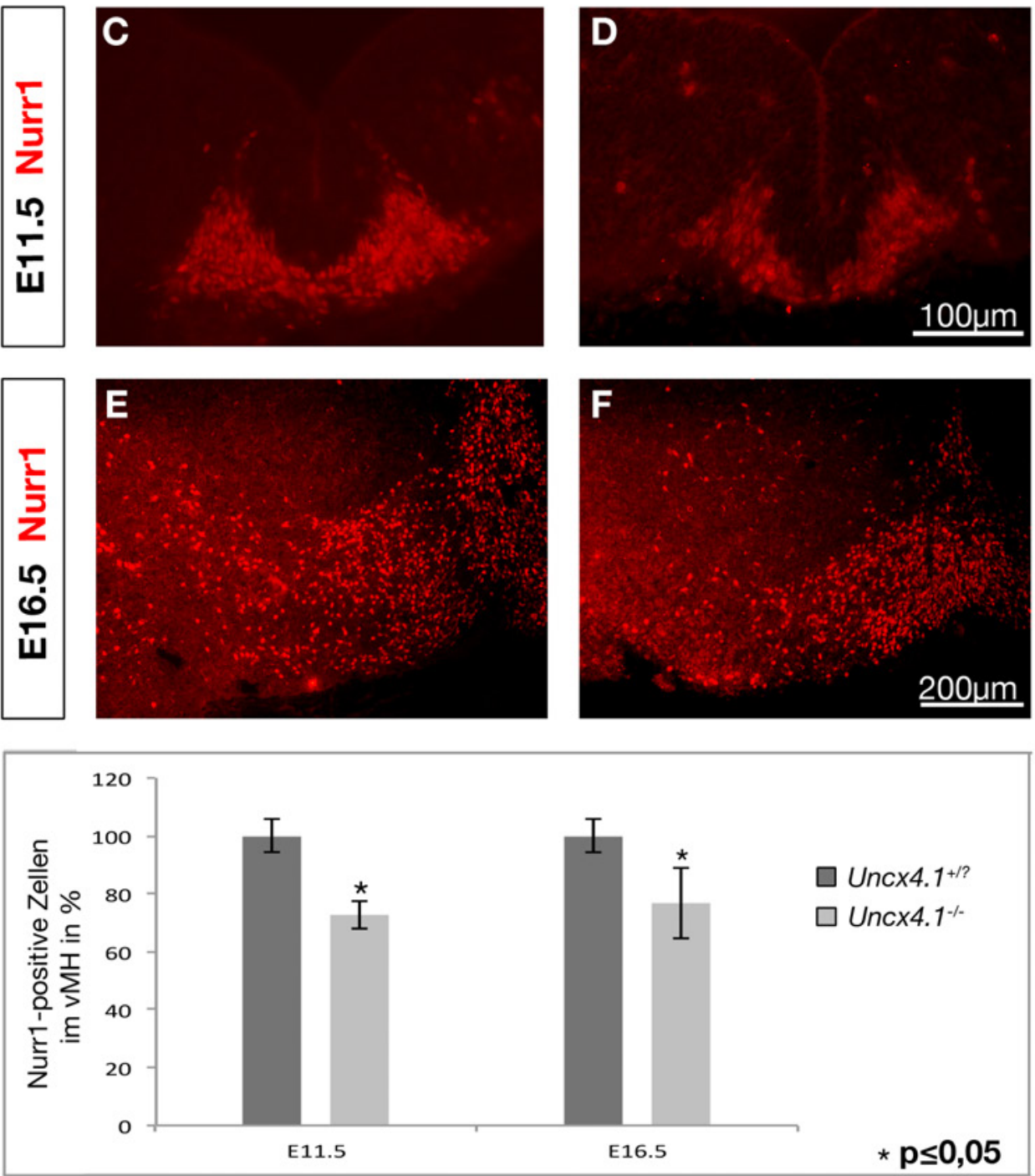

Abb. 18: Die Anzahl Nurr1-positiver Neuronen ist während der Entwicklung in Abwesenheit von Uncx4.1 gleichbleibend. (A-B) ISH auf coronalen Gewebeschnitten des Embryonalstadiums 11.5 mit einer gegen Mashl gerichteten RNA-Sonde. (C-F) Antikörperfärbung mit anti-Nurr1 auf coronalen Gewebeschnitten von Mausebryonen des Stadiums E11.5 (C-D) und E16.5 (E-F). (G) Statistische Auswertung der Nurr1-positiven Zellen im ventralen Mittelhirn. Die Fehlerbalken zeigen die Standardabweichung. Der p-Wert wurde mit dem „student's t-test“ ermittelt, $\mathrm{n}=3$. vMH: ventrales Mittelhirn. 


\subsubsection{Die Expression von Uncx4.1 im Mittelhirn Lmx1a-defizienter Embryonen}

Ein Verlust der Uncx4.1-Expression in Lmxla-defizienten Embryonen könnte Hinweise darauf liefern, dass Uncx4.1 in der Kaskade der Transkriptionsfaktoren, die während der Bildung der mDA Neuronen reguliert werden, abwärts von Lmxla liegt. Eine IHC auf coronalen Gewebeschnitten Lmxla-defizienter Embryonen gegen Uncx4.1 zeigt, dass die Expression von Uncx4.1 in Abwesenheit von Lmxla nicht beeinflusst ist (Abb. 19, A-B). Da es sich um eine KnockinLinie handelt, bei der anstelle von Lmxla GFP exprimiert wird, zeigt die Expression von GFP an, wo normalerweise Lmxla-Transkripte detektierbar sind.

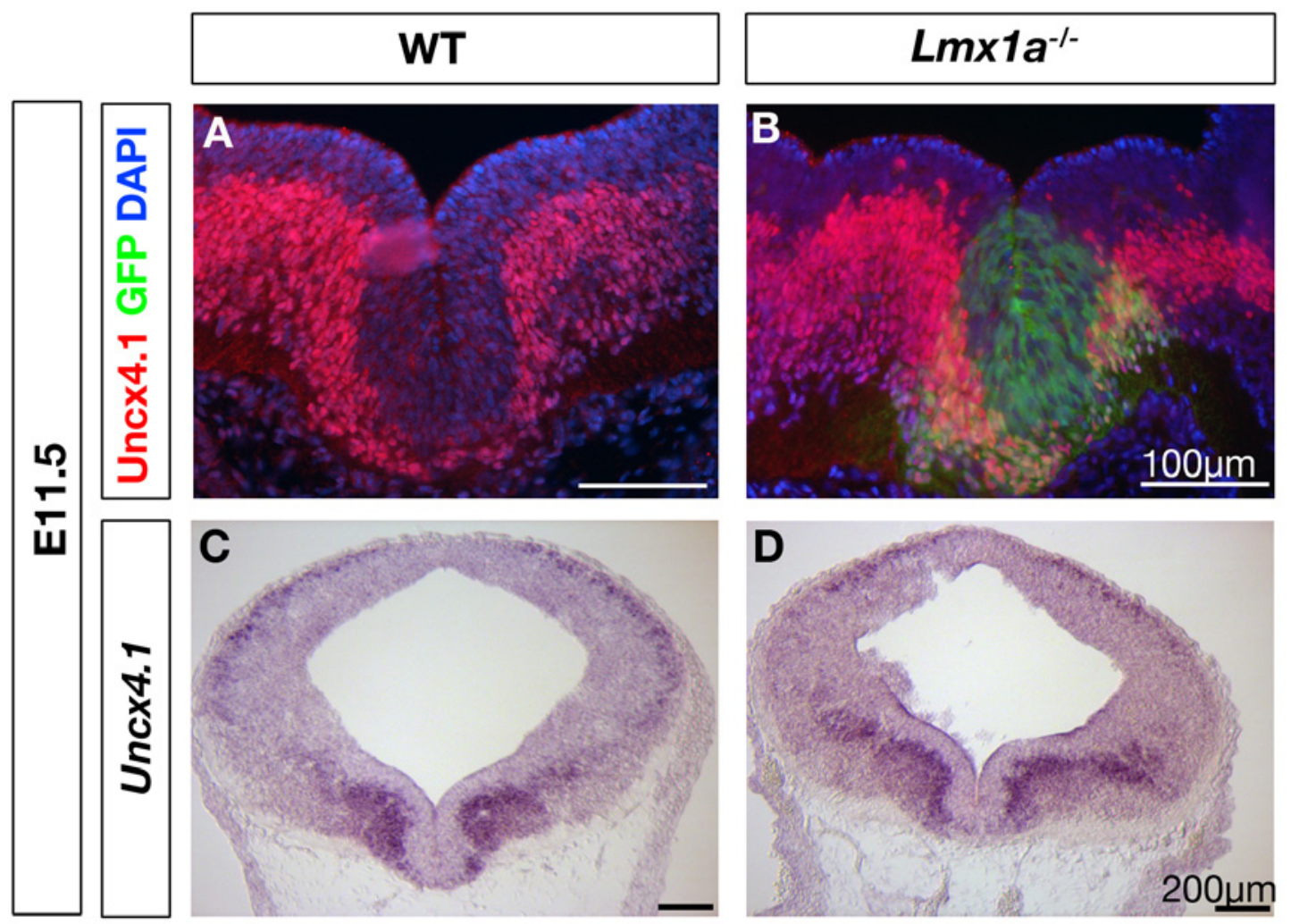

Abb. 19: Uncx4.1-positive Zellen in Lmxla-defizienten Mäusen. (A-B) IHC gegen Uncx4.1 (rot) und GFP (grün) auf coronalen Gewebeschnitten des Stadiums 11.5. Die Gegenfärbung erfolgte mit DAPI. (C) und (D) zeigen eine ISH mit einer gegen Uncx4.1 gerichteten RNA-Sonde von WT (C) und Lmxla ${ }^{-/}$(D) Embryonen an E11.5.

Es konnten sowohl in Lmxla homozygoten, als auch in heterozygoten Embryonen GFP und Uncx4.1 co-positive Zellen detektiert werden (Abb. 19, B. Daten heterozygoter Tiere nicht gezeigt). Eine ISH mit einer gegen Uncx4.1 gerichteten RNA-Sonde bestätigt, dass der Verlust von Lmxla keinen Einfluss auf die Expression von Uncx4.1 ausübt (Abb. 19, C-D). 


\subsubsection{Die Expression von Uncx4.1 im Mittelhirn Ngn2-defizienter Embryonen}

Kele et al. (2006) zeigten, dass ein Funktionsverlust von Ngn2 zu einer Reduzierung der Neuronen in der ventromedialen Mantelzone führt. Dies geht mit einer Rückhaltung der Zellen in der ventrikulären Zone einher. Ebenso konnten Kele et al. zeigen, dass die meisten Vorläuferzellen der dopaminergen Neuronen des Mittelhirns nicht ausdifferenzieren, sondern arrestiert werden, bevor sie den vollständigen neuronalen Phänotyp annehmen konnten (Kele et al., 2006). Die Analyse der Uncx4.1-Expression in Ngn2-defizienten Embryonen der Embryonalstadien 11.5 und 13.5 zeigt, dass eine Inaktivierung von Ngn2 zu einem Verlust Uncx4.1-positiver Zellen in der Mantelzone des ventralen Mittelhirns führt. So können an E11.5 (Abb. 20, A-B) und an E13.5 (Abb. 20, C-D) keine Uncx4.1-positiven Zellen an der ventralen Mittelline von Ngn2defizienten Embryonen detektiert werden. Auch bei der hier verwendeten Mauslinie handelt es sich um eine Knockin-Linie. Hierbei wird GFP anstelle von Ngn2 unter dem Ngn2-Promotor exprimiert.

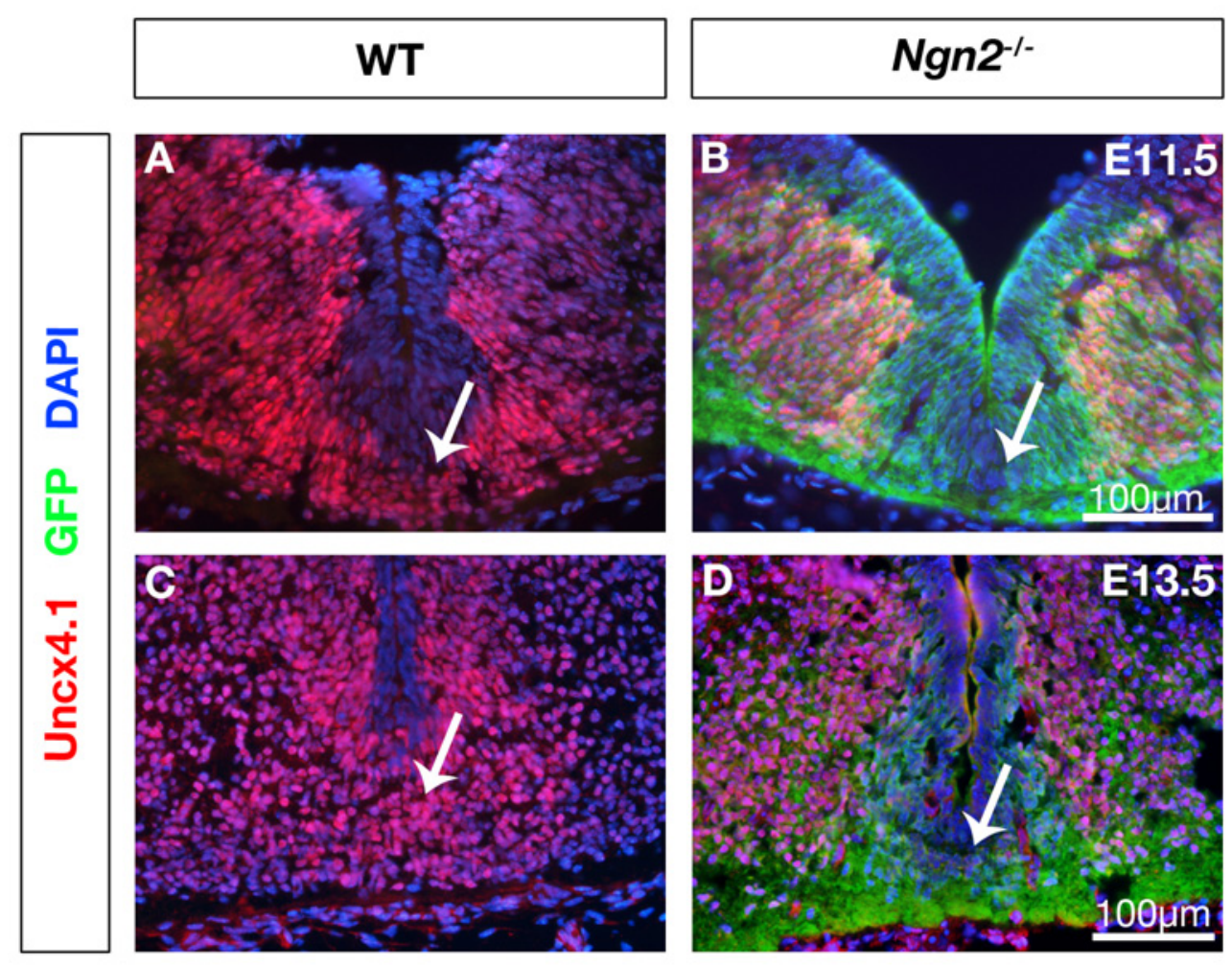

Abb. 20: Ngn2-defiziente Neuronen der ventralen Mittellinie weisen keine Uncx4.1-Expression auf. (A-D) IHC gegen Uncx4.1 (rot) und GFP (grün) auf coronalen Gewebeschnitten von WT- und Ngn2 \% Embryonen der Stadien 11.5 (A-B) und 13.5 (C-D). Die Pfeile deuten auf den Bereich des ventralen Mittelhirns, indem die Domäne der mDA Neuronen zu finden ist. Die Gegenfärbung erfolgte mit DAPI. 


\subsubsection{Analyse der $\beta$-Catenin Expression im ventralen Mittelhirn Uncx4.1-defizienter Embryonen}

$\beta$-Catenin ist eine wichtige Komponente des kanonischen Wnt-Signalweges (Akiyama, 2000, Mosimann et al., 2009). Es konnte gezeigt werden, dass der Verlust von $\beta$-Catenin in der Shhoder TH-Domäne zu einem Verlust dopaminerger Neuronen im Mittelhirn führt (Tang et al., 2009) und $\beta$-Catenin eine wichtige Rolle bei der Neurogenese der dopaminergen Neuronen zukommt (Tang et al., 2010). Um zu überprüfen, ob der Funktionsverlust von Uncx4.1 zu einer Veränderung der $\beta$-Catenin Expression führt und somit in den $\beta$-Catenin/Wnt-Signalweg involviert ist, wurde eine Immunfärbung auf coronalen Gewebeschnitten mit anti- $\beta$-Catenin durchgeführt. Es kann beobachtet werden, dass die Inaktivierung von Uncx4.1 an E12.5 keinen Unterschied in der $\beta$-Catenin Expression hervor ruft (Abb. 21, A-B). An E13.5 ist jedoch festzustellen, dass die Expression von $\beta$-Catenin im ventralen Mittelhirn, in dem Bereich, in dem sich die dopaminergen Neuronen befinden, deutlich reduziert ist (Pfeile in Abb. 21, C-D).
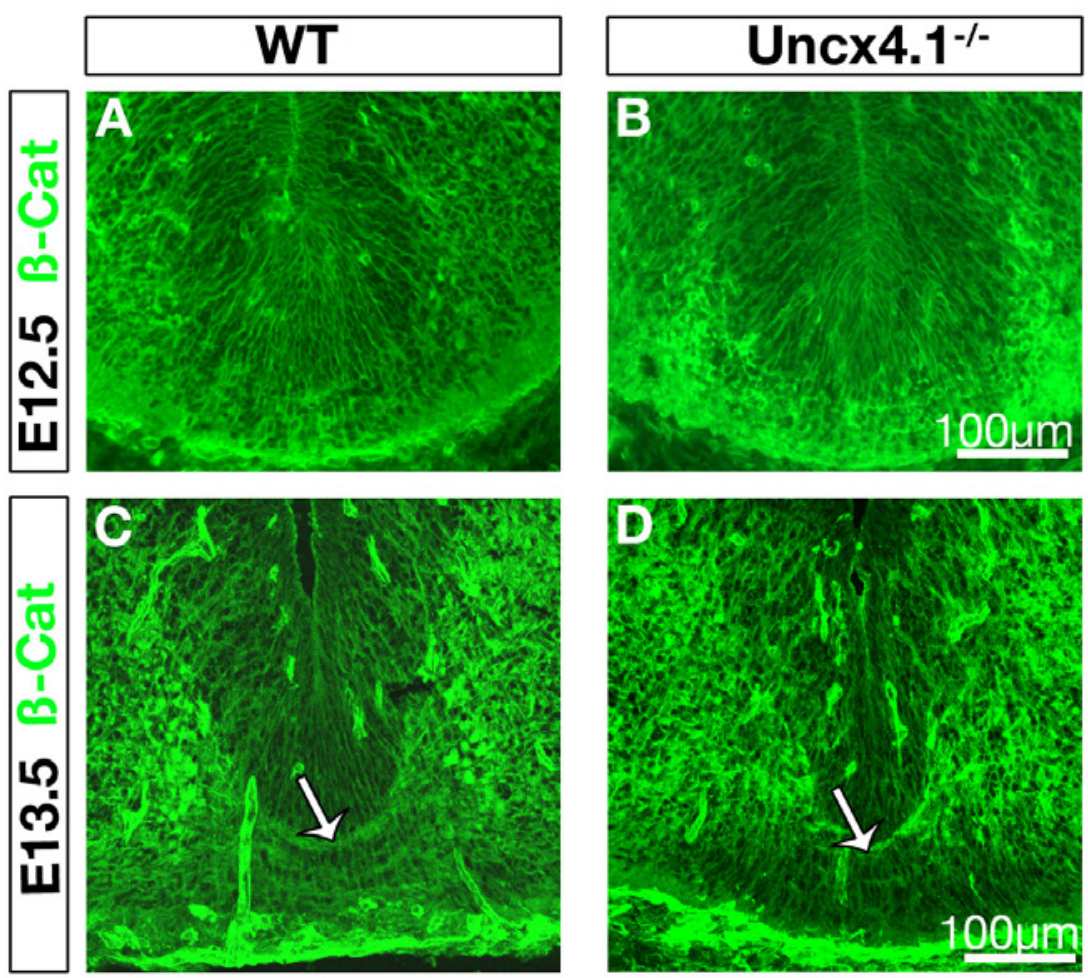

Abb. 21: Analyse der $\beta$-Catenin Expression in Abwesenheit von Uncx4.1. IHC von $\beta$-Catenin auf coronalen Gewebeschnitten Uncx4.1\%- und Kontrollembryonen der Stadien E12.5 (A-B) und E13.5 (C-D). Bei (C-D) handelt es sich um konfokale Aufnahmen. Die Pfeile deuten auf den Bereich des ventralen Mittelhirns, indem eine Veränderung detektiert werden konnte. 


\title{
2.2.9 Die Analyse dopaminerger Neuronen in Abwesenheit von Uncx4.1 mit Hilfe einer konditionalen Knockoutlinie
}

Da die Nachkommen des globalen Uncx4.1-Knockouts am ersten Tag nach der Geburt sterben, wurde für die Analyse adulter Stadien eine konditionale Knockoutlinie verwendet. Die Verpaarung der Tiere und die Tamoxifeninjektion erfolgte wie in den Kapiteln 5.2.2 und 5.2.3 beschrieben. Um allerdings zu überprüfen, ob die gefloxten Bereiche bei der Verpaarung mit einer Cre-Linie tatsächlich entfernt werden und die gefloxte Linie effizient ist, wurde der konditionale Knockout zunächst mit Tieren der CMV-Cre Linie (Schwenk et al., 1995) verpaart. Bei dieser Linie ist Cre ubiquitär exprimiert, so dass bei einer Verpaarung derselbe Phänotyp wie der des globalen Knockouts erwartet wird. Die Analyse der Rippen zeigte, dass der Phänotyp dem des klassischen Uncx4.1-Konckouts entspricht (Daten nicht gezeigt). Eine Immunfärbung mit anti-Uncx4.1 zeigt den totalen Verlust von Uncx4.1 im Mittelhirn der Maus (Abb. 22). Somit kann die konditionale Knockoutlinie für die Analyse adulter Stadien verwendet werden.
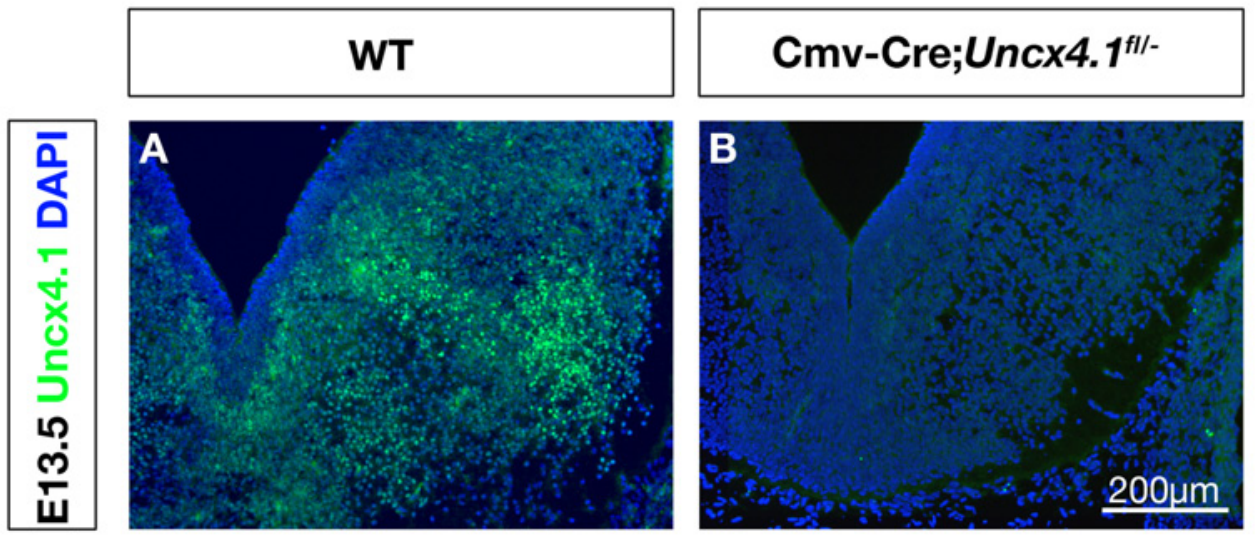

\begin{abstract}
Abb. 22: Cmv-Cre;Uncx4. I $^{f /-}$ Embryonen exprimieren kein Uncx4.1 im Mittelhirn der Maus. (A-B) IHC mit anti-Uncx4.1 auf coronalen Gewebeschnitten an E13.5 von Wildtypen (A)und Mutanten (B). In den Mutanten ist kein Uncx4.1-Protein mehr detektierbar (B). Die Gegenfärbung erfolgte mit DAPI.

\section{Cre-ER;Uncx4.1 $1^{f /-}$ Mausmutanten zeigen morphologische Defekte in der Domäne der mDA Neuronen}

Für die Analyse adulter Tiere wurde zunächst die Cre-ER Linie (Hayashi \& McMahon, 2002) verwendet. Bei dieser Linie ist Cre wie bei der CMV-Cre Linie ubiquitär exprimiert. Allerdings bindet der natürliche Ligand nicht an den mutierten Östrogenrezeptor, sondern es bindet nur der synthetische Ligand 4-hydroxytamoxifen. Dies erlaubt die Expression von Cre in Abhängigkeit von Tamoxifen. Als Zeitpunkt der Tamoxifeninjektion wurde zunächst E12.5 gewählt, 
da Uncx4.1 zu diesem Zeitpunkt noch stark im Mittelhirn exprimiert und die Skelettbildung weitestgehend abgeschlossen ist. Bei einer Tamoxifenverabreichung zu früheren Zeitpunkten besteht die Gefahr der Malformierung des Skeletts, was wiederum den Tod der Neugeborenen zur Folge haben könnte. Die Embryonen wurden zwischen E17.5 und E20, je nach Kondition der Mutter, entnommen und Ammen zur Aufzucht überlassen. Der Tag der Entnahme ist im Folgenden als P0 bezeichnet.

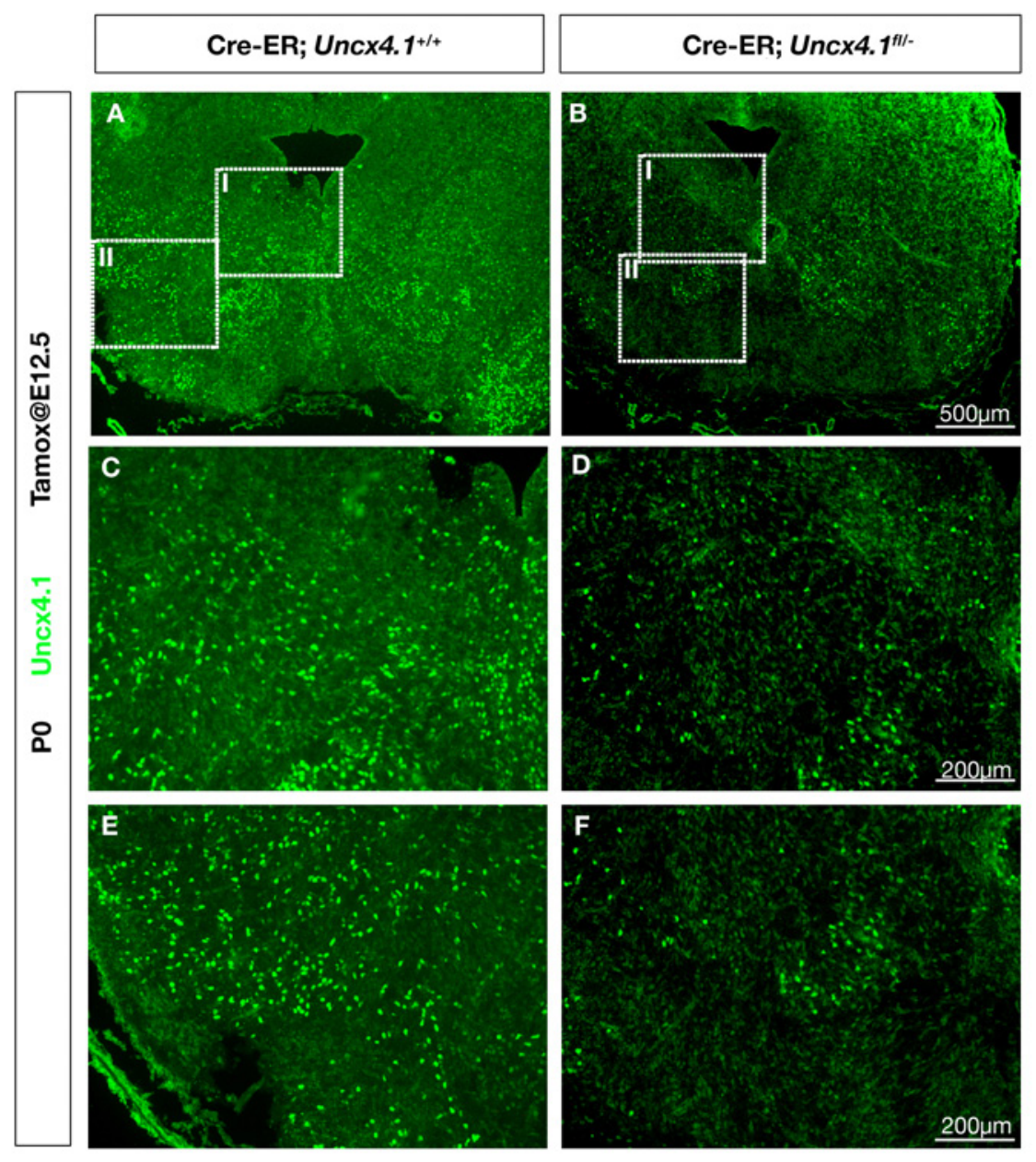

Abb. 23: Cre-ER;Uncx4.1 ${ }^{f / /}$ Embryonen zeigen einen deutlichen Verlust von Uncx4.1 im Mittelhirn der Maus. (A-F) IHC mit anti-Uncx4.1 auf coronalen Gewebeschnitten des Mittelhirns von Mäusen an P0. (C, D) Vergrößerungen des Ausschnitts I in (A) und (B). (E, F) Vergrößerung des Ausschnitts II in (A) und (B). Den Müttern wurde Tamoxifen an E12.5 intraperitoneal verabreicht.

Um zu untersuchen, ob die Inaktivierung von Uncx4.1 erfolgreich war, wurden Neugeborene Tiere an P0, deren Müttern an E12.5 Tamoxifen verabreicht wurde, analysiert. Eine Immunfärbung gegen Uncx4.1 auf coronalen Gewebeschnitten zeigt, das ein Großteil der Uncx4.1positiven Zellen nicht mehr detektierbar ist (Abb. 23). Daraus lässt sich ableiten, dass die Inaktivierung von Uncx4.1 mit der durchgeführten Vorgehensweise erfolgreich ist.

Anschließend wurde die Entwicklung der mDA Neuronen in Cre-ER;Uncx4.1 ${ }^{f /-}$ analysiert. Be- 
reits an P0 zeigt sich, dass die Expression von TH verändert ist (Abb. 24, E-F). So kann festgestellt werden, dass der Abstand zwischen der VTA und SN in den konditionalen Mausmutanten vergrößert ist (Abb. 24, gelbe Pfeile in E-F). Es ist allerdings zu erwähnen, dass die Analyse an P0 bei nur einem Tier erfolgte und diese Ergebnisse damit als vorläufig anzusehen sind. Allerdings ist dieser Defekt auch auf Gewebeschnitten adulter Tiere bei einer Immunfärbung gegen TH zu verzeichnen (Abb. 24, weiße Pfeile in A-B). Des Weiteren ist ein Verlust TH-positiver Neuronen in dem lateralen Bereich der SN adulter Tiere festzustellen (Abb. 24, graue Pfeile in A-B). Dieselben Beobachtungen können bei einer IHC mit anti-DAT gemacht werden (Abb. 24 . C-D).

Um zu ermitteln, ob eine spätere Inaktivierung von Uncx4.1 ebenfalls Einfluss auf die Entwicklung der dopaminergen Neuronen im Mittelhirn nimmt, wurde das Tamoxifen den Jungtieren vier Wochen nach der Geburt verabreicht. Hierbei lässt sich feststellen, dass der Funktionsverlust von Uncx4.1 zu einem so späten Zeitpunkt keinen Einfluss auf die Expression von TH (Abb. 24, G-H) und DAT (Daten nicht gezeigt) im Vergleich zu den Kontrolltieren nimmt.

Die Deletion von Uncx4.1 führt während der späteren Embryonalentwicklung zu einem Verlust dopaminerger Neuronen in den lateralen Bereichen der SN und zu einem veränderten Expressionsmuster in der VTA, wohingegen die Deletion vier Wochen nach der Geburt keine Auswirkung auf die Expression von TH und DAT hat. 


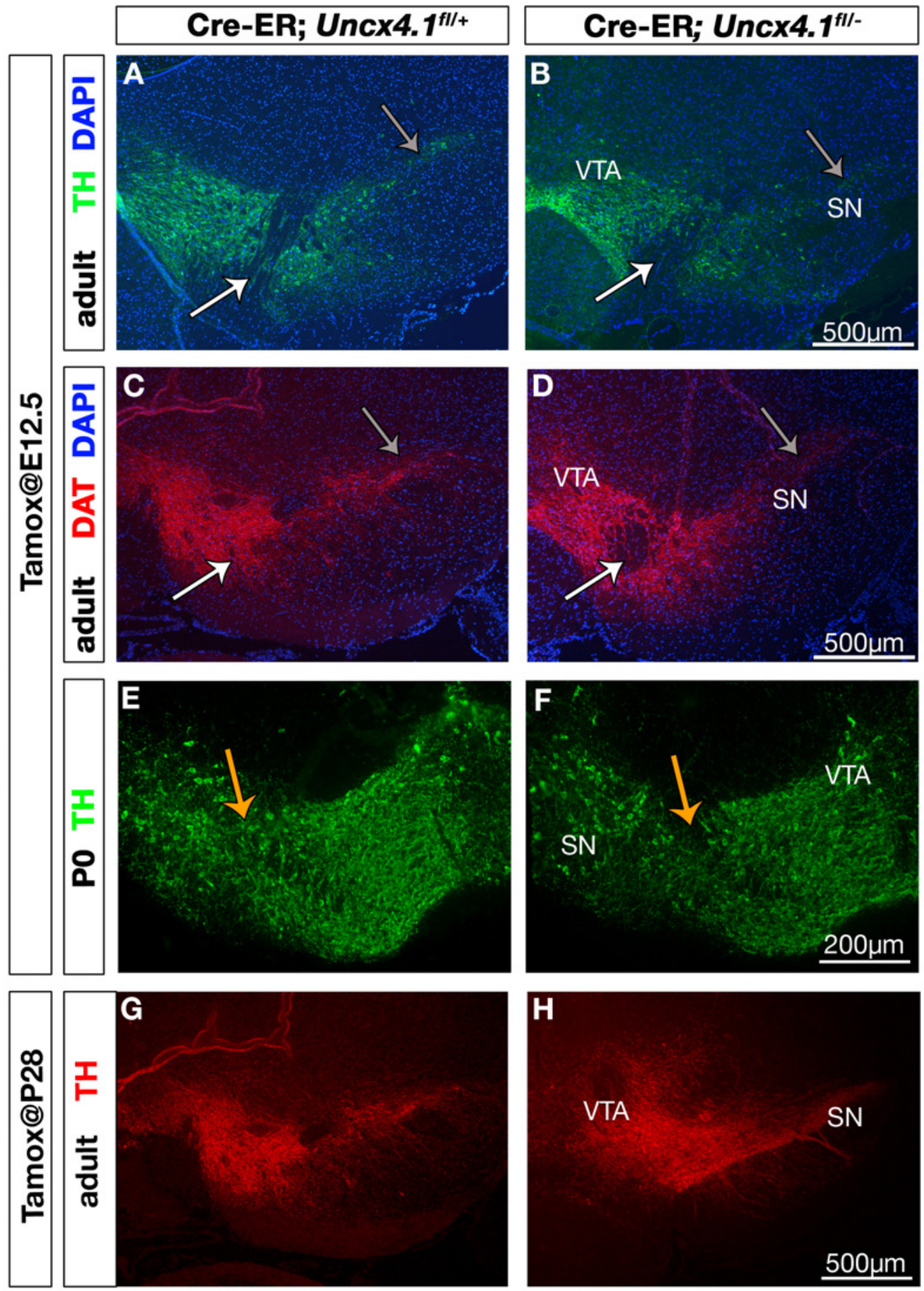

Abb. 24: Analyse von Markern dopaminerger Neuronen des Mittelhirns auf coronalen Gewebeschnitten adulter Cre-ER;Uncx4. f $^{f /-}$ Mäuse. (A-D) IHC coronaler Gewebeschnitte adulter Mäuse mit anti-TH (A-B) und anti-DAT (C-D). (E-F) Anti-TH auf coronalen Gewebeschnitten von Tieren an P0. Den Müttern wurde Tamoxifen an E12.5 intraperitoneal verabreicht. Die weißen Pfeile deuten auf den Bereich der VTA, in dem weniger dopaminerge Neuronen verzeichnet werden können, wohingegen die grauen Pfeile auf den Verlust in der SN hindeuten. Die orangen Pfeile zeigen den vergrößerten Abstand zwischen VTA und SN an. (G-H) IHC coronaler Gewebeschnitte adulter Mäuse mit anti-TH, die erst vier Wochen nach der Geburt mit Tamoxifen behandelt wurden. 


\section{Analyse der dopaminergen Neuronen in Foxa2-Cre;Uncx4.1 ${ }^{f /-}$ Mutanten}

Für die Inaktivierung von Uncx4.1 zu einem früheren Zeitpunkt als E12.5 wurde die Foxa2Cre Linie (Park et al., 2008) verwendet. Wie bereits vorher erwähnt, ist Foxa2 ein wichtiger Faktor bei der Entwicklung der dopaminergen Neuronen und wird bereits früh im ventralen Mittelhirn exprimiert (Ferri et al., 2007; Kittapa et al., 2007; Lin et al., 2009). Die Verpaarung der Mäuse wurde wie in Kapitel 5.2.2 beschrieben durchgeführt. Die Tamoxifenverabreichung erfolgte an E10.5 durch orale Applikation. Die Embryonen wurden je nach Kondition der Mutter zwischen E17.5 und E20 entnommen und Ammen zur Aufzucht überlassen. Die Analyse der Nachkommen erfolgte drei bis sechs Monate nach der Geburt.

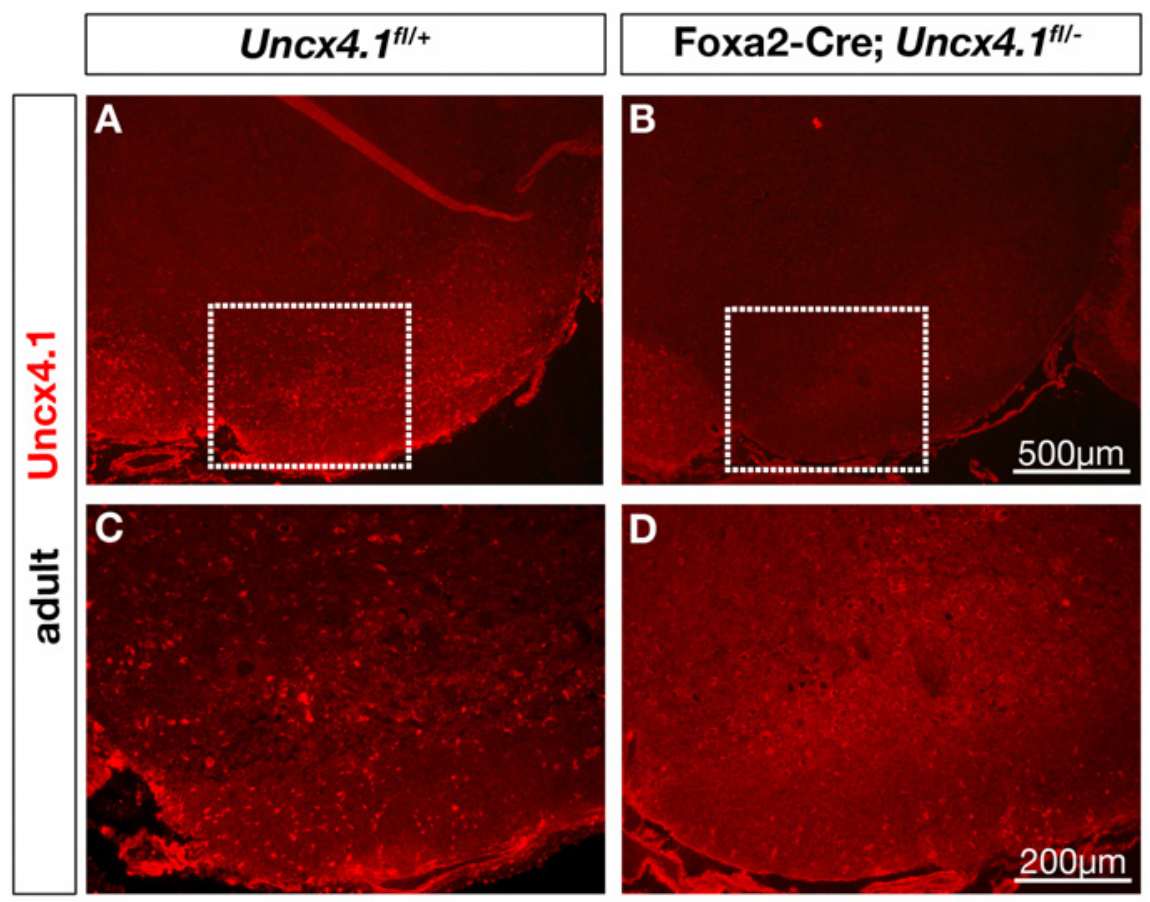

Abb. 25: Foxa2-Cre;Uncx4.1 ${ }^{f /-}$ Mausmutanten zeigen einen Verlust der Uncx4.1-Expression im ventralen Mittelhirn. (A-D) IHC mit anti-Uncx4.1 auf coronalen Gewebeschnitten adulter Mausgehirne von Kontrolltieren und Mutanten. (C) und (D) zeigen die Vergrößerungen der Ausschnitte in (A) und (B).

Die erfolgreiche Inaktivierung von Uncx4.1 wurde mittels IHC von adultem Gewebe überprüft. Im ventralen Mittelhirn ist deutlich ein Verlust des Uncx4.1-Proteins erkennbar (Abb. 25). 


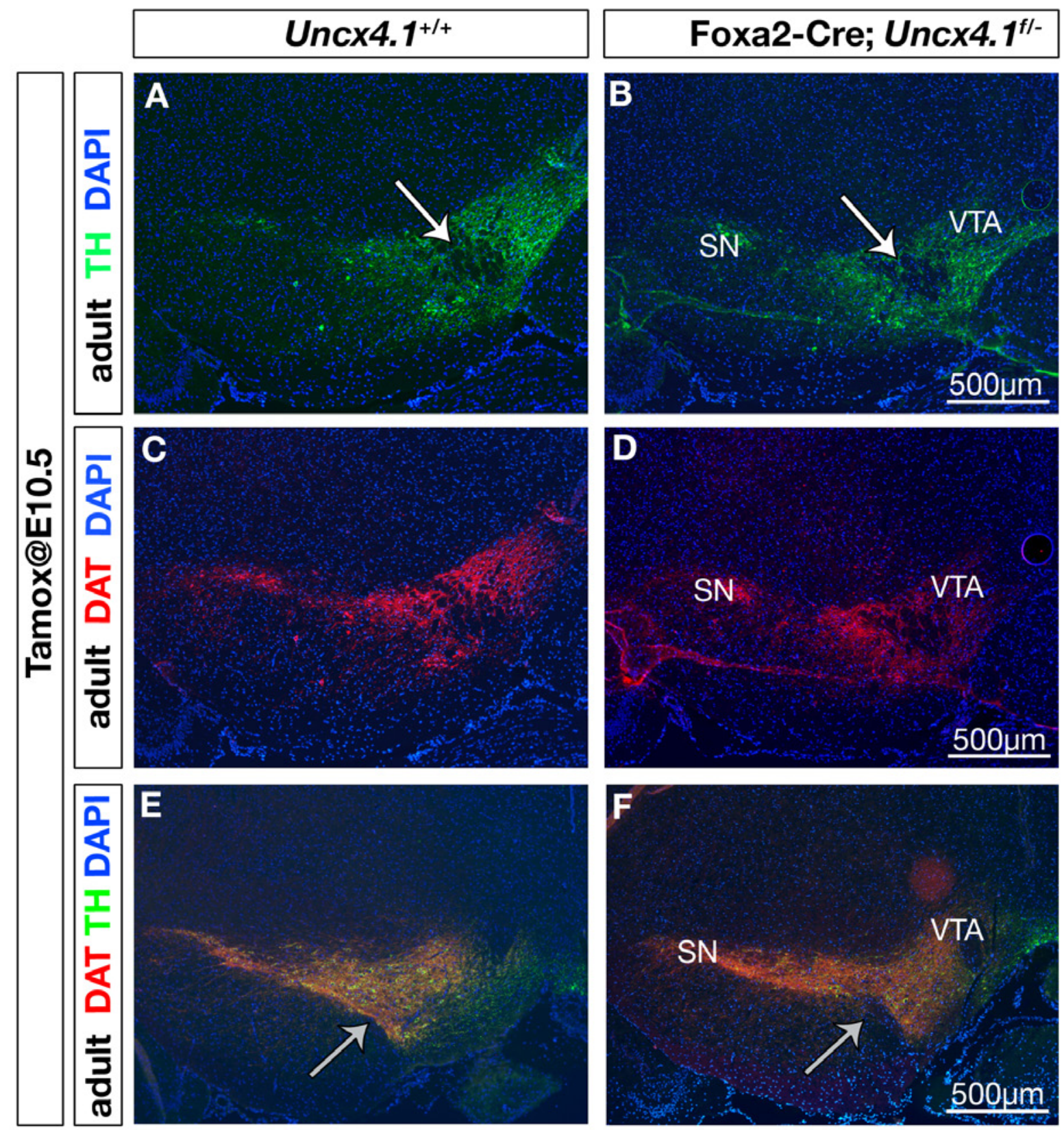

Abb. 26: Analyse von Markern dopaminerger Neuronen des Mittelhirns auf coronalen Gewebeschnitten adulter Foxa2-Cre; Uncx4. f $^{f /-}$ Mäuse. (A-D) IHC gegen TH (A-B) und DAT (C-D) auf coronalen Gewebeschnitten adulter Mausgehirne. (E-F) Doppelimmunfärbung mit anti-TH (grün) und anti-DAT (rot) auf Gewebeschnitten adulter Foxa2-Cre;Uncx4. $1^{f /-}$ und Kontrollgehirnen. Die weißen Pfeile deuten auf den TH-negativen Bereich in der VTA. Die grauen Pfeile zeigen den Verlust der TH- und DAT-Expression. VTA: Ventrales tegmentales Areal, SN: Substantia nigra. Die Verabreichung von Tamoxifen erfolgte an E10.5 mittels oraler Applikation. Gegenfärbung mit DAPI.

Bei der Analyse der dopaminergen Neuronen in den Foxa2-Cre;Uncx4. $1^{f /-}$ Mutanten ist zu beobachten, dass die Expression von TH und DAT im lateralen Bereich der SN nicht beeinträchtigt ist (Abb. 26). Allerdings scheint der Bereich der TH-Expression kleiner als in den Kontrolltieren und es kann ein vergrößerter TH-negativer Bereich in der VTA detektiert werden (Abb. 26, 
A-B, E und F). Selbiges ist bei der Expressionsanalyse von DAT festzustellen (Abb. 26, C-F). Neben diesen Ergebnissen zeigt die Analyse der konditionalen Foxa2-Cre;Uncx4. $1^{f /-}$-Mutanten im rostral gelegenen Mittelhirn ein Verlust der TH- und DAT-Expression in der VTA (Abb. 26, graue Pfeile in E und F).

Zusammengenommen kann festgehalten werden, dass die Expression von Uncx4.1 in der Foxa2-Domäne wichtig für die korrekte Etablierung der dopaminergen Neuronen im ventralen Mittelhirn ist. Die Expression von TH und DAT scheint in der lateral gelegenen Substantia nigra in den Foxa2-Cre;Uncx4. $1^{f /-}$ Mutanten nicht beeinträchtigt zu sein. Dies lässt vermuten, dass der Ursprung dieser Neuronen nicht in der Foxa2-Domäne zu finden ist, oder dass die konditionelle Inaktivierung nicht alle Bereiche der Domäne erfasst.

\subsection{Untersuchungen zur Funktion von Uncx4.1 während der Entwicklung GABAerger Neuronen im embryonalen Mittelhirn}

Die in dieser Arbeit durchgeführte Expressionsanalyse von Uncx4.1 zeigt, dass Uncx4.1 in GABAergen Neuronen exprimiert wird (Abb. 11). Daneben konnte gezeigt werden, dass die Anzahl der mDA Neuronen in Abwesenheit von Uncx4.1 deutlich verringert ist. Um zu untersuchen, ob Uncx4.1 an der Entwicklung der GABAergen Neuronen im Mittelhirn beteiligt ist und ob die dopaminergen Neuronen ihre Identität in ein GABAerges Zellschicksal ändern, wurde die Expression verschiedener Marker GABAerger Neuronen im Mittelhirn Uncx4.1-defizienter Mausembryonen untersucht.

Die Inaktivierung von Uncx4.1 zeigt keinen Einfluss in der Entwicklung GABAerger Neuronen des Mittelhirns

Die Transkriptionsfaktoren Helt, Mash1 und Gata2 sind notwendig für die korrekte Entwicklung GABAerger Neuronen im Mittelhirn (Nakatani et al., 2007; Miyoshi \& Bessho, 2004; Peltopuro \& Kala, 2010; Kala et al., 2009). Die unveränderte Expression von Helt und Mash1 in Uncx4.1-defizienten Embryonen (Abb. 27, A-B und Abb. 18, A-B) erklärt sich durch die ausschließlich ventrikuläre Expression dieser Marker. Die GABAergen Marker Gad67, Nkx2.2 und Olig2 sind in Uncx4.1-Nullmutanten an E11.5 (Abb. 27. C, D, I und J)), E12.5 (Abb. 27. G,H) und E16.5 (Abb. 27, E, F, K und L) ebenfalls normal exprimiert. 
Insgesamt zeigt die Inaktivierung von Uncx4.1 keine Veränderung des GABAergen Phänotyps im ventralen Mittelhirn der Mausmutanten und eine normale Expressionsdomäne der GABAergen Neuronen. Eine Umschaltung des dopaminergen Zellschicksals zu einem GABAergen Zellschicksal kann somit nahezu ausgeschlossen werden.
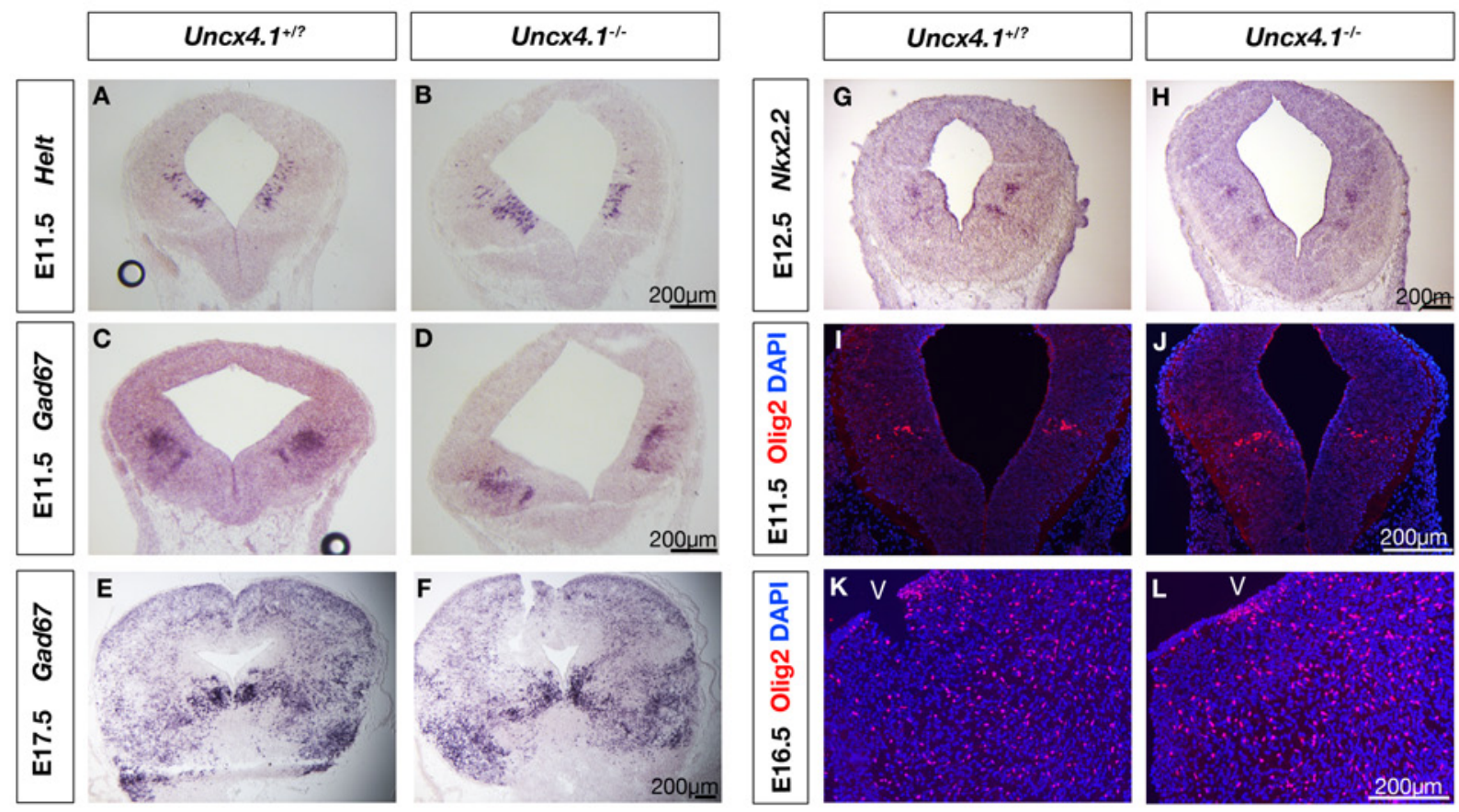

Abb. 27: GABAerge Neuronen sind in Uncx4.1-defizienten Embryonen normal entwickelt. (A-H) ISH coronaler Gewebeschnitte von Uncx4.1 ${ }^{\text {- }}$ Embryonen und Kontrolltieren mit RNA-Sonden gegen Helt (A-B), Gad67 (C-F) und Nkx2.2 (G-H). (I-L) Immunfärbung coronaler Gewebeschnitte gegen Olig2 (rot) der Stadien E11.5 (I-J) und E16.5 (K-L). V markiert den III. Ventrikel. 


\subsection{Untersuchungen zur Funktion von Uncx4.1 während der Entwicklung glutamaterger Neuronen im embryonalen Mittelhirn}

In dieser Arbeit konnte gezeigt werden, dass Uncx4.1 neben dopaminergen und GABAergen Neuronen, auch in glutamatergen Neuronen des Mittelhirns exprimiert ist (vgl. Kapitel 2.1.2, sowie Abb. 10 und Abb. 11). Daher wurde untersucht, ob die Inaktivierung von Uncx4.1 eine Bedeutung für die Entwicklung von glutamatergen Neuronen des ventralen Mittelhirns hat. Zudem sollte untersucht werden, ob der Verlust der mDA Neuronen in Uncx4.1-defizienten Mausembryonen mit einer Erhöhung glutamaterger Neuronen einhergeht und sich somit ihr Zellschicksal ändert.

\subsubsection{Die Inaktivierung von Uncx4.1 hat Einfluss auf bestimmte Subtypen der glutamatergen Neuronen im Mittelhirn}

Der Transkriptionsfaktor Brn3a ist u.a. im Ganglion trigeminale, den Spinalganglien und dem Nucleus ruber exprimiert (Xiang et al., 1996; Eng et al., 2001; Agarwala \& Ragsdale, 2002). Daneben ist die Expression von Brn3a auch im dorsalen Mittelhirn detektierbar (Agarwala \& Ragsdale, 2002; Nakatani et al., 2007; Kala et al., 2009; Prakash et al., 2009). Da Brn3a im Mittelhirn von glutamatergen Neuronen exprimiert wird (Nakatani et al., 2007; Kala et al., 2009, Prakash et al., 2009), wurde der Transkriptionsfaktor als Marker glutamaterger Neuronen verwendet.

Uncx4.1 $1^{-/-}$Mausembryonen zeigen, im Vergleich zu den Kontrollembryonen, im ventralen Mittelhirn ein erhöhtes Level an Brn3a-mRNA. Dies ist sowohl an E11.5 (Daten nicht gezeigt), E12.5 (Abb. 28, A-B) und an E13.5 (Daten nicht gezeigt) detektierbar. Im dorsalen Mittelhirn ist allerdings keine Veränderung in der Expression von Brn3a zu verzeichnen (Abb. 28, A-B und Daten nicht gezeigt). Siml ist ebenfalls in frühen Entwicklungsstadien in den glutamatergen Neuronen des Nucleus ruber detektierbar (Nakatani et al., 2007). Es zeigt sich, dass das Signal der Siml Expression an E12.5 in Uncx4.1 $1^{-/}$Embryonen im Vergleich zum Wildtyp erhöht ist (Abb. 28, G-H). Dies konnte interessanterweise nicht an E11.5 (Daten nicht gezeigt) beobachtet werden. 


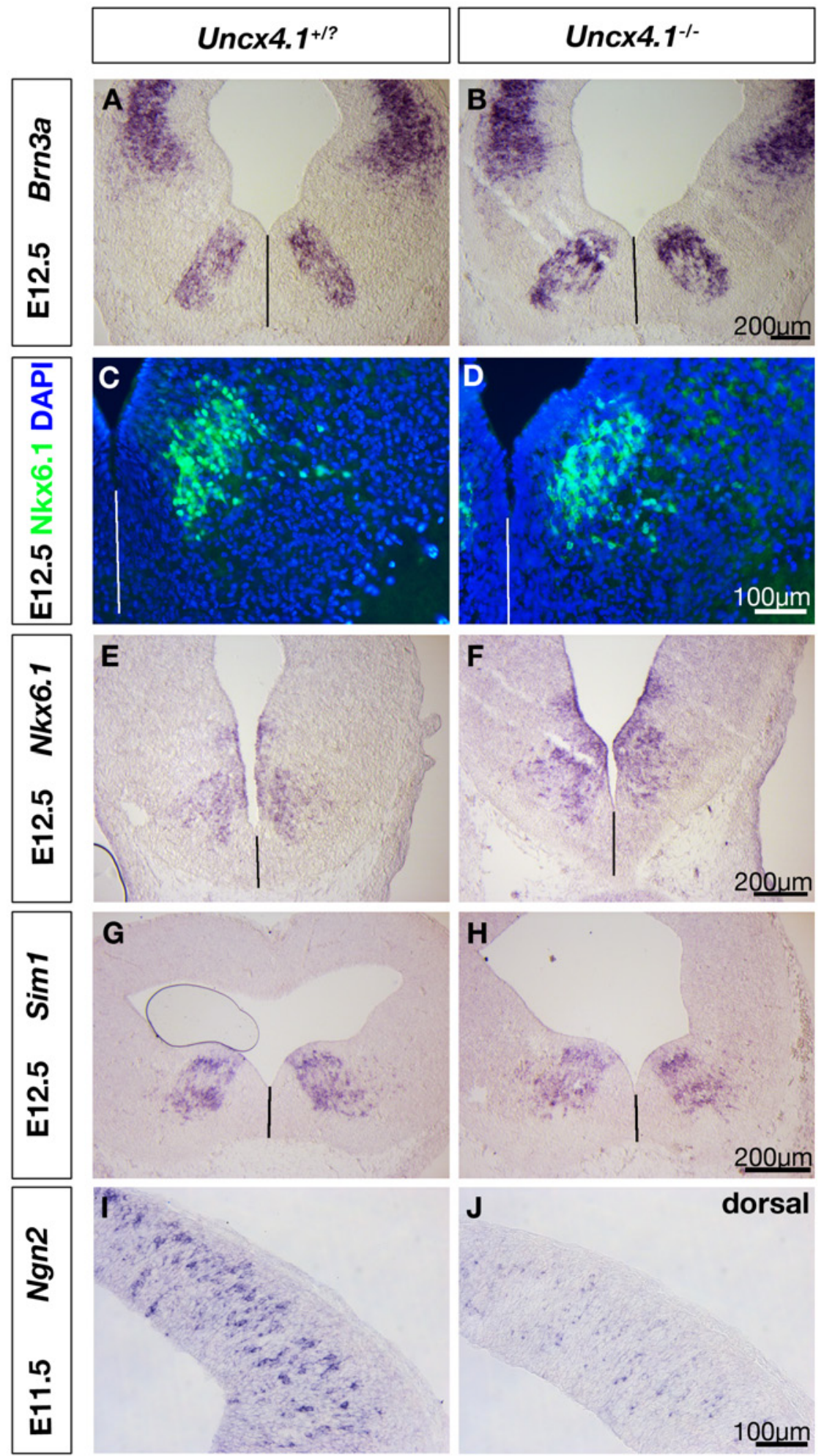

Abb. 28: Analyse glutamaterger Marker in Uncx4.1-defizienten und Kontrollembryonen. (A-H) ISHAnalysen von Brn3a-mRNA (A-B), Nkx6.1-mRNA (E-F) und Siml-mRNA (G-H) auf coronalen Gewebeschnitten des Stadiums E12.5. (C-D) Zeigt eine Immunfärbung gegen Nkx6.1 (grün) an E12.5 von Kontroll- und Uncx4.1defizienten Embryonen. (I-J) Detektion von Ngn2-mRNA mittels ISH auf coronalen Gewebeschnitten im dorsalen Mittelhirn von Mausembryonen an E11.5. Die schwarzen und weißen Linien markieren die Mittellinie des ventralen Mittelhirns. 
Der Transkriptionsfaktor Nkx6.1 ist notwendig für die korrekte Bildung Brn3a-positiver Neuronen des Nucleus ruber (Prakash et al., 2009). Das Level an Nkx6.1-mRNA ist an E12.5 in Abwesenheit von Uncx4.1 erhöht, wohingegen die Anzahl Nkx6.1-positiver Zellen unverändert bleibt (Abb. 28).

Wie bereits in Kapitel 2.1.2 erwähnt, ist Ngn2 in glutamatergen Neuronen des dorsalen Mittelhirns exprimiert. Eine ISH zeigt, dass Ngn2 im dorsalen Mittelhirn Uncx4.1-defizienter Embryonen stark reduziert ist, wohingegen die Expression von Brn3a in diesem Bereich unverändert bleibt. Dennoch deuten die Ergebnisse darauf hin, dass Uncx4.1 eine Rolle während der glutamatergen Neurogenese zukommt.

Is11 ist ein Marker der glutamatergen Oculomotorneuronen (Fogel et al., 2008, Waite et al., 2011). Die Anzahl Isl1-positiver Zellen ist weder an E11.5 (Abb. 29, A-B) noch an E17.5 (Abb.29, C-D) verändert.

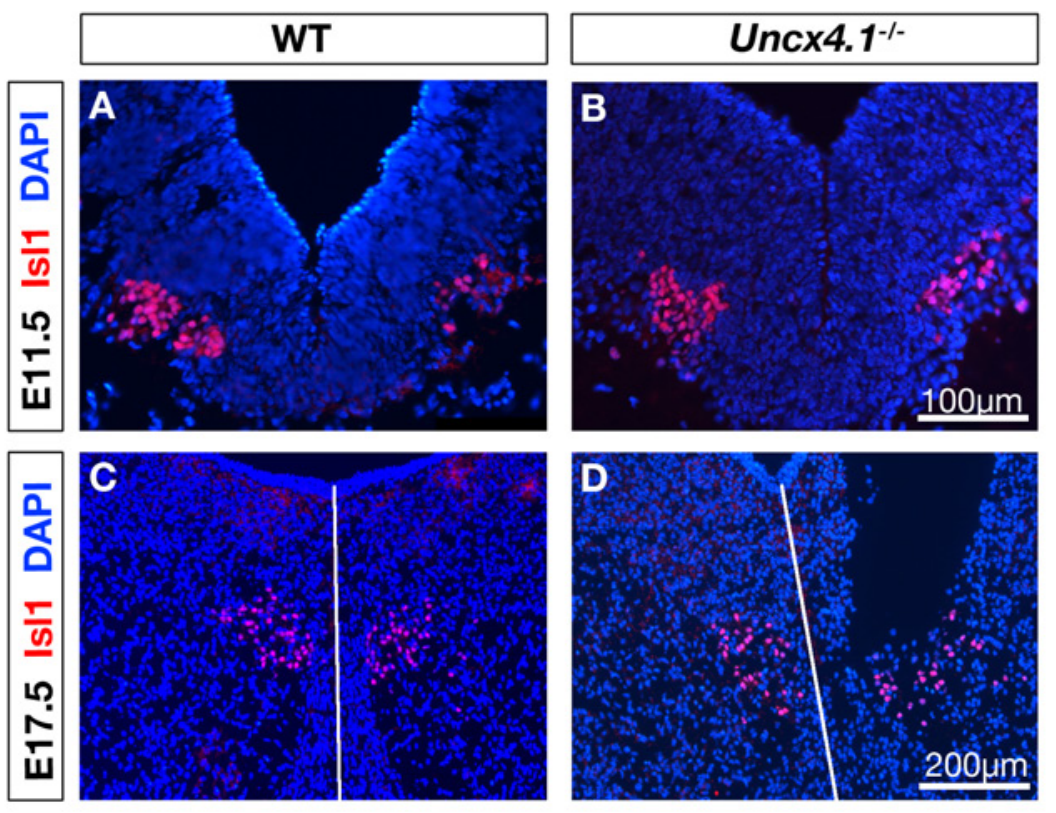

Abb. 29: Die Anzahl der Isl1-positiven Oculomotorneuronen ist in Abwesenheit von Uncx4.1 unverändert. IHC mit anti-Isl1 (rot) auf coronalen Gewebeschnitten der Stadien 11.5 (A-B) und E17.5 (C-D). Die weiße Linie in C-D markiert die ventrale Mittelline.

Zusammenfassend konnte in diesem Kapitel gezeigt werden, dass der Funktionsverlust von Uncx4.1 zu einem erhöhten mRNA Level einiger Marker des Nucleus ruber im ventralen Mittelhirn führt, wohingegen der Funktionsverlust im dorsalen Mittelhirn die Expression von Ngn2 reduziert. 


\subsubsection{Die Anzahl Pax6-positiver Zellen des ventralen Mittelhirns ist in Abwesenheit von Uncx4.1 ab E13.5 erhöht}

Im murinen Vorderhirn ist der Transkriptionsfaktor Pax6 im dorsalen Telencephalon in einem gegenläufigen Gradienten mit Emxl exprimiert. Aus dieser Region gehen hauptsächlich glutamaterge Neuronen hervor (Schuurmans et al., 2004; Kroll \& O'Leary, 2005). Im Mittelhirn ist Pax6 ebenfalls in einer Subgruppe glutamaterger Neuronen in der Basalplatte detektierbar (Kala et al., 2009). Es zeigt sich, dass die Inaktivierung von Uncx4.1 keinen Einfluss auf die Anzahl Pax6-positiver Neuronen im ventralen Mittelhirn an E11.5 und E12.5 ausübt (Abb. 30. A-B, G-H und K). Allerdings ist eine erhöhte Anzahl Pax6-positiver Zellen ab E13.5 im Vergleich zu den Kontrollembryonen zu verzeichnen (Abb. 31, C-D und K). Die Erhöhung beträgt 54,9 \%. An E17.5 ist die Anzahl Pax6-positiver Neuronen noch immer um 26,43 \% höher als in den Kontrollembryonen (Abb. 30, E-F und K). Um festzustellen, ob mehr Pax6-positive Zellen im ventralen Bereich detektiert werden können, wurde eine Doppelimmunfärbung mit anti-Pax6 und anti-Foxa2 durchgeführt (Abb. 30, G-J). Die Expressionsdomäne von Foxa2 zeigt an E12.5 und E13.5 einen sehr schmalen Bereich, der frei ist von Foxa2-positiven Zellen (gestrichelte weiße Linie in Abb. 31,G-J). Es zeigt sich, dass bei einer Inaktivierung von Uncx4.1 auf coronalen Gewebeschnitten des ventralen Mittelhirns mehr Pax6-positive Zellen jenseits der Linie detektiert werden können (Abb. 30, I-J). An E12.5 ist aber keine deutliche Expansion der Pax6positiven Neuronen im Vergleich zu den Kontrollembryonen zu verzeichnen (Abb. 30, G-H). Dies geht mit der Beobachtung einher, dass die Anzahl Pax6-positiver Neuronen erst ab dem Embryonalstadium 13.5 signifikant erhöht ist.

Zusammenfassend lässt sich feststellen, dass ein Funktionsverlust von Uncx4.1 ab E13.5 erhöhte Zellzahlen Pax6-positiver Neuronen hervor ruft, was auch in der weiteren Entwicklung an E17.5 festgestellt werden kann. 


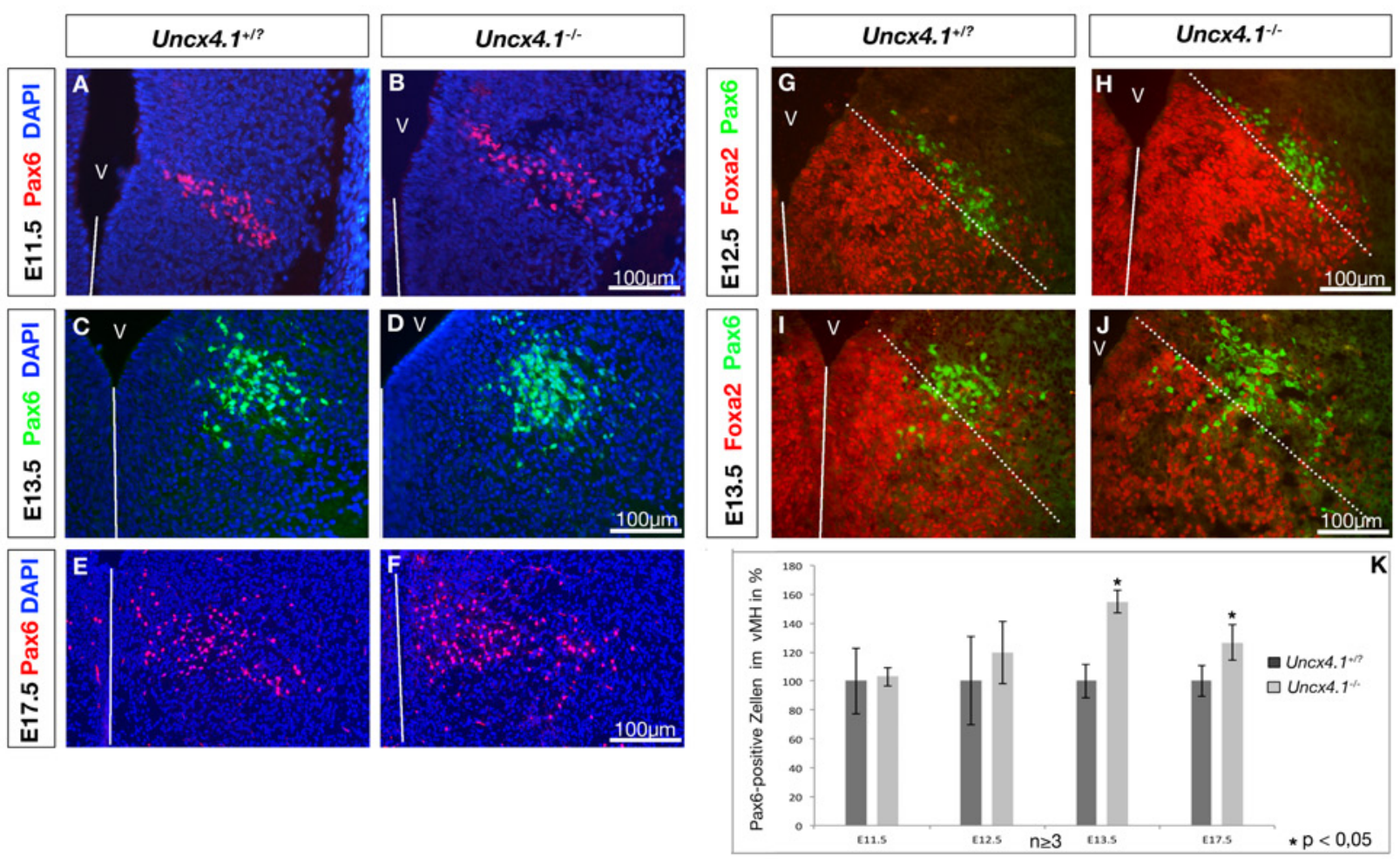

Abb. 30: Die Anzahl Pax6-positiver Zellen ist in Abwesenheit von Uncx4.1 ab E13.5 erhöht. (A-F) IHC mit anti-Pax6 auf coronalen Gewebeschnitten des ventralen Mittelhirns von Kontroll- und Uncx4.1 ${ }^{-/-}$-Embryonen der Stadien E11.5 (A-B), E13.5 (C-D), E17.5 (E-F). (G-J) zeigen eine Doppelimmunfärbung gegen Pax6 (grün) und Foxa2 (rot) an E12.5 (G-H) und E13.5 (I-J). (K) Statistische Analyse der Pax6-positiven Zellzahlen im ventralen Mittelhirn von Kontrolltieren im Vergleich zu Uncx4.1-Nullembryonen. Die weiße gestrichelte Linie in (G-J) zeigt die Lücke in der Expression von Foxa2. Die weißen durchgezogenen Linien markieren die Mittelinie des ventralen Mittelhirns. v markiert den III. Ventrikel.

\subsubsection{Uncx4.1 und Ngn2 sind in Pax6-defizienten Mäusen normal exprimiert}

Da die Expression von Pax6 in Uncx4.1-defizienten Embryonen ab E12.5 hochreguliert ist (Abb. 31), wurde untersucht ob die Expression von Uncx4.1 in Abwesenheit von Pax6 ebenfalls beeinträchtigt ist. Eine IHC und ISH zeigen, dass die Expression von Uncx4.1 weder an E11.5 (Abb. 31, A-B) noch an E16.5 (Abb. 31, C-F) in $\mathrm{Pax6}^{-1-}$ Mausembryonen verändert ist. Da in Uncx4.1-defizienten Mausembryonen ein Verlust von Ngn2-mRNA (Abb. 17, G-H), ebenso wie eine erhöhte Anzahl Pax6-positiver Zellen detektierbar war (Abb. 31), wurde die Expression von Ngn2 auf coronalen Gewebeschnitten von Gehirnen der Pax6-Nullembryonen untersucht. Die Analyse zeigt, dass keine Veränderung in der Ngn2-mRNA detektierbar ist. 

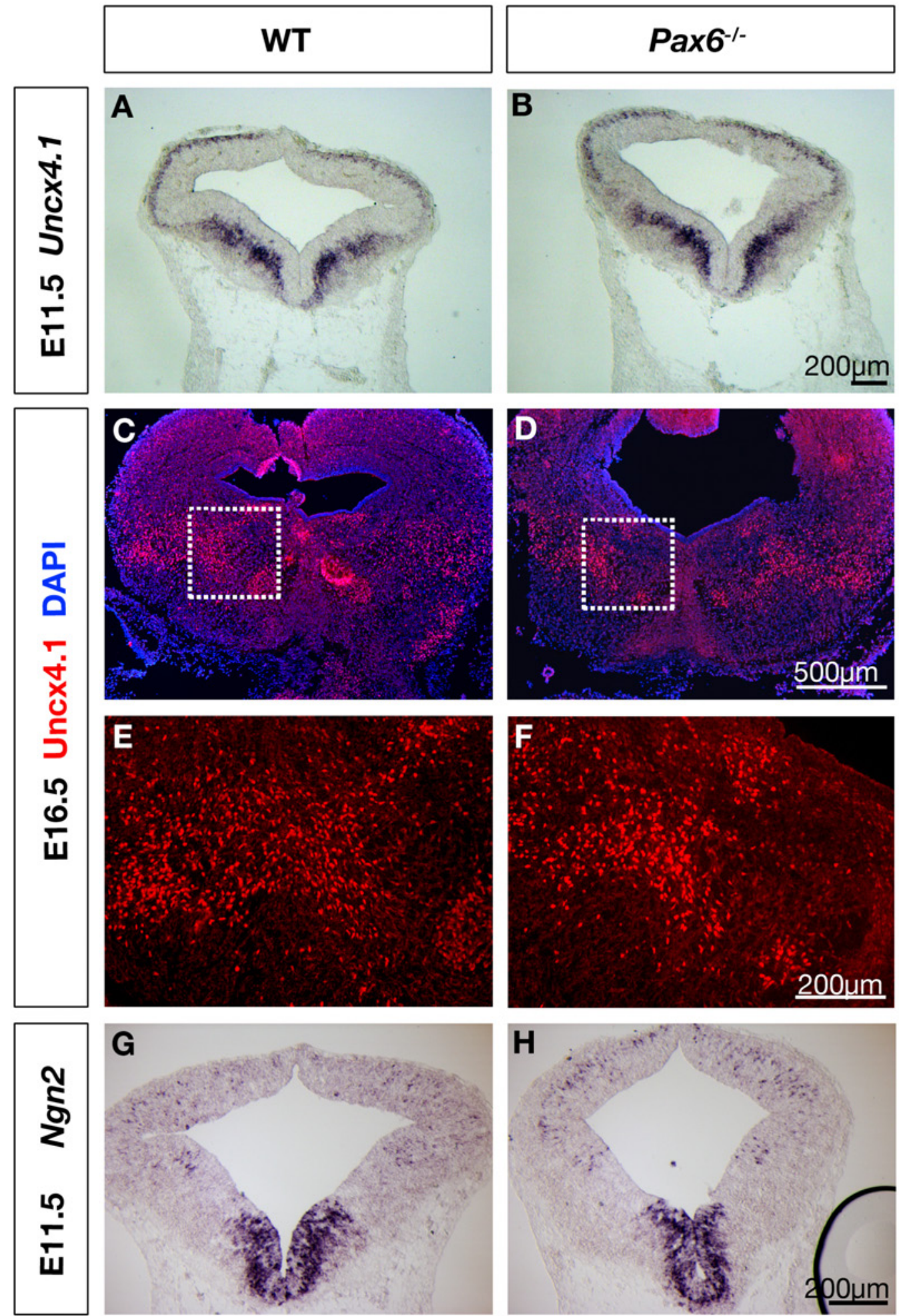

Abb. 31: Die Expression von Uncx4.1 und Ngn2 ist in Abwesenheit von Pax6 unverändert. (A-B) ISH mit einer gegen Uncx4.1 gerichteten RNA-Sonde auf coronalen Gewebeschnitten des Stadiums E11.5 von WT und Pax6defizienten Embryonen. (C-F) IHC mit anti-Uncx4.1 auf coronalen Gewebeschnitten des Stadiums E16.5. (E-F) zeigt die Vergrößerung des Ausschnitts in (C) und (D). (G-H) zeigt eine ISH mit einer gegen Ngn2 gerichteten RNA-Sonde des Stadiums E11.5 auf coronalen Gewebeschnitten des Mittelhirns. 


\subsection{Protein-Interaktionsstudien von Uncx4.1 mit Ngn2 und Pax6}

Kele et al. (2006) berichteten eine vermehrte Expression von Pax6 in Abwesenheit von Ngn2. Zusammen mit den Ergebnissen dieser Arbeit, die zeigen dass die Expression von Ngn2 in Abwesenheit von Uncx4.1 reduziert ist, wohingegen mehr Pax6-positive Zellen im ventralen Mittelhirn detektiert werden können, liegt die Vermutung nahe, dass Uncx4.1 mit Ngn2 und Pax6 auf Proteinebene interagiert. Zur Überprüfung dieser Hypothese wurde eine CoImmunopräzipitation (Co-IP) durchgeführt.

\subsubsection{In-vitro Analyse der potentiellen Interaktion von Uncx4.1, Ngn2 und Pax6 in HeLa und Hek293T Zellen}

Die zu testenden Proteine (Uncx4.1, Ngn2 und Pax6) wurden zunächst per Transfektion in HeLa und Hek293T Zellen zur Expression gebracht, ehe zwei Stunden nach der Transfektion eine Immunfärbung der Zellen vorgenommen wurde. Zur Detektion von Uncx4.1 wurde anti-c-Myc verwendet, da Uncx4.1 mit einem c-Myc-Tag vorliegt (genaueres ist in den Kapiteln 5.4.2 und 5.4.3 im Material und Methodenteil der Arbeit beschrieben). Zur Detektion von Ngn2 wurde ein HA Antikörper verwendet, da für die Immunocytochemische Färbung (ICC) nur Ngn2 mit einem HA-Tag transfiziert wurde. Pax6 wurde mit einem anti-Pax6 Antikörper angefärbt. Die Analyse der transienten Transfektion mit anschließender ICC zeigt, dass sowohl Uncx4.1, als auch Ngn2 und Pax6 im Zellkern exprimiert und somit co-lokalisiert sind (Abb. 32). Zu beobachten ist weiterhin, dass bei einer Expression in HeLa Zellen alle c-Mycpositiven Zellen ebenfalls HA positiv sind (Abb. 32, D), was in Hek293T Zellen nicht der Fall ist (Abb. 32, H). Allerdings ist im Allgemeinen festzustellen, dass in Hek293T Zellen wesentlich mehr c-Myc-positive Zellen detektiert werden können, als in HeLa Zellen (Abb. 32). Es ist ebenso zu beobachten, dass bei einer Transfektion von HeLa Zellen alle Pax6-positiven Zellen ebenfalls HA exprimieren (Abb. 32, C), wohingegen die Expression von Pax6 in Hek293T Zellen weniger effizient ist. Dies hat zur Folge, dass nur ein Bruchteil der HA-positiven Zellen eine Co-Lokalisation mit Pax6 aufweisen (Abb. 32, G). Aufgrund dieser Ergebnisse wurden für die Co-Immunopräzipitation mit Uncx4.1 und Ngn2 Hek293T Zellen und für die mit Ngn2 und Pax6 HeLa Zellen verwendet. 


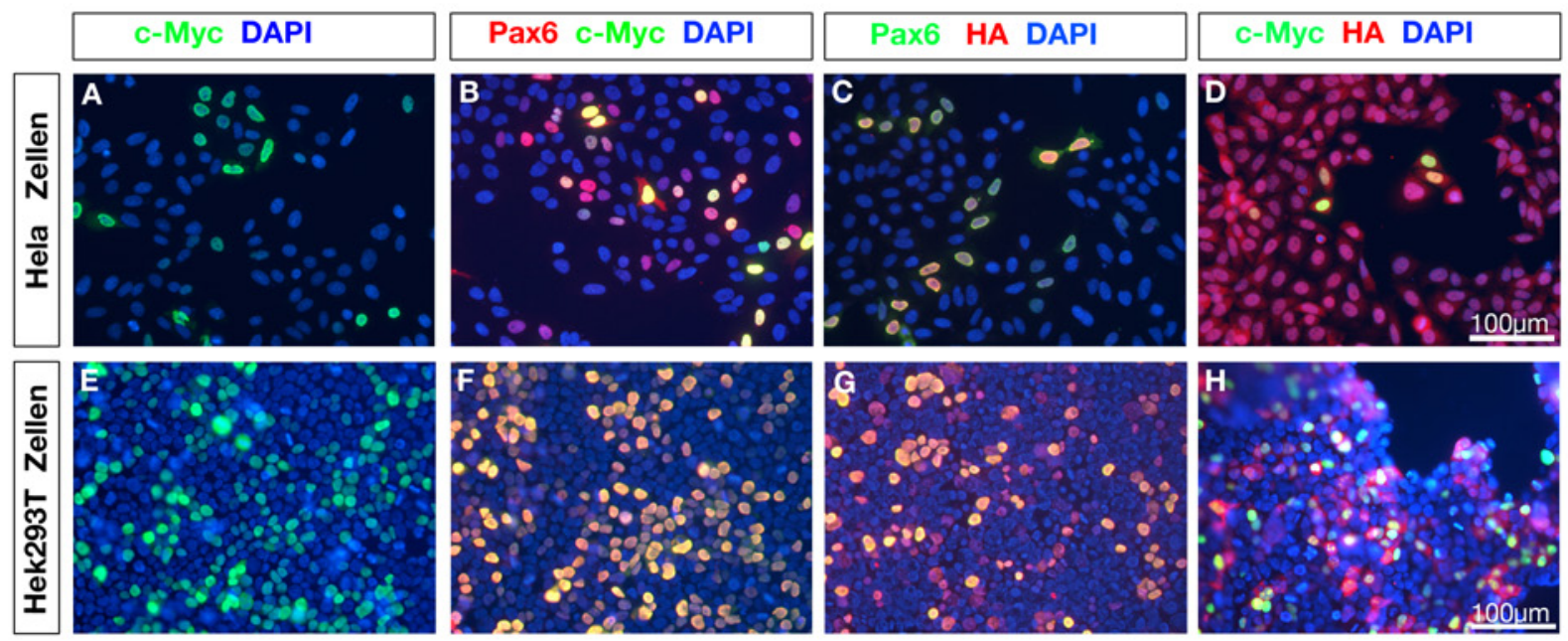

Abb. 32: Immunfärbung der transfizierten Zellen (A, E) Zu sehen ist eine Antikörperfärbung gegen c-Myc auf HeLa (A) und Hek293T (E) Zellen. (B, F) ICC gegen c-myc auf HeLa (B) und Hek293T (F) Zellen, 24 Stunden nach der Transfektion. (C) und (G) zeigen eine ICC gegen Pax6 und HA auf HeLa (C) und Hek293T (G) Zellen. In (D) und (H) ist eine Immunfärbung gegen c-Myc und HA zu sehen, wobei (D) HeLa Zellen und (H) Hek293T Zellen zeigt. Die Gegenfärbung erfolgte mit DAPI.

\subsubsection{Ngn2 und Pax6 interagieren auf Protein-Protein Ebene miteinander}

Um die Interaktion von Uncx4.1, Ngn2 und Pax6 zu überprüfen, wurde eine Co-IP von Uncx4.1 mit Pax6, Uncx4.1 mit Ngn2 und Ngn2 mit Pax6 durchgeführt (die Transfektion und die Co-IP sind in den Kapiteln 5.5.4 und 5.4.2 beschrieben). Die Western Blot Analyse zeigte jedoch, dass nur Ngn2 und Pax6 eine Protein-Protein Interaktion eingehen (Abb. 33, C). Uncx4.1 und Ngn2, sowie Uncx4.1 und Pax6 zeigen keine Protein-Protein Interaktion (Abb. 33, A und B).

Zusammenfassend lässt sich jedoch festhalten, dass zwar Ngn2 und Pax6 in-vitro in direkter Interaktion miteinander stehen, die Bildung eines Proteinkomplexes aus Ngn2, Pax6 und Uncx4.1 jedoch ausgeschlossen werden kann, da Uncx4.1 keine Protein-Protein Interaktion mit Ngn2 zeigt (Abb. 33, C). 

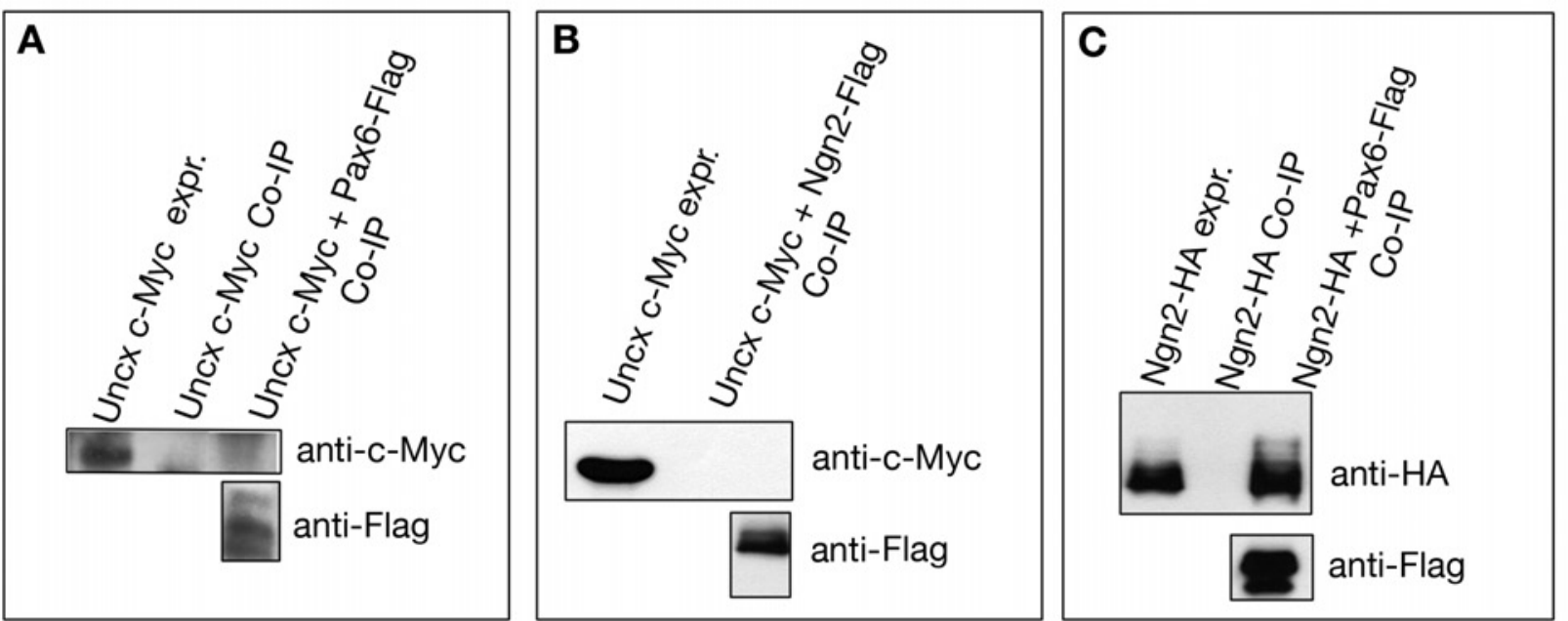

Abb. 33: Ngn2 und Pax6 zeigen Protein-Protein Interaktion. (A-C) Western Blot Analyse der CoImmunopräzipitation von Uncx4.1 mit Pax6 (A), Uncx4.1 mit Ngn2 (B) und Ngn2 mit Pax6 (C). Der Input der Expression betrug $10 \%$.

\subsection{Analyse der Pax6-positiven Zellen in Ngn2-defizienten Mäusen}

Da die Anzahl Pax6-positiver Zellen in Abwesenheit von Uncx4.1 beginnend mit E13.5 erhöht ist (Kap. 2.4.2) und gezeigt werden konnte, dass Pax6 und Ngn2 auf Protein-Protein Ebene miteinander interagieren (Kap. 2.5.2), liegt die Vermutung nahe, dass die Hochregulation der Pax6-Expression auf die Reduzierung von Ngn2 in Abwesenheit von Uncx4.1 zurückzuführen ist. Unterstützt wird diese Hypothese durch eine Beobachtung von Kele et al. (2006) wonach die Expression von Pax6 an E11.5 in Ngn2-defizienten Mäusen ebenfalls erhöht sein soll. Kele et al. berichten allerdings nur von vorläufigen Ergebnissen. Eine Antikörperfärbung gegen Pax6 und GFP zeigt, dass die Anzahl Pax6-positiver Zellen an E11.5 bei einer Inaktivierung von Ngn2 nicht verändert ist (Abb. 34, A-B und E). Da bei einem Funktionsverlust von Uncx4.1 erst ab dem Embryonalstadium 13.5 eine erhöhte Anzahl Pax6-positiver Zellen im ventralen Mittelhirn zu verzeichnen ist, wurden ebenfalls coronale Gewebeschnitte Ngn2-defizienter Embryonen an E13.5 untersucht. Aber auch hier ist kein Unterschied in der Anzahl Pax6-positiver Neuronen festzustellen (Abb. 34, C-E).

Die Expression von Pax6 weist in Ngn2-defizienten Mausembryonen keinen Unterschied im Vergleich zum WT auf. 


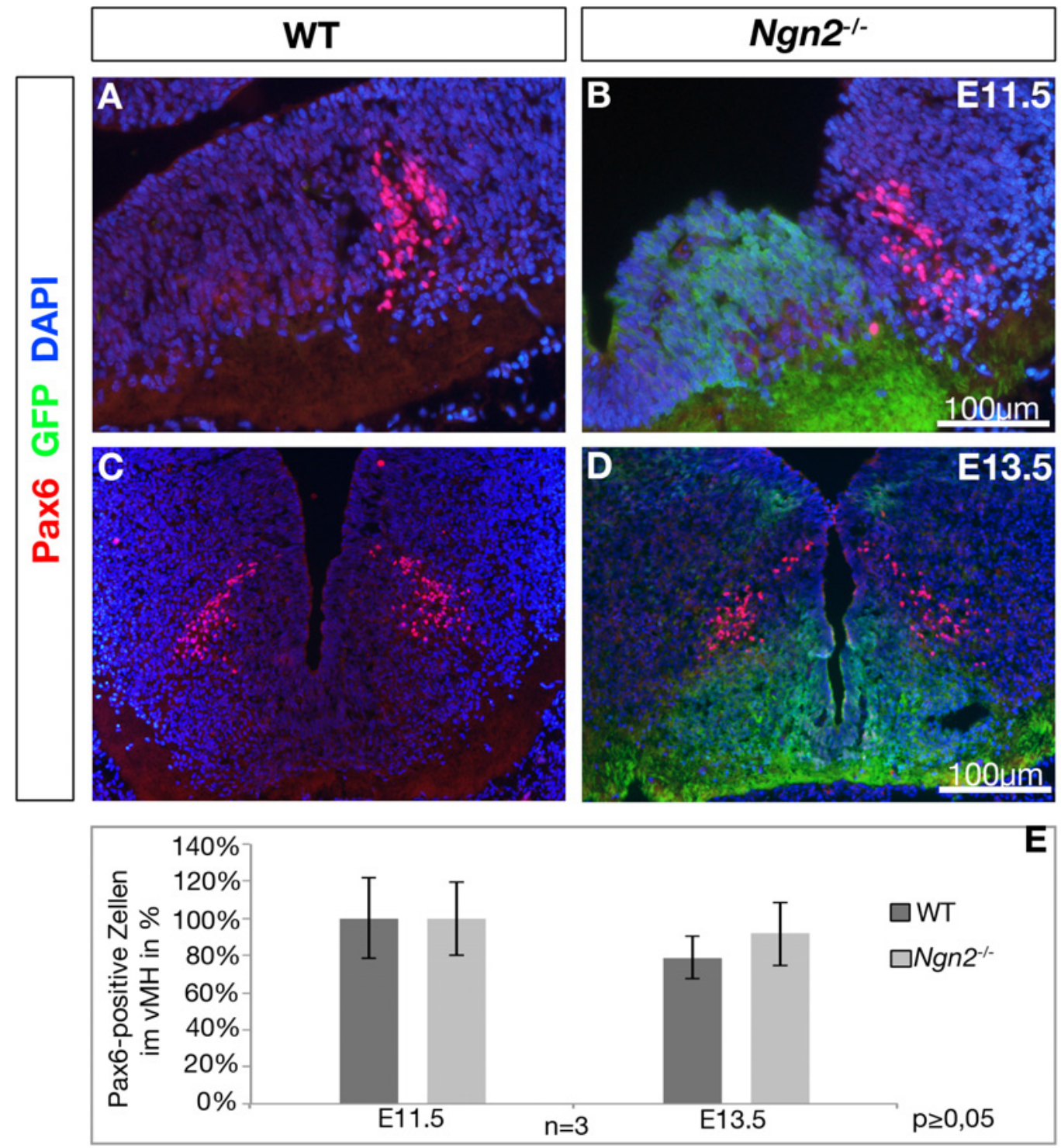

Abb. 34: Die Anzahl Pax6-positiver Zellen ist in Ngn2-defizienten Mausembryonen im Vergleich zum WT nicht verändert. (A-D) IHC gegen Pax6 (rot) und GFP (grün) in Ngn2 $2^{-/}$und WT Embryonen an E11.5 (A-B) und E13.5 (C-D). (E) zeigt die statistische Auswertung der gezählten Pax6-positiven Zellen im ventralen Mittelhirn in Prozent. Die Anzahl Pax6-positiver Zellen ist in $\mathrm{Ngn}^{-\%}$-Mausembryonen im Vergelich zum WT nicht signifikant verändert. Die Fehlerbalken zeigen die Standardabweichung. Der p-Wert wurde mittels „student's t-test“ ermittelt. vMH: ventrales Mittelhirn.

\subsection{Analyse der Oligodendrozyten in Abwesenheit von Uncx4.1}

Um zu analysieren ob die Inaktivierung von Uncx4.1 Auswirkungen auf das gliogene Zellschicksal hat, wurde die Expression von GFAP auf coronalen Gewebeschnitten durchgeführt. Da an E17.5 nur sehr wenige Zellen des Mittelhirns GFAP-positiv sind (Daten nicht gezeigt), wurden adulte Gehirne der konditionalen Cre-ER;Uncx4.1 ${ }^{f /-}$ Mausmutanten für die Analyse herangezogen. 


\section{Die Expression des Oligodendrozytenmarkers GFAP ist im Mittelhirn von}

\section{Cre-ER;Uncx4.1 $1^{f /-}$ Mäusen verändert}

Bei der Expressionsanalyse von GFAP zeigt sich, dass im Vergleich mit den Kontrollen mehr GFAP-positive Zellen im ventralen Mittelhirn der Cre-ER;Uncx4.1 $1^{f /-}$ Mausmutanten detektierbar sind (Abb. 35). Die Analyse verschiedener Gehirne jedoch zeigte, dass die erhöhte GFAP Expression nicht immer einheitlich war. So waren stärke, als auch eine leichtere Erhöhung als der in Abb. 35 dargestellten Ergebnisse, detektierbar. Dieser Umstand ist durch den verwendeten experimentellen Ansatz erklärbar. So ist es möglich, dass in den Fällen der stärkeren GFAP Expression die Effizienz der Cre-Linie höher war als in den Fällen mit einer schwächeren Erhöhung.

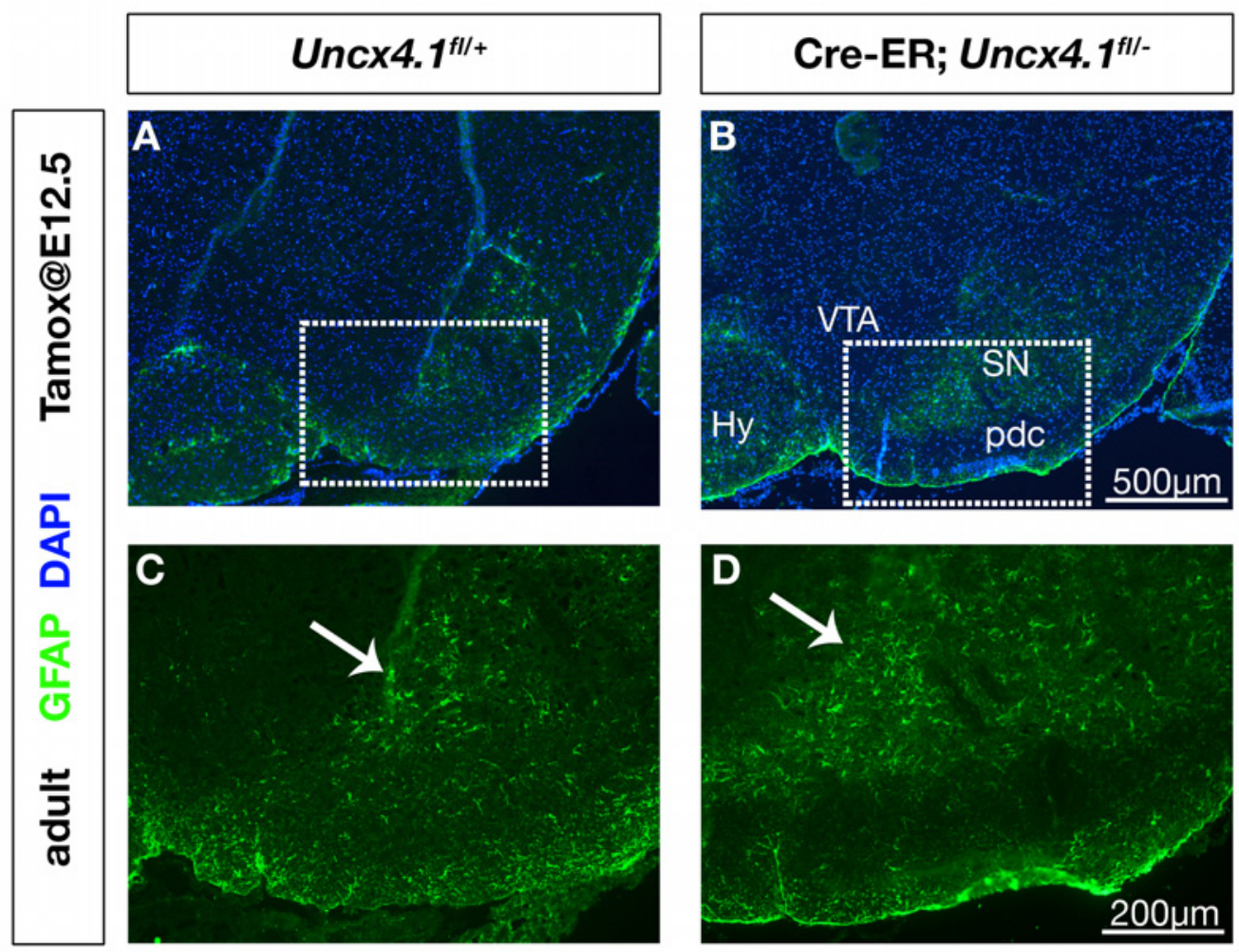

Abb. 35: Die Expression von GFAP im Mittelhirn adulter Cre-ER;Uncx4.1 ${ }^{f /-}$ Mäuse. (A-D) IHC gegen GFAP auf coronalen Gewebeschnitten adulter Mausgehirne. (C) zeigt die Vergrößerung des Ausschnitts in (A) und (D) des Ausschnitts in (B). Die Pfeile markieren die Veränderte GFAP Expression. Hy: Hypophyse, pdc: Pedunculus cerebri, SN: Substantia nigra, VTA: ventrales tegmentales Areal 


\subsection{Untersuchungen der Axone in Uncx4. ${ }^{1 /-}$-Mausembryonen}

Das Unc-4 Gen von Caenorhabditis elegans ist ein Homolog von Uncx4.1 mit einer 88\%igen Übereinstimmung (Rovescalli et al., 1996; Mansouri et al., 1997; Neidhardt et al., 1997). Die Expression von Unc-4 in C. elegans ist in VA- aber nicht in VB-Motorneuronen detektierbar (Miller et al., 1992; Miller \& Niemeyer, 1995). Gemeinsam mit seinem Co-Repressor Unc-37 kontrolliert Unc-4 die Repression spezifischer neuronaler Gene und bestimmt so den synaptischen Eingang der Motorneuronen (Winnier et al., 1999; Von Stetina et al., 2007). Eine weitere Funktion von Unc-4 ist die Regulation des Expressionslevels verschiedener vesikulärer Proteine (Lickteig et al., 2001). Aufgrund der Homologie von Uncx4.1 mit dem Unc-4 Gen liegt die Vermutung nahe, dass auch der Transkriptionsfaktor Uncx4.1 eine Rolle bei der axonalen Entwicklung und der Regulation der vesikulären Proteinebenen spielt. Diese Hypothese wurde mittels verschiedener experimenteller Ansätze untersucht und die Ergebnisse werden im Folgenden dargestellt.

\subsubsection{Die Level der synaptischen Proteine sind nicht in Abwesenheit von Uncx4.1 unverändert}

Vorhergehende Studien haben gezeigt, dass das Gen Unc-4 das Proteinlevel der synaptischen Vesikel in C. elegans reguliert (Lickteig et al., 2001). So zeigen einige vesikuläre Proteine in Abwesenheit von Unc-4 eine veränderte Expression. Zu diesen Proteinen gehören der vesikuläre Acetylcholintransporter (VACht), Synaptogamin, Synaptobrevin und Rab3a ( „ras-related“ Protein 3a) (Lickteig et al., 2001). Nicht vesikuläre Proteine wie z.B. Syntaxin zeigen keine veränderte Expression (Lickteig et al., 2001). Um zu überprüfen ob die Inaktivierung von Uncx4.1 Einfluss auf die Expression vesikulärer und nicht-vesikulärer Proteine nimmt, wurde eine Western Blot Analyse durchgeführt. Hierzu wurde zunächst ein Proteinextrakt ganzer Gehirne des Embryonalstadiums 18.5 hergestellt und anschließend mittels Western Blot Analyse untersucht. Die Western Blot Analyse wurde gemeinsam mit Dr. Frederique Varoqueaux am Max-Planck-Institut für experimentelle Medizin (Göttingen) durchgeführt.

Das Proteinlevel des vesikulären Acetylcholintransporters (VACht), welcher bis zur Ausschüttung in den Synapsen gespeichert bleibt (Usdin et al., 1995; Arvidsson et al., 1997), ist in Uncx4.1 Mausmutanten des Stadiums E18.5 nicht verändert (Abb. 36). Ebenso wenig ist ein 


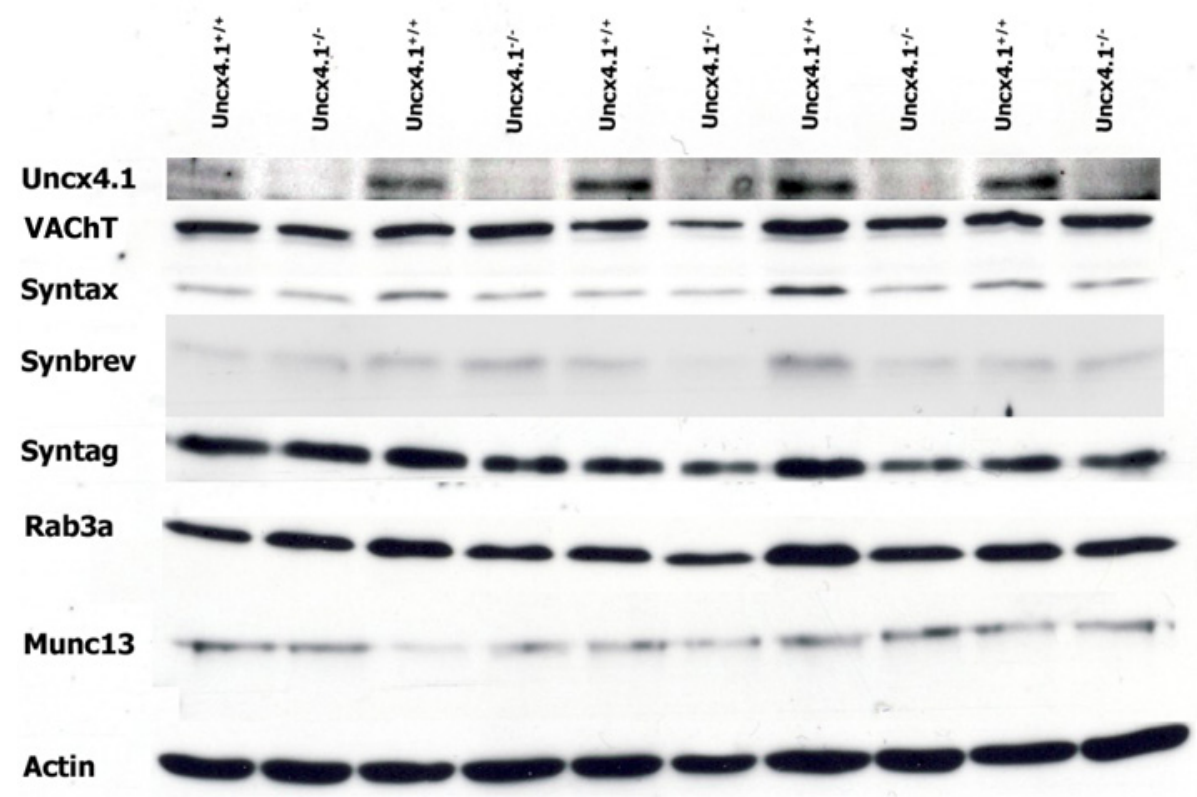

Abb. 36: Die Level verschiedener vesikulärer und nicht vesikulärer postsynaptischer Proteine sind in Uncx4.1 ${ }^{-/}$Embryonen unverändert. Western Blot Analyse von fünf Uncx4.1-defizienten und fünf WT Embryonen des Stadiums E18.5. VACht: vesikulärer Acetylcholintransporter, Syntax: Syntaxin, Synbrev: Synaptobrevin, Syntag: Syntagmin, Rab3a: „ras-related“-Protein 3a.

Unterschied in den Leveln der Proteine Synaptogamin, Synaptobrevin oder Rab3a detektierbar (Abb. 36). Der Funktionsverlust von Uncx4.1 hat auch keinen Einfluss auf die nicht-vesikulären Proteine wie Syntaxin oder Munc13, das Säugetierhomolog von Unc-13 aus C. elegans (Brose et al., 1995).

Die gewonnen Ergebnisse zeigen, dass ein Verlust der Uncx4.1 Aktivität in Mäusen keinen Einfluss auf das Proteinlevel vesikulärer oder nicht-vesikulärer, synaptischer Proteine ausübt. 


\subsubsection{Die Axone der Colliculi superiores sind in Uncx4.1-Nullmutanten verändert}

Neben der Bedeutung für das Proteinlevel vesikulärer Synapsen spielt Unc-4 in C. elegans auch eine Rolle bei der Spezifikation der Axone. So konnte in der Vergangenheit gezeigt werden, dass ein Verlust von Unc-4 in den Nematoden zu strukturellen Defekten in der Morphologie der Motorneuronen führt (Miller et al., 1992; White et al., 1992). Gemeinsam mit seinem CoRepressor hält Unc-4 den axonalen Eingang der VA Motorneuronen aufrecht, indem spezifische Gene für VB Motorneuronen reprimiert werden (Pflugrad et al., 1995; Winnier et al., 1999; Von Stetina et al., 2007).

Synapsine sind neuro-spezifische Phosphoproteine, welche mit kleinen synaptischen Vesikeln assoziiert sind, die in sensorischen Nerven und terminalen Nervenenden zu finden sind. Hier sind sie hauptsächlich mit der Membran der synaptischen Vesikel verbunden (Camilli et al., 1983; Greengard et al., 1993) und können zur Analyse von axonalen Defiziten herangezogen werden. Die konfokale Analyse der IHC mit anti-Synapsin I+II zeigt, dass in Abwesenheit von Uncx4.1 die Axone der Kommissur der Colliculi supreriores im dorsalen Mittelhirn an E16.5 (Abb. 37) und E17.5 (Daten nicht gezeigt) verändert sind. So scheint es, dass bei einem Funktionsverlust von Uncx4.1 eine Kompensation der Axone stattfindet (Abb. 37, Pfeile in C und D). Im ventralen Mittelhirn konnte keine Veränderung der Expression verzeichnet werden (Daten nicht gezeigt).

Neben Synapsin wurde auch Calbindin für die Detektion axonaler Defekte im dorsalen Mittelhirn der Maus herangezogen. Calbindin ist ein intrazelluläres Protein, das Kalzium bindet und somit die kalziumabhängigen Signalwege in Neuronen während der Entwicklung reguliert (Wasserman \& Fullmer, 1989; Nemere et al., 1991). Aufgrund dieser Tatsache eignet es sich als neuronaler Marker (Baimbridge et al., 1992). Besonders häufig wird Calbindin herangezogen um Purkinjezellen im Cerebellum nachzuweisen (Iacopino et al., 1990; Ishikawa et al., 1995, Sudarov \& Joyner, 2007). Calbindin wurde verwendet um axonale Defekte in den Uncx4.1 $1^{-1}$ Mausembryonen aufzuzeigen. In Uncx4.1-defizienten Mittelhirnen lassen sich bereits an E13.5 Unterschiede feststellen. 


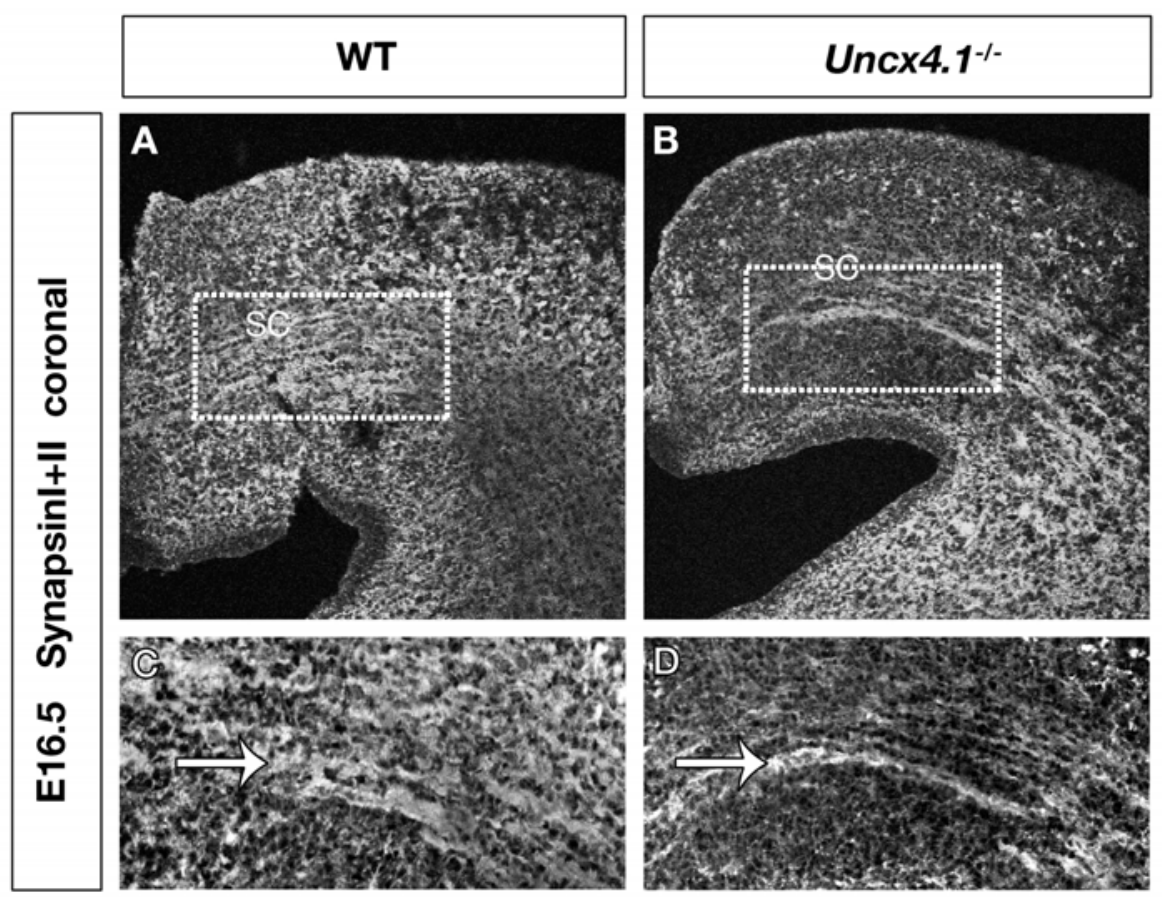

Abb. 37: Die Inaktivierung von Uncx4.1 führt zu einer Kompensation der Synapsin I+II Expression in den Colliculi superiores. Konfokale Aufnahmen einer IHC coronaler Gewebeschnitte an E16.5 mit anti-Synapsin I+II (A-D). (C) und (D) zeigen die Vergrößerungen des Ausschnitts in (A) und (B). Die Pfeile in (C) und (D) deuten auf die Kompensation der Axone der Colliculi superiores. SC: Colliculi superiores.

In den Kontrollen ist die Expression von Calbindin im dorsalen Mittelhirn in zwei klar voneinander abgrenzbaren Domänen erkennbar (Abb. 38, A-D). In den Mutanten zeigt sich jedoch, dass sich diese Domänen in Abwesenheit von Uncx4.1 vermischen (Abb. 38, weiße Pfeile in C-D). Auf sagittalen Gewebeschnitten an E18.5 sind mehr Calbindin-positive Neuronen im dorsalen Teil der Colliculi supreriores der Uncx4.1-defizienten Mausembryonen detektierbar, als in den Kontrolltieren (Abb. 38, weiße Pfeile in G-H). Im ventralen Teil der Colliculi supreriores allerdings sind weniger Calbindin-positive Neuronen zu verzeichnen (Abb. 38, G-H).

Zusammenfassen lässt sich feststellen, dass der Funktionsverlust von Uncx4.1 Unterschiede in der Expression von Synapsin I+II sowie Calbindin in dem Bereich des Colliculus superiores im dorsalen Mittelhirn hervor ruft. Anscheinend führt der Verlust der Uncx4.1 Aktivität zu einer Kompensation oder möglicherweise einer Verdickung der Axone in den Colliculi superiores im Vergleich zum Wildtyp. 

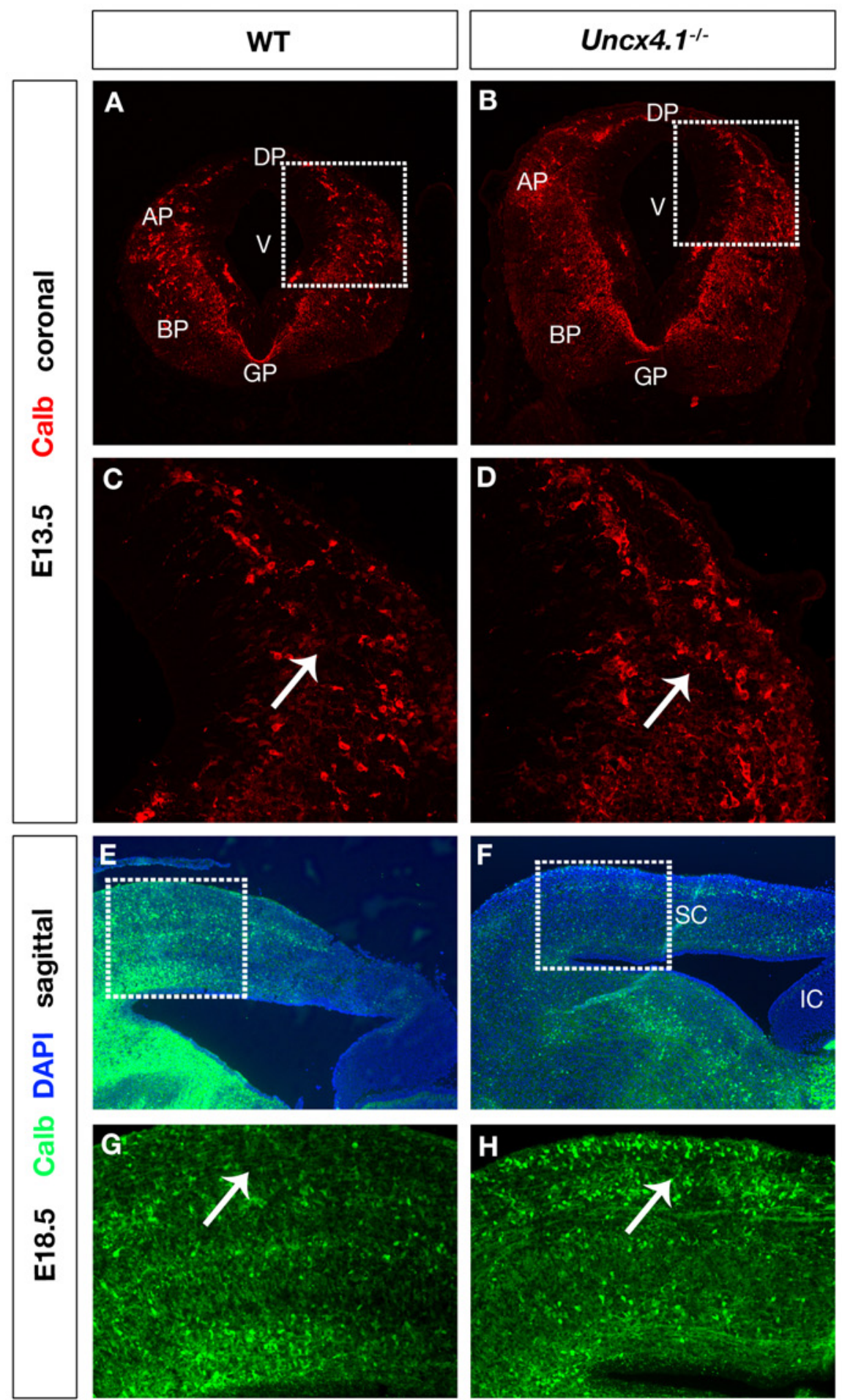

Abb. 38: Die Inaktivierung von Uncx4.1 führt zu einer Veränderung der Calbindin Expression in den Colliculi superiores. (A-D) Konfokale Aufnahmen einer IHC auf coronalen Gewebeschnitten von Mausembryonen an E13.5 mit anti-Calbindin (rot). (C) Vergrößerung des Ausschnitts in (A). (D) Vergrößerung des Ausschnitts in (B). (E-H) IHC gegen Calbindin (grün) auf sagittalen Gewebeschnitten des Embryonalstadiums 18.5. Die Pfeile in (C-D) und (G-H) deuten auf den Bereich der veränderten Calbindin-Expression im dorsalen Mittelhirn. AP: Alarplatte, BP: Basalplatte, DP: Deckplatte, GP: Bodenplatte IC: Colliculi inferiores, SC: Colliculi superiores, V: III. Ventrikel. 


\subsubsection{Die Inaktivierung von Uncx4.1 führt zu verkürzten Axonen und einer verringerten Anzahl axonaler Auswüchse}

Die Ergebnisse der Calbindin- und Synapsin I+II Färbung aus Kapitel 2.8.2 deuten darauf hin, dass die Axone der Colliculi superiores in Abwesenheit von Uncx4.1 beeinträchtigt sind. In früheren Studien konnte gezeigt werden, dass es möglich ist, die Morphologie dieser Axone mittels einer retrograden Axonfärbung unter Verwendung von DiI sichtbar zu machen (Tardif, 2002; Chebat et al., 2006). Daher wurde eine DiI Färbung durchgeführt. Hierzu wurde eine konstante Menge der gelösten DiI Kristalle mit Hilfe einer Injektionspumpe in das dorsale Mittelhirn appliziert. Es wurde immer dieselbe Menge an DiI verabreicht. Ein Beispiel für die Injektionsstelle findet sich in Abbildung 39 (A-B, die weißen Kreise markieren den Bereich der Injektionsstelle), welche ein WT und ein Uncx4.1-defizientes Gehirn nach der Injektion zeigt. Die Analyse der Gehirne folgte nach 7 (Daten nicht gezeigt), 8 oder 10 Tagen (Daten nicht gezeigt), wobei sich gezeigt hat, dass die Ergebnisse acht Tage nach der Injektion am deutlichsten sind.

Die Ergebnisse der DiI Injektion bestätigen die Vermutung, dass in Uncx4.1-defizienten Mausembryonen axonale Defekte im Bereich der Colliculi superiores vorliegen. So ist erkennbar, dass an E18.5 (Abb. 39, C-D) eine geringere Anzahl axonaler Auswüchse nach lateral zu verzeichnen ist (Abb. 39, weiße Pfeile in C-D). Zusätzlich sind die detektierten Axone in Uncx4.1 ${ }^{-1-}$ Embryonen kürzer als in den Kontrolltieren (Abb. 39, C-D). Dies ist auch im Embryonalstadium $16.5 \mathrm{zu}$ beobachten (Abb. 39. E-F). Es ist allerdings zu erwähnen, dass jeweils nur drei Tiere pro Genotyp untersucht wurden und die Technik der DiI Injektion nicht immer zu 100\% identisch durchführbar ist. Um statistisch signifikante und abgesicherte Ergebnisse zu erhalten, müssten noch weitere Tiere untersucht werden.

Um Einblicke darüber zu erhalten, in wie weit die Morphologie der Axone in Uncx4.1defizienten Mausembryonen verändert ist, wurden weitere morphologische Studien durchgeführt. Hierbei wurde auf die von Camillio Golgi entwickelte Golgi Färbung zurückgegriffen. Mit Hilfe dieser Technik ist es möglich zehn Prozent aller Neuronen anzufärben und so deren Morphologie sichtbar zu machen (Pannese, 1999; Pilati et al., 2008). Dadurch, dass nicht alle Neuronen angefärbt werden, ist es möglich detaillierte Einblicke über die Struktur der gefärbten Neuronen zu erhalten. Die Analyse der Golgi Färbung bestätigt die Ergebnisse der DiI Färbung. Auch die mittels Golgi angefärbten Neuronen der Uncx4.1 ${ }^{-/-}$Embryonen weisen an E18.5 weni- 
ger axonale Auswüchse in rostraler oder caudaler Richtung im Vergleich zu den Kontrolltieren (Abb. 40) auf.
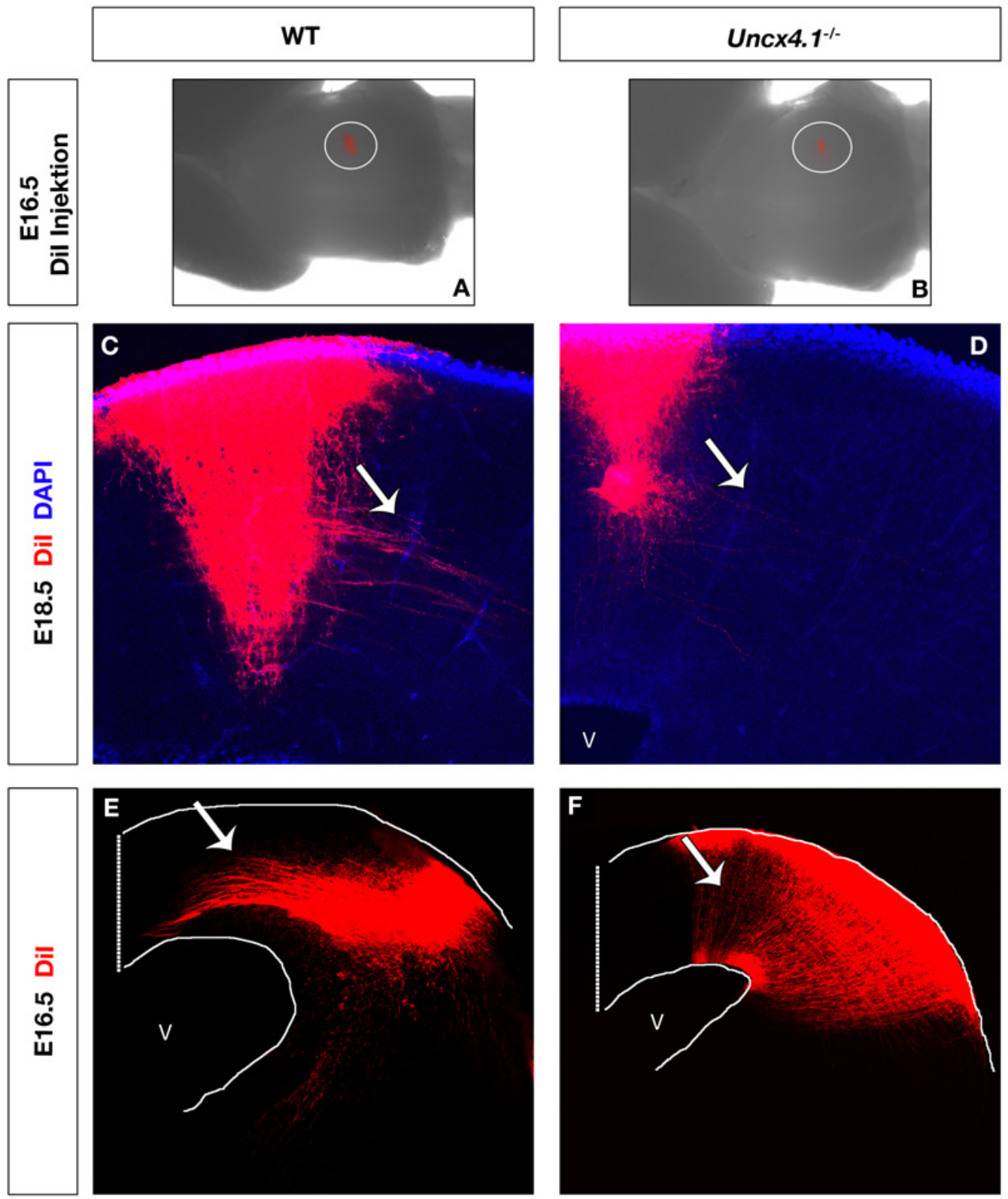

Abb. 39: DiI Färbung der Neuronen im dorsalen Mittelhirn an E16.5 und E18.5. (A-B) Beispielhafter Vergleich der Injektionsstelle von WT (A) und Uncx4.1-defizienten (B) Gehirnen von Mausembryonen, wobei der weiße Kreis den Bereich der DiI-Injektionsstele markiert. Der rote Punkt zeigt das injizierte Dil. (C-F) Konfokale Aufnahmen der DiI Färbung (rot) auf Vibratomschnitten an E18.5 (C-D) und E16.5 (E-F). Nach Injektion wurden die Gehirne 8 Tage bei $4{ }^{\circ} \mathrm{C}$ in $4 \%$ PFA gelassen, ehe sie geschnitten und analysiert wurden. Die Pfeile zeigen auf die lateral verlaufenden Axone in den Colliculi superiores. V: III. Ventrikel.

Anscheinend ist die Anzahl der Axone pro Neuron in den Uncx4.1-defizienten Mausembryonen im Allgemeinen verringert, was die Ergebnisse der DiI Färbung unterstützt (Abb. 40, C und D). Zusätzlich dazu sind die meisten axonalen Auswüchse in Abwesenheit von Uncx4.1 kürzer als in den Kontrolltieren. Um diese Ergebnisse zu unterstützen ist es allerdings notwendig weitere 
Studien, z.B. mittels Zellkulturexplanten der Axone, durchzuführen.

Diese Ergebnissen lassen vermuten, dass der Transkriptionsfaktor Uncx4.1 eine Rolle während der axonalen Entwicklung oder ihrer Ausrichtung spielt.
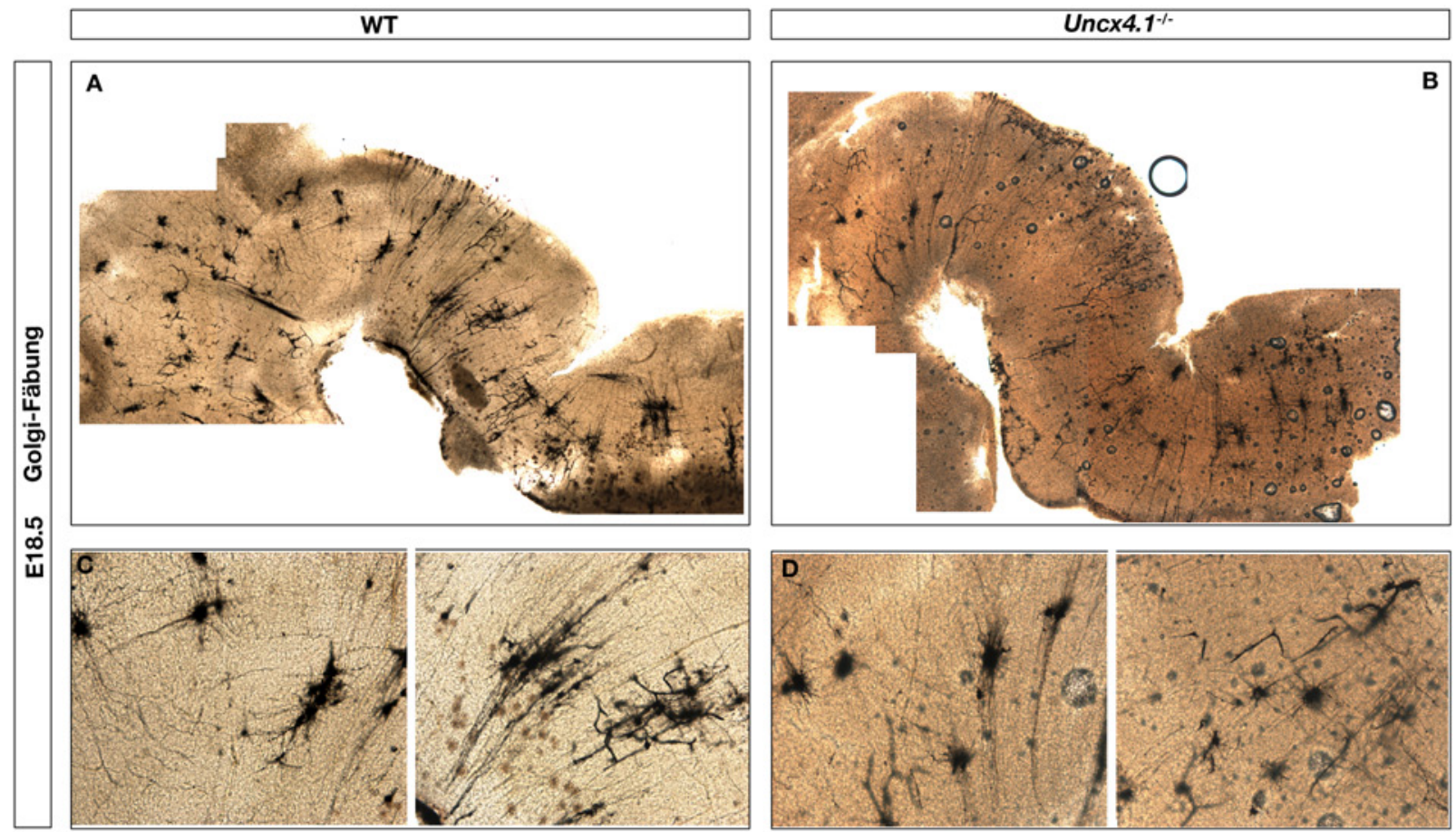

Abb. 40: Uncx4.1-Nullembryonen zeigen morphologische Veränderungen der Neuronen im Mittelhirn. (AD) Golgi Färbung von sagittalen Gewebeschnitten des Stadiums E18.5 von WT (A, C) und Uncx4.1 ${ }^{-/}$Embryonen (B, D). (C) zeigt einige Neuronen aus (A) in der Vergrößerung, (D) zeigt einige Neuronen aus (B) in der VergröBerung. 


\section{Diskussion}

Die Rolle der Homöobox enthaltenden Transkriptionsfaktoren bei der Koordination der Expression, sowie Interaktion während der Entwicklung der Vertebraten ist ein weites, noch nicht vollkommen erforschtes Feld der Biologie. Daher bleiben bis heute viele Transkriptionsfaktoren und ihre Funktion unbeschrieben. Das Gen Uncx4.1 gehört ebenfalls zu den Transkriptionsfaktoren, die eine Homöodomäne enthalten und dessen Funktionen im Gehirn weitestgehend ungeklärt sind. Obwohl die ersten Transkripte von Uncx4.1 bereits an E9.5 im Mesencephalon detektiert werden können (Mansouri et al., 1997; Neidhardt et al., 1997), wurde bisher keine Funktionsanalyse von Uncx4.1 im Mittelhirn durchgeführt.

In der vorliegenden Arbeit wurde zunächst die Expression von Uncx4.1 während der Embryonalentwicklung des Mittelhirns untersucht. Da die Ergebnisse darauf hindeuteten, dass Uncx4.1 in nahezu allen postmitotischen Zellen der unterschiedlichen Neuronengruppen (dopaminergen, GABAergen und glutamatergen) des Mittelhirns exprimiert ist, wurde anschließend untersucht, welche Rolle Uncx4.1 bei der Entwicklung der einzelnen Neuronenpopulationen spielt. Ein besonderer Fokus lag hier auf der Entwicklung der dopaminergen Neuronen, da die Expression von Uncx4.1 an E11.5 in nahezu allen TH-positiven Neuronen verzeichnet werden konnte. Zudem sind dopaminerge Neuronen von besonderer Bedeutung, da Teile dieser Neuronenpopulation bei Patienten mit Morbus Parkinson degenerieren (Fahn, 2003). Die in dieser Arbeit dargestellten Ergebnisse legen nahe, dass Uncx4.1 ein neuer Faktor im regulatorischen Netzwerk dopaminerger Neuronen im Mittelhirn ist und seine regulatorische Funktion möglicherweise über das proneurale Gen Ngn2 ausübt. Daneben deutet eine erhöhte Zellzahl glutamaterger Pax6-positiver Zellen, ebenso wie der Verlust der Ngn2-mRNA im dorsalen Mittelhirn, darauf hin, dass Uncx4.1 auch an der glutamatergen Neurogenese beteiligt ist. Im Gegensatz dazu scheint eine Funktion während der GABAergen Neurogenese nahezu ausgeschlossen zu sein, da die Expression verschiedener Marker GABAerger Neuronen nicht beeinflusst ist. Neben den neuronalen Subpopulationen wurden auch die Axone im dorsalen Mittelhirn untersucht. Diese Arbeit liefert erste Anhaltspunkte, dass Uncx4.1 eine Rolle bei der korrekten Bildung der Axone in den Colliculi superiores zukommt. 


\subsection{Uncx4.1 ist in postmitotischen Neuronen des Mittelhirns exprimiert}

Die in dieser Arbeit durchgeführte Expressionsanalyse von Uncx4.1 im embryonalen Mittelhirn der Maus offenbart, dass Uncx4.1 an E11.5 in der gesamten Mantelzone des Mittelhirns exprimiert ist und in späteren Entwicklungsstadien (E13.5 und E17.5) in einem Salz-und-Pfeffer Muster mit Uncx4.1-negativen Zellen in der Mantelzone vorliegt. Dies deutet auf eine postmitotische Expression von Uncx4.1 hin und konnte durch eine Co-Detektion von Uncx4.1 und Tuj1 bestätigt werden. Im ventralen Mittelhirn exprimieren nahezu alle Uncx4.1-positiven Zellen an E11.5 auch Tuj1, während im dorsalen Mittelhirn sowohl Uncx4.1-positive/Tuj1-negative, als auch Uncx4.1-negative/Tuj1-positive Zellen detektiert werden können. Die Existenz von Uncx4.1-positiven, aber Tuj1-negativen Zellen im dorsalen Mesencephalon deutet darauf hin, dass die Expression von Uncx4.1 wahrscheinlich während der letzten mitotischen Phase beginnt, kurz bevor die Vorläuferzellen den Zellzyklus verlassen und postmitotisch werden.

Die Co-Lokalisation von Uncx4.1 und TH zeigt, dass Uncx4.1 von reifen dopaminergen Neuronen exprimiert wird. Daneben ist Uncx4.1 aber auch in unreifen dopaminergen Neuronen exprimiert, was durch die Co-Lokalisation mit Ngn2 deutlich wird (Kele et al., 2006). Der Fund Ngn2 und Uncx4.1 co-positiver Zellen in den lateralen Bereichen der Basalplatte und dem dorsalen Mittelhirn zeigt auf, dass Uncx4.1 auch von glutamatergen Neuronen exprimiert wird (Nakatani et al., 2007; Kala et al., 2009). Dies wird durch die Co-Detektion von Uncx4.1 und Foxa2 in der gesamten Mantelzone des ventralen Mittelhirns bestätigt. Ebenso zeigt die Co-Lokalisation mit Foxa2, dass Uncx4.1 von dopaminergen und GABAergen Neuronen exprimiert wird (Nakatani et al., 2007; Kala et al., 2009; Waite et al., 2011).

Die aus dieser Arbeit gewonnenen Daten lassen die Schlussfolgerung zu, dass Uncx4.1 in dopaminergen, GABAergen und glutamatergen Neuronenpopulationen des Mittelhirns exprimiert ist und seine Expression nicht auf eine bestimmte neuronale Abstammung zurückzuführen ist. Sammeta et al. (2010) schlussfolgerten, dass die Expression von Uncx4.1 einsetzt, sobald die Vorläufer ein neuronales Schicksal annehmen. Es wurde auch berichtet, dass Uncx4.1 ebenfalls in basalen Vorläuferzellen des Bulbus olfactorius exprimiert ist. Im Gegensatz dazu, ist keine Uncx4.1 Expression in neuronalen Progenitoren des Mittelhirns detektierbar. Dies deutet darauf hin, dass die Expression im Mittelhirn später, und nicht direkt mit der Adaption eines neuronalen Zellschicksals, einsetzt. Dennoch ist anzunehmen, dass sie unabhängig von dem neuronalen 
Subtyp ist. Die Vermutung von Sammeta et al. (2010), dass die Induktion der Uncx4.1 Expression durch das proneurale Gen Mashl in den proneuralen Vorläuferzellen ausgelöst werden könnte, wird durch die Ergebnisse dieser Arbeit unterstützt. So ist Mash1 an E11.5 nahezu in allen neuronalen Progenitoren des Mittelhirns exprimiert (Kala et al., 2009; , Peltopuro \& Kala, 2010), während Uncx4.1 zu diesem Zeitpunkt in allen Bereichen der Mantelzone detektiert werden kann. Zudem können, einhergehend mit der fehlenden Expression von Mash1 (Peltopuro \& Kala, 2010), an E10.5 keine Uncx4.1 Transkripte in der Bodenplatte beobachtet werden. Interessant wäre in diesem Zusammenhang eine Analyse Mash1-defizienter Mittelhirne, hinsichtlich eines möglichen Expressionsverlustes von Uncx4.1, wie im Bulbus olfactorius beschrieben (Sammeta et al., 2010).

Zusammengenommen konnte in dieser Arbeit demonstriert werden, dass der Transkriptionsfaktor Uncx4.1, unabhängig von der neuronalen Abstammung, in postmitotischen Neuronen des Mittelhirns exprimiert ist. Weiterhin liefert die Expressionsanalyse von Uncx4.1 Hinweise darauf, dass die Expression von Uncx4.1 nach der von Mash1 folgt.

\subsection{Die Funktion von Uncx4.1 während der Entwicklung dopaminerger Neuronen im Mittelhirn}

Der Verlust dopaminerger Neuronen in der SN des ventralen Mittelhirns ist mit einer der bis heute bekanntesten, neurologischen Krankheiten assoziiert: Morbus Parkinson (Lang \& Lozano, 1998a b; Fahn, 2003). Aufgrund der klinischen Relevanz der Parkinsonschen Krankheit, hat die Entschlüsselung des regulatorischen Netzwerkes dieser Neuronen in den letzten Jahren an Bedeutung gewonnen. Denn nur bei genauer Kenntnis aller beteiligten Faktoren können erfolgreiche Strategien zur Generierung dopaminerger Neuronen für z.B. Zelltransplantationstherapien entwickelt und umgesetzt werden (Winkler \& Kirik, 2005). So gelang es in den letzten Jahren verschiedene Transkriptionsfaktoren, wie Otx2, Msx1, Foxa2, Lmx1a, Lmx1b, Ngn2, Nurr1 und Pitx3 als Regulatoren des Netzwerkes zu identifizieren und zu charakterisieren (SaucedoCardenas et al., 1998; Wallen et al., 1999; Smidt et al., 2004; Maxwell et al., 2005; Andersson et al., 2006b a; Blaess et al., 2006; Kele et al., 2006; Prakash et al., 2006; Ferri et al., 2007; Ono et al., 2007; Chung et al., 2009; Lin et al., 2009; Nakatani et al., 2010; Mavromatakis et al., 2011). Trotz des mittlerweile umfangreichen Wissens über die Initiierung, Spezifikation und Differenzierung der mDA Neuronen sind noch immer nicht alle beteiligten Faktoren bekannt 
oder blieben bislang unerforscht.

Die nahezu vollständige Co-Detektion von Uncx4.1 mit TH in den frühen Embryonalstadien (E11.5) führte zu der Annahme, dass Uncx4.1 möglicherweise eine Rolle bei der Entwicklung der dopaminergen Neuronen spielt. Die daraufhin durchgeführte Expressionsanalyse verschiedener Marker von mDA Neuronen in Uncx4.1 $1^{\text {- }}$ Embryonen zeigt, dass alle untersuchten Marker im Vergleich zu den Kontrolltieren reduziert sind. Eine quantitative Analyse bestätigte dies (eine Zusammenfassung der Marker findet sich in Tab. 1). Diese Ergebnisse deuten auf einen allgemeinen partiellen Verlust dopaminerger Neuronen im Mittelhirn Uncx4.1-defizienter Embryonen hin. Interessanterweise allerdings ist an E17.5 ein deutlich größerer Verlust von Calbindin- und Calretinin-positiven Zellen in Uncx4.1-defizienten Tieren, im Vergleich mit anderen mDA Markern, zu verzeichnen. Da Calbindin und Calretinin vorzugsweise in den dopaminergen Neuronen der VTA exprimiert sind (Liang et al., 1996; Nemoto et al., 1999), und frühere Studien Calbindin bereits als Marker der mDA Neuronen in der VTA verwendet haben (Andersson et al., 2006a), deutet der erhöhte Verlust dieser Zellen darauf hin, dass Uncx4.1 eine wichtigere Bedeutung in den mDA Neuronen der VTA, als in denen der SN, zukommt.

\begin{tabular}{|l|l|l|l|}
\hline Gen/Protein & Untersuchtes Stadium & Marker für: & Effekt \\
\hline \hline TH & E11.5 & mDA Neuronen & 26\%iger Verlust \\
TH & E17.5 & mDA Neuronen & 26\%iger Verlust \\
DAT & E17.5 & mDA Neuronen & Reduzierung der Expression \\
Pitx3 & E17.5 & mDA Neuronen & $31 \%$ iger Verlust \\
Nurr1 & E11.5 & mDA Neuronen & $28 \%$ iger Verlust \\
Nurr1 & E16.5 & mDA Neuronen & $24 \%$ iger Verlust \\
Calbindin & E17.5 & mDA Neuronen der VTA & $43 \%$ iger Verlust \\
Calretinin & E17.5 & mDA Neuronen der VTA & $58 \%$ iger Verlust \\
Foxa2 & E11.5 & mDA Neuronen, GABAerge und glutamaterge Neuronen & unverändert \\
Foxa2 & E12.5 & mDA Neuronen, GABAerge und glutamaterge Neuronen & unverändert \\
Lmx1a & E11.0 & mDA Neuronen & unverändert \\
Lmx1a & E12.5 & mDA Neuronen & unverändert \\
Ngn2 & E11.5 & mDA Neuronen und glutamaterge Neuronen & Reduzierung der Expression \\
\hline
\end{tabular}

Tab. 1: Zusammenfassung der Veränderung dopaminerger Neuronen im ventralen Mittelhirn Uncx4.1defizienter Embryonen. Es wurden mindestens n=3 Embryonen pro Marker und Stadium untersucht.

Eine verminderte Proliferation oder erhöhte Apoptose sind nicht für den Verlust der mDA Neuronen in Uncx4.1-defizienten Tieren verantwortlich, da sowohl die Anzahl der proliferierenden Zellen, als auch die Anzahl apoptotischer Zellen in Abwesenheit von Uncx4.1 unverändert ist. Dies ist gegensätzlich zu den Untersuchungen im Bulbus olfactorius, denn dort konnte bei einem Aktivitätsverlust von Uncx4.1 eine verminderte Proliferations-, sowie eine deutlich erhöhte Apoptoserate festgestellt werden (Sammeta et al., 2010). Dies mag darauf zurückzuführen sein, dass Uncx4.1 im Mittelhirn nicht in Vorläuferzellen, wie im Bulbus olfactorius (Saito et al., 1996; Sammeta et al., 2010), sondern nur in postmitotischen Neuronen, expri- 
miert wird. Neben Proliferationsdefekten und einer vermehrten Apoptose kann auch eine zeitliche Verzögerung der Differenzierung als Ursache für die Reduzierung der mDA Neuronen in Uncx4.1-Mausmutanten ausgeschlossen werden, denn die Expression von Tuj1 war im Vergleich zu Kontrolltieren nicht verändert. Aufgrund dieser Ergebnisse, kann ausgeschlossen werden, dass Uncx4.1 eine Rolle während der Initiation der dopaminergen Neurogenese zukommt. Da Uncx4.1 hauptsächlich von reifen mDA Neuronen (markiert durch TH und Uncx4.1 CoExpression) exprimiert wird, ist es sehr wahrscheinlich, dass Uncx4.1 für Differenzierung der mDA Neuronen von Bedeutung ist. Hingegen ist Uncx4.1 nicht für den Erhalt der mDA Neuronen notwendig, da es an E11.5 in nahezu allen TH-positiven Neuronen co-exprimiert ist, was an E17.5 nicht mehr der Fall ist (Daten nicht gezeigt). Diese Vermutung wird durch die Analysen der konditionalen Knockoutlinie Cre-ER;Uncx4.1 $1^{f /-}$ unterstützt, da in diesen Mutanten kein allgemeiner Verlust der mDA Neuronen verzeichnet werden kann. Die Inaktivierung von Uncx4.1 durch Tamoxifen erfolgte bei diesen Tieren erst an E12.5. Zu diesem Zeitpunkt ist die Generierung der dopaminergen Neuronen des Mittelhirns bereits weitestgehend abgeschlossen. Somit wäre ein Verlust der mDA Neuronen in diesen Mausmutanten nur dadurch zu erklären, dass Uncx4.1 eine Rolle während der Erhaltung der dopaminergen Neuronen zukommt.

Das proneurale Gen Ngn2 ist notwendig für die Differenzierung der mDA Neuronen und seine Expression beginnt nach der von Uncx4.1. In Abwesenheit von Ngn2 ist die Anzahl dopaminerger Neuronen drastisch reduziert (Andersson et al., 2006a; Kele et al., 2006). Da der Funktionsverlust von Uncx4.1 eine Reduzierung der Ngn2-mRNA bewirkt, ist es möglich, dass der Verlust der mDA Neuronen das Resultat der verminderten Ngn2 Expression ist. In Ngn2-Mausmutanten sind an E11.5 kaum Nurr1-positive Zellen zu verzeichnen, wohingegen an E13.5 deutlich mehr Nurr1-positive Neuronen vorhanden sind (Andersson et al., 2006a; Kele et al., 2006). Kele et al. (2006) vermuten, dass die Regeneration Nurr1-positiver Zellen in $\mathrm{Ngn}^{-/-}$Embryonen auf eine Kompensation durch Mash1 zurückzuführen ist, da die Expression von Mash1 an der ventralen Mittellinie ab E13.5 wieder detektierbar ist, wohingegen sie an E11.5 nicht zu verzeichnen ist. Trotz der verminderten Expression von Ngn2 in Uncx4.1-defizienten Mausembryonen kann keine Regeneration Nurr1-positiver Zellen verzeichnet werden. Dies kann durch die normale Expression von Mashl in Abwesenheit von Uncx4.1, im Vergleich zu den Kontrolltieren, erklärt werden. Diese Ergebnisse unterstützen die Theorie von Kele et al. (2006), dass Mash1 wesentlich an der Regeneration Nurr1-positiver Zellen beteiligt ist. Der Verlust der Uncx4.1 Expression im Bereich reifer mDA Neuronen Ngn2-defizienter Mausembryonen mag schlicht 
auf die Tatsache zurückzuführen sein, dass ihre Generierung in Abwesenheit von Ngn2 verzögert ist, denn in den Embryonalstadien E11.5 und E13.5 sind in $\mathrm{Ngn}^{-/-}$keine bzw. kaum reife mDA Neuronen detektierbar.

Durch die gewonnenen Ergebnisse der Co-Immunopräzipitation, kann ausgeschlossen werden, dass Ngn2 und Uncx4.1 eine Protein-Protein-Interaktion eingehen. Möglicherweise findet eine direkte Regulation von Ngn2 durch Uncx4.1 statt, wahrscheinlicher ist jedoch, dass Uncx4.1 zunächst weitere Gene in der Kaskade reprimiert oder aktiviert, die dann ihrerseits die Expression von Ngn2 regulieren. Es ist möglich, dass Uncx4.1 gemeinsam mit einem Co-Repressor agiert und eine reprimierende Funktion hat, wie es beim Homolog Unc4 in C.elegans der Fall ist (Miller et al., 1993; Winnier et al., 1999; Lickteig et al., 2001; Von Stetina et al., 2007; Jafari et al., 2011). Da einige Transkriptionsfaktoren, wie z.B. Oct4 (Pan et al., 2002), sowohl inhibitorische als auch aktivierende Funktionen besitzen, kann nicht ausgeschlossen werden, dass Uncx4.1 als Aktivator fungiert.

Nakatani et al. (2010) konnten zeigen, dass das Protein Sim1 in der Lage ist die Differenzierung der mDA Neuronen zu reprimieren, weshalb die erhöhte Expression von Sim1 an E12.5 in Uncx4.1 $1^{-1-}$ Embryonen ebenfalls dazu beitragen könnte, dass in Abwesenheit von Uncx4.1 weniger mDA Neuronen gebildet werden. Dies ist jedoch recht unwahrscheinlich, da an E11.5 keine erhöhte Siml Expression beobachtet werden kann, obwohl die Anzahl der TH- und Nurr1positiven Neuronen bereits reduziert ist.

Die Expression von Lmxla ist in Abwesenheit von Uncx4.1 nicht verändert, genauso wenig wie die Expression von Uncx4.1 in Abwesenheit von Lmxla. Somit kann eine Interaktion dieser beiden Faktoren nahezu ausgeschlossen werden. Diese Ergebnisse deuten auf die Existenz zweier Signalwege hin, die an der Entwicklung der mDA Neuronen beteiligt sind.

Des Weiteren konnte in dieser Arbeit gezeigt werden, dass die Expression von $\beta$ - Catenin in Uncx4.1 $1^{-/}$Embryonen ab E13.5 im ventralen Mittelhirn herunter reguliert ist, an E12.5 aber noch normal exprimiert wird. $\beta$ - Catenin kommt in der Entwicklung der mDA Neuronen verschiedene Aufgaben zu. So beeinflusst $\beta$ - Catenin unter anderem die Neurogenese der mDA Neuronen und wurde als wichtiger Co-Faktor der Genregulation in diesem Bereich beschrieben (Tang et al., 2009; Chilov et al., 2010). Dass der Verlust der mDA Neuronen in Uncx4.1defizienten Embryonen auf die Reduzierung der $\beta$ - Catenin Expression im ventralen Mittelhirn zurückzuführen ist, ist unwahrscheinlich, da die mDA Neuronen bereits an E11.5 reduziert sind, wenn die Expression von $\beta$-Catenin noch unbeeinflusst ist. Interessanterweise ist $\beta$-Catenin an 
der Migration der dopaminergen Neuronen der VTA und SN beteiligt (Tang et al., 2009). Während der Entwicklung migrieren postmitotische mDA Neuronen zunächst nach ventral entlang den Fasern der radialen Gliazellen, ehe sie beginnen lateral entlang der tangential angeordneten Nervenfasern zu wandern (Kawano et al., 1995, Ohyama et al., 1998, Gale \& Li, 2008). Bei der Analyse der in dieser Arbeit verwendeten konditionalen Knockoutlinie Cre-Er;Uncx4. $1^{f /-}$ war keine signifikante Veränderung in der Gesamtzellzahl TH-positiver Neuronen zu verzeichnen. Dennoch war bei diesen Mutanten eine verminderte TH-Expression im lateralen Bereich der SN, ebenso wie ein größerer Abstand zwischen der VTA und SN, festzustellen. Dies deutet auf Migrationsdefekte hin, die auf die verminderte $\beta$-Catenin Expression zurückgeführt werden könnten. Obwohl in Foxa2-Cre;Uncx4.1 $1^{f /-}$ kein Verlust der lateralen TH-positiven Neuronen der SN zu verzeichnen war, wurde dennoch ebenfalls der vergrößerte Abstand zw. VTA und SN detektiert. Um zu spezifizieren, ob es sich tatsächlich um Migrationsdefekte handelt sind jedoch weitere Analysen notwendig.

Zusammengenommen konnte in dieser Arbeit gezeigt werden, das Uncx4.1 ein neuer Transkriptionsfaktor ist, der an dem regulatorischen Netzwerk der dopaminergen Neuronen des Mittelhirns beteiligt ist und seinen Einfluss wahrscheinlich über die Regulation von Ngn2 ausübt. Ob eine direkte oder eine indirekte Regulation durch weitere Faktoren erfolgt, konnte nicht abschließend geklärt werden. Neben der Aufgabe der Differenzierung spielt Uncx4.1 vermutlich auch eine Rolle bei der Migration der dopaminergen Neuronen, was durch die Analyse der konditionalen Mausmutanten deutlich wird. An der Erhaltung reifer mDA Neuronen ist Uncx4.1 allem Anschein nach nicht beteiligt.

\subsection{Uncx4.1 spielt keine Rolle während der Entwicklung der GABAergen Neuronen im embryonalen Mittelhirn der Maus}

Im Gegensatz zu der Entwicklung GABAerger Neuronen im Vorderhirn, ist Mashl im Mittelhirn für ihre Entwicklung essenziell (Casarosa et al., 1999; Miyoshi \& Bessho, 2004). Es wird vermutet, dass Uncx4.1 während der Neurogenese sequenziell nach Mash1 exprimiert wird (Kap. 3.1, (Sammeta et al., 2010)). Da Uncx4.1 in postmitotischen GABAergen Neuronen detektiert werden konnte ist anzunehmen, dass Uncx4.1 während ihrer Differenzierung beteiligt ist. Es wäre möglich, dass Uncx4.1, ähnlich wie Gata2, als postmitotischer Selektor fungiert (Kala et al., 2009). Neben dem Vorkommen GABAerger Neuronen in der Basal- und Alarplatte 


\begin{tabular}{|l|l|l|l|}
\hline Gen/Protein & Untersuchtes Stadium & Marker für: & Effekt \\
\hline \hline Helt & E11.5 & GABAerge Neuronen der VZ & unverändert \\
Mash1 & E11.5 & GABAerge Neuronen der VZ & unverändert \\
Gad67 & E11.5 & GABAerge Neuronen der MZ & unverändert \\
Gad67 & E17.5 & GABAerge Neuronen der MZ & unverändert \\
Nkx2.2 & E12.5 & GABAerge Neuronen VZ und MZ & unverändert \\
Gata2 & E11.5 & GABAerge Neuronen der MZ & unverändert \\
Olig2 & E17.5 & GABAerge Neuronen der MZ & unverändert \\
Olig2 & E17.5 & GABAerge Neuronen der MZ & unverändert \\
Foxa2 & E11.5 & dopaminerge, glutamaterge und GABAerge Neuronen der VZ und MZ & unverändert \\
Foxa2 & E12.5 & dopaminerge, glutamaterge und GABAerge Neuronen der VZ und MZ & unverändert \\
\hline
\end{tabular}

Tab. 2: Zusammenfassung der Veränderung GABAerger Marker im ventralen Mittelhirn Uncx4.1defizienter Embryonen. Die verschiedenen Marker sind mit Ausnahme von Mashl nicht in allen GABAergen Neuronen, sondern nur in Subpopulationen der GABAergen Neuronen, exprimiert. Es wurden mindestens $n=2$ Embryonen pro Marker und Stadium untersucht. VZ: ventrikuläre Zone, MZ: Mantelzone.

des Mittelhirns, sind in frühen Entwicklungsstadien (E11.5) auch GABAerge Neuronen in der Bodenplatte lokalisiert (Kala et al., 2009). Später findet man sie auch im Bereich der VTA und SN (Steffensen et al., 1998; Korotkova et al., 2004). Da die Reduzierung der dopaminergen Neuronen nicht auf Zellproliferationsdefekte, Apoptose oder eine verzögerte Reifung zurückzuführen ist, wurde überprüft, ob die dopaminergen Neuronen ihre Identität in ein GABAerges Zellschicksal ändern. Bei keinem der verwendeten Marker GABAerger Neuronen war eine Veränderung in ihrer Expression in Uncx4.1-defizienten Mausmutanten zu verzeichnen (Tab.2), was darauf schließen lässt, dass Uncx4.1 nicht an ihrer Differenzierung beteiligt ist. Es ist allerdings zu beachten, dass mit Ausnahme von Mashl keiner der verwendeten Marker in den GABAergen Neuronen der SN oder VTA bzw. der Bodenplatte (an E11.5) exprimiert ist. Daher kann nicht ganz ausgeschlossen werden, dass die dopaminergen Neuronen ein GABAerges Zellschicksal in diesem ventromedialen Bereich annehmen. Da bislang jedoch keine Marker dieser speziellen Subpopulation GABAerger Neuronen bekannt sind, konnten hierzu keine Studien durchgeführt werden. Dennoch ist es aufgrund der vorgestellten Daten sehr unwahrscheinlich, dass Uncx4.1 das GABAerge Zellschicksal beeinflusst. Um zu überprüfen, ob sich die Identität der dopaminergen Neuronen in ein GABAerges Zellschicksal verändert hat, wären z.B. 'Patch-clamp' Messungen möglich und sollten in einer weiterführenden Analyse durchgeführt werden (Neher \& Sakmann, 1976). 


\subsection{Die Funktion von Uncx4.1 während der Entwicklung der glutamatergen Neuronen des Mittelhirns}

Die glutamatergen Neuronen des Mittelhirns sind sowohl im ventralen als auch im dorsalen Mittelhirn lokalisiert. An E11.5 grenzt die Domäne Brn3a-, als auch Sim1-positiver, glutamaterger Neuronen direkt an die der dopaminergen Neuronen (Nakatani et al., 2007; Kala et al., 2009; Waite et al., 2011). In dieser Arbeit sollte untersucht werden, ob die reduzierten dopaminergen Neuronen ein glutamaterges Zellschicksal annehmen. Hierfür wurde die Expression verschiedener neuronaler Marker auf coronalen Gewebeschnitten analysiert (eine Übersicht befindet sich in Tab. 3). Es konnte gezeigt werden, dass die Marker der glutamatergen Neuronen des Nucleus ruber (Sim1 und Brn3a) in Uncx4.1\%- Mausmutanten eine verstärkte mRNA Expression aufweisen. Der Transkriptionsfaktor Nkx6.1, der an der korrekten Entwicklung dieser Neuronenpopulation beteiligt ist (Prakash et al. 2009), zeigt ebenfalls eine erhöhte mRNA Expression, während mittels IHC kein Unterschied in der Expression auszumachen ist. Es ist bekannt, dass die Menge an mRNA und Protein in der Zelle variieren kann und die Proteinexpression nicht immer mit der mRNA Menge in Beziehung steht (Gygi et al., 1999; Lichtinghagen et al., 2002; Zermeno et al., 2009). Hierfür könnten post-transkriptionale oder -translationale Modifikationen die Ursache sein (Anderson \& Seilhamer, 1997). Möglich wäre auch, dass ein erhöhtes Proteinlevel mittels der angewendeten Methode (IHC) nicht nachweisbar war. Frühere Studien zeigten bereits, dass eine in situ Hybridisierung unter Umständen sensitiver ist, als eine Immunohistochemische Analyse (Alonso et al., 1992; Lee et al., 2003). Zusammengenommen deuten die Ergebnisse der erhöhten Brn3a- und Sim1-mRNA darauf hin, dass Uncx4.1 eine Funktion während der Entwicklung der glutamatergen Neuronen des Nucleus ruber zukommt, und dass die erhöhte Expression von Brn3a und Siml möglicherweise auf die erhöhte Nkx6.1 mRNA zurïckzuführen ist (Prakash et al., 2009).

Pax6 ist in einer kleinen Subgruppe glutamaterger Neuronen in der lateralen Basalplatte des Mittelhirns exprimiert (Kala et al., 2009). In der vorliegenden Arbeit konnte gezeigt werden, dass die Anzahl Pax6-positiver Zellen in Uncx4.1-defizienten Mausembryonen ab dem Embryonalstadium 13.5 erhöht ist. So sind an E13.5 ca. 55 \% mehr Pax6-positive Zellen zu verzeichnen, wohingegen an E17.5 nur noch ca. $25 \%$ mehr Pax6-positive Zellen im Vergleich zu Wildtypen detektierbar sind. Dies reflektiert die erhöhte Neurogenese die an E13.5, im Vergleich zu E17.5, abläuft (Finlay \& Darlington, 1995). Durch eine Doppelimmunfärbung wurde deutlich, dass 


\begin{tabular}{|c|c|c|c|}
\hline Gen/Protein & Untersuchtes Stadium & Marker für: & Effekt \\
\hline Brn3a & E11.5 & glutamaterge Neuronen des NR und des dorsalen Mittelhirns & $\begin{array}{l}\text { ventral stärkere Expression, dorsal } \\
\text { unverändert }\end{array}$ \\
\hline Brn3a & E12.5 & glutamaterge Neuronen des NR und des dorsalen Mittelhirns & $\begin{array}{l}\text { ventral stärkere Expression, dorsal } \\
\text { unverändert }\end{array}$ \\
\hline Brn3a & E13.5 & glutamaterge Neuronen des NR und des dorsalen Mittelhirns & $\begin{array}{l}\text { ventral stärkere Expression, dorsal } \\
\text { unverändert }\end{array}$ \\
\hline Sim 1 & E11.5 & glutamaterge Neuronen des NR & unverändert \\
\hline Sim1 & E12.5 & glutamaterge Neuronen des NR & stärkere Expression \\
\hline Nkx6.1 - IHC & E12.5 & glutamaterge Neuronen in der BP & unverändert \\
\hline Nkx6.1 - ISH & E12.5 & glutamaterge Neuronen in der BP & stärkere Expression \\
\hline Pax6 & E11.5 & glutamaterge Neuronen der lateralen BP & unverändert \\
\hline Pax6 & E12.5 & glutamaterge Neuronen der lateralen BP & unverändert \\
\hline Pax6 & E13.5 & glutamaterge Neuronen der lateralen BP & 55\% mehr Pax6-positive Zellen \\
\hline Pax6 & E17.5 & glutamaterge Neuronen der lateralen BP & 26\% mehr Pax6-positive Zellen \\
\hline $\operatorname{Ngn} 2$ & E11.5 & dopaminerge und glutamaterge Neuronen & reduzierte Expression \\
\hline Foxa2 & $\mathrm{E} 11.5, \mathrm{E} 12.5$ & dopaminerge, glutamaterge und GABAerge Neuronen & unverändert \\
\hline Isl1 & E11.5 & glutamaterge Oculomotor Neuronen & unverändert \\
\hline
\end{tabular}

Tab. 3: Zusammenfassung der Veränderung spezifischer Marker glutamaterger Neuronen im Mittelhirn Uncx4.1-defizienter Embryonen. Die verschiedenen Marker sind nur in Subpopulationen der glutamatergen Neuronen exprimiert. Es wurden mindestens n=3 Embryonen pro Marker und Stadium untersucht (außer für Sim1 und Nkx6.1 (ISH), hier wurden jeweils nur zwei untersucht). NR: Nucleus ruber, BP: Basalplatte.

mehr Pax6-positive Zellen im ventralen Bereich zu finden sind, was für eine Expansion dieser Domäne Richtung ventral spricht. Dies muss allerdings durch weitere Analysen bestätigt werden. Da Kele et al. (2006) berichteten, dass vorläufige Daten eine erhöhte mRNA Expression von Pax6 in Ngn2-defizienten Mäusen zeigen, wurde zunächst davon ausgegangen, dass der Verlust der Ngn2-mRNA der Grund für die erhöhte Pax6 Expression sei. Diese Vermutung konnte zunächst durch die Ergebnisse der Co-Immunopräzipitation bestätigt werden, da Ngn2 und Pax6 auf Protein-Protein Ebene miteinander interagieren. Dies Ergebnis bestätigt frühere Resultate von Tripathi et al. (2009). Die Autoren konnten mittels in silico Analyse eine potenzielle Protein-Protein Bindung von Ngn2 und Pax6 vorhersagen (Tripathi \& Mishra, 2009). Eine nähere Untersuchung von $\mathrm{Ngn2}^{-/}$Mausembryonen zeigte im Vergleich zu Kontrolltieren keine Veränderung der Anzahl Pax6-positiver Zellen. Daraus kann abgeleitet werden, dass die erhöhte Anzahl Pax6-positiver Zellen in Uncx4.1 ${ }^{-/}$Mausembryonen nicht durch die Reduzierung der Ngn2-mRNA hervorgerufen wird und Uncx4.1 somit wichtige Funktionen während der glutamatergen Neurogenese übernimmt. Die Bildung eines Proteinkomplexes von Pax6 und Uncx4.1 kann jedoch ausgeschlossen werden, da mittels Co-IP keine Interaktion dieser beiden Proteine nachweisbar war. Die Tatsache, dass die Expression von Uncx4.1 in Pax6-defizienten 
Mausembryonen unverändert ist lässt vermuten, dass Pax6 in der Signalkaskade abwärts von Uncx4.1 agiert.

Vorhergehende Studien im murinen Cortex und Mesencephalon haben gezeigt, dass Ngn2 ein glutamaterges Zellschicksal fördert (Schuurmans et al., 2004; Nakatani et al., 2007). Im dorsalen Mittelhirn ist Ngn2 in glutamatergen Neuronen detektierbar (Nakatani et al., 2007; Kala et al., 2009). Die nahezu vollständige Reduzierung der Ngn2-mRNA im dorsalen Mittelhirn Uncx4.1-defizienter Mausembryonen weist demnach ebenfalls auf die Involvierung von Uncx4.1 bei der Spezifikation oder Differenzierung eines glutamatergen Zellschicksals hin. Interessanterweise konnte kein Unterschied in der Expression von Brn3a im dorsalen Mittelhirn verzeichnet werden, was die Existenz von Neuronen mit einem glutamatergen Phänotyp aufzeigt. Die Expression von Ngn2 ist also möglicherweise nicht notwendig für die Etablierung eines glutamatergen Zellschicksales in diesem Gehirnareal. Wahrscheinlicher ist es jedoch, dass die noch immer vorhandenen, geringen Mengen an Ngn2-mRNA im dorsalen Mittelhirn Uncx4.1-defizienter Mausembryonen noch ausreichen, um die glutamaterge Linie erfolgreich zu differenzieren. Unterstützt wird dies durch die erhöhte Expression von Brn3a im Nucleus ruber, aber nicht im dorsalen Mittelhirn.

Die erhöhte Expression verschiedener Marker im Nucleus ruber und die Reduzierung der Ngn2-mRNA im dorsalen Mittelhirn, deutet auf die Existenz verschiedener Signalwege während der Entwicklung der glutamatergen Neuronen hin.

Zusammenfassend ist festzuhalten, dass die erhöhte Expression verschiedener Marker im Nucleus ruber und die erhöhte Anzahl Pax6-positiver Zellen, ebenso wie der Verlust der Ngn2-mRNA darauf hindeutet, dass Uncx4.1 an der glutamatergen Neurogenese beteiligt ist. Aufgrund seiner fehlenden Expression in mitotischen Zellen und seiner Funktion in dopaminergen Neuronen ist anzunehmen, dass Uncx4.1 während der Differenzierung der glutamatergen Neuronen involviert ist. Die Frage, der in dieser Arbeit nachgegangen wurde, ob die reduzierten dopaminergen Neuronen ein glutamaterges Zellschicksal annehmen, kann nicht abschließend geklärt werden. Aufgrund der erhöhten Expression der glutamatergen Marker im Nucleus ruber und der räumlichen Nähe dieser Neuronen zu den mDA Neuronen ist es jedoch recht wahrscheinlich, dass einige mDA Neuronen in Abwesenheit von Uncx4.1 ein glutamaterges Zellschicksal annehmen. Somit wird der Verlust der mDA Neuronen durch eine Akkumulation glutamaterger Neuronen kompensiert. Es ist möglich, dass Uncx4.1 im Mittelhirn als postmitotisches Selektorgen fungiert (Cheng et al., 2004; Kala et al., 2009), indem es das 
glutamaterge Zellschicksal zu Gunsten des dopaminergen Zellschicksals unterdrückt. Bereits in der Vergangenheit konnte im Rückenmark eine ähnliche Funktion des Homöobox enthaltenden Transkriptionsfaktors Lbx 1 gezeigt werden. Lbxl agiert im Hinterhirn als Selektorgen während der Spezifizierung von Vorläufern in somatosensorische und viszerosensorische Neuronen (Sieber et al., 2007). Um die Funktion von Uncx4.1 als Selektorgen zu bestätigen, müssen noch weitere Analysen folgen. Neben zusätzlichen Untersuchungen Uncx4.1-defizienter Mäuse würden sich einige in vitro Studien anbieten. So wäre es möglich Uncx4.1-defiziente Neurosphären zu generieren: dabei werden neurale Vorläuferzellen kultiviert und schließlich die verschiedenen differenzierten neuronalen Subtypen quantifiziert (Reynolds \& Weiss, 1992). So könnte untersucht werden ob in Abwesenheit von Uncx4.1 tatsächlich mehr glutamaterge als dopaminerge Neuronen entstehen.

\subsection{Potentielle Rolle von Uncx4.1 während der Gliogenese}

Proneurale bHLH-Proteine im murinen Cortex begünstigen die Entwicklung zu einem neuronalen Zellschicksal, während sie gleichzeitig das gliogene Zellschicksal unterdrücken (Sauvageot \& Stiles, 2002; Schuurmans \& Guillemot, 2002). Neben Ngn1 und Mash1 ist auch das Protein Ngn2 an der Unterdrückung des gliogenen Zellschicksals beteiligt (Nieto et al., 2001). In der vorliegenden Studie konnte gezeigt werden, dass in Gehirnen von konditionalen Cre-ER;Uncx4.1 $1^{f /-}$ Mäusen eine starke Erhöhung des Astrozytenmarkers GFAP im ventralen Mittelhirn vorliegt. Demnach könnte der partielle Verlust der Ngn2-mRNA in Uncx4.1defizienten Embryonen zu einer Förderung des gliogenen Zellschicksals und damit zu der Erhöhung von GFAP führen. Weiterführende molekulare Markeranalysen der Uncx4.1 Mausmutanten könnten zur Klärung hinsichtlich dieser Fragestellung beitragen.

\subsection{Potentielle Rolle von Uncx4.1 bei der Bildung der Axone in den Colliculi superiores}

Der Transkriptionsfaktor Uncx4.1 ist ein Homolog des Unc-4 Proteins des Nematoden $C$. elegans (Rovescalli et al., 1996; Mansouri et al., 1997). Unc-4-defiziente Nematoden zeigen eine gestörte Verbindung der VA Motorneuronen. So innervieren die Interneuronen, welche 
normalerweise ausschließlich die VB Motorneuronen innervieren, ebenfalls die VA Motorneuronen (Miller et al., 1992; White et al., 1992; Pflugrad et al., 1995), was in einer gestörten Rückwärtsbewegung, der sogenannten „Unc-Bewegung“ resultiert. Spätere Studien konnten zeigen, dass Unc4 zusammen mit einem Co-Repressor Unc-37, ceh-12 (ein Mitglied der HB9 Familie der Homöoproteine) reprimiert und somit an der korrekten Spezifikation des Transmitterphänotyps beteiligt ist (Von Stetina et al., 2007). Aufgrund der Tatsache, dass das Fehlen von Unc-4 in C. elegans axonale Defekte hervor ruft und sowohl die Expression von Unc-4 als auch HB9 in den Vertebraten stark konserviert ist, wurden in dieser Arbeit Untersuchungen zur korrekten Bildung und Positionierung der Axone im Mittelhirn durchgeführt.

Calbindin ist in verschiedenen Säugetieren in einigen Neuronen der Colliculi superiores detektierbar und steht scheinbar nicht immer in Abhängigkeit eines bestimmten Zelltyps, sondern in Zusammenhang mit der funktionellen Organisation dieser Gehirnstruktur (Behan et al., 1992; Lanea et al., 1997; Gonzalez-Soriano et al., 2000). Bereits an E13.5 deutet eine veränderte Calbindin Proteinexpression auf coronalen Gewebeschnitten Uncx4.1-defizienter Embryonen auf axonale Defekte der Colliculi superiores hin. So konnte gezeigt werden, dass die normalerweise getrennten Expressionsdomänen von Calbindin im dorsalen Mittelhirn von Uncx4.1 $1^{-/}$Mausembryonen ineinander übergehen und die beiden Domänen nicht mehr klar voneinander abgrenzbar sind. Auch auf sagittalen Gewebeschnitten sind an E17.5 Unterschiede zu verzeichnen. So kann im dorsalen Teil der Colliculi superiores eine erhöhte Menge an Calbindin im Vergleich zu den Kontrolltieren ausgemacht werden, während die Menge in dem ventralen Bereich der Colliculi superiores verringert ist.

Synapsine gehören zu den Phosphoproteinen. Vergangene Studien haben gezeigt, dass beide Proteine eine Rolle in der Regulation der Axogenese spielen und an der axonalen Entwicklung beteiligt sind (Chin et al., 1995; Ferreira et al., 1998). Synapsin I+II sind normalerweise in den Nervenenden der Axone lokalisiert (Camilli et al., 1983; Greengard et al., 1993). In Uncx4.1defizienten Mäusen sind Synapsin I+II nicht mehr auf der ganzen dorso-ventralen Achse der Colliculi superiores exprimiert, sondern akkumulieren in diesem Bereich. Übereinstimmend mit dieser Beobachtung sind die Ergebnisse der DiI-Färbung ausgefallen. In Abwesenheit von Uncx4.1 sind weniger lateral verlaufende Axone detektierbar, als in Kontrolltieren. Zusätzlich dazu scheinen die vorhandenen Axone kürzer zu sein, als es normalerweise der Fall wäre.

Die Signifikanz dieser Beobachtung erfordert jedoch zusätzliche Versuche, da nur je drei Gehirne pro Genotyp untersucht werden konnten und diese Methode aufgrund mehrerer 
Variablen schwer reproduzierbar ist.

Die verkürzten Axone und die geringere Anzahl an axonalen Auswüchsen pro Neuron zeigt sich auch bei der angewandten Golgi-Färbung. Beachtet werden muss natürlich, dass bei der Golgi-Methode, wie bereits an anderer Stelle erwähnt, nur ca. zehn Prozent aller Neuronen angefärbt werden. Damit ist nicht gewährleistet, dass immer die gleichen Neuronentypen angefärbt wurden. Einen generellen Überblick gibt diese Färbung dennoch und unterstützt die Annahme, dass Uncx4.1-defiziente Mausembryonen axonale Defekte der Colliculi superiores aufweisen. Dies stimmt auch mit früheren Studien im Vorderhirn überein, in denen gezeigt wurde, dass Uncx4.1 ebenfalls an der korrekten axonalen Projektion magnozellulärer Neuronen zu posterioren Bereichen der Hypophyse beteiligt ist (Asbruek et al., 2006). Daneben konnten weitere Studien die Beteiligung von Homöoboxgenen an der axonalen Wegfindung (engl. „,axonal pathfinding“) zeigen (Kania et al., 2000).

Die Western Blot-Analyse der vesikulären und nicht-vesikulären Proteine zeigte in Uncx4.1defizienten Mausembryonen keine Veränderung im Vergleich zu den Kontrolltieren. Dies kann mehrere Gründe haben. 1. Die Unterschiede betragen weniger als $20 \%$ und können somit mittels Westerblot-Analyse nicht detektiert werden, oder 2. es gibt keinen Unterschied in der Proteingesamtmenge. Für die zweite Möglichkeit sprechen die Ergebnisse der Synapsin I+II Färbung. In diesem Fall scheint, wie bereits weiter oben erwähnt, das Protein in einem Bereich zu akkumulieren, was somit zwar axonale Defekte nach sich ziehen könnte, aber kein Unterschied in der Gesamtproteinmenge detektierbar wäre. Auch muss bei der Auswertung der Westernblot-Analyse mit in Betracht gezogen werden, dass zum Vergleich von Uncx4.1 ${ }^{-1-}$ und Wildtypen Proteinextrakte ganzer Gehirne verwendet wurden und somit geringe Unterschied in einem kleinen Bereich, wie dem dorsalen Mittelhirn, unterrepräsentiert wären. Die unveränderte Expression vesikulärer Proteine steht im Widerspruch zu den Ergebnissen der Unc-4-Mutanten in C. elegans, denn dort konnte gezeigt werden, dass vesikuläre Proteine, wie z.B. Synaptogamin und Synaptobrevin reduziert sind, während nicht vesikuläre Proteine unbeeinträchtigt sind (Lickteig et al., 2001).

Zusammengenommen zeigen die verkürzten Axone und geringeren axonalen Auswüchse, sowie die Unterschiede in der Calbindin und Synapsin I+II Färbung der Colliculi superiores deutlich, dass Uncx4.1 eine Rolle während der axonalen Entwicklung zukommt. Welche Funktion Uncx4.1 hierbei genau übernimmt konnte nicht geklärt werden. Es ist aber zu vermuten, dass Uncx4.1, wie sein Homolog Unc-4, mit einem Co-Repressor agiert. Der Verlust 
der Ngn2 Expression im dorsalen Mittelhirn Uncx4.1-defizienter Mäuse könnte ebenfalls für den axonalen Phänotyp in diesen Mausmutanten verantwortlich sein. Im Thalamus konnte, anhand der Analyse Ngn2-defizienter Mäuse, gezeigt werden, dass Ngn2 an der Spezifikation axonaler Projektionen in diesem Gehirnareal von Bedeutung ist und Ngn2 somit eine Rolle während der axonalen Entwicklung spielt (Seibt et al., 2003). 


\section{Zusammenfassung}

Der Transkriptionsfaktor Uncx4.1 ist bereits früh im Mesencephalon muriner Embryonen detektierbar, dennoch wurde bisher keine funktionelle Analyse von Uncx4.1 im Mittelhirn durchgeführt. Die vorliegende Arbeit beinhaltet die ersten Untersuchungen zur Funktion des Transkriptionsfaktors Uncx4.1 im Mittelhirn der Maus. Die Ergebnisse können wie folgt zusammengefasst werden:

1. Uncx4.1 ist nahezu ausschließlich in postmitotischen Neuronen des Mittelhirns exprimiert. Eine vergleichende Expressionsanalyse mit verschiedenen Markern dopaminerger, GABAerger und glutamaterger Neuronen zeigte deutlich, dass die Expression nicht auf ein neuronales Schicksal begrenzt ist, sondern Uncx4.1 in nahezu allen Neuronenpopulationen detektierbar ist. Die Expression von Uncx4.1 in der Übergangszone der mitotischen und postmitotischen Neuronen deutet auf eine Rolle von Uncx4.1 während der neuronalen Differenzierung hin.

2. Neben der Expressionsstudie wurden die dopaminergen, GABAergen und glutamatergen Neuronenpopulationen des Mittelhirns mit Hilfe einer globalen und einer konditionalen Knockoutlinie untersucht:

- Uncx4.1 konnte als neuer Faktor des regulatorischen Netzwerkes zur Bildung dopaminerger Neuronen im ventralen Mittelhirn identifiziert werden. Bei einem Verlust von Uncx4.1 ist die Anzahl dopaminerger Neuronen der VTA und SN reduziert. Die Expression von Uncx4.1 in postmitotischen Zellen und die vollständige Co-Detektion von TH und Uncx4.1 im embryonalen Mittelhirn an E11.5 lässt vermuten, dass Uncx4.1 eine Rolle während der Differenzierung der mDA Neuronen zukommt. Dabei übt Uncx4.1 seinen Einfluss höchstwahrscheinlich über die Regulation des proneuralen Gens Ngn2 aus. Die Ergebnisse der konditionalen Knockoutlinie zeigen, dass Uncx4.1 möglicherweise eine Funktion während der Migration der dopaminergen Neuronen zukommt, da die Mutanten im Vergleich zu den Kontrolltieren einen größeren Abstand der VTA und SN aufweisen. Des Weiteren konnte in Cre-ER;Uncx4. ${ }^{f /-}$ Mäusen festgestellt werden, dass weniger mDA Neuronen in der lateralen SN detektierbar sind, während die Gesamtzellzahl unbeeinflusst bleibt. 
- Das Schicksal GABAerger Neuronen im Mittelhirn scheint hingegen unbeeinflusst von Uncx4.1 zu sein, da die Analyse der GABAergen Marker keine Unterschiede im Vergleich von Uncx $4.1^{\%}$ - und Kontrollembryonen aufweist.

- In glutamatergen Neuronen des Mittelhirns kommt Uncx4.1 ebenfalls eine Funktion während der Differenzierung zu. So zeigen molekulare Markerstudien, dass bei einem Funktionsverlust von Uncx4.1 eine stärkere mRNA Expression einiger Marker des Nucleus ruber detektiert werden kann. Aufgrund der Lokalisation dieser Neuronen neben den mDA Neuronen (an E11.5) ist es möglich, dass die mDA Neuronen ein glutamaterges Zellschicksal annehmen. So ist, neben einer erhöhten Expression von Markern des Nucleus ruber, ab E13.5 auch eine erhöhte Anzahl glutamaterger Pax6-positiver Zellen zu verzeichnen. Interessanterweise jedoch ist die Expression von Ngn2 im dorsalen Mittelhirn drastisch reduziert.

Im Allgemeinen ist festzuhalten, dass Uncx4.1 eine generelle Funktion während der neuronalen Differenzierung zukommt. Über welche molekularen Signalwege Uncx4.1 im einzelnen genau agiert, bleibt allerdings Gegenstand weiterführender Studien und konnte nicht abschließend geklärt werden. Es ist jedoch wahrscheinlich, dass Uncx4.1 als eine Art postmitotisches Selektorgen fungiert und der Verlust der dopaminergen Neuronen im ventralen Mittelhirn durch eine Akkumulation glutamaterger Neuronen kompensiert wird. Somit könnte Uncx4.1 das glutamaterge Zellschicksal zu Gunsten des dopaminergen Zellschicksals unterdrücken.

3. Neben der Funktion von Uncx4.1 während der Differenzierung neuronaler Subgruppen konnte in dieser Arbeit ebenfalls gezeigt werden, dass Uncx4.1 an der Entwicklung der Axone der Colliculi superiores beteiligt ist. So sind die Axone dieser Region verkürzt und es sind weniger laterale Auswüchse detektierbar. Neben den morphologischen Unterschieden konnten auch Unterschiede in der Expression verschiedener Marker nachgewiesen werden. Es wäre möglich, dass der axonale Phänotyp nur eine Konsequenz des Verlustes der Ngn2-mRNA in diesem Bereich ist. 


\section{Material und Methoden}

\subsection{Molekularbiologische Methoden}

\subsubsection{Extraktion genomischer DNA aus Gewebeproben}

Zur Gewinnung genomischer DNA aus Mausgewebe wurde die Gewebeprobe zunächst in ein 1,5 ml Reaktionsgefäß überführt und $500 \mu 1$ Lysispuffer (Zusammensetzung siehe Tab. 4), sowie $25 \mu \mathrm{l}$ Proteinase $\mathrm{K}(10 \mathrm{mg} / \mathrm{ml}$ in $50 \mathrm{mM}$ Tris- $\mathrm{HCl} \mathrm{pH} \mathrm{8,0} \mathrm{und} \mathrm{1,5} \mathrm{M} \mathrm{Kalziumacetat)} \mathrm{zugegeben.}$ Anschließend wurde das Gewebe je nach Gewebemenge bei $55^{\circ} \mathrm{C}$ für 5 bis 24 Stunden in einem Thermomixer unter leichtem Schütteln inkubiert. Um nicht lysierte Gewebereste zu entfernen folgte eine 15 minütige Zentrifugation bei $13.000 \mathrm{rpm}$. Danach wurde der Überstand in ein neues Reaktionsgefäß überführt. Zur Fällung der DNA wurden $500 \mu 1$ Isopropanol zugegeben, bevor eine weitere Zentrifugation für fünf Minuten bei $13.000 \mathrm{rpm}$ folgte. Der Überstand wurde verworfen und das Pellet mit $1000 \mu 170 \%$ igem Ethanol gewaschen, ehe ein weiterer Zentrifugationsschritt (5 Minuten bei $13.000 \mathrm{rpm}$ ) folgte. Anschließend wurde das Pellet 7 Minuten bei Raumtemperatur (RT) getrocknet und in 70-100 $\mu$ l autoklaviertem $\mathrm{dH}_{2} \mathrm{O}$ bei $37^{\circ} \mathrm{C}$ gelöst.

\begin{tabular}{|l|l|}
\hline Chemikalie & Konzentration \\
\hline \hline Tris- $\mathrm{HCl} \mathrm{pH} 8,0$ & $100 \mathrm{mM}$ \\
EDTA $0,5 \mathrm{M}$ & $5 \mathrm{mM}$ \\
$\mathrm{SDS} 10 \%$ & $0,2 \%$ \\
$\mathrm{NaCl} 5 \mathrm{M}$ & $200 \mathrm{mM}$ \\
\hline
\end{tabular}

Tab. 4: Zusammensetzung des Lysispuffers für den Verdau muriner Gewebeproben.

\subsubsection{Präparation von Plasmid-DNA aus E.coli}

Zur Isolierung von Plasmid-DNA aus E.coli wurden je nach gewünschter DNA-Menge entweder $5 \mathrm{ml}$ oder $200 \mathrm{ml}$ LB-Medium (Tab. 5) mit dem Bakterienstamm angeimpft. Zur Vermeidung von Kontaminationen wurden, je nach Resistenz des Plasmides, Antibiotika mit einer Endkonzentration von $100 \mu \mathrm{l} / \mathrm{ml}$ zugegeben. Als Antibiotika wurden üblicherweise Ampicillin oder Kanamyzin verwendet. Die Inkubation erfolgte über Nacht bei $200 \mathrm{rpm}$. Am nächsten Tag wurde die Plasmid-DNA, wie vom Hersteller beschrieben, aufgereinigt. Für kleine DNA-Mengen 
wurde das QIAprep ${ }^{\circledR}$ Miniprep Kit und für größere DNA-Mengen das QIAfilter ${ }^{\circledR}$ Plasmid Maxi Kit (beides QIAGEN) verwendet. Die Aufnahme des Pellets erfolgte entweder in TE-Puffer ( $\mathrm{pH} 8,5$, Tab. 6) oder in $\mathrm{dH}_{2} \mathrm{O}$.

\begin{tabular}{|l|l|}
\hline Chemikalie & Menge \\
\hline \hline Bacto Trypton & $10 \mathrm{~g}$ \\
Hefeextrakt & $5 \mathrm{~g}$ \\
$\mathrm{NaCl}$ & $10 \mathrm{~g}$ \\
$\mathrm{NaOH} 1 \mathrm{M}$ & $7,5 \mathrm{ml}$ \\
\hline
\end{tabular}

Tab. 5: Zusammensetzung des LB-Mediums Zusammensetzung des LB-Mediums. Nach Zugabe aller Komponenten wurde mit $\mathrm{dH}_{2} \mathrm{O}$ auf einen Liter aufgefüllt.

\begin{tabular}{|l|l|}
\hline Chemikalie & Menge \\
\hline \hline Tris- $\mathrm{HCl} \mathrm{pH} 8,51 \mathrm{M}$ & $1 \mathrm{ml}$ \\
EDTA 0,5 M & $0,2 \mathrm{ml}$ \\
$\mathrm{dH}_{2} \mathrm{O}$ & $98,8 \mathrm{ml}$ \\
\hline
\end{tabular}

Tab. 6: Zusammensetzung des TE-Puffers Der $\mathrm{pH}$ Wert des eingesetzten Tris- $\mathrm{HCl}$ variiert je nach gewünschtem $\mathrm{pH}$ Wert des Puffers. Nach Zugabe aller Komponenten, wurde der $\mathrm{pH}-$ Wert gemessen und ggf. mit $1 \mathrm{M} \mathrm{HCl}$ oder $1 \mathrm{M} \mathrm{NaOH}$ auf den gewünschten Wert eingestellt.

\subsubsection{Ethanolpräzipitation von DNA}

Zur Konzentrierung der DNA wurde eine Ethanolpräzipitation durchgeführt. Hierzu wurde der Volumenanteil der DNA, sofern die DNA in Wasser gelöst vorlag, mit dem gleichen Volumenanteil TE-Puffer (pH 8,0, Tab. 6) versetzt. Lag die DNA bereits in TE-Puffer vor, wurde direkt das doppelte Volumen verwendet und 3 M Natriumacetat mit einer Endkonzentration von $10 \%$ zugefügt. Nach kurzer Fällung in flüssigem Stickstoff folgte ein Zentrifugationsschritt bei $0{ }^{\circ} \mathrm{C}$ und $12.000 \mathrm{~g}$ für 10 Minuten. Anschließend wurde das Pellet 2 mal mit 70\%igem Ethanol gewaschen. Nach dem letzten Waschschritt wurde der Überstand verworfen und das Pellet für ca. 8 Minuten getrocknet, ehe es in $50 \mu \mathrm{l}$ Wasser oder TE-Puffer ( $\mathrm{pH} 8,0)$ aufgenommen und eine Stunde bei $37^{\circ} \mathrm{C}$ gelöst wurde.

\subsubsection{Phenol-Chloroform-Extraktion von DNA}

Zur Reinigung der DNA von Proteinrückständen, Enzymen etc. wurde eine Phenol-Chloroform-Extraktion durchgeführt. Dazu wurde der DNA ein Volumenanteil Phenol-Chloroform-Isoamylalkohol (Verhältnis 25:24:1) zugesetzt und für 2 Minuten gevortext. Nach Zentrifugation bei 13.000 rpm für 5 Minuten wurde die wässrige Phase in ein neues Reaktionsgefäß überführt, ein Volumen Chloroform-Isoamylalkohol (Verhältnis 24:1) zugegeben, ebenfalls gevortext und zentrifugiert. Die wässrige Phase wurde erneut in ein neues Reaktionsgefäß transferiert und mit 1/25 Volumen 7 M Ammoniumacetat und einem 2,5 fachen 
Volumen eisgekühltem 100\%igem Ethanol versetzt. Nach der Fällung in flüssigem Stickstoff wurde für 5 Minuten bei $13.000 \mathrm{rpm}$ und $4{ }^{\circ} \mathrm{C}$ zentrifugiert. Anschließend wurde das Pellet zwei mal mit 70\%igem Ethanol gewaschen, ehe es für 7 Minuten bei RT getrocknet wurde. Je nach DNA Menge wurde das Pellet in 10-100 $\mu$ l autoklaviertem $\mathrm{dH}_{2} \mathrm{O}$ aufgenommen.

\subsubsection{Konzentrationsbestimmung der DNA und RNA}

Zur Konzentrationsbestimmung der DNA wurde ein Nanodrop ${ }^{\circledR}$ ND-1000 Spektrophotometer (PeQlab) verwendet und die optische Dichte (OD) bei $280 \mathrm{~nm}$ und $260 \mathrm{~nm}$ gemessen. Zur Bestimmung des Reinheitsgerades wurde der Quotient aus der OD bei $260 \mathrm{~nm}$ und $280 \mathrm{~nm}$ gebildet. Die DNA wurde nur weiter verwendet, wenn der Wert des Quotienten zwischen 1,7 und 2,1 lag.

\subsubsection{Polymerase-Kettenreaktion (PCR)}

Die Polymerase-Kettenreaktion (PCR) ermöglicht es spezifische DNA-Fragmente mit Hilfe spezifischer Primer zu amplifizieren. Als DNA-Templates wurden DNA Präparate aus murinem Gewebe, sowie Plasmid-DNA verwendet. Für die Genotypisierung der transgenen und Knockout-Mäuse wurde die GoTag ${ }^{\circledR}$ Polymerase von Promega verwendet. Für Klonierungen wurde entweder die Pwo Polymerase von Roche oder ebenfalls die GoTag ${ }^{\circledR}$ Polymerase verwendet. Der Vorteil der Pwo Polymerase gegenüber der Taq Polymerase beruht darin, dass sie eine Korrekturlesefunktion und daher eine geringere Fehlerrate bei der Synthese hat. Die Polymerasen wurden den Angaben der Hersteller entsprechend verwendet. Die Zusammensetzung des PCR-Ansatzes ist in Tabelle 7 aufgelistet, die verwendeten Primer sind in Tabelle 8 zu finden.

\begin{tabular}{|l|l|}
\hline Lösung & Menge für 50 $\mu \mathrm{l}$ \\
\hline \hline autoklaviertes $\mathrm{dH}_{2} \mathrm{O}$ & $37,85 \mu \mathrm{l}$ \\
5x PCR Puffer, GoTaq (Promega) & $10 \mu \mathrm{l}$ \\
20 mM dNTP Nukleotid-Mix (Genecraft) & $0,75 \mu \mathrm{l}$ \\
Senseprimer & $0,1 \mu \mathrm{l}$ \\
Antisenseprimer & $0,1 \mu \mathrm{l}$ \\
5U DNA-Polymerase & $0,2 \mu \mathrm{l}$ \\
DNA-Template & $1 \mu \mathrm{l}$ \\
\hline
\end{tabular}

Tab. 7: Zusammensetzung eines $50 \mu \mathrm{l}$ umfassenden PCR-Ansatzes. Die verwendeten Primer sind in Tabelle 8 aufgelistet. U: Einheit (engl. ,Unit“) 
Die Primer für die Genotypisierung der Lmxla Mäuse wurden alle drei gemeinsam in einem Ansatz verwendet. Die Menge des dritten Primers betrug ebenfalls 0,1 $\mu$ l. Für die Genotypisierung der Ngn2 Mäuse wurden bei der Primerkombination Ngn2 (WT1) und Ngn2 (WT2) noch 1,7 $\mu$ l DMSO zugesetzt. Die zugesetzten Mengen wurden von der Menge an autoklaviertem $\mathrm{dH}_{2} \mathrm{O}$ abgezogen.

\begin{tabular}{|c|c|c|}
\hline Primer & Sense/Antisense & Sequenz \\
\hline Genotypisierung & & \\
\hline Uncx4.1 (WT1) & sense & GTGGCCGGCGAAAGCCAGCCC \\
\hline Uncx4.1(WT2) & antisense & GACTCGACCAGGTCCAGGCGC \\
\hline Uncx4.1(Mut) & antisense & CCTCCAGTACAGCGCGGCTGA \\
\hline Ngn2 (WT1) & sense & GGACATTCCCGGACACACAC \\
\hline Ngn2 (WT2) & antisense & GCATCACCTTCACCCTCTCC \\
\hline Ngn2 (Mut) & antisense & AGATGTAATTGTGGGCGAAG \\
\hline Lmx1a (WT1) & sense & TGGACACTGCTTCGTCCTG \\
\hline Lmx1a (WT2) & antisense & CGAAGAGGGTGCTGTCTGG \\
\hline Lmx1a (Mut) & antisense & CTTGTAGTTGCCGCGTCCT \\
\hline Uncx4.1 floxed (WT1) & sense & TAGAAGCGAGGCCCGATTGTAGT \\
\hline Uncx4.1 floxed (WT2) & antisense & CAGAAGGAAGCCTGATCATCACAAC \\
\hline Uncx4.1 floxed (Mut) & antisense & AATTAGCAGAAGGCGCCAGTGTG \\
\hline Neol & sense & CAGCTGTGCTCGACGTTGTCACTG \\
\hline $\mathrm{Neo} 2$ & antisense & CCATGATATTCGGCAAGCAGGCATCG \\
\hline Cre1 & sense & CGATGCAACGAGTGATGAGGTTCG \\
\hline $\mathrm{Cre} 2$ & antisense & AGCATTGCTGTCACTTGGTCGTGG \\
\hline Klonierung & & \\
\hline Ngn2-NotI & sense & CAAAGAATCTGCGGCCGCATGTTCGTCAAATCTGAGACTCTG \\
\hline Ngn2-BamHI & antisense & GTTACGGGATCCCTAGATACAGTCCCTGGCGAGGGGCAG \\
\hline
\end{tabular}

Tab. 8: Verwendete Primersequenzen.

Alle PCR- Reaktionen wurden mit einem Mastercycler ${ }^{\circledR}$ Gradient (Eppendorff) mit einem Standardprogramm durchgeführt (Tab. 9). Die Annealingtemperatur wurde je nach Schmelztemperatur der verwendetem Primer angepasst. Die Primer wurden entweder von Operon oder Sigma-Aldrich hergestellt.

\begin{tabular}{|l|l|l|l|}
\hline Schritt-Nr. & Vorgang & Temperatur & Dauer \\
\hline \hline 1 & Initiale Denaturierung & $94{ }^{\circ} \mathrm{C}$ & $4 \mathrm{~min}$ \\
2 & Denaturierung & $94{ }^{\circ} \mathrm{C}$ & $45 \mathrm{sek}-1 \mathrm{~min}$ \\
3 & Annealing & $55^{\circ} \mathrm{C}-65^{\circ} \mathrm{C}$ & $45 \mathrm{sek}-1 \mathrm{~min}$ \\
4 & Elongation & $72^{\circ} \mathrm{C}$ & $40 \mathrm{sek}-1 \mathrm{~min}$ \\
5 & Abschließende Elongation & $72{ }^{\circ} \mathrm{C}$ & $6-10 \mathrm{~min}$ \\
\hline
\end{tabular}

Tab. 9: Verwendetes Standard-PCR Programm. Die Schritte 2 - 4 wurden 30 - 38 mal wiederholt ehe die abschließende Elongation folgte. Die Annealingtemperatur variierte je nach Schmelzpunkt der verwendeten Primer. Die Dauer der einzelnen Zyklen variierte ebenfalls je nach verwendetem Primerpaar. 


\subsubsection{Agarose-Gelelektrophorese}

Zur Analyse der Genotypisierung, der Überprüfung des Restriktionsverdaus, zur Isolierung einzelner DNA-Fragmente oder zur Überprüfung der RNA Probensynthese wurden 0,8 - 1,2\%ige Agarose-Gele verwendet. Zur Herstellung wurde zunächst die gewünschte Menge Agarose (Roth) mit 0,5x TBE Puffer (Tab. 10 versetzt und erhitzt bis die Agarose vollständig gelöst war. Anschließend wurde Ethidiumbromid mit einer finalen Konzentration von $0,3 \mu \mathrm{l} / \mathrm{ml}$ zugegeben und das Gel bei $4{ }^{\circ} \mathrm{C}$ in einer Gelelektrophoresekammer polymerisiert. Die DNAoder RNA-Probe wurde mit 6x Ladepuffer (0,25\% (w/v) Bromphenlblau, 0,25\% (w/v) Xylencyanol FF, $30 \%(\mathrm{v} / \mathrm{v})$ Glycerol in $\mathrm{dH}_{2} \mathrm{O}$ ) versetzt und auf das Gel aufgetragen. Die DNA wurde allerdings nur mit Ladepuffer versetzt, wenn sie nicht aus einer Genotypisierungsreaktion hervorgegangen ist, denn für Genotypisierungen wurde der 5x Green GoTaq ${ }^{\circledR}$ Flexi Puffer (Promega) verwendet, welcher bereits einen Ladepuffer erhält. Zusätzlich zum 6x Ladepuffer wurden RNA-Proben noch mit TE-Puffer ( $\mathrm{pH} 7,5)$ versetzt. Die Elektrophorese erfolgte bei 80 - 120 Volt in 0,5x TBE-Puffer. Die mit Ethidiumbromid gefärbte DNA wurde mit Hilfe von UV-Licht bei einer Wellenlänge von $258 \mathrm{~nm}$ sichtbar gemacht.

\begin{tabular}{|l|l|l|}
\hline Chemikalie & Konzentration 10x & Konzentration 0,5x \\
\hline \hline Tris-Base & $890 \mathrm{mM}$ & $44,5 \mathrm{mM}$ \\
Borat & $890 \mathrm{mM}$ & $44,5 \mathrm{mM}$ \\
EDTA $(\mathrm{pH} 8,0)$ & $20 \mathrm{mM}$ & $1 \mathrm{mM}$ \\
\hline
\end{tabular}

Tab. 10: 10x TBE-Puffer in $\mathbf{d H}_{2} \mathbf{O}$. Zur Herstellung des 0,5x TBE Puffers wurde der 10x TE Puffer mit dest. $\mathrm{H}_{2} \mathrm{O}$ verdünnt.

\subsubsection{Extraktion von DNA aus Agarose-Gelen}

Zur Aufreinigung spezifischer DNA-Fragmente aus Agarose-Gelen (z.B. für Klonierungen) wurde die gewünschte Bande unter schwachem UV-Licht mittels eines Skalpells isoliert und in ein 1,5 ml Reaktionsgefäß überführt. Die Aufreinigung erfolgte unter Verwendung des GeneClean ${ }^{\circledR}$ SpinKits (MPIbio) und wurde entsprechend den Angaben des Herstellers durchgeführt.

\subsubsection{Aufreinigung von PCR-Produkten}

Zur Klonierung der amplifizierten PCR-Produkte war es wichtig das Produkt zunächst aufzureinigen um unspezifische Produkte, Reste von Primern etc. zu entfernen. Hierzu wurde das 
GeneClean ${ }^{\circledR}$ SpinKit (MPIbio) entsprechend den Angaben des Herstellers verwendet.

\subsubsection{Restriktionsverdau von DNA}

Zur Linearisierung, Vorbereitung von Plasmid-Vektoren oder dem Verdau von PCR Fragmenten wurde ein Restriktionsverdau durchgeführt. Die Restriktionsenzyme wurden nach Angaben des Herstellers verwendet. Die Enzyme wurden entweder über New England Biolabs, Roche oder Promega bezogen. Für den Verdau wurde der Reaktionsansatz mit einem finalen Volumen von $50 \mu \mathrm{l} / \mathrm{ml}$ - $150 \mu \mathrm{l} / \mathrm{ml}$ (je nach eingesetzter DNA-Menge) für 2 Stunden oder über Nacht bei $37{ }^{\circ} \mathrm{C}$ inkubiert. Für die Präparation der Plasmid-Vektoren für die Klonierung waren mehrere Restriktionsenzyme erforderlich. Sofern für beide Enzyme dieselben optimalen Bedingungen notwendig waren erfolgte ein gleichzeitiger Verdau mit beiden Enzymen. Waren die optimalen Bedingungen abweichend erfolgte ein sequenzieller Restriktionsverdau, wobei das Produkt zwischen beiden Verdaus mittels GeneClean ${ }^{\circledR}$ SpinKit (MPIbio) aufgereinigt wurde. Der Verdau wurde mittels Agarose-Gelelektrophorese überprüft. Eine Liste der verwendeten Vektoren und Plasmide findet sich in Tabelle 11 .

\subsubsection{DNA-Ligation}

Die Ligation zweier DNA-Fragmente erfolgte mittels der T4 Ligase von Promega nach Angaben des Herstellers. Es wurden 100 ng DNA-Fragment eingesetzt. Das Verhältnis zwischen eingesetztem DNA-Fragment und verwendetem Vektor betrug 3:1. Die Ligation erfolgte über Nacht bei $16{ }^{\circ} \mathrm{C}$. Anschließend erfolgte eine Transformation des Ligationsproduktes in E.coli DH5 $\alpha$ Zellen (Promega). Eine Liste der verwendeten Plasmide befindet sich in Tabelle 11. 


\begin{tabular}{|l|l|l|l|l|}
\hline Name & Vektor & eingefügtes DNA-Fragment & Verwendungszweck & Herkunft \\
\hline \hline & & & & \\
Ngn2-FLag & pFLAG-CMV & PM \\
Ngn2-HA & Ngn2 & Ngn2 & Proteinexpression & diese Arbeit \\
pCS2-Pax6-FLAG & pCS2+FLAG & Pax6-FLAG & Proteinexpression & Dr. M.S. Diaconu \\
pCDNA3.Uncx4.1 myc & pCDNA3 & Uncx4.1-Myc & Proteinexpression & Abteilungs-Stock \\
& & & & Prof. A. Kispert \\
Hh16.1 & pBlueskript II SK & Shh & ISH & Abteilungs-Stock \\
Nkx6.1 & pBlueskript II SK & Nkx6.1 & ISH & Abteilungs-Stock \\
Nkx2.2 & pBlueskript II SK & Nkx2.2 & ISH & Abteilungs-Stock \\
Gad67 4 HindIII & pT7T3 & Gad67 & ISH & Abteilungs-Stock \\
Is11 & pGM-T easy & Is11 & ISH & Abteilungs-Stock \\
Pax6 & pBlueskript II SK & Pax6 & ISH & Abteilungs-Stock \\
Ngn2 & pGEM-3 & Ngn2 & ISH & Abteilungs-Stock \\
Gata2 & pBlueskript II SK & Gata2 & ISH & Prof. M. Zenke \\
Sim1 & & Sim1 & ISH & Abteilungs-Stock \\
H2-A4 & pBlueskript II SK & Helt & ISH & Prof. J. Guimera \\
Brn3a & pCRII-TOPO & Brn3a & ISH & Prof. A. Simeone \\
Uncx4.1 & pBlueskript II SK & Uncx4.1 & ISH & Abteilungs-Stock \\
Pitx3 & & Pitx3 & ISH & Prof. A. Simeone \\
Lmx1a & & Lmx1a & Prof. P. Burbach \\
\hline
\end{tabular}

Tab. 11: Liste der verwendeten Plasmide. Sofern bekannt, wurde der Vektor, in dem die DNA eingebracht wurde, mit angegeben.

\subsubsection{Sequenzierungen}

Zur Kontrolle der DNA Sequenzen nach den oben beschriebenen Schritten wurde eine Sequenzierung durchgeführt. Hierzu wurde das Taq Dye Deoxy Terminator Kit (Perkin Elmer) und des ABI Prism 377 DNA Sequenziergerät (Applied Biosystems) verwendet. Die Sequenzierungen wurden von Sigurt Hille aus der Abteilung Molekulare Zellbiologie (Max-Planck-Institut für biophysikalische Chemie, Göttingen) durchgeführt.

\subsubsection{Herstellung kalzium-kompetenter Zellen}

Zur Herstellung kalzium-kompetenter Zellen wurde eine Kolonie von E.coli DH5 $\alpha$ oder $50 \mu 1$ bereits vorhandener kompetenter Zellen über Nacht in 2x $5 \mathrm{ml}$ LB Medium ohne Antibiotika (Tab. 5) bei $37{ }^{\circ} \mathrm{C}$ und $200 \mathrm{rpm}$ inkubiert. Am nächsten Morgen wurden 2x $50 \mathrm{ml} \mathrm{LB} \mathrm{Me}$ dium mit 2,5 ml der Vorkultur angeimpft und für ca. zwei Stunden bei $37{ }^{\circ} \mathrm{C}$ und $200 \mathrm{rpm}$ inkubiert. Danach wurden die Zellen in $50 \mathrm{ml}$ Reaktionsgefäße überführt und bei $2000 \mathrm{rpm}$ für zehn Minuten bei $4{ }^{\circ} \mathrm{C}$ abzentrifugiert. Anschließend wurde das Pellet in $25 \mathrm{ml}$ eisgekühltem Kalziumchlorid (50 $\mathrm{mM} \mathrm{CaCl}_{2}$ ) resuspendiert und es folgte ein weiterer Zentrifugationsschritt und eine erneute Resuspension des Pellets mit 3 ml eisgekültem Kalziumchlorid. Schließlich erfolgte die Zugabe von $10 \%$ Glycerol und es wurden $100 \mu$ l Aliquote bei $-80{ }^{\circ} \mathrm{C}$ eingefroren. 


\subsubsection{Transformation von DNA in kalzium-kompetente Zellen}

Zur Transformation wurden zunächst $100 \mu \mathrm{l}$ Zellen auf Eis aufgetaut und $2 \mu \mathrm{l}$ des Ligationsansatzes oder der Plasmid-DNA zugefügt. Zur Ligation wurde das Reaktionsgemisch zunächst für 20 Minuten auf Eis inkubiert, ehe es für 45 Sekunden bei $42^{\circ} \mathrm{C}$ im Wasserbad erwärmt wurde. Folgend wurden die Zellen für zwei Minuten auf Eis gestellt und anschließend mit $900 \mu 1$ LB-Medium ohne Antibiotika versetzt. Das Reaktionsgemisch wurde für $30 \mathrm{~min}$ bei $37{ }^{\circ} \mathrm{C}$ ohne Schütteln inkubiert, bevor je $100 \mu \mathrm{l}, 200 \mu \mathrm{l}$ und $500 \mu \mathrm{l}$ der Suspension mittels eines sterilen Drigalsgispatels auf LB-Agarplatten (je nach Resistenz des Plasmides mit geeignetem Antibiotikum versetzt) ausgestrichen und der Rest des Ansatzes verworfen wurde. Zur Kultivierung der Bakterien wurden die Agarplatten über Nacht bei $4{ }^{\circ} \mathrm{C}$ inkubiert.

\subsubsection{Herstellung von Glycerolstocks}

Zur Lagerung der transformierten Bakterien wurden $500 \mu \mathrm{l}$ einer frischen Bakterienkultur mit $10 \%$ Glycerol versetzt und für eine Minute in flüssigem Stickstoff gefroren. Anschließend wurde der Stock bei $-80{ }^{\circ} \mathrm{C}$ gelagert.

\subsubsection{Aufreinigung von total RNA aus Hefe}

Für die in situ Hybridisierung (ISH) war es notwendig die benötigte total RNA aus der Hefe zunächst aufzureinigen, was der Reduzierung des Hintergrundes bei der ISH diente. Hierfür wurden 4x $250 \mathrm{mg}$ total RNA (engl. „,total RNA from yeast“, Roche) abgewogen und je in ein $50 \mathrm{ml}$ Reaktionsgefäß überführt und unter Zugabe von $25 \mathrm{ml}$ TE-Puffer (pH 7,5, Tab. 6) bei $60{ }^{\circ} \mathrm{C}$ im Wasserbad gelöst. Da die RNA nur schwer löslich war wurde mehrmals für fünf Minuten gevortext. Anschließend wurde je ein Volumenanteil Phenol pH 4,5 (Amresco) zugegeben und für 30 Minuten gevortext, ehe eine 30 minütige Inkubation auf einem Rollschüttler erfolgte. Nach 20 minütiger Zentrifugation bei RT und 3500 rpm wurde die wässrige Phase in ein neues Reaktionsgefäß überführt und die organische Phase verworfen. Die Vorgänge des Vortexens, Schüttelns und Zentrifugierens wurden insgesamt 3x wiederholt. Am Schluss wurde zu der wässrigen Phase je $1 \mathrm{ml} 5 \mathrm{M} \mathrm{NaCl}$ zugegeben und der Reaktionsansatz gut vermischt. Anschließend erfolgten drei Extraktionsschritte. Hierzu wurde der Reaktionsansatz zunächst mit 
einem Volumenanteil Chloroform versetzt und ebenfalls für 30 Minuten gevortext, ehe eine Inkubation auf einem Rollschüttler für 30 Minuten erfolgte. Nach anschließender Zentrifugation, bei 3500 rpm für 15 Minuten, wurde die wässrige Phase in ein neues Reaktionsgefäß überführt. Nach dreimaliger Wiederholung wurden der wässrigen Phase 2,5 Volumenanteile eisgekühltem Ethanol zugefügt und das Gemisch über Nacht bei $-20{ }^{\circ} \mathrm{C}$ präzipitiert. Am nächsten Morgen erfolgte eine 20 minütige Zentrifugation bei 10.000 rpm. Der Überstand wurde verworfen und das Pellet mit 80\%igem Ethanol gewaschen. Nach erneuter Zentrifugation wurde das Pellet für einige Minuten getrocknet, ehe es in je $5 \mathrm{ml}$ TE-Puffer pH 7,5 gelöst wurde. Die Konzentrationsbestimmung erfolgte, wie in Kapitel 5.1 .5 beschrieben.

\subsubsection{Herstellung DIG und Fluorescein markierter Proben}

Für die in situ Hybridisierung war es zunächst notwendig entsprechend markierte antisense RNA-Sonden herzustellen. Solche Marker sind u.a. Digoxigenin-11-UTP (DIG) und Fluorescein-12-dUTP (Fluorescein), die später mittels spezifischer Antikörper nachgewiesen werden können. Für die Herstellung DIG und Fluorescein markierter RNA wurde der in Tabelle 12 beschriebene Syntheseansatz pipettiert und für $37^{\circ} \mathrm{C}$ bei 2 - 4 Stunden inkubiert. Falls die SP6 RNA-Polymerase verwendet wurde, erfolgte die Inkubation bei $40{ }^{\circ} \mathrm{C}$. Im Anschluss an die Inkubation wurde die DNA mittels DNAse (1U/ $\mu$ l, Promega) verdaut. Zur Kontrolle der Transkription und des DNA Verdaus wurde $1 \mu \mathrm{l}$ des Reaktionsansatzes auf ein 1\%iges Agarosegel aufgetragen ehe die RNA gefällt wurde $(2 \mu \mathrm{l}$ 0,2 M EDTA, 2,5 $\mu \mathrm{l} 4 \mathrm{M} \mathrm{LiCl}, 75 \mu \mathrm{l} 100 \%$ EtOH). Die Fällung erfolgte für eine Minute in flüssigem Stickstoff. Zur Aufreinigung der Probe wurde der Reaktionsansatz zunächst bei $4{ }^{\circ} \mathrm{C}$ und $13.000 \mathrm{rpm}$ für 15 Minuten zentrifugiert. Im Anschluss wurde das Pellet mit $100 \mu 1$ 100\%igem Ethanol gewaschen, ehe eine erneute Zentrifugation erfolgte. Nach Trocknung des Pellets wurde die RNA in $100 \mu$ l DEPC- $\mathrm{H}_{2} \mathrm{O} 10$ Minuten bei $65^{\circ} \mathrm{C}$ gelöst. Die Probe wurde bei $-20{ }^{\circ} \mathrm{C}$ gelagert.

\begin{tabular}{|l|l|}
\hline Reagenz & Menge \\
\hline \hline autoklaviertes $\mathrm{dH}_{2} \mathrm{O}$ & $13,5 \mu \mathrm{l}$ \\
10x Transkriptionspuffer (Roche) & $2 \mu \mathrm{l}$ \\
DIG oder Fluorescein markierter Nucleotid Mix (Roche) & $2 \mu \mathrm{l}$ \\
DNA-Template (liniarisierte Plasmid-DNA) & ca. $2 \mu \mathrm{g}$ \\
RNAsin (Promega) & $1 \mu \mathrm{l}$ \\
RNA Polymerase (T7, T3 oder SP6) & $1 \mu \mathrm{l}$ \\
\hline
\end{tabular}

Tab. 12: Ansatz zur Herstellung DIG- oder Fluorescein-markierter RNA. 


\subsection{Tierexperimentelle Methoden}

\subsubsection{Tiere}

Alle verwendeten Mauslinien wurden auf einen C57/BL6 Hintergrund gekreuzt und auf diesem erhalten. Wildtyp C57/BL6 Mäuse wurden von Charles River bezogen. Einzig die verwendete Foxa2-Cre Linie wurde auf einem gemischten Hintergrund (C57/BL6 gekreuzt mit CD1) gehalten. Als Ammen wurden Weibchen aus dem Auszuchtstamm CD1 verwendet, die ebenfalls von Charles River bezogen wurden. Die Behandlung der Tiere erfolgte entsprechend der Regulationen des Regierungsbezirks Braunschweig. Eine Liste aller in dieser Arbeit verwendeten Mauslinien findet sich in Tabelle 13 .

\begin{tabular}{|c|c|c|}
\hline Name & Beschreibung & Referenz \\
\hline CD1 & Wildtyptiere des CD1 Auszuchtstammes & Charles River \\
\hline C57/BL6 & Wildtyptiere des C57/BL6 Inzuchtstammes & Charles river \\
\hline U6 & globaler Uncx4.1-Knockout & (Mansouri et al. 2000) \\
\hline $\operatorname{Unx} 4.1^{\mathrm{f} / \mathrm{fl}}$ & konditionaler Uncx4.1-Knockout & (Leitges et al. 2000 ) \\
\hline Foxa2-Cre & Induzierbare Cre Linie unter dem Promotor von Foxa 2 & (Park et al., 2008) \\
\hline Cre-ER & Induzierbare Cre Linie. Cre ist ubiquitiär exprimiert. & (Hayashi \& McMahon, 2002) \\
\hline Cmv-Cre & nicht induzierbare Cre-Linie. Cre ist ubiquitär exprimiert. & (Schwenk et al. 1995) \\
\hline Ngn2-KiGFP & globaler Ngn2-Knockout & (Seibt et al., 2003) \\
\hline Lmx la-ko & globaler Lmxla-Knockout & (Griesel et al. 2011) \\
\hline Pax6 & globaler Pax6-Knockout & (St-Onge et al. 1997) \\
\hline
\end{tabular}

Tab. 13: Liste der verwendeten Mauslinien.

Als Kontrolltiere für die Analyse des globalen Uncx4.1-Knockouts wurden entweder WT oder für Uncx4.1 heterozygote Embryonen verwendet, da diese Tiere keinen Phänotyp zeigen. Wenn WT und heterozygote Tiere als Kontrollen verwendet wurden, dann ist der Phänotyp folgendermaßen angegeben: Uncx4.1 $1^{+/ ?}$.

\subsubsection{Generierung konditionaler Uncx4.1 Mausmutanten}

Für die konditionale Inaktivierung von Uncx4.1 wurden zunächst der globale Uncx4.1Knockout mit der gewünschten Cre-Linie verpaart um Uncx4.1 heterozygote Tiere zu generieren, welche ebenfalls Cre positiv sind. Anschließend wurden diese Tiere mit der konditionalen Uncx4. $1^{f / f l}$ Linie verpaart. Eine Übersicht über die Verpaarung findet sich in Abb. 41. Bei der Verwendung einer induzierbaren Cre-Linie wurde den Tieren zum gewünschten Zeitpunkt der 
Inaktivierung Tamoxifen verabreicht. Da die Mütter meistens nicht in der Lage waren die Jungen nach Verabreichung des Tamoxifens zu gebären, wurden die Embryonen zwischen E17.5 und E20 (je nach Kondition der Mutter) entnommen und zu CD1-Ammen gesetzt.

1.

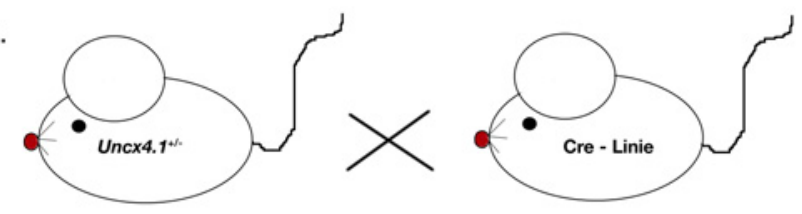

2.
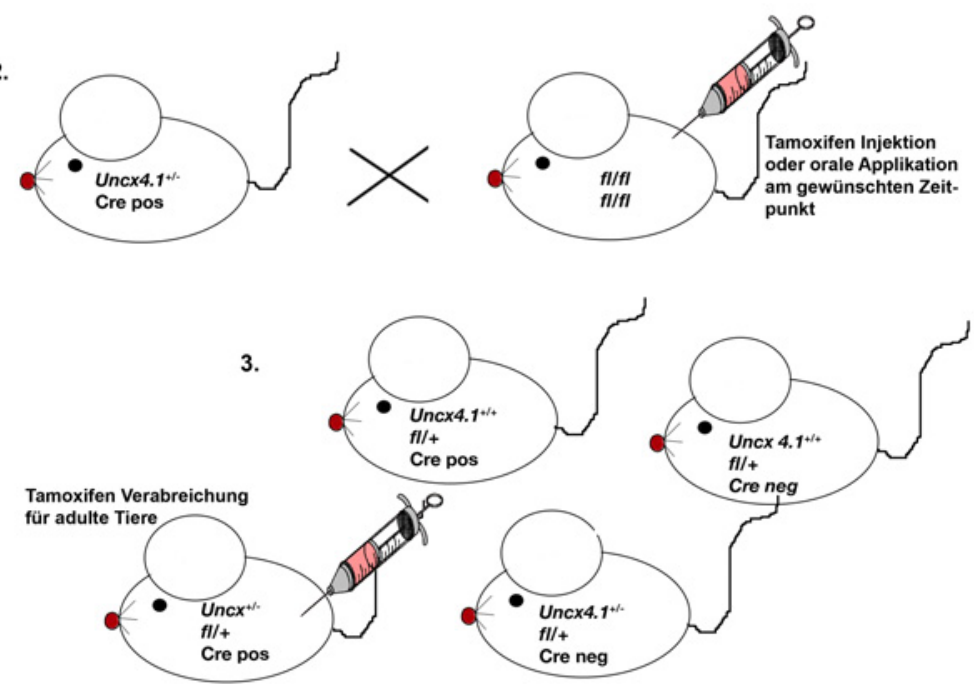

4.

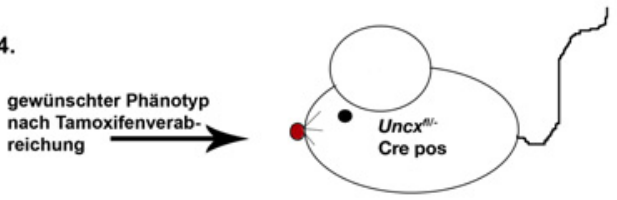

Abb. 41: Verpaarungs-Strategie konditionaler Uncx4.1 Mausmutanten. (1.) Zunächst wurden heterozygote Tiere des konservativen Knockouts mit Tieren der gewünschten Cre-Linie verpaart. (2.) Die Cre positiven und Uncx4.1 heterozygoten Tiere wurden anschließend mit gefloxten Tieren des konditionalen Knockouts verpaart. (2.) und (3.) Tamoxifen wurde entweder den tragenden Müttern appliziert (2.) oder den Cre-positiven Nachkommen (3.), die ein gefloxtes Uncx4.1-Allel und ein knockout Allel besaßen. (4.) Zeigt den gewünschten Phänotyp nach der Tamoxifenverabreichung.

\subsubsection{Tamoxifenverabreichung}

Zunächst wurden $20 \mathrm{mg}$ Tamoxifen (Sigma) in $1 \mathrm{ml}$ Keimöl (Sigma) bei $37^{\circ} \mathrm{C}$ unter Ausschluss von Licht bei leichtem Schütteln auf einem Thermoblock gelöst. Das Tamoxifen wurde bis zu vier Wochen bei $4{ }^{\circ} \mathrm{C}$ gelagert. Zur Induktion von Cre wurde entweder den tragenden oder den 
drei Wochen alten Tieren das auf $37^{\circ} \mathrm{C}$ vorgewärmte Tamoxifen verabreicht. Die Verabreichung erfolgte entweder mit Hilfe einer Spritze intraperitoneal oder oral mittels einer Magensonde. Die Menge des verabreichten Tamoxifens betrug 0,5 mg oder $1 \mathrm{mg}$ pro $10 \mathrm{~g}$ Körpergewicht der Maus. Eine Übersicht über die Zeitpunkte der Tamoxifenverabreichung und Analyse der Tiere findet sich in Abbildung 42 .

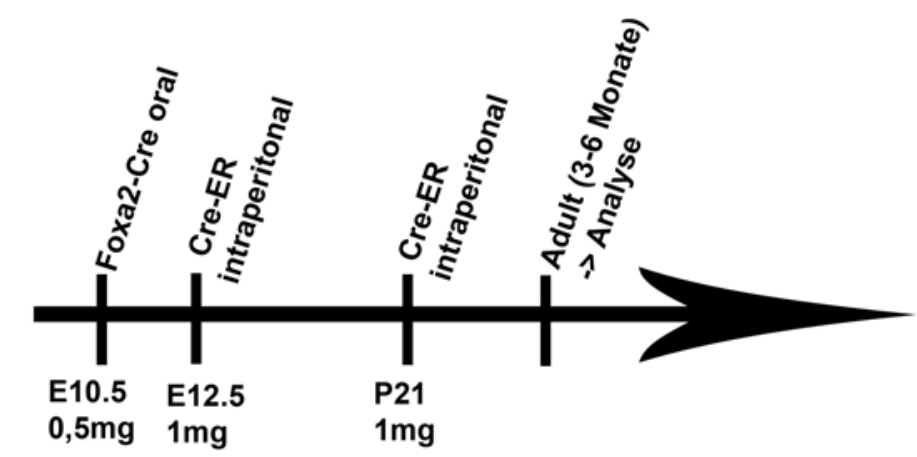

Abb. 42: Zeitliche Übersicht der Tamoxifenverabreichung. Die Verabreichung von Tamoxifen bei Tieren, die mit der Foxa2-Cre Linie gekreuzt wurden erfolgte durch orale Applikation an Tag E10.5. Es wurde eine Menge von $0.5 \mathrm{mg}$ Tamoxifen pro $10 \mathrm{~g}$ Körpergewicht der Maus verabreicht. Tieren die mit der Cre-ER Linie gekreuzt worden sind, wurde das Tamoxifen intraperitoneal an Tag E12.5 oder P21 gespritzt. Hierbei wurde eine Menge von $1 \mathrm{mg}$ Tamoxifen pro $10 \mathrm{~g}$ Körpergewicht verabreicht. Die Analyse der Tiere erfolgte drei oder sechs Monate nach der Geburt.

\subsubsection{BrdU-Injektion}

Für Proliferationsstudien wurde das chemische Thymidinanalogon BrdU (5'-Brom-2'-desoxyuridin) injiziert. Liegt BrdU vor, kann dieses anstelle von Thymidin während der DNA-Synthese in den neuen Strang inkorporiert werden und somit als Markierung proliferierender Zellen verwendet werden. Der BrdU- Nachweis erfolgte mit Hilfe eines spezifischen Antikörpers. Zur Herstellung einer BrdU-Lösung wurden zunächst 0,028 gr BrdU (Roche) in $1714 \mu \mathrm{l}$ 1x PBS (Zusammensetzung Tab. 15) bei $37{ }^{\circ} \mathrm{C}$ unter leichtem Schütteln gelöst. Von dieser Lösung wurden den tragenden Müttern zum gewünschten Zeitpunkt je $100 \mu \mathrm{l}$ pro $10 \mathrm{~g}$ Körpergewicht intraperitoneal injiziert. Das gelöste BrdU wurde bis zu drei Monaten bei $-20{ }^{\circ} \mathrm{C}$ gelagert. 


\subsection{Histologische Methoden}

\subsubsection{Präparation von Embryonen und adulten Gehirnen}

Für die Analyse von Embryonalstadien wurde der Tag des Vaginalplugs als embryonaler Tag 0.5 angenommen (E0.5). War das gewünschte Embryonalstadium erreicht, wurden die trächtigen Mütter mittels zervikaler Dislokation getötet und die Embryonen entnommen. Die Körper, Köpfe oder Gehirne wurden heraus präpariert und entweder in das gewünschte Medium eingebettet oder für die DiI Färbung verwendet. Für die Vorbereitung von adulten Gehirnen wurden die Tiere zunächst ebenfalls mittels zervikaler Dislokation getötet, ehe das Gehirn heraus präpariert wurde.

\subsubsection{Einbetten in Kryomatrix}

Nach der Präparation des Gewebes wurde dies zunächst kurz in 1x PBS (Tab. 15) gewaschen ehe es in 4\%igem PFA (Paraformaldehyd, Fluka) fixiert wurde. Die Dauer der Fixierung war abhängig von der Größe des zu fixierenden Gewebes (Tab. 14).

\begin{tabular}{|l|l|l|}
\hline Stadium & Art des Gewebes & Dauer der PFA-Fixierung \\
\hline \hline E10.5 & Kopf & 45 Minuten \\
E11.5 & Kopf & 1 Stunde \\
E12.5 & Kopf & 2 Stunden \\
E13.5 & Kopf & 2,5 Stunden \\
E14.5 & Kopf & 3 Stunden \\
E16.5 & Kopf & 4 Stunden \\
E16.5 & Gehirn & 1,5 Stunden \\
E17.5 & Kopf & 5 Stunden \\
E17.5 & Gehirn & 2 Stunden \\
P0 & Gehirn & 6 Stunden \\
Adult & Gehirn & über Nacht \\
\hline
\end{tabular}

Tab. 14: Dauer der PFA-Fixierung von Gewebe für das Einbetten in Kryomatrix. Die Gewebe wurden in $4 \%$ PFA fixiert.

Im Anschluss an die Fixierung, erfolgte dreimaliges Waschen in 1x PBS für 20 Minuten, ehe das Gewebe für 30 Minuten in eine $15 \%$ ige Sucroselösung (in 1x PBS) überführt wurde. Anschließend wurde es in eine 30\%ige Sucroselösung (in PBS) gegeben, wo es verblieb bis das Gewebe vollständig abgesunken war. Dieser Vorgang dauerte unter Umständen bis zu 20 Stunden. Nachdem das Gewebe abgesunken war, wurde es für eine halbe Stunde in einen Mix aus $30 \%$ Sucrose und Kryomatrix (Tissue Freezing Medium ${ }^{\circledR}$ Einbettmedium, Leica) überführt 
bevor es für eine weitere halbe Stunde in reine Kryomatrix gegeben wurde. Alle Schritte erfolgten auf Eis unter leichtem Schütteln. Zum Schluss wurde das Gewebe auf Trockeneis in Kryomatrix eingebettet und bis zur weiteren Verarbeitung bei $-20{ }^{\circ} \mathrm{C}$ gelagert.

\begin{tabular}{|l|l|}
\hline Chemikalie & Menge für 20x PBS \\
\hline \hline $\mathrm{NaCl}$ & $160 \mathrm{~g}$ \\
$\mathrm{KCl}$ & $4 \mathrm{~g}$ \\
$\mathrm{Na}_{2} \mathrm{HPO}_{4}$ & $26,44 \mathrm{~g}$ \\
$\mathrm{NaH}_{2} \mathrm{PO}_{4}$ & $1,95 \mathrm{~g}$ \\
$\mathrm{KH}_{2} \mathrm{PO}_{4}$ & $4 \mathrm{~g}$ \\
\hline
\end{tabular}

Tab. 15: 20x PBS . Nach Zugabe aller Komponenten wurde mit $\mathrm{dH}_{2} \mathrm{O}$ auf einen Liter aufgefüllt und die Lösung autoklaviert. Zur Herstellung 1x PBS wurde die 20x PBS Stocklösung mit $\mathrm{dH}_{2} \mathrm{O}$ verdünnt.

\subsubsection{Einbetten in Paraffin}

Für eine Paraffineinbettung wurde das Gewebe wie in Tab. 16 beschrieben behandelt und anschließend mit Hilfe einer Einbettmaschine (Leica) eingebettet. Die Lagerung der Paraffinblöcke bis zur weiteren Verarbeitung erfolgte bei $4{ }^{\circ} \mathrm{C}$.

\begin{tabular}{|l|l|}
\hline Reagenz & Dauer \\
\hline \hline & \\
$0,89 \%$ PFA Saline & über Nacht \\
PBS & 20 Minuten \\
$50 \%$ Ethanol & $3 \times 2$ Minuten \\
$70 \%$ Ethanol & $2 \times 1$ Stunde \\
$90 \%$ Ethanol & $2 \times 1$ Stunde \\
$95 \%$ Ethanol & $2 \times 1$ Stunde \\
$100 \%$ Ethanol & $2 \times 1$ Stunde \\
Isopropanol & $2 \times 1$ Stunde oder über Nacht \\
Isopropanol/Toluol $(75 \% / 25 \%)$ & über Nacht \\
Isopropanol/Toluol $(50 \% / 50 \%)$ & $2 \times 1$ Stunde \\
Isopropanol/Toluol $(25 \% / 75 \%)$ & $2 \times 1$ Stunde \\
Toluol & über Nacht \\
Paraffin & $3 \times 1$ Tag \\
& \\
\hline
\end{tabular}

Tab. 16: Aufbereitung des Gewebes für die Paraffineinbettung.

\subsubsection{Einbetten in $2 \%$ „Low Melting Point“Agarose}

Für die Einbettung des Gewebes in 2\% „Low Melting Point“Agarose (Thermo Scientific) wurde die Agarose zunächst in 0,5x TBE erhitzt, bis die Agarose vollständig gelöst war und anschließend auf Eis gekühlt. Dann wurde das Gewebe auf Eis eingebettet. 


\subsubsection{Anfertigung von Gewebeschnitten}

Mit Hilfe eines Kryotoms (Leica) wurden aus den in Kryomatrix eingebetteten Gewebeblöcken 10 bzw. $18 \mu \mathrm{m}$ dicke Schnitte angefertigt. Die Schnitte wurden auf je vier alternierende Adhäsions-Objektträger (Menzel-Gläser, Superfrost Ultra Plus ${ }^{\circledR}$ ) aufgezogen und max. eine Stunde bei ca. $30{ }^{\circ} \mathrm{C}$ getrocknet, ehe sie bei $-20^{\circ} \mathrm{C}$ gelagert wurden. Die Paraffinblöcke wurden mittels eines Mikrotoms (Leica) ebenfalls in 10 oder $18 \mu \mathrm{m}$ dicke Schnitte geschnitten und zur Glättung in ein ca. $40{ }^{\circ} \mathrm{C}$ warmes Wasserbad überführt, ehe sie alternierend aufgezogen und über Nacht bei $37{ }^{\circ} \mathrm{C}$ getrocknet wurden. Die Lagerung bis zur weiteren Verwendung erfolgte bei $4{ }^{\circ} \mathrm{C}$. In Low Melting Point Agarose eingebettetes Gewebe wurde mittels eines Vibratoms (Leica) in 100 - $150 \mu \mathrm{m}$ dicke Schnitte geschnitten. Die anschließend im Wasser freischwimmenden Präparate wurden dann auf Adhäsions-Objektträger aufgezogen und im Falle einer folgenden Golgi-Färbung eine Woche bei RT getrocknet.

\subsubsection{Indirekte Immunfluoreszenzfärbung (IHC) auf Gewebeschnitten}

Für die indirekte Immunfluoreszenzfärbung wurden entweder $10 \mu \mathrm{m}$ dicke Paraffin- oder Kryoschnitte verwendet. Die Paraffinschnitte wurden zunächst entparaffiniert und mit einem hitzebeständigen Fettstift umrandet (ImmEdge Pen, Vector) ehe sie in einer absteigenden Ethanolreihe entwässert wurden. Zur Demaskierung der Antigene wurden die Gewebeschnitte für eine Minute in einer auf Zitronensäure basierenden Demaskierungslösung (Vetrashield, Vector Laboratories) in einem Dampfkochtopf unter maximalem Druck gekocht. Anschließend wurden die Objektträger in $\mathrm{dH}_{2} \mathrm{O}$ überführt, ehe sie 3 mal in 1x PBS gewaschen wurden. Um ein mögliches Hintergrundsignal zu vermeiden bzw. zu reduzieren wurden die Schnitte für 70 Minuten mit einer Blocklösung inkubiert. Die Blocklösung bestand aus $10 \%$ Serum und 0,1 \% Triton-X-100 in PBS. Bei dem verwendeten Serum handelte es sich je nach Antikörper entweder um FCS, NGS oder BSA. Die Inkubation mit dem primären Antikörper erfolgte 16 - 72 Stunden bei $4{ }^{\circ} \mathrm{C}$. Eine Liste der verwendeten Antikörper und Verdünnungen befindet sich in Tabelle 18 . Nach der Inkubation mit dem primären Antikörper wurden die Schnitte zunächst 3 mal für 7 Minuten mit 1x PBS gewaschen ehe ein Fluophor-gekoppelter sekundärer Antikörper (Tab. 18) appliziert und 70 Minuten bei RT inkubiert wurde. Nach Auswaschen des sekundären Antikörpers mit 1x PBS (3 mal 7 Minuten) wurden die Gewebeschnitte in Vectashield ${ }^{\circledR}$ Mounting Medium mit DAPI (Vector Laboratories) eingedeckelt und mit Nagellack versiegelt. Für die indirekte 
Fluoreszenzfärbung auf Kryoschnitten wurde das Protokoll ab der Überführung der Präparate in 1x PBS genauso durchgeführt wie für Paraffinpräparate (Tab. 17). Alle Fluoreszenzaufnahmen der Präparate wurden entweder mit einem BX-60 Fluoreszenzmikroskop (Olympus) und der Cell^P Software (Olympus) oder mit einem Konfokalen-Lasermikroskop (LSM 410 invert, Leica) gemacht. Die Bilder wurden anschließend mit Photoshop 10.0 (Adobe) übereinander gelegt, sowie Größe, Kontrast und Helligkeit angepasst. Konfokale Aufnahmen wurden mit der Software ImageJ bearbeitet.

\begin{tabular}{|c|c|c|}
\hline Schritt-Nr. & Reagenz & Dauer \\
\hline 1 & Histoclear & $3 \times 15 \min$ \\
\hline 2 & $100 \%$ Ethanol & $2 \times 2 \min$ \\
\hline 3 & $95 \%$ Ethanol & $3 \times 20 \min$ \\
\hline 4 & $70 \%$ Ethanol & 2x 1 Stunde \\
\hline 5 & $50 \%$ Ethanol & 2x 1 Stunde \\
\hline 6 & $30 \%$ Ethanol & 2x 1 Stunde \\
\hline 7 & $\mathrm{dH}_{2} \mathrm{O}$ & $2 \times 5 \min$ \\
\hline 8 & Kochen in Demaskierungslösung & 1 min bei höchstem Druck \\
\hline 9 & $\mathrm{dH}_{2} \mathrm{O}$ & über Nacht 2x 5 min \\
\hline 10 & $1 \mathrm{x}$ PBS & $3 \times 7 \mathrm{~min}$ \\
\hline 11 & Blocklösung & $70 \mathrm{~min}$ \\
\hline 12 & primärer Antikörper in Blocklösung & 16-72 Stunden \\
\hline 13 & $1 \mathrm{x}$ PBS & $3 \times 7 \mathrm{~min}$ \\
\hline 14 & sekundärer Antikörper in Blocklösung & $70 \mathrm{~min}$ \\
\hline 15 & 1x PBS & $3 \times 7 \min$ \\
\hline
\end{tabular}

Tab. 17: Übersicht über die Schritte der IHC. Die Färbung von Paraffinschnitten umfasste Schritt-Nr. 1-15, während die Färbung von Kryopräparaten die Schritte 10-15 umfasste. Nachdem das letzte mal in PBS gewaschen wurde (Schritt-Nr. 15), wurden die Präparate in Eindeckmedium mit DAPI eingedeckelt und mit Nagellack versiegelt.

\subsubsection{BrdU-Färbung}

Zum Nachweis proliferierender Zellen in der S-Phase wurde BrdU verwendet (Präparation der Embryonen siehe Kap. 5.2.47. Für die Proliferationsanalyse wurden Embryonen des Embryonaltages 14.5 verwendet, in Kryomatrix eingebettet und Kryoschnitte angefertigt. Die Gewebeschnitte wurden zunächst 15 Minuten in 1x PBS gewaschen, ehe sie für 30 Minuten in $2 \mathrm{~N}$ $\mathrm{HCl}$ überführt und bei $37{ }^{\circ} \mathrm{C}$ inkubiert wurden. Anschließend wurden die Gewebeschnitte $2 \mathrm{x}$ 30 Minuten in 1x PBS gewaschen, ehe sie mit einem Fettstift (ImmEdge Pen, Vector) umrandet wurden. Das Blocken erfolgte 60 Minuten bei $4{ }^{\circ} \mathrm{C}(10 \%$ FCS, 0,01\% Tween-20 in 1x PBS). Der primäre Antikörper (Tab. 18) wurde appliziert und über Nacht bei $4{ }^{\circ} \mathrm{C}$ inkubiert. Am nächsten Morgen wurden die Objektträger 2x 15 Minuten in 1x PBS gewaschen und der 


\begin{tabular}{|c|c|c|c|c|c|}
\hline Antikörper & Herkunft & Bezugsquelle & Verdünnung & Verwendungszweck & Serum \\
\hline Primäre Antikörper & & & & & \\
\hline anti-Uncx 4.1 & Kaninchen & Dr. S. Blanke & $1: 750$ & $\begin{array}{l}\text { ICC \& IHC, Kryo- } \\
\text { und Paraffinschnitte }\end{array}$ & FCS oder BSA \\
\hline anti-Pax6 & Kaninchen & Covance & $1: 300$ & $\begin{array}{l}\text { ICC \& IHC, Kryo- } \\
\text { und Paraffinschnitte }\end{array}$ & FCS \\
\hline anti-Pax6 & Maus & DSHB & $1: 200$ & $\begin{array}{l}\text { IHC auf Kryoschnit- } \\
\text { ten }\end{array}$ & FCS \\
\hline anti-Calbindin & Kaninchen & Swant & $1: 200$ & $\begin{array}{l}\text { IHC, Kryo- und Paraf- } \\
\text { finschnitten }\end{array}$ & FCS \\
\hline anti-Calretinin & Kaninchen & Sigma & & $\begin{array}{l}\text { IHC, Kryo- und Paraf- } \\
\text { finschnitten }\end{array}$ & FCS \\
\hline anti-DAT & Ratte & Santa Cruz & $1: 100$ & IHC,Kryoschnitte & FCS \\
\hline anti-Hnf $3 ß$ & Ziege & Santa Cruz & $1: 150$ & IHC, Kryoschnitte & BSA \\
\hline anti-Nkx6.1 & Kaninchen & P.Serup & $1: 1000$ & IHC, Kryoschnitte & FCS \\
\hline anti-Nkx6.1 & Maus & DSHB & $1: 100$ & IHC, Kryoschnitte & BSA \\
\hline anti-Nestin & Kaninchen & Abcam & $1: 200$ & IHC, Kryoschnitte & FCS \\
\hline anti-Tuj & Maus & Covance & $1: 100$ & IHC, Kryoschnitte & FCS \\
\hline anti-Lhx1 & & DSHB & $1: 100$ & IHC, Kryoschnitte & BSA \\
\hline anti-TH & Kaninchen & Sigma & $1: 300$ & $\begin{array}{l}\text { IHC, Kryo- und Paraf- } \\
\text { finschnitte }\end{array}$ & FCS \\
\hline anti-TH & Maus & Chemicon & $1: 8000$ & $\begin{array}{l}\text { IHC, Kryo- und Paraf- } \\
\text { finschnitte }\end{array}$ & BSA und FCS \\
\hline anti-Pitx3 & Kaninchen & P. Burbach & $1: 700$ & IHC, Kryoschnitte & FCS \\
\hline anti-Pitx3 & Kaninchen & Zymed & $1: 300$ & IHC, Kryoschnitte & BSA \\
\hline anti-Nurr1 & Ziege & B\&D Pharmingen & $1: 150$ & IHC, Kryoschnitte & BSA \\
\hline anti-S100ß & Kaninchen & Dako & $1: 200$ & IHC, Kryoschnitte & FCS \\
\hline anti-GFAP & Kaninchen & Chemicon & $1: 750$ & IHC, Kryoschnitte & FCS \\
\hline anti-Aldh1a1 & Kaninchen & Abcam & $1: 100$ & IHC, Kryoschnitte & FCS oder BSA \\
\hline anti-Synapsin I+II & Kaninchen & Synaptic Systems & $1: 500$ & IHC, Kryoschnitte & FCS \\
\hline anti-Is11 & Kaninchen & Abcam & $1: 300$ & IHC, Kryoschnitte & FCS \\
\hline anti-Lmx 1a & Kaninchen & Millipore & & IHC, Kryoschnitte & FCS \\
\hline anti-5-HT & Kaninchen & Sigma & $1: 2500$ & IHC, Paraffinschnitte & FCS \\
\hline anti-5-HT & Kaninchen & Sigma & $1: 5000$ & IHC, Kryoschnitte & FCS \\
\hline anti-ß-Catenin & Maus & BD PharMingen & $1: 800$ & IHC, Kryoschnitte & FCS \\
\hline anti-GFP & Huhn & Abcam & $1: 100$ & IHC, Kryoschnitte & $\begin{array}{l}\text { BSA, FCS oder } \\
\text { NGS }\end{array}$ \\
\hline anti-Olig2 & Kaninchen & Chemicon & $1: 500$ & $\begin{array}{l}\text { IHC, Kryo- und Paraf- } \\
\text { finschnitte }\end{array}$ & FCS \\
\hline anti-BrdU & Maus & Roche & $1: 50$ & IHC, Kryoschnitte & FCS \\
\hline anti-Flag & Kaninchen & Sigma & $1: 1000$ & ICC \& WB & $\begin{array}{l}5 \% \text { FCS (ICC), } \\
5 \% \text { Milchpulver } \\
\text { (WB) }\end{array}$ \\
\hline anti-HA & Ratte & Roche & $1: 1000$ & ICC \& WB & $\begin{array}{l}5 \% \text { FCS (ICC), } \\
5 \% \text { Milchpulver } \\
\text { (WB) }\end{array}$ \\
\hline anti-c-myc & Maus & Santa Cruz & $1: 500$ & ICC \& WB & $\begin{array}{l}\text { FCS (ICC), } 5 \% \\
\text { Milchpulver } \\
\text { (WB) }\end{array}$ \\
\hline Sekundäre Antikörper & & & & & \\
\hline Anti-Kaninchen-HRP & Ziege & Dianova & $1: 10.000$ & & \\
\hline Anti-Maus-HRP & Ziege & Dianova & $1: 10.000$ & & \\
\hline Anti-Ratte-HRP & Ziege & Dianova & $1: 10.000$ & & \\
\hline Anti-Kaninchen-Alexa594 & Ziege & Molecular probes & $1: 1000$ & & \\
\hline Anti-Kaninchen-Alexa594 & Esel & Molecular probes & $1: 1000$ & & \\
\hline Anti-Kaninchen-Alexa488 & Esel & Molecular probes & $1: 500$ & & \\
\hline Anti-Maus-Alexa594 & Ziege & Molecular probes & $1: 700$ & & \\
\hline Anti-Ratte-Alexa594 & Ziege & Molecular probes & $1: 500$ & & \\
\hline Anti-Ratte-Alexa488 & Ziege & Molecular probes & $1: 500$ & & \\
\hline Anti-Ziege-Alexa594 & Esel & Molecular probes & $1: 500$ & & \\
\hline Anti-Ziege-Alexa488 & Esel & Molecular probes & $1: 500$ & & \\
\hline Anti-Huhn-Alexa594 & Ziege & Molecular probes & $1: 500$ & & \\
\hline
\end{tabular}

Tab. 18: Verwendete Antikörper. Das FCS, BSA oder NGS gibt an welches Serum zum Blocken verwendet wurde. 
sekundäre Antikörper für 90 Minuten bei RT inkubiert, ehe zwei weitere Waschschritte in 1x PBS für 30 Minuten erfolgten. Zum Abschluss wurden die Schnitte in Eindeckmedium (Vectrashield mit DAPI) eingedeckelt und mit Nagellack versiegelt.

\subsubsection{LacZ Färbung ganzer Embryonen}

Für den Nachweis von $\beta$-Galaktosidaseaktivität in ganzen Embryonen wurde eine LacZFärbung durchgeführt. Hierzu wurde das Gewebe zunächst gründlich in 1x PBS gewaschen, ehe es für eine Stunde in Fix A (Tab. 19) fixiert wurde. Im Anschluss wurde die Fixierlösung ausgewaschen (3x 20 Minuten in 1x PBS), ehe das Gewebe mittels X-gal Färbelösung (Tab.20) bei $37^{\circ} \mathrm{C}$ gefärbt wurde. Die Färbung erfolgte so lange, bis das Signal vollständig entwickelt war, dann folgte die Aufklärung der Embryonen. Hierzu wurde das Gewebe zunächst zwei mal in 1x PBS gewaschen ehe es in einer aufsteigenden Glycerolreihe $(15 \%, 30 \%, 50 \%, 70 \%$ und $80 \%$ ) aufgeklärt wurde. Das Gewebe wurde in $80 \%$ igem Glycerol bei $4{ }^{\circ} \mathrm{C}$ gelagert.

\begin{tabular}{|l|l|}
\hline Reagenz & Menge \\
\hline \hline $37 \%$ Formaldehyd & $0,675 \mathrm{ml}$ \\
$25 \%$ Glutaralde- & $0,2 \mathrm{ml}$ \\
hyd & \\
$10 \%$ NP-40 & $0,05 \mathrm{ml}$ \\
$20 \mathrm{x}$ PBS & $1,25 \mathrm{ml}$ \\
$\mathrm{dH}_{2} \mathrm{O}$ & $22,825 \mathrm{ml}$ \\
\hline
\end{tabular}

Tab. 19: Zusammensetzung der Fix A Fixierlösung für die LacZ-Färbung

\begin{tabular}{|l|l|}
\hline Reagenz & Menge \\
\hline \hline 1x PBS & $9,35 \mathrm{ml}$ \\
X-Gal $(40 \mathrm{mg} / \mathrm{ml})$ & $0,25 \mathrm{ml}$ \\
$200 \mathrm{mM} \mathrm{K}_{3} \mathrm{Fe}(\mathrm{CN})_{6}$ & $0,25 \mathrm{ml}$ \\
$200 \mathrm{mM} \mathrm{K}_{4} \mathrm{Fe}(\mathrm{CN})_{6}$ & $0,25 \mathrm{ml}$ \\
$100 \mathrm{mM} \mathrm{MgCl}_{2}$ & $0,2 \mathrm{ml}$ \\
\hline
\end{tabular}

Tab. 20: Zusammensetzung der LacZ-Färbelösung. Das X-Gal wurde in Dimethylformamid angesetzt.

\subsubsection{LacZ Färbung von Kryoschnitten}

Zur Visualisierung der $\beta$-Galaktosidaseaktivität auf Kryoschnitten wurden die Gewebeschnitte zunächst für 10 Minuten bei $4{ }^{\circ} \mathrm{C}$ fixiert (0,2\% Glutaraldehyd in 1x PBS). Anschließend wurden sie 3x 5 Minuten mit LacZ-Puffer (Tab. 21) bei RT gewaschen und in völliger Dunkelheit bei $37{ }^{\circ} \mathrm{C}$ gefärbt (Färbelösung siehe Tab. 20). Die Färbung dauerte 16 - 96 Stunden. Nachdem das Signal sichtbar war, wurden die Kryoschnitte zum Abstoppen der Färbereaktion 2x 5 Minuten bei Raumtemperatur in 1x PBS gewaschen, ehe sie mit Mowiol ${ }^{\circledR}$ 4-88 (Roth) eingedeckelt wurden. 


\begin{tabular}{|l|l|}
\hline Reagenz & Menge \\
\hline \hline & \\
$1 \mathrm{M} \mathrm{MgCl}$ & $1 \mathrm{ml}$ \\
$10 \% \mathrm{NP}-40$ & $1 \mathrm{ml}$ \\
$1 \% \mathrm{NaDOC}$ & $5 \mathrm{ml}$ \\
$20 \mathrm{x}$ PBS & $25 \mathrm{ml}$ \\
$\mathrm{dH}_{2} \mathrm{O}$ & $468 \mathrm{ml}$ \\
\hline
\end{tabular}

Tab. 21: LacZ-Fixierungslösung für Kryoschnitte.

\subsubsection{TUNEL-Methode}

Zur Visualisierung apoptotischer Zellen wurde die TUNEL-Methode (engl. „TdT-mediated dUTP-biotin nick end labeling ") angewandt (Gavrieli et al., 1992). Während der Apoptose wird die DNA von Endonukleasen zersetzt, so dass DNA-Bruchstücke entstehen. Die dabei freiwerdenden Hydroxylgruppen werden mit Hilfe einer terminalen Desoxynukleotid-Transferase (TdT) markiert, da das Enzym die Kopplung eines mit z.B. Fluoreszin gekoppelten Farbstoffes ermöglicht. Die Farbstoffe können anschließend mittels Antikörperfärbung sichtbar gemacht werden. Für die Durchführung des TUNEL-Testes wurde das ApopTag ${ }^{\circledR}$ Red in situ Apoptosis Detection Kit (Millipore) entsprechend den Angaben des Herstellers verwendet. Es wurden Kryoschnitte für den TUNEL-Test herangezogen.

\subsubsection{Golgi-Färbung}

Zur Analyse der Axone von Nervenzellen im Mittelhirn wurde eine Golgi-Färbung durchgeführt. Diese Färbung basiert auf der Imprägnierung mit Silbernitrat. Der Vorteil der GolgiFärbung beruht darin, dass nur ein geringer Prozentsatz aller Neuronen angefärbt wird und diese daher sehr gut visualisiert werden können und ihr Verlauf somit gut verfolgt werden kann. Für die Golgi-Färbung wurde das FD Rapid GolgiStain ${ }^{\text {TM }}$ Kit (FD Neruotechnologies) verwendet. Es wurden Gehirne von E16.5 und E17.5 alten Embryonen gefärbt. Das Protokoll wurde bis auf folgende Ausnahme nach Angaben des Herstellers durchgeführt: Anstatt Gefrierschnitte des Gewebes anzufertigen wurden die gefärbten Gehirne teilweise in $2 \%$ „Low Melting Point "Agarose eingebettet und mit einem Vibratom wie in Kapitel 5.3.5 beschrieben geschnitten. Die Dokumentation erfolgte mit einem BX-60 Fluoreszenzmikroskops (Olympus) und der Cell^P Software (Olympus). Bearbeitet wurden die Bilder anschließend mit Photoshop 10.0 (Adobe). 


\subsubsection{Dil-Färbung}

Um den Verlauf der Axone der Colliculi superiores zu visualisieren wurde eine Färbung der Axone mittels DiI (CellTracker CM-DiI, Molecular Probes) durchgeführt. $50 \mu \mathrm{g}$ des CellTrackers wurden in $1 \mathrm{ml}$ Methanol gelöst. Zur Applikation des DiI's wurden embryonale Gehirne der Stadien E16.5 und E17.5 heraus präpariert und in eisgekühltes 1x PBS überführt. Anschließend erfolgte die Injektion des gelösten Farbstoffes mittels vorher speziell präparierter Glaskapillaren und einer Injektionsvorrichtung. Pro Experiment wurde immer dieselbe Menge DiI injiziert. Nach der Applikation des Farbstoffes wurden die Gehirne für 7 - 14 Tage in 4\%igem PFA bei $4{ }^{\circ} \mathrm{C}$ fixiert. Während dieser Zeit konnte der Farbstoff entlang der axonalen Zellmembran wandern und so die Axone färben. Anschließend wurden die Gehirne mit 1x PBS gewaschen und in $2 \%$ „Low Melting Point“Agarose eingebettet. Mit einem Vibratom wurden $100 \mu \mathrm{m}$ dicke Gewebeschnitte hergestellt, welche in Vectrashield mit DAPI eingedeckelt wurden. Fluoreszenzaufnahmen wurden mit einem Konfokalen-Lasermikroskop (LSM 410 invert, Leica) gemacht und anschließend mit Software ImageJ übereinander gelegt und bearbeitet.

\subsubsection{Detektion von mRNA mittels in situ Hybridisierung (ISH) auf Gewebeschnitten}

Zur Detektion der Expression von RNA in Gewebeproben wurde die sogenannte in situ Hybridisierung (ISH) auf Kryoschnitten durchgeführt (Moorman et al., 2001). Im Falle einer Einzelfärbung wurden grundsätzlich DIG markierte RNA-Sonden verwendet. Wenn eine Doppelfärbung durchgeführt wurde, dann wurden DIG und Fluorescein markierte RNA-Sonden verwendet. Die ISH erfolgte über mehrere Tage. Am ersten Tag wurden die Gewebeschnitte zunächst für 15 Minuten in $4 \%$ PFA fixiert, ehe sie 2x 5 Minuten in 1x PBS gewaschen wurden. Um das Gewebe permeabel zu machen, wurden die Schnitte für 3 - 5 Minuten (je nach Embryonalstadium) mit Proteinase K (20 $\mu \mathrm{g} / \mathrm{ml}$ Proteinase $\mathrm{K}$ in $50 \mathrm{mM}$ Tris- $\mathrm{HCl} \mathrm{pH} 8,0,5 \mathrm{mM}$ EDTA in DEPC-dH $\mathrm{H}_{2} \mathrm{O}$ ) behandelt. Die Proteinase K Aktivität wurde mittels Inkubation in 1\%igem Glycin in 1x PBS für 5 Minuten gestoppt. Dann wurden die Gewebeschnitte in 1x PBS (2x 5 min) gewaschen, ehe eine erneute Fixierung folgte (4 \% PFA und 0,2\% Glutaraldehyd in 1x PBS). Um die Fixierlösung zu entfernen, wurden die Gewebeschnitte zwei mal 5 Minuten in 1x PBS gewaschen. Im Anschluss folgte die Prehybridisierung in einer Feuchtekammer bei $70{ }^{\circ} \mathrm{C}$ in Hybridisierungslösung (Tab.22). Für die Hybridisierung wurden die RNA-Sonden zunächst bei 
$80{ }^{\circ} \mathrm{C}$ für 3 Minuten denaturiert, ehe sie in Hybridisierungspuffer verdünnt auf die Schnitte appliziert wurden. Die Verdünnung betrug je nach Qualität der RNA 1:20 - 1:100. Wenn eine ISH mit zwei Proben durchgeführt wurde, dann wurden die DIG und Fluorescein markierten Sonden gleichzeitig aufgetragen. Die Inkubation erfolgte 16 Stunden bei $70^{\circ} \mathrm{C}$ in einer Feuchtekammer mit 2x SSC pH 4,5 und $50 \%$ Formamid in DEPC- $\mathrm{dH}_{2} \mathrm{O}$.

\begin{tabular}{|l|l|}
\hline Reagenz & Menge \\
\hline \hline & \\
Formamid (Merck) & $50 \%$ \\
20x SSC pH 4,5 & $25 \%$ \\
Blockpulver (Boehringer) & $1 \mathrm{~g}$ \\
$0,5 \mathrm{M}$ EDTA & $1 \%$ \\
$10 \%$ CHAPS & $1 \%$ \\
Tween-20 (Merck) & $0,1 \%$ \\
Heparin & $1 \mathrm{mg} / \mathrm{ml}$ \\
total RNA aus Hefe & $1 \mathrm{mg} / \mathrm{ml}$ \\
\hline
\end{tabular}

Tab. 22: Zusammensetzung des Hybridisierungspuffers. Die Lösung wurde mit autoklaviertem $\mathrm{dH}_{2} \mathrm{O}$ angesetzt.

Nach der Hybridisierung war es wichtig ungebundene Probe wieder von den Schnitten herunter zu waschen. Dazu wurden die Objektträger zunächst in 2x SSC pH 4,5 bei RT gewaschen, ehe sie 3x 30 Minuten mit $50 \%$ 2x SSC (pH 4,5) in Formamid bei $65^{\circ} \mathrm{C}$ im Wasserbad inkubiert wurden. Anschließend wurden die Schnitte zur Equilibrierung des Gewebes 2x 10 Minuten in KTBT (Tab. 23) gewaschen. Im Falle einer Doppelfärbung erfolgte vor dem Waschen in KTBT noch eine Inkubation in TNE (10mM Tris- $\mathrm{HCl}$ pH 7,5, $500 \mathrm{mM} \mathrm{NaCl}, 1 \mathrm{mM}$ EDTA) mit RNAase A (20 $\mu \mathrm{g} / \mathrm{ml})$. Um mögliche Hintergrundfärbung zu vermeiden und unspezifische Bindungsstellen des Antikörpers zu blockieren wurden die Schnitte für 2 Stunden in Blocklösung (20 \% FCS in KTBT) inkubiert. Anschließend folgte die Inkubation des Antikörpers (1:2000 Anti-Digoxigenin-AP $\mathrm{F}_{\mathrm{ab}}$-Fragmente (Roche) in Blocklösung) bei $4{ }^{\circ} \mathrm{C}$ über Nacht in einer mit $\mathrm{dH}_{2} \mathrm{O}$ gefüllten Feuchtekammer.

\begin{tabular}{|l|l|}
\hline Reagenz & Menge \\
\hline \hline & \\
$1 \mathrm{M} \mathrm{Tris}-\mathrm{HCl} \mathrm{pH} 7,5$ & $100 \mathrm{ml}$ \\
$5 \mathrm{M} \mathrm{NaCl}$ & $60 \mathrm{ml}$ \\
$1 \mathrm{M} \mathrm{KCl}$ & $20 \mathrm{ml}$ \\
Tween-20 (Merck) & $20 \mathrm{ml}$ \\
$\mathrm{dH}_{2} \mathrm{O}$ & $1800 \mathrm{ml}$ \\
\hline
\end{tabular}

Tab. 23: KTBT Zusammensetzung. Außer des Tween-20's wurden alle Lösungen vorher autoklaviert.

Um ungebundenen Antikörper zu entfernen wurden die Gewebeschnitte am nächsten Tag exzessiv in KTBT gewaschen (zunächst 3x 5 Minuten, gefolgt von 3x 30 Minuten). Im Anschluss 
wurden die Schnitte in NTMT (Tab. 24) überführt, ehe die Farbreaktion durch Applikation der Färbelösung (NTMT mit $200 \mu$ l NBT/BCIP (Roche)) gestartet wurde. Die Farbreaktion erfolgte bei RT und unter regelmäßigem Wechsel der Färbelösung. War es notwendig über mehrere Tage zu Färben, so wurden die Schnitte über Nacht bei $4{ }^{\circ} \mathrm{C}$ gelagert. Die Farbreaktion wurde durch Waschen in 1x PBT (1x PBS $+1 \%$ Tween-20) gestoppt (4x 5 Minuten). Im Falle einer Einzelfärbung wurden die Schnitte anschließend mit Mowiol ${ }^{\circledR} \_488$ (Roth) eingedeckelt. Erfolgte eine Doppelfärbung wurden die Schnitte nach dem Waschen in 1x PBS für 15 Minuten in $4 \%$ PFA fixiert, ehe sie in 1x PBS gewaschen wurden (2x 5 Minuten). Um das zuerst applizierte DIG-AP Enzym zu inaktivieren wurden die Gewebeschnitte bei $65{ }^{\circ} \mathrm{C}$ in KTBT inkubiert (30 Minuten). Im Anschluss daran wurde das Gewebe in KTBT (3x 10 Minuten, RT) equilibriert ehe die Blocklösung appliziert wurde (2 Stunden, RT). Im Anschluss erfolgte die Inkubation der Gewebeschnitte mit anti-Fluorescein-AP $F_{a b}$-Fragmenten (1:1500 in Blocklösung, Roche) über Nacht bei $4{ }^{\circ} \mathrm{C}$ in einer Feuchtekammer.

\begin{tabular}{|l|l|}
\hline Reagenz & Menge \\
\hline \hline & \\
$1 \mathrm{M}$ Tris-Cl pH 9,5 & $100 \mathrm{ml}$ \\
$5 \mathrm{M} \mathrm{NaCL}$ & $20 \mathrm{ml}$ \\
$1 \mathrm{M} \mathrm{MgCl}$ & $50 \mathrm{ml}$ \\
Tween-20 (Merck) & $1 \mathrm{ml}$ \\
$\mathrm{dH}_{2} \mathrm{O}$ & $892 \mathrm{ml}$ \\
Levamisol & $0,24 \mathrm{~g}$ \\
\hline
\end{tabular}

Tab. 24: NTMT Zusammensetzung. Das Levamisol wurde erst kurz vor Gebrauch zugegeben.

Am nächsten Tag wurde ungebundener Antikörper durch Waschen in KTBT (3x 5 Minuten, gefolgt von 3x 30 Minuten) entfernt ehe die Schnitte 3 mal für 5 Minuten in NTMT inkubiert wurden. Die Farbreaktion wurde wie bereits oben beschrieben durchgeführt, nur wurden anstelle von NBT/BCIP eine INT/BCIP Lösung verwendet (75 $\mu 1$ INT/BCIP in NTMT). Abgestoppt wurde die Reaktion ebenfalls durch Waschen in 1x PBT (4x 5 Minuten), ehe sie in Mowiol $^{\circledR}-488$ (Roth) eingedeckelt wurden. Die Dokumentation erfolgte entweder mit einem BX-60 oder einem SZX-12 Fluoreszenzmikroskop (Olympus). Anpassung der Größe, der Helligkeit oder des Kontrastes wurden mit Photoshop Version 10.0 (Adobe) durchgeführt.

\subsubsection{Statistische Analyse}

Um festzustellen, ob die Anzahl positiver Zellen in den Mutanten signifikant verändert war, wurde ein „student's t-test“ (engl.) durchgeführt. Bei embryonalen Stadien wurden zunächst 
alle positiven Zellen des Mittelhirns in jedem vierten Schnitt gezählt. Aus diesem Wert wurde ein Mittelwert gebildet. Dies wurde für mindestens drei verschiedene Tiere (pro WT und Mutante) gemacht. Auf die Mittelwerte wurde der „student's t-test“ unter Verwendung von Excel (Microsoft) angewandt. Betrug der Wert weniger als 0,05 ( $<<0,05)$, dann wurde angenommen, dass die Veränderung signifikant ist. Die statistische Analyse adulter Gehirne wurde vom Prinzip her ebenso wie die Analyse embryonaler Stadien durchgeführt. Es wurde aber immer nur jeder siebte Schnitt eines halben Mittelhirns ausgezählt. Da das Gehirn symmetrisch aufgebaut ist, macht es keinen Unterschied ob das gesamte Hirn oder nur die Hälfte ausgezählt wird. Zusätzlich zum „student's t-test“ wurde die Standardabweichung berechnet. Die Werte wurden alle normalisiert, so dass der Wert des WT als $100 \%$ angenommen und davon ausgehend der Prozentwert der Mutanten berechnet werden konnte. In den Graphen sind die Prozentwerte und die Standardabweichung angegeben.

\subsection{Zellbiologische Methoden}

\subsubsection{Zelllinien}

In dieser Arbeit wurden HeLa (humane Cervixcarcinom-Zellen) Zellen und Hek293T (humane, embryonale Nieren-Zellen die zusätzlich ein SV40 T-Antigen exprimieren) Zellen verwendet.

\subsubsection{Transiente Transfektion}

Zur transienten Transfektion von Zellen wurde das Transfektionsreagenz Lipofectamin ${ }^{\mathrm{TM}} 2000$ (Invitrogen) verwendet. 24 Stunden vor der Transfektion wurden HeLa oder Hek293T Zellen in Gewebeschalen oder auf Lab-Tek ${ }^{\mathrm{TM}} \mathrm{II}-\mathrm{CC} 2^{\mathrm{TM}}$ Objektträgern (Nunc) so ausplattiert, dass am Tage der Transfektion eine 90\%ige Konfluenz vorlag. Die Kultivierung der Zellen erfolgte bei $37{ }^{\circ} \mathrm{C}$ in luftgesättigter Atmosphäre und $5 \% \mathrm{CO}_{2}$ in DMEM-Medium mit 4mM L-Glutamin, 4, 5\% Glukose (Invitrogen) und $10 \%$ inaktiviertem FCS. Die Plasmid-DNA wurde in serumfreien OPTI“ MEM ${ }^{\circledR} \mathrm{I}$ (Invitrogen) verdünnt (24 $\mu \mathrm{g}$ in 1,5 ml für eine 100-mm Kulturschale, $2 \mu \mathrm{g}$ in $100 \mu \mathrm{l}$ für eine Objektträger-Kammer). Die verwendete Plasmid-DNA wurde zuvor einer Ethanolpräzipitation unterzogen. Der Einsatz von Lipofectamin ${ }^{\mathrm{TM}} 2000$ und die Transfektion erfolgte nach Angaben des Herstellers. Die Zellen wurden bei $37{ }^{\circ} \mathrm{C}$ wie oben beschrieben kultiviert. 


\subsubsection{Indirekte Immunfluoreszenz auf Zellen (ICC)}

Um Nachzuweisen ob die Methode der Transfektion erfolgreich war und um Nachzuweisen ob die Proteine in der Zelle co-lokalisiert sind wurde eine indirekte Immunfluoreszenz auf Zellen durchgeführt. Hierzu wurden die Zellen zunächst wie oben Beschrieben unter Verwendung von Lab-Tek ${ }^{\mathrm{TM}} \mathrm{II}-\mathrm{CC} 2^{\mathrm{TM}}$ Objektträgern (Nunc) transfiziert. Nach 16 Stunden Inkubationszeit wurde das Medium gewechselt und die Kultivierung schließlich nach 24 Stunden gestoppt. Das Medium wurde vorsichtig entfernt und die Zellen 2 mal in 1x PBS gewaschen. Anschließend wurden die Zellen mit 3,74\% Formamid (in 1x PBS) für 20 Minuten fixiert, ehe sie erneut in 1x PBS gewaschen wurden (3x 5 Minuten). Um die Zellen zu Permeabilisieren wurden sie zunächst 5 Minuten in 1x PBS mit 0,5\% Triton X-100 und anschließend in 1x PBS mit 0,1\% Tween-20 (2x 5 Minuten) inkubiert. Um unspezifische Bindungsstellen abzusättigen wurden die Zellen 70 Minuten in Blocklösung (10 \% FCS in 1x PBS) inkubiert. Im Folgenden wurde der primäre Antikörper appliziert und die Zellen über Nacht bei $4{ }^{\circ} \mathrm{C}$ unter leichtem Schütteln aufbewahrt. Am nächsten Tag erfolgte dreimaliges Waschen in PBT $(0,1 \%$ Tween-20 in 1x PBS) ehe der sekundäre Antikörper appliziert wurde. Die Inkubation des sekundären Antikörpers erfolgte 45 Minuten bei RT in vollkommener Dunkelheit. Zum Entfernen des sekundären Antikörpers wurden die Zellen erneut in PBT (3x 7 Minuten) im Dunkeln gewaschen ehe sie in Vectashield ${ }^{\circledR}$ mit DAPI (Vector laboratories) eingedeckelt und mit Nagellack versiegelt wurden. Aufnahmen wurden mit dem BX-60 Fluoreszenzmikroskop (Olympus) und der Cell^P Software (Olympus) gemacht.

\subsection{Proteinbiochemische Methoden}

\subsubsection{Herstellung von Gesamtproteinextrakt aus Gewebe}

Zur Herstellung von Gesamtproteinextrakt aus Gewebe wurden Gehirne von Embryonen des Stadiums E17.5 in $1 \mathrm{ml}$ Homogenisierungspuffer $(320 \mathrm{mM}$ Sucrose, $5 \mathrm{mM}$ Hepes-NaOH pH 7,4, 5 mM EDTA) mit einem Gewebe-Lysierer (Tissue Lyser LT, Quiagen) homogenisiert. $\mathrm{Zu}$ dem Homogenisierungspuffer wurden kurz vor Gebrauch Proteaseinhibitoren zugesetzt (eine Tablette Complete Protease Inhibitor Cocktail, EDTA frei (Roche) pro $10 \mathrm{ml}$ Puffer). Die Homogenisierung erfolgte für 3 Minuten mit 50 Oszillation bei $4{ }^{\circ} \mathrm{C}$. Wenn es nicht sofort weiter verwendet wurde, wurde das Gesamtproteinextrakt bei $-80{ }^{\circ} \mathrm{C}$ gelagert. 


\subsubsection{Herstellung von Gesamtproteinextrakt aus Zellen}

Für die Herstellung von Gesamtproteinextrakt aus Zellen wurde zunächst das Medium verworfen und die Zellen in einem ml Lyse-Puffer (20 mM Tris-HCl pH 7,4, $1 \mathrm{M} \mathrm{NaCl}, 1 \mathrm{mM}$ DTT, $1,0 \%$ Triton- $\left.X^{\circledR}-100\right)$ für 30 Minuten bei $4{ }^{\circ} \mathrm{C}$ unter leichtem Schütteln lysiert. Nach der Inkubation wurden die Zellen mit Hilfe eines Zellschabers von der Kulturschale gelöst und das Zell-Lysat in ein 1,5 ml Reaktionsgefäß überführt. Es folgte eine Zentrifugation bei $12.000 \mathrm{rpm}$ für 10 Minuten bei $4{ }^{\circ} \mathrm{C}$. Das Zell-Lysat wurde sofort für die Co-Immunopräzipitation weiter verwendet.

\subsubsection{Konzentrationsbestimmung von Proteinen}

Zur Konzentrationsbestimmung von Proteinen wurde ein BCA-Kit (BCA Protein Assay Reagenz, Thermo Scientific) entsprechend den Angaben des Herstellers verwendet. Zur Bestimmung der Proteinkonzentration wurde zunächst eine Eichreihe erstellt, ehe $10 \mu \mathrm{l}$ der Probe mit $200 \mu 1$ BCA-Reagenz versetzt und die die Absorption bei $562 \mathrm{~nm}$ gemessen wurde. Für die Eichreihe wurden Messungen mit 0, 1, 2, 3, 4, 6, 8 und $10 \mu$ BSA eingesetzt. Die Proteinkonzentration der Probe konnte dann mit Hilfe der erstellten Eichreihe abgelesen werden.

\subsubsection{Co-Immunopräzipitation}

Zur Studie von Protein-Protein Interaktionen wurde eine Methode der Co-Immunopräzipitation angewandt. Hierzu wurden HeLa oder Hek293T Zellen wie in Kapitel 4.5.1 beschrieben kultiviert und transfiziert. Um eine frühzeitige Degenerierung der Proteine zu verhindern, wurde 16 Stunden nach der Transfektion, der Proteasomeninhibitors MG132 (Sigma) in einer Endkonzentration von $10 \mu \mathrm{l}$ zugegeben. Nach weiterer Kultivierung der Zellen für 8 Stunden wurden die Zellen wie in Kapitel ??sec: Zell-lysat) beschrieben lysiert, ehe eine Co-Immunopräzipitation mittels FLAG ${ }^{\circledR}$ Tagged Protein Immunoprecipitation Kit (Sigma) entsprechend den Angaben des Herstellers durchgeführt wurde. Die Dauer der einzelnen Waschschritte betrug 15 Minuten und es wurden $950 \mu$ l Zell-Lysat über Nacht bei $4{ }^{\circ} \mathrm{C}$ inkubiert. Der optionale Waschschritt wurde ebenfalls mit eingeschlossen. Die Elution wurde mit dem Kit beiliegenden 2x SDS Probenpuffer durchgeführt. 


\subsubsection{SDS-Polyacrylamidgelelektrophorese (SDS-PAGE)}

Zur Auftrennung der Proteine nach ihrem Molekulargewicht wurde eine SDS-Polyacrylamidgel-elektrophorese (SDS-PAGE) durchgeführt. Um eine gute Trennung der Proteinmoleküle zu erreichen, wurden die Proben zunächst in einem weitporigen Sammelgel gesammelt ehe sie in einem engporigen Trenngel aufgetrennt werden. Für die Herstellung der Gele wurde zunächst das Trenngel (Zusammensetzung siehe Tab. 25) gegossen und mit Isopropanol überschichtet, was eine Polymerisation unter Luftausschluss gewährleistet. Anschließend wurde das Isopropanol entfernt und das Sammelgel darauf gegossen (Zusammensetzung siehe Tab. 25). Das Gel wurde mittels einer Hamilton-Spritze geladen und bei $25 \mathrm{~mA}$, in einer mit 1x Laufpuffer (0,125 M Tris, 0,96 M Glycin und 0,1\% SDS in $\mathrm{dH}_{2} \mathrm{O}$ ) gefüllten Gelkammer, laufen gelassen, bis der verwendete Proteinmarker gut aufgetrennt war. Als Proteinmarker wurde der Precision Plus Protein ${ }^{\text {TM }}$ All Blue Marker von Biorad verwendet.

\begin{tabular}{|l|l|l|l|}
\hline Reagenz & Menge für ein 12\%iges Trenngel & Menge für ein 15\%iges Trenngel & Menge für das Sammelgel \\
\hline \hline & & & \\
$30 \%$ Acrylamid-Bisacrylamid (Roth) & $12 \mathrm{ml}$ & $30 \mathrm{ml}$ & $4 \mathrm{ml}$ \\
$4 \mathrm{x}$ Trenngelpuffer & $7,5 \mathrm{ml}$ & $7,5 \mathrm{ml}$ & - \\
$4 \mathrm{x}$ Sammelgelpuffer & - & - & $6 \mathrm{ml}$ \\
$\mathrm{d} \mathrm{H}_{2} \mathrm{O}$ & $10,5 \mathrm{ml} \mathrm{ml}$ & $14 \mathrm{ml}$ \\
$10 \%$ APS & $100 \mu \mathrm{l}$ & $100 \mu \mathrm{l}$ & $160 \mu \mathrm{l}$ \\
TEMED & $100 \mu \mathrm{l}$ & $100 \mu \mathrm{l}$ & $16 \mu \mathrm{l}$ \\
\hline
\end{tabular}

Tab. 25: Zusammensetzung der Trenn- und Sammelgele für die SDS-PAGE Der 4x Trenngelpuffer besteht aus 1,5 M Tris und 0,4 \% SDS in $\mathrm{dH}_{2} \mathrm{O}$ mit pH 8,8, während der 4x Sammelgelpuffer aus 0,5 M Tris und 0,4 \% SDS in $\mathrm{dH}_{2} \mathrm{O}$ besteht und einen $\mathrm{pH}-$ Wert von 6,8 aufweist.

\subsubsection{Western Blotting}

Für eine Western Blot Analyse wurden die Proteine, die in einem SDS-Gel getrennt wurden zunächst mittels eines Transfers auf eine PVDF-Membran (Immobilon-P Transfer Membran, Millipore) übertragen. Dazu wurde das Gel auf ein Whatman-Papier gelegt, auf das Gel wurde eine aktivierte PVDF-Membran und darauf ein weiteres Whatman-Papier gelegt. Anschließend wurde es in eine Blotkammer (BioRad) eingespannt. Der Transfer erfolgte über Nacht bei $4{ }^{\circ} \mathrm{C}$ und 15 Volt. Bevor die PVDF-Membran verwendet werden konnte, wurde sie 30 Sekunden in Methanol aktiviert, in Wasser gewaschen und anschließend 15 Minuten in 1x Transferpuffer inkubiert. Das Whatman-Papier wurde vor Verwendung ebenfalls 15 Minuten in 1x Transferpuffer inkubiert. Am nächsten Tag wurde der Transfer für 3 Stunden auf $30 \mathrm{~V}$ hoch gestellt ehe die Membran entfernt und zur Absättigung unspezifischer Bindestellen für 90 Minuten 
in Blocklösung (5 \% Milchpulver, $1 \%$ Tween-20 in 1x PBS) überführt wurde. Anschließend wurde die Membran mit dem ersten Antikörper (Verdünnt in Blocklösung, siehe Tab. 18) über Nacht bei $4{ }^{\circ} \mathrm{C}$ inkubiert. Am folgenden Tag wurde die Membran 3x 20 Minuten in 1x PBT (1 \% Tween-20 in 1x PBS) gewaschen und der mit HRP (Meerettichperoxidase) gekoppelte sekundäre Antikörper appliziert (Tab. 18). Die Einwirkzeit betrug 90 Minuten. Nach erneutem Waschen in 1x PBT (3x 20 Minuten) erfolgte die Detektion mittels Chemilumineszenz. Hierzu wurde das SuperSignal ${ }^{\circledR}$ West Pico Chemilumineszent Substrate und das SuperSignal ${ }^{\circledR}$ West Femto Maximum Sensitivity Substrate Kit (beides Thermo Scientific) nach Angaben des Herstellers verwendet. Für die Entwicklung wurden BioMax MR Röntgenfilme (Kodak) und eine Curix 60 Entwicklermaschine (Agfa) verwendet. 


\section{Literatur}

Acampora, D., Mazan, S., Lallemand, Y., Avantaggiato, V., Maury, M., Simeone, A., \& Brulet, P. (1995). Forebrain and midbrain regions are deleted in Otx2-/- mutants due to a defective anterior neuroectoderm specification during gastrulation. Development, 115, 3279-3290.

Agarwala, S. \& Ragsdale, C. W. (2002). A role for midbrain arcs in nucleogenesis. Development, 129, 5779-5788.

Akiyama, T. (2000). Wnt/beta-catenin signaling. Cytokine Growth Factor Rev., 11, 273-282.

Alonso, M., Gomez, F., Munoz, E., Abad, M., Roldan, M., Curiel, I., Paz, J., Bullon, A., \& Lopez-Bravo, A. (1992). Comparative study of in situ hybridization and immunohistochemical techniques for the detection of human papillomavirus in lesions of the uterine cervix. Eur J Histochem, 36, 271-278.

Anderson, L. \& Seilhamer, J. (1997). A comparison of selected mrna and protein abundances in human liver. Electrophoresis, 18, 533-537.

Anderson, S., Eisenstat, D., Shi, L., \& Rubenstein, J. (1997). Interneuron migrationc from basal forebrain to neocortex: dependence on dlx genes. Science, 128, 474-476.

Andersson, E., Jensen, J., Parmar, M., Guillemont, F., \& Björklund, A. (2006a). Development of the mesencephalic dopaminergic neuron system is compromised in the absence of neurogenin2. Development, 133, 507-516.

Andersson, E., Tryggvason, U., Deng, Q., Friling, S., Alekseenko, Z., Robert, B., Perlmann, T., \& Ericson, J. (2006b). Identification of intrinsic determinants of midbrain dopamine neurons. Cell, 124, 393-405.

Ang, S.-L. (2006). Transcriptional control of midrbain dopaminergic neuron development. Development, 133, 3499-3506.

Arvidsson, U., Riedl, M., Elde, R., \& Meister, B. (1997). Vesicular acetylcholine transporter (vacht) protein: A novel and unique marker for cholinergic neurons in the central peripheral nervous systems. The Journal of Comparative Neurology, 378, 454-467. 
Asbruek, C. H. J., van Doorinck, J. H., Mansouri, A., Smidt, M. P., \& Burbach, J. P. H. (2006). Neurophysial dysmorphogenesis in mice lacking the homeobox gene uncx4.1. Journal of Molecular Endocrinology, 36, 65-71.

Azmitia, E. C. \& Whitaker-Azmitia, P. M. (2008). Anatomy. cell biology and maturation of the serotonergic System:. American Collage of Neuropsychopharmacology, Online publication:, www.acnp.org/g4/GN401000042/Ch042.html.

Baimbridge, G. K., Cello, M. R., \& Rogers, J. H. (1992). Caldum-bin@ng proteins in the nervous system. Trends in Neuroscience, 15, 303-308.

Bally-Cuif, L., Alvarado-Mallart, R., Darnell, D., \& Wassef, M. (1992). Relationship between wnt- 1 and en-2 expression domains during early development of normal and ectopic metmesencephalon. Development, 115, 999-1009.

Bally-Cuif, L. \& Wassef, M. (1994). Ectopic induction and reorganization of wnt-1 expression in quail/chick chimeras. Development, 120, 3379-3394.

Behan, M., Jourdain, A., \& Bray, G. (1992). Calcium binding protein (calbindin d28k) immunoreactivity in the hamster superior colliculus: ultrastructure and lack of co-localization with gaba. Exp Brain Res., 89, 115-124.

Bennett, M. R. \& Balcar, V. J. (1999). Forty years of amino acid transmission in the brain. Neurochemistry international, 35, 269-280.

Björklund, A. \& Dunnett, S. B. (2007). Dopamine neuron systems in the brain: an update. Trends in Neurosciences, 30, 194-202.

Blaess, S., Corrales, J. D., \& Joyner, A. L. (2006). Sonic hedgehog regulates gli activator and repressor functions with spatial and temporal precision in the mid/hindbrain region. Development, 133, 1799-1809.

Bonilla, S., Hall, A. C., Pinto, L., Attardo, A., Götz, M., Huttner, W. B., \& Arenas, E. (2008). Identification of midbrain floor plate radial glia-like cells as dopaminergic progenitors. Glia, $56,809-820$.

Briscoe, J. \& Ericson, J. (1999). The specification of neuronal identity by graded sonic hedgehog signalling. Seminars in Cell and Developmental Biology, 10, 353-362. 
Briscoe, J., Pierani, A., Jessell, T., , \& Ericson, J. (2000). A homeodomain protein code specifies progenitor cell identity and neuronal fate in the ventral neural tube. Cell, 101, 435-445.

Briscoe, J., Sussel, L., Serup, P., Hartigan-O’Connor, D., Jessell, T., \& Rubenstein, J.L.and Ericson, J. (1999). Homeobox gene nkx2.2 and specification of neuronal identity by graded sonic hedgehog signalling. Nature, 398, 622-627.

Broccoli, V., Boncinelli, E., \& Wurst, W. (1999). The caudal limit of otx2 expression positions the isthmic organizer. Nature, 401, 164-168.

Brodski, C., Weisenhorn, D. M., Signore, M., Sillaber, I., Oesterheld, M., Broccoli, V., Acampora, D., Simeone, A., \& Wurst, W. (2003). Location and size of dopaminergic and serotonergic cell populations are controlled by the position of the midbrain-hindbrain organizer. Journal of Neuroscience, 23, 4199-4207.

Brose, N., Hofmann, K., Hata, Y., \& Südhof, T. C. (1995). Mammalian homologous of Caenorhabditis elegans unc-13 gene define novel family of $\mathrm{c}_{2}$-domain proteins. The Journal of Biological Chemistry, 270, 25273-25280.

Cagniard, B., Balsam, P. D., Brunner, D., \& Xiaoxi, Z. (2006). Mice with chronically elevated dopamine exhibit enhanced motivation, but not learning, for a food reward. Neuron, 51, $1362-1370$.

Camilli, P. D., Cameron, R., \& Greengard, P. (1983). Synapsin 1 (protein 1), a nerve terminalspecific phosphoprotein 1. its general distribution in synapses of the central and peripheral nervous system demonstrated by immunofluorescence in frozen and plastic sections. Journal of Cell Biology, 96, 1337-1354.

Casarosa, S., Fode, C., \& Guillemot, F. (1999). Mash1 regulates neurogenesis in the ventral telencephalon. Development, 126, 525-534.

Chebat, D.-R., Boire, D., \& Ptito, M. (2006). Development of the commissure of the superior colliculus in the hamster. The Journal of Comparative Neurology, 494, 887-902.

Cheng, L., Arata, A., Mizuguchi, R., Qian, Y., Karunaratne, A., Gray, P.A. Arata, S., Shirasawa, S., Bouchard, M., Luo, P., Chen, C., Busslinger, M. Goulding, M., Onimaru, H., \& Ma, Q. (2004). Tlx3 and tlx1 are post-mitotic selector genes determining glutamatergic over gabaergic cell fates. Nature Neuroscience, 7, 510-517. 
Cheng, L., Samad, O. A., Xu, Y., Mizuguchi, R., Luo, P., Shirasawa, S., Goulding, M., \& Ma, Q. (2005). Lbx 1 and tlx3 are opposing switches in determining gabaergic versus glutamatergic transmitter phenotypes. Nature Neuroscience, 8, 1510-1515.

Chi, C. L., Martinez, S., Wurst, W., \& Martin, G. R. (2003). The isthmic organizer signal fgf8 is required for cell survival in the prospective midbrain and cerebellum. Development, 130, 2633-2644.

Chiang, C., Ying, L. T. T., Lee, E., Young, K. E., Corden, J. L., Westphal, H., \& Beachy, P. A. (1996). Cyclopia and defective axial patterning in mice lacking sonic hedgehog gene function. Nature, 381, 407-413.

Chilov, D., Sinjushina, N., Saarimäki-Vire, J., Taketo, M., \& Partanen, J. (2010). beta-catenin regulates intercellular signalling networks and cell-type specific transcription in the developing mouse midbrain-rhombomere 1 region. PLoS One, 5, e10881.

Chin, L.-H., Li, L., Ferreira, A., Kosik, K., \& Greengard, P. (1995). Impairment of axonal development and of synaptogenesis in hippocampal neurons of synapsin i-deficient mice. Proc. Natl. Acad. Sci. USA, 92, 9239-9234.

Chizhikov, V. V. \& Millen, K. J. (2005). Roof plate-dependent patterning of the vertebrate dorsal central nervous system. Developmental Biology, 277, 287-295.

Chung, S., Leung, A., Baek-Soo Han, B.-S., Chang, M.-Y., Moon, J.-I. Chun-Hyung Kim, C.H., Hong, S., Pruszak, J., Isacson, O., \& Kim, K.-S. G. (2009). Wnt1-lmx1a forms a novel autoregulatory loop and controls midbrain dopaminergic differentiation synergistically with the shh-foxa2 pathway. Cell -Stem Cell, 5, 646-658.

Corbin, J., Gaiano, N., Machold, R., Langston, A., , \& Fishell, G. (2000). The gsh2 homeodomain gene controls multiple aspects of telencephalic development. Development, 127, 45007-5020.

Cortázar, D., Kunz, C., Selfridge, J., Lettieri, T., Saito, Y., MacDougall, E., Wirz, A., Schuermann, D., Jacobs, A. L., Siegrist, F., Steinacher, R., Jiricny, J., Bird, A., \& Schär, P. (2011). Embryonic lethal phenotype reveals a function of tdg in maintaining epigenetic stability. $\mathrm{Na}$ ture, 470, 419-432. 
Craven, S. E., Lim, K.-C., Ye, W., Engel, J. D., de Sauvage, F., \& Rosenthal, A. (2004). Gata2 specifies serotonergic neurons downstream of sonic hedgehog. Development, 131, 11651173.

Crossley, P. H., Martinez, S., \& Martin, G. R. (1996). Midbrain development induced by fgf8 in the chick embryo. Nature, 380, 66-68.

Danielian, P. S., Muccino, D., Rowitch, D. H., Michael, S. K., \& McMahon, A. P. (1998). Modification of gene activity in mouse embryos in utero by a tamoxifen-inducible form of cre recombinase. Current Biology, 8, 1323-1326.

Deschamps, J. (2007). Ancestral and recentzly reruited global control of the Hox genes in development. Current Opinion in Genetics \& Development, 17, 422-427.

Ding, Y.-Q., Marklund, U., Yuan, W., Yin, J., Wegman, L., Ericson, J., Deneris, E., Johnson, R. L., \& Chen, Z. (2003). Lmxlb is essential for the development of serotonergic neurons. Nature Neuroscience, 398, 933-938.

Echelard, Y., Epstein, D. J., Stjacques, B., Shen, L.and Mohler, J., McMahon, J. A., \& McMahon, A. P. (1993). Sonic-hedgehog, a member of a family of putative signaling molecules, is implicated in the regulation of cns polarity. Cell, 75, 1417-1430.

Elsworth, J. D. \& Roth, R. H. (1997). Dopamine synthesis, uptake, metabolism, and receptors: Relevance to gene therapy of Parkinson's disease. Experimental Neurology, 144, 4-9.

Eng, S., Gratwick, K., Rhee, J., Fedtsova, N., Gan, L., \& Turner, E. (2001). Defects in sensory axon growth precede neuronal death in brn3a-deficient mice. J Neurosci, 21, 541-549.

Erlander, M. G., Tillakaratne, N., Feldblum, S., Patel, N., \& Tobin, A. J. (1991). Two genes encode distinct glutamate decarboxylases. Neuron, 7, 91-100.

Fahn, S. (2003). Description of parkinson's disease as a clinical syndrome. Annals of the New York Academy of Science, 991, 1-14.

Ferreira, A. \& Caceres, A. (1992). The expression of the class iii beta-tubulin isotype in developing neurons in culture. J Neurosci. Res, 32, 516-529.

Ferreira, A., Chin, L.-S., Li, L., Lanier, L. M., Kosik, K. S., \& Greengard, P. (1998). Distinct roles of synapsin i and synapsin ii during neuronal development. Molecular Medicine, 4, $22-28$. 
Ferri, A. L., Lin, W., Mavromatakis, Y. E., Wang, J. C., Sasaki, H., Whitsett, J. A., \& Ang, S. L. (2007). Foxa1 and foxa2 regulate multiple phases of midbrain dopaminergic neuron development in a dosage-dependent manner. Development, 134, 2761-9.

Finlay, B. L. \& Darlington, R. B. (1995). Linked regularities in the development and evolution of mammalian brains. Sience, 268, 1578-1584.

Fode, C., Gradwohl, G., Morin, X., Dierich, A., LeMeur, M., Goridis, C., \& Guillemont, F. (1998). The bhlh protein neurogenin2 is a determination factor for epibranchial placodederived sensory neurons. Neuron, 20, 483-494.

Fode, C., Ma, Q., Casarosa, S., Ang, S.-L., Anderson, D. J., \& Guillemont, F. (2000). A role for neuronal determination genes in specifying the dorsoventral identety of telencephalic neurons. Genes and Development, 14, 1164-1169.

Fogel, J. L., Chiang, C., Huang, X., \& Agarwala, S. (2008). Ventral specification and perturbed boundary formation in the mouse midbrain in the absence of hedgehog signaling. Developmental Dynamics, 237, 1359-1372.

Gale, E. \& Li, M. (2008). Midbrain dopaminergic neuron fate specification: Of mice and embryonic stem cells. Molecular brain, 1,8 .

Garcia-Fernàndez, J. (2005). The genesis and evolution of homeobox gene clusters. Nature Reviews Genetics, 6, 881-894.

Gaspar, P., Cases, O., \& Maroteaux, L. (2003). The developmental role of serotonin: news from mouse molecular genetics. Nat Rev Neurosci, 4, 1002-1012.

Gavrieli, Y., Sherman, Y., \& Ben-Sasson, S. (1992). Identification of programmed cell death in situ via specific labeling of nuclear dna fragmentation. J Cell Biol, 119, 493-501.

Gellon, G. \& McGinns, W. (1998). Shaping animal body plans in development and evolution by modulation of hox expression patterns. BioEssays, 20, 116-125.

Gilbert, S. F. (2006). Developmental Biology. Sinauer Associates, Inc.

Gonzalez-Soriano, J. Gonzalez-Flores, M., Conteras-Rodrigues, J., Rodriguez-Veiga, E., \& Martinez-Sainz, P. (2000). Calbindin d28k and parvalbumin immunoreactivity in the rabbit superior colliculus: An anatomical study. The Anatomical Record, 259, 334-346. 
Greengard, P., Valtorta, F., Czernik, A. J., \& Benfenati, F. (1993). Synaptic vesicle phosphoproteins and regulation of synaptic function. Sience, 259, 780-785.

Griesel, G., Krug, C., Yurlova, L., Diaconu, M., \& Mansouri, A. (2011). Generation of knockout mice expressing a gfp-reporter under the control of the $1 m x 1$ la locus. Gene Expr. Patterns, Epub ahead of print, Epub ahead of print.

Griesel, G., Treichel, D., Collombat, P., Krull, J., Zembrzycki, A., van den Akker, W. M., Gruss, P., Simeone, A., \& Mansouri, A. (2006). Sp8 controls the anteroposterior patterning at the midbrain-hindbrain border. Development, 133, 1779-187.

Gruber, P. \& Gould, D. J. (2010). The red nucleus: Past, present, and future. Neuroanatomy, 9, $1-3$.

Guo, C., Qiu, H. Y., Huang, Y., Chen, H., Yang, R. Q., Chen, S. D., Johnson, R. L., Chen, Z. F., \& Ding, Y. Q. (2007). Lmx1b is essential for fgf8 and wnt1 expression in the isthmic organizer during tectum and cerebellum development in mice. Development, 134, 317-325.

Gygi, S., Rochon, Y., Franza, B., \& Aebersold, R. (1999). Correlation between protein and mrna abundance in yeast. Mol. Cell Biol., 19, 1720-1730.

H. Nakamura, K. M., Takagi, S., \& Fujisawa, H. (1991). Projection of the retinal ganglion cells to the tectum differentiated from the prosencephalon. Neurosci. Res., 11, 189-197.

Hayashi, S. \& McMahon, A. (2002). Efficient recombination in diverse tissues by a tamoxifeninducible form of cre: a tool for temporally regulated gene activation/inactivation in the mouse. Dev. Bio, 244, 305-318.

Hendricks, T., Fyodorov, D., Wegman, L., Lelutiu, N., Pehek, E., Yamamoto, B., Silver, J., Weeber, E., Sweatt, J., \& Deneris, E. (2003). pet-1 ets gene plays a critical role in 5-ht neuron development and is required for normal anxiety-like and aggressive behaviour. Neuron, 37, 233-247.

Hwang, D. Y., Hong, S., Jeong, J. W., Choi, S., Kim, H., Kim, J., \& Kim, K. S. (2009). Vesicular monoamine transporter 2 and dopamine transporter are molecular targets of pitx 3 in the ventral midbrain dopamine neurons. Journal of Neurochemistry, 111, 1202-1212. 
Iacopino, A. M., Rhoten, W. B., \& Christakos, S. (1990). Calcium binding protein (calbindind28k) gene expression in the developing and aging mouse cerebellum. Molecular Brain Research, 8, 283-290.

Ishikawa, K., Mizusawa, H., Fujita, T., Ohkoshi, N., Doi, M., Komatsuzaki, Y., Iwamoto, H., Ogata, T., \& Shoji, S. (1995). Calbindin-d 28k immunoreactivity in the cerebellum of spinocerebellar degeneration. Journal of Neurological Sciences, 129, 179-185.

Jacobs, F. M. J., van Erp, S., van der Linden, A. J. A., von Oerthel, L., Burbach, J. P. H., \& Smidt, M. P. (2009). Pitx3 potentiates nurr1 in dopamine neuron terminal differentiation through release of smrt-mediated repression. Development, 136, 531-540.

Jafari, G., Appleford, P. J., Seago, J., Pocock, R., \& Woollard, A. (2011). The unc-4 homeobox protein represses mab-9 expression in da motor neurons in caenorhabditis elegans. Mechanisms of Development, 128, 49-58.

Joksimovic, M., Anderegg, A., Roy, A., Campochiaro, L., Yun, B., Kittappa, R., McKay, R., \& Awatramani, R. (2009a). Spatiotemporally separable shh domains in the midbrain define distinct dopaminergic progenitor pools. PNAS, 106, 19185-19190.

Joksimovic, M., Yun, B. A., Kittappa, R., Anderegg, A. M., Wchang, W., Taketo, M. M., McKay, R. D. G., \& Awatramani, R. B. (2009b). Wnt antagonism of shh facilitates midbrain floor plate neurogenesis. Nature Neuroscience, 12, 125-131.

Joseph C. Pearson, D. L. \& McGinnis, W. (2005). Modulating hox gene functions during animal body patterning. Nature Reviews Genetics, 6, 893-904.

Joyner, A. L., Liu, A., \& Millet, A. (2000). Otx2, gbx2 and fgf8 interact to position and maintain a mid-hindbrain organizer. Current Opinion in Cell Biology, 12, 736-741.

Kadkhodaei, B., Ito, T., Joodmardi, E., Mattsson, B., Rouillard, C., Carta, M., Muramatsu, S.I., Sumi-Ichinose, C., Nomura, T., Metzger, D., Chambon, P., Lindqvist, E., Larsson, N.G., Olson, L., Björklund, A., Ichinose, H., \& Perlmann, T. (2009). Nurr1 is required for maintenance of maturing and adult midbrain dopamine neurons. Journal of Neuroscience, 29, 15923-15932.

Kala, K., Haugas, M., Lilleväli, K., Guimera, J., Wurst, W., Salminen, M., \& Partanen, J. (2009). Gata2 is a tissue-specific post-mitotic selector gene for midbrain gabaergic neurons. Development, 136, 253-262. 
Kania, A., Johnson, R. L., \& Jessel, T. M. (2000). Coordinate roles for lim homeobox genes in directing the dorsoventral trajectory of motor axons in the vertebrate limb. Cell, 102, $161-173$.

Kawano, H., Ohyamaa, K., Kawamuraa, K., \& Nagatsu, I. (1995). Migration of dopaminergic neurons in the embryonic mesencephalon of mice. Development in brain research, 86, 101113.

Kele, J., Simplicio, N., Ferri, A. L., Mira, H., Guillemont, F., Arenas, E., \& Ang, S.-L. (2006). Neurogenin 2 is required for the development of ventral midbrain dopaminergic neurons. $D e-$ velopment, 133, 495-505.

Kelley, A. E. \& Berridge, K. C. (2002). The neurosience of natural rewards: relevance to addictive drugs. Journal of Neuroscience, 22, 3306-3311.

Kikuta, H., Kanai, M., Ito, Y., \& Yamasu, K. (2003). gbx2 homeobox gene is required for the maintenance of the isthmic region in the zebrafish embryonic brain. Developmental Dynamics, 228, 433-450.

Kittapa, R., Chang, W. W., Awatramani, R., \& McKay, D. (2007). The foxa2 gene controls the birth and spontaneous degeneration of dopamine neurons in old age. PLoS Biol, 5, e325.

Korotkova, T. M., Ponomarenko, A., Brown, R., \& Haas, H. (2004). Functional diversity of ventral midbrain dopamine and gabaergic neurons. Molecular Neurobiology, 29, 243-259.

Kroll, T. T. \& O’Leary, D. (2005). Ventralized dorsal telencephalic progenitors in pax6 mutant mice generate gaba interneurons of a lateral ganglionic eminence fate. PNAS, 102, 73747379.

Lanea, R. D., Allana, D. M., Bennett-Clarkea, C. A., Howella, D. L., \& Rhoadesa, R. W. (1997). Projection status of calbindin- and parvalbumin-immunoreactive neurons in the superficial layers of the rat's superior colliculus. Visual Neuroscience, 14, 277-286.

Lang, A. E. \& Lozano, A. M. (1998a). Parkinson's disease - first of two parts. The New England Journal of Medicine, 339, 1044-1053.

Lang, A. E. \& Lozano, A. M. (1998b). Parkinson's disease - second of two parts. The New England Journal of Medicine, 339, 1130-1143. 
Lee, J., Choi, Y., Choi, H., \& Myung, K. (2003). Tnfalpha expression in the paraffin-embedded tissues of leprosy. Korean J. Dermatol, 38, 363-371.

Lee, K. J. \& Jessell, T. M. (1999). The specification of dorsal cell fates in the vertebrate central nervous system. Annual Reviews Neuroscience, 22, 261-294.

Leitges, M., Neidhardt, L., Haenig, B., Hermann, B., \& Kispert, A. (2000). The paired homeobox gene uncx 4.1 specifies pedicles, transverse processes and proximal ribs of the vertebral column. Development, 127, 2259-2267.

Lendahl, U., Zimmerman, L., \& Mckay, R. (1990). Cns stem cells express a new class of intermediate filament protein. Cell, 60, 585-595.

Lewandoski, M. (2001). Conditional control of gene expression in the mouse. Nature Reviews Genetics, 2, 743-755.

Li, J. Y. H. \& Joyner, A. L. (2001). Otx2 and Gbx2 are required for refinement and not induction of mid-hindbrain gene expression. Development, 128, 4979-4991.

Li, S., Misra, K., Matise, M., , \& Xiang, M. (2005). Foxn4 acts synergistically with mash1 to specify subtype identity of v2 interneurons in the spinal cord. Proc. Natl. Acad. Sci. U. S. A., $102,10688-10693$.

Liang, C., Sinton, C., Sonsalla, P., \& German, D. (1996). Midbrain dopaminergic neurons in the mouse that contain calbindin-d28k exhibit reduced vulnerability to mptp-induced neurodegenerationt. Neurodegeneration, 282, 313-8.

Lichtinghagen, R., Musholt, P., Lein, M., Römer, A., Rudolph, B., Kristiansen, G., Hauptmann, S., Schnorr, D., Loening, S., \& Jung, K. (2002). Different mrna and protein expression of matrix metalloproteinases 2 and 9 and tissue inhibitor of metalloproteinases 1 in benign and malignant prostate tissue. Eur Urol, 42, 398-406.

Lickteig, K. M., Duerr, J. S., Frisby, D. L., Hall, D. H., Rand, J. B., \& Miller, D. M. (2001). Regulation of neurotransmitter vesicles by the homeodomain protein unc- 4 and its transcriptional corepressor unc-37/groucho in Caenorhabditis elegans cholinergic motor neurons. The journal of Neuroscience, 21, 2001-20014. 
Lin, W., Metzakopian, E., Mavromatakis, Y., Gao, N., Balaskas, N., Sasaki, H., Briscoe, J., Whitsett, J., Goulding, M., Kaestner, K., \& Ang, S. (2009). Foxa1 and foxa2 function both upstream of and cooperatively with $\operatorname{lm} x 1 \mathrm{a}$ and $\operatorname{lm} x 1 \mathrm{~b}$ in a feedforward loop promoting mesodiencephalic dopaminergic neuron development. Developmental Biology, 333, 386-396.

Liu, A. M., Losos, K., \& Joyner, A. L. (1999). Fgf8 can activate gbx2 and transform regions of the rostral mouse brain into a hindbrain. Nature, 126, 4827-4838.

Ma, Q., Fode, C., Guillemont, F., \& Anderson, D. (1999). Neurogenin1 and neurogenin2 cntrol two distinct waves of neurogenesis in devloping dorsal root ganglia. Genes and Development, $13,1717-1728$.

Manak, J. \& Scott, M. (1994). A class act: conservation of homeodomain functions. Development Supplement, (pp. 61-77).

Mansouri, A. (2001a). Knockout and Knock-in Animals. John Wiley \& Sons, Ltd: http://dx.doi.org/10.1038/npg.els.0003840.

Mansouri, A. (2001b). Mouse Knockouts: Modifying the Mouse Genome by using Embryonic Stem Cells. John Wiley \& Sons, Ltd: http://dx.doi.org/10.1002/9780470015902.a0002668.pub2.

Mansouri, A., Voss, A., Thomas, T., Yokota, Y., \& Gruss, P. (2000). Uncx4.1 is required for the formation of the pedicles and proximal ribs and acts upstream of pax9. Development, 127, $2251-2258$.

Mansouri, A., Yokota, Y., Wehr, R., Copeland, N. G., Jenkins, N. A., \& Gruss, P. (1997). Pairedrelated murine homeobox gene expressed in the developing sclerotome, kidney and nervous system. Developmental Dynamics, 210, 53-65.

Martinez, S., Crossley, P. H., Cobos, I., Rubenstein, J. L. R., \& Martin, G. R. (1999). Fgf8 induces formation of an ectopic isthmic organizer and isthmocerebellar development via a repressive effect on otx 2 expression. Development, 126, 1189-1200.

Martinez, S., Wassef, M., \& Alvarado-Mallart, R. M. (1991). Induction of a mesencephalic phenotype in the 2-day-old chick prosencephalon is preceded by the early expression of the homeobox gene en. Neuron, 6, 971-981. 
Matsunaga, E., Katahira, T., \& Nakamura, H. (2002). Role of $1 m x 1 b$ and wnt1 in mesencephalon and metencephalon development. Development, 129, 5269-5277.

Matsuo, I., Kuratani, S., Kimura, C., Takeda, N., \& Aizawa, S. (1995). Mouse otx2 functions in the formation and patterning of rostral head. Genes and Development, 9, 2646-2658.

Mavromatakis, Y. E., Lin, W., Metzakopian, E., Ferri, A. L. M., Yan, C. H., Sasaki, H., Whisett, J., \& Ang, S. (2011). Foxa1 and foxa2 positively and negatively regulate shh signalling to specify ventral midbrain progenitor identety. Mechanisms of Development, 128, 90-102.

Maxwell, S., Ho, H., Kuehner, E., Zhao, S., \& Li, M. (2005). Pitx3 regulates tyrosine hydroxylase expression in the substantia nigra and identifies a subgroup of mesencephalic dopaminergic progenitor neurons during mouse development. Dev Biol., 282, 467-79.

McMahon, A. P. \& Bradley, A. (1990). The wnt-1 (int-1) protooncogene is required for development of a large region of the mouse-brain. Cell, 62, 1073-1085.

McMahon, A. P., Joyner, A. L., Bradley, A., \& McMahon, J. A. (1992). The midbrain hindbrain phenotype of wnt-1-/-wnt-1- mice results from stepwise deletion of engrailed-expressing cells by 9.5 days postcoitum. Cell, $69,581-595$.

Meyers, N., E., Lewandoski, M., \& Martin, G. R. (1998). An fgf8 mutant allelic series generated by cre- and flp-mediated recombination. Nature Genetics, 18, 136-141.

Miller, D., Niemeyer, C., \& Chitkara, P. (1993). Dominant unc-37 mutations suppress the movement defect of a homeodomain mutation in unc-4, a neural specificity gene in caenorhabditis elegans. Genetics, 135, 741-753.

Miller, M., Shen, M., Shamu, C., Bürglin, T., Ruvkun, G., Dubois, M., Ghee, M., \& Wilson, L. (1992). C. elegans Unc-4 gene encodes a homeodomain protein that determines the pattern of synaptic input to specific motor neurons. Nature, 355, 841-845.

Miller, M. D. I. \& Niemeyer, C. (1995). Expression of the Unc-4 homeoprotein in Caenorhabditis elegans motor neurons specifies presynaptic input. Development, 121, 2877-2886.

Millonig, J. H., Millen, K. J., \& Hatten, M. E. (2000). The mouse dreher gene lmx 1a controls formation of the roof plate in the vertebrate cns. Nature, 403, 764-769. 
Miyoshi, G. \& Bessho, Y. (2004). Identification of a novel basic helix-loop-helix gene, heslike, and its role in gabaergic neurogenesis. J. Neurosci, 24, 3672-3682.

Moorman, A., Houwling, A., de Boer, P., \& Christoffels, V. (2001). Sensitive nonradioactive detection of mrna in tissue sections: novel application of the whole-mount in situ hybridization protocol. J Histochem Cytochem, 49, 1-8.

Mosimann, C., Hausmann, G., \& Basler, K. (2009). Beta-catenin hits chromatin: regulation of wnt target gene activation. Nat Rev Mol Cell Biol, 10, 276-286.

Mukhopadhyay, R., Ho, Y.-S., Swiatek, P. J., Rosen, B. P., \& Bhattacharjee, H. (2006). Targeted disruption of the mouse Asnal gene results in embryonic lethality. FEBS Letters, 580, 38893894.

Nakamura, H., Nakano, K., Igawa, H., Takagi, S., \& Fujisawa, H. (1986). Plasticity and rigidity of differentiation of brain vesicles studied in quail-chick chimeras. Cell Differentiation, 19, 187-193.

Nakatani, T., Kumaia, M., Mizuharaa, E., Minakia, Y., \& Ono, Y. (2010). Lmx1a and lmx1b cooperate with foxa2 to coordinate the specification of dopaminergic neurons and control of floor plate cell differentiation in the developing mesencephalon. Developmental Biology, $339,101-113$.

Nakatani, T., Minaki, Y., Kumai, M., \& Ono, Y. (2007). Helt dertermines gabaergic over glutamatergic neuronal fate by repressing ngn genes in the developing mesencephalon. Development, 134, 2783-2793.

Neher, E. \& Sakmann, B. (1976). Single-channel currents recorded from membrane of denervated frog muscle fibers. Nature, 260, 799-801.

Neidhardt, L. M., Kispert, A., \& Hermann, B. G. (1997). A mouse gene of the paired-related homeobox class expressed in the caudal somite compartment and in the developing vertebral column, kidney and nervous system. Dev Genes Evol, 207, 330-339.

Nemere, I., Leathers, V., B.S., T., Luben, R., \& Norman, A. (1991). Redistribution of calbindind28k in chick intestine in response to calcium transport. Endocrynology, 129, 2972-824. 
Nemoto, C., Hida, T., \& Arai, R. (1999). Calretinin and calbindin-d28k in dopaminergic neurons of the rat midbrain: a triple-labeling immunohistochemical study. Brain Res., 846, 3138.

Nieto, M., Schuurmans, C., Britz, O., , \& Guillemot, F. (2001). Neural bhlh genes control the neuronal versus glial fate decision in cortical progenitors. Neuron, 29, 244-249.

Nieuwkoop, P. D. (1991). The successive steps in the pattern-formation of the amphibian central-nervous-system. Development, Growth \& Differentiation, 33, 149-154.

Nunes, I., Tovmasian, L. T., Silva, M., Burke, R. E., \& Stephen P. Goff, S. (2003). Pitx3 is required for development of substantia nigra dopaminergic neurons. PNAS, 100, 4245-4250.

Ohyama, K., Kawano, H., Asou, H., Fukuda, T., Oohira, A., Uyemura, K., \& Kawamura, K. (1998). Coordinate expression of 11 and 6b4 proteoglycan/phosphacan is correlated with the migration of mesencephalic dopaminergic neurons in mice. Brain Res Dev Brain Res, 15, 219-226.

O’Leary, D. D. \& McLaughlina, T. (2005). Mechanisms of retinotopic map development: Ephs, ephrins, and spontaneous correlated retinal activity. Progress in Brain Research, 147, 43-65.

Ono, Y., Nakatani, T., Sakamoto, Y., Mizuhara, E., Minaki, Y., Kumai, M., Hamaguchi, A., Nishimura, M., Inoue, Y., Takahasi, J., \& imai, T. (2007). Differences in neurogenic potential in floor plate cells along an anteroposterior location: midbrain dopaminergic neurons originate from mesencephalic floor plate cells. Development, 134, 3213-3225.

Pan, G., Chang, Z., Schöler, H., \& Pei, D. (2002). Stem cell pluripotency and transcription factor oct4. Cell Research, 12, 321-329.

Panhuysen, M., Weisenhorn, D. M. V., Blanquet, V., Brodski, C., Heinzmann, U., Beisker, W., \& Wurst, W. (2004). Effects of wnt1 signaling on proliferation in the developing mid-/hindbrain region. Molecular and Cellular Neuroscience, 26, 101111.

Pannese, E. (1999). The golgi stain: Invention, diffusion and impact on neurosciences. Journal of the History of the Neurosciences, 8, 132-140.

Park, E., Sun, X., Nichol, P., Saijoh, Y., Martin, J., \& Moon, A. (2008). System for tamoxifeninducible expression of cre-recombinase from the foxa2 locus in mice. Dev. Dyn., 237, 447453. 
Parras, C. M., Schuurmans, C., Scardigli, R., Kim, J., Anderson, D. J., \& Guillemont, F. (2002). Divergent functions of the proneural genes mash1 and ngn2 in the specification of neuronal subtype identety. Genes and Development, 16, 324-338.

Peltopuro, P. \& Kala, K. (2010). Distinct requirements for ascl1 in subpopulations of midbrain gabaergic neurons. Dev Biol, 343, 63-70.

Pflugrad, A., Meir, J., Barnes, R., \& Miller, D. I. (1995). The Groucho-like transcription factor UNC-37 functions with the neural specifity gene Unc-4 to govern motor neuron identety in C. elegans. Development, 124, 1699-1709.

Pilati, N., Baker, M., Panteleimonitis, S., Donga, R., \& Hamann, M. (2008). A rapid method combining golgi and nissl dtaining to study neuronal morpgology and cytoarchitecture. Journal of Histochemistry and Cytochemistry, 56, 539-550.

Prakash, N., Brodski, C., Naserke, T., Puelles, E., Gogoi, R.and Hall, A., Panhuysen, M., Echevarria, D.and Sussel, L., Weisenhorn, D., Martinez, S.and Arenas, E., Simeone, A., \& Wurst, W. (2006). A wnt1-regulated genetic network controls the identity and fate of midbraindopaminergic progenitors in vivo. Development, 133, 89-98.

Prakash, N., Puelles, E., Freude, K., Trümbach, D., Omodei, D., Di Salvio, M., Sussel, L., Ericson, J., Sander, M., Simeone, A., \& Wurst, W. (2009). Nkx6-1 controls the identety and fate of red nucleus and oculomotor neurons in the mouse midbrain. Development, 136, 2549-2555.

Prakash, N. \& Wurst, W. (2004). Specification of midbrain territory. Cell Tissue Research, 318, $5-14$.

Prakash, N. \& Wurst, W. (2006). Development of dopaminergic neurons in the mammalian brain. Cellular and molecular life science, 63, 187-206.

Puelles, E. (2007). Genetic control of basal midbrain development. Journal of Neuroscience Research, 85, 3530-3534.

Puelles, E., Acampora, D., Gogoi, R., Tuorto, F., Papalia, A., Guillemot, F., Ang, S.-L., \& Simeone, A. (2006). Otx2 controls identity and fate of glutamatergic progenitors of the thalamus by repressing gabaergic differentiation. The Journal of Neuroscience, 26, 59555964. 
Reynolds, B. \& Weiss, S. (1992). Generation of neurons and astrocytes from isolated cells of the adult mammalian central nervous system. Science, 255, 1707-1710.

Rossant, J. \& Tam, P. P. L. (2009). Blastocyst lineage formation, early embryonic asymmetries and axis patterning in the mouse. Development, 136, 701-713.

Rovescalli, A., Asoh, S., \& Nierenberg, M. (1996). Cloning and characterization of four murine homeobox genes. Proceedings of the National Academy of Science, 93, 10691-10696.

Saito, T., Lo, L., Anderson, D. J., \& Mikoshiba, K. (1996). Identification of novel paired homeodomain protein related to c. elegans unc-4 as a potential downstream target of mash1. Dev Biol, 180, 143-155.

Sammeta, N., Hardina, D. L., \& McClintocklow, T. S. (2010). Uncx regulates proliferation of neural progenitor cells and neuronal survival in the olfactory epithelium. Molecular and Cellular Neuroscience, 45, 398-407.

Sanes, D., Reh, T., \& Harris, W. (2006). Development of the Nervous System. Academic Press.

Saucedo-Cardenas, O., Quintana-Hau, J., Le, W., Smidt, M., Cox, J., De Mayo, F., Burbach, J., \& Conneely, O. (1998). Nurr1 is essential for the induction of the dopaminergic phenotype and the survival of ventral mesencephalic late dopaminergic precursor neurons. Proc Natl Acad Sci USA, 95, 4013-4018.

Sauvageot, C. \& Stiles, C. (2002). Molecular mechanisms controlling cortical gliogenesis. Current Opinion in Neurobiology, 12, 244-249.

Scardigli, R., Schuurmans, C., Gradwohl, G., \& Gillemont, F. (2001). Crossregulation between neurogenin2 and pathways specifying neuronal identity in the spinal cord. Neuron, 31, 203217.

Schrägle, J., Huang, R., Christ, B., \& Pröls, F. (2004). Control of the temporal and spatial Uncx4.1 expression in the paraxial mesoderm of avian embryos. Anat Embryol, 208, 323332.

Schuurmans, C., Armant, O., Nieto, M., Stenman, J. M., Britz, O., Klenin, N., Brown, C., Langevin, L.-M., Seibt, J., Tang, H., Cunningham, J. M., Dyck, R., Walsh, C., Campbell, K., Polleux, F., \& Guillemot, F. (2004). Sequential phases of cortical specification involve neurogenin-dependent and -independent pathways. The EMBO Journal, 23, 2892-2902. 
Schuurmans, C. \& Guillemot, F. (2002). Molecular mechanisms underlying cell fate specification in the developing telencephalon. Current Opinion in Neurobiology, 12, 26-34.

Schwenk, F., Baron, U., \& Rajewsky, K. (1995). A cre-transgenic mouse strain for the ubiquitous deletion of loxP-flanked gene segments including deletion in germ cells. Nucleic Acids Res, 23, 5080-508.

Seibt, J., Schuurmans, C., G.Gradwhol, Dehay, C., Vanderhaeghen, P., \& an F. Polleux, F. G. (2003). Neurogenin 2 specifies the connectivity of thalamic neurons by controlling axon responsiveness to intermediate target cues. Neuron, 39, 4013-4018.

Sieber, M. A., Storm, R., de-la Torre, M. M., Müller, T., andKatja Reuter, H. W., Vasyutina, E., \& Birchmeier, C. (2007). Lbx1 acts as a selector gene in the fate determination of somatosensory and viscerosensory relay neurons in the hindbrain. The Journal of Neuroscience, 27 , 4902-4909.

Simeone, A. (2000). Positioning the isthmic organizer - where otx 2 and gbx 2 meet. Trends in Genetics, 16, 237-240.

Simon, H. H., Saueressig, H., Wurst, W., Goulding, M. D., \& O’Leary, D. D. M. (2001). Fate of midbrain dopaminergic neurons controlled by the engrailed genes. Journal of Neuroscience, $21,3126-3134$.

Smidt, M., Smits, S., Bouwmeester, H., Hamers, F., van der Linden, A., Hellemons, A., Graw, J., \& Burbach, J. (2004). Early developmental failure of substantia nigra dopamine neurons in mice lacking the homeodomain gene pitx3. Development, 131, 1145-55.

Smidt, M. P., Asbreuk, C. H. J., Cox, J. J., Chen, H., Johnson, R. L., \& Burbach, J. P. H. (2000). A second independent pathway for development of mesencephalic dopaminergic neurons requires $\operatorname{lmx} 1$ b. Nature Neuroscience, 111, 337-341.

Smidt, M. P., van Schaick, H., Lanctôt, C., Tremblay, J., Cox, J., van der Kleij, A. A., Wolterink, G., Drouin, J., \& Burbach, J. P. (1997). A homeodomain gene ptx3 has highly restricted brain expression in mesencephalic dopaminergic neurons. Proc Natl Acad Sci USA, 94(24), $13305-10$.

Smits, S. M., Ponnio, T., Conneely, O. M., Burbach, J. P. H., \& Smidt, M. P. (2003). Involvement of nurr1 in specifying the neurotransmitter identity of ventral midbrain dopaminergic neurons. European Journal of Neuroscience, 18, 1731-1738. 
St-Onge, L., Sosa-Pineda, B., Chowdhury, K., Mansouri, A., \& Gruss, P. (1997). Pax6 is required for differentiation of glucagon-producing alpha-cells in mouse pancreas. Nature, 387, 406-409.

Steffensen, S. C., Svingos, A. L., Pickel, V. M., \& Henriksen, S. J. (1998). Electrophysiological characterization of gabaergic neurons in the ventral tegmental area. The Journal of Neuroscience, 18, 8003-8015.

Sudarov, A. \& Joyner, A. (2007). Cerebellum morphogenesis: the foliation pattern is orchestrated by multi-cellular anchoring centers. Neural Development, 2, doi:10.1186/1749-8104-226.

Tang, M., Miyamoto, Y., \& Huang, E. (2009). Multiple roles of ß-catenin in controlling the neurogenic niche for midbrain dopamine neurons. Development, 136, 2027-2038.

Tang, M., Miyamoto, Y., \& Huang, E. (2010). Interactions of wnt/ß-catenin signaling and sonic hedgehog regulate the neurogenesis of ventral midbrain dopamine neurons. J Neurosci, 30, 9280-9291.

Tardif, E.and S. Clarke, S. (2002). Commissural connections of human suprerior colliculus. Neuroscience, 2, 363-372.

Tripathi, R. \& Mishra, R. (2009). In silico analysis of pax6 interacting proteins indicates missing molecular links in development of brain and associated disease. International Journal of Biological and Life Sciences, 8, 2012.

Usdin, T. B., Eiden, L. E., Bonner, T. I., \& Erickson, J. D. (1995). Molecular biology of the vesicular ach transporter. Trends in Neurosience, 18, 218-224.

van den Munckhof, P., Luk, K., Ste-Marie, L., Montgomery, J., Blanchet, P., Sadikot, A., \& Drouin, J. (2003). Pitx3 is required for motor activity and for survival of a subset of midbrain dopaminergic neurons. Development, 130, 2535-2542.

Von Stetina, S. E., Fox, R. M., Watkins, K. L., \& Starich, T. A. (2007). Unc-4 represses ceh$12 / \mathrm{hb} 9$ to specify synaptic inputs to va motor neurons in C. elegans. Genes and Development, $21,332-346$.

Waite, M., Skidmore, J., Billi, A., Martin, J., \& Martin, D. (2011). Gabaergic and glutamatergic identities of developing midbrain Pitx2 neurons. Developmental Dynamics, 240, 333-346. 
Wallen, A. \& Perlmann, T. (2003). Transcriptional control of dopamine neuron development. Annals of the New York Academy of Sience, 991, 48-60.

Wallen, A., Zetterstrom, R., Solomin, L., Arvidsson, M., Olson, L., \& Perlmann, T. (1999). Fate of mesencephalic ahd2-expressing dopamine progenitor cells in nurr1 mutant mice. Exp. Cell Res., 153, 737-746.

Wassarman, K., Lewandoski, M., Campbell, K., Joyner, A., Rubenstein, J., Martinez, S., \& Martin, G. (1997). Specification of the anterior hindbrain and establishment of a normal $\mathrm{mid} /$ hindbrain organizer is dependent on gbx2 gene function. Development, 224, 2923-2934.

Wasserman, R. \& Fullmer, C. (1989). On the molecular mechanism of intestinal calcium transport. Adv Exp Med Biol, 249, 45-65.

White, J. G., Southgate, E., \& Thompson, J. (1992). Mutations in the Caenorhabditis elegans unc-4 gene alter the snaptic input to ventral motor neurons. Nature, 355, 838-841.

Winkler, C. \& Kirik, D. (2005). Cell transplantation in parkinson's disease: how can we make it work? Trends Neurosci., 28, 86-92.

Winnier, A., Meir, J., Ross, J., Tavernaraktis, N., Driscoll, M., Ishihara, T., Katsura, I., \& Miller, D. (1999). UNC-4/UNC-37-dependent repression of motor neuron-specific genes control synaptic choice in Caenorhabditis elegans. Genes and Development, 13, 2774-2786.

Wolpert, L., Tickle, C., Lawrence, P., Meyerowitz, E., Robertson, E., Smith, J., \& Jessel, T. (2011). Principles of Development. Oxford Univerity press.

Wurst, W., Auerbach, A. B., \& Joyner, A. L. (1994). Multiple developmental defects in engrailed-1 mutant mice - an early mid-hindbrain deletion and patterning defects in forelimbs and sternum. Development, 120, 2065-2075.

Wurst, W. \& Bally-Cuif, L. (2001). Neural plate patterning: Upstream and downstream of the isthmic organizer. Nature Reviews Neuroscience, 2, 99-108.

Xiang, M., Lin, G., Zhou, L., Klein, W., \& Nathans, J. (1996). Targeted deletion of the mouse pou-domain gene brn-3a causes a selective loss of neurons in the brainstem and trigeminal ganglion, uncoordinated limb movement, and impaired suckling. PNAS, 93, 11950-11955. 
Ye, W., Shimamura, K., Rubenstein, J. L. R., Hynes, M., \& Rosenthal, A. (1998). Fgf and shh signals control dopaminergic and serotonergic cell fate in the anterior neural plate. Cell, 93, $755-766$.

Zermeno, V., Espindola, S., Mendoza, E., \& Hernandez-Echeagaray, E. (2009). Differential expression of neurotrophins in postnatal c57bl/6 mice striatum. Int J. Biol. Sci, 5, 118-127.

Zetterstrom, R. H., Solomin, L., Jansson, L., Hoffer, B., Olson, L., \& Perlmann, T. (1997). Dopamine neuron agenesis in Nurr1-Deficient mice. Sciencet, 276, 248-250.

Zhao, Z.-Q., Scott, M., Chiechio, S., Wang, J.-S., Renner, K. J., Gereau IV, R. W., Johnson, R. L., Deneris, E. S., \& Chen, Z.-F. (2006). Lmxlb is required for maintenance of central serotonergic neurons and mice lacking central serotonergic system exhibit normal locomotor activity. The Journal of Neuroscience, 26, 12781-12788.

Zhou, Y.and Yamamoto, M. \& Engel, J. (2000). Gata2 is required for the generation of v2 interneurons. Development, 127, 3829-3838. 


\section{Danksagung}

\section{Mein herzlicher Dank gilt...}

... Prof. Wimmer für die Bereitschaft die Betreuung dieser Arbeit zu übernehmen und für ein offenes Ohr für Fragen aller Art.

.... Ahmed Mansouri für Aufnahme in seine Arbeitsgruppe und die Bereitstellung des Themas. Auch möchte ich mich besonders für die immerwährende Hilfe und Diskussionsbereitschaft bedanken, sowie für so manch kritischen Blick, durch den ich den richtigen Umgang mit Experimenten und die kritische Auswertung wissenschaftlicher Ergebnisse gelernt habe. Danke!

...PD Dr. Anastassia Stoykova, Prof. Reinhard Schuh, Prof. Martin Göpfert und Prof. Walter Paulus für ihr Entgegenkommen und die Bereitschaft sich meiner Prüfungskommission anzuschließen. Außerdem möchte ich Anastassia Stoykova herzlich für alle Ratschläge und Hilfestellungen der letzten Jahre danken.

... allen Mitarbeitern der Abteilung Molekulare Zellbiologie für die Hilfestellungen und die schöne Atmosphäre. Mein besonderer Dank gilt Thomas Schulz für die fortwährende Hilfe und die Bereitschaft mir das technische „Know-How“ beizubringen. Dr. Stephen Blanke möchte ich besonders herzlich für die Herstellung des Uncx4.1 Antikörpers danken. Dr. Mihaela Diaconu danke ich für die Bereitstellung des Ngn2-HA Plasmides und die hilfreichen Tips und Tricks zur Durchführung der Co-IP und des Western Blottings. Zeeshan Ahmad möchte ich recht herzlich für die schöne Laboratmosphäre in den letzten Jahren danken. Martina Daniel und Petra Rus danke ich besonders für die technischen Hilfestellungen aller Art und die super Atmosphäre in der Histologie - mit euch macht sogar das Schneiden Spaß. Ganz herzlich möchte ich mich auch bei unseren Engeln Bojka, Manuela und Geli bedanken - ihr erleichtert uns den Laboralltag wirklich sehr mit eurem unermüdlichen Einsatz!

... Vanessa Paul, Simon Kordowich, Alexander Klimke, Marco Tylkowski und Christian Krug für die immerwährende Bereitschaft die täglichen Probleme des Laboralltages zu diskutieren und für jegliche Hilfestellung. Auch möchte ich mich für die schönen Abende außerhalb des Labors bedanken. Christian möchte ich besonders dafür danken, dass er immer bereit war die kleinen Mupelmäuse zu versorgen, wenn es mich mal wieder in die Heimat verschlagen hat. Ich danke euch als Kollegen und Freunde.

... Christiane Heuchel, Alexandra Kurth und dem ganzen Maushausteam für ihre exzellente Arbeit. Ganz besonders möchte ich mich bei Christiane für ihr Engagement und ihre Ausdauer bedanken immerwährend und zu jeder Zeit eine super Arbeit zu leisten und die Tiere im Auge zu haben - trotz einer sehr schweren Zeit. Danke Christiane! 
... Dr. Frederique Varoqueaux und Klaus Hellmann für die Hilfestellungen und die Durchführung der Analyse der synaptischen Proteine.

... Dr. Martin H. J. Jaspers für die immerwährende Hilfe „,mal schnell“ ein paar Aufnahmen am konfokalen Mikroskop zu machen.

... meiner lieben Schwester Mandy und meinen Eltern, die immer an mich geglaubt und mir diesen Werdegang ermöglicht haben. Vielen Dank für eure bedingungslose Unterstützung - ihr seid die besten Eltern die man sich wünschen kann!

... meinem Freund der mich immer unterstützt und an mich geglaubt hat. Danke für die Geduld und die tatkräftige Unterstützung, besonders in den letzten Wochen - du hast mich immer ermutigt und mir den Rückhalt gegeben, den ich brauchte. Dankeschön! 


\section{Curriculum vitae}

Persönliche Angaben:

Tamara Rabe

Deisterstr. 17

37081 Göttingen

tamara.rabe@gmx.de

Geburtsdatum: 16.12 .1982

Familienstand: ledig

Staatsangehörigkeit: Deutsch

\section{Wissenschaftliche Ausbildung:}

seit 2008

Wissenschaftliche Mitarbeiterin am Max-Planck-Institut für biophysikalische Chemie in Göttingen

Abteilung: Molekulare Zellbiologie, Forschungsgruppe: Molekulare Zelldifferenzierung

Dissertation zum Thema:„Funktionelle Analyse des Transkriptionsfaktors Uncx4.1 im murinen Mittelhirn“

2008 - 2011 Zugehörigkeit zum Programm des DFG Forschungszentrums Molekularphysiologie des Gehirns (CMPB)

2002 - 2007 Studium der Biologie an der Carl von Ossietzky Universität Oldenburg

Ausbildungsschwerpunkte: Genetik, Molekularbiologie, Mikrobiologie, Physiologie

Abschluss: Diplom Biologin 


\section{Publikationen:}

Rabe,T.I., Grisel, G., Blanke, S., Burbach,P.H., Guillemot, F., Kispert, A., Varoqueaux, F. and Mansouri, A. (2011), „The transcriptionfactor Uncx4.1 is involved in the development of midbrain dopaminergic neurons", Manuskript in Vorbereitung 